Alexandre Manoel dos Santos

(Organizador)

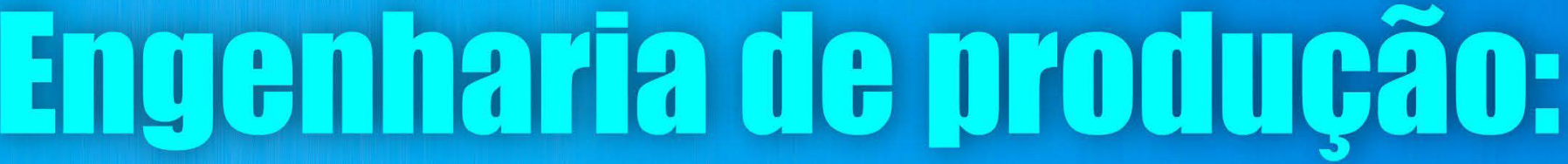 novas fronteiras, soluções, problemas e desafios
}

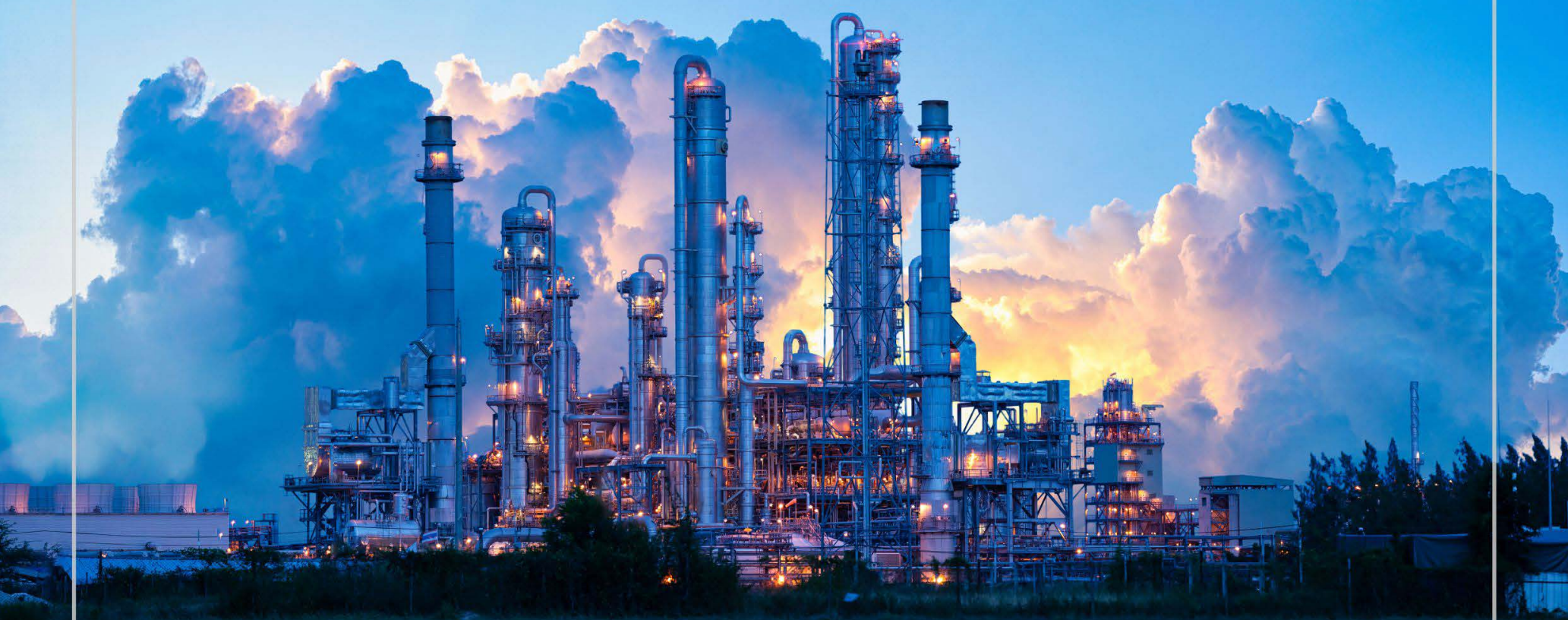




\section{Direģão Exiltopial}

Prof. ${ }^{\circ}$ Dr. Adriano Mesquita Soares

Organizador

Prof. ${ }^{\circ}$ Dr. Alexandre Manoel dos Santos

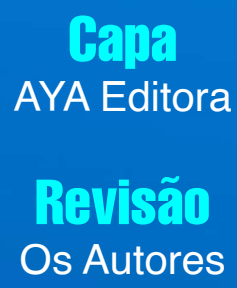

Executiva ile Nogícios

Ana Lucia Ribeiro Soares

\section{Produf̧ão Ecititorial \\ AYA Editora}

Imagens dit Bapa

br.freepik.com

Ár-a io Bonhecimento

Engenharia

\section{Gonselho Ediforial}

Prof. ${ }^{\circ}$ Dr. Aknaton Toczek Souza

Centro Universitário Santa Amélia

Prof. ${ }^{a}$ Dr. ${ }^{a}$ Andreia Antunes da Luz

Faculdade Sagrada Família

Prof. ${ }^{\circ}$ Dr. Carlos López Noriega

Universidade São Judas Tadeu e Lab. Biomecatrônica -

Poli - USP

Prof. ${ }^{\circ}$ Me. Clécio Danilo Dias da Silva

Centro Universitário FACEX

Prof. ${ }^{a}$ Dr. ${ }^{a}$ Daiane Maria De Genaro Chiroli

Universidade Tecnológica Federal do Paraná

Prof. ${ }^{a}$ Dr. ${ }^{a}$ Déborah Aparecida Souza dos Reis

Universidade do Estado de Minas Gerais

Prof. ${ }^{a}$ Dr. ${ }^{a}$ Eliana Leal Ferreira Hellvig

Universidade Federal do Paraná

Prof. ${ }^{\circ}$ Dr. Gilberto Zammar

Universidade Tecnológica Federal do Paraná

Prof. ${ }^{a}$ Dr. ${ }^{a}$ Ingridi Vargas Bortolaso

Universidade de Santa Cruz do Sul

Prof. ${ }^{a}$ Ma. Jaqueline Fonseca Rodrigues

Faculdade Sagrada Família

Prof. ${ }^{\circ}$ Dr. João Luiz Kovaleski

Universidade Tecnológica Federal do Paraná

Prof. ${ }^{\circ}$ Me. Jorge Soistak

Faculdade Sagrada Família

Prof. ${ }^{\circ}$ Me. José Henrique de Goes

Centro Universitário Santa Amélia

Prof. ${ }^{a}$ Dr. ${ }^{a}$ Leozenir Mendes Betim

Faculdade Sagrada Família e Centro de Ensino

Superior dos Campos Gerais

Prof. ${ }^{a}$ Ma. Lucimara Glap

Faculdade Santana
Prof. ${ }^{\circ}$ Dr. Luiz Flávio Arreguy Maia-Filho Universidade Federal Rural de Pernambuco Prof. ${ }^{\circ}$ Me. Luiz Henrique Domingues Universidade Norte do Paraná Prof. ${ }^{\circ}$ Dr. Marcos Pereira dos Santos Faculdade Rachel de Queiroz Prof. ${ }^{\circ}$ Me. Myller Augusto Santos Gomes Universidade Estadual do Centro-Oeste Prof. ${ }^{a}$ Dr. ${ }^{a}$ Pauline Balabuch Faculdade Sagrada Família Prof..$^{\circ}$ Me. Pedro Fauth Manhães Miranda Centro Universitário Santa Amélia Prof. ${ }^{a}$ Dr. ${ }^{a}$ Regina Negri Pagani Universidade Tecnológica Federal do Paraná Prof. ${ }^{2}$ Ma. Rosângela de França Bail Centro de Ensino Superior dos Campos Gerais Prof. ${ }^{\circ}$ Dr. Rudy de Barros Ahrens Faculdade Sagrada Família Prof. ${ }^{\circ}$ Dr. Saulo Cerqueira de Aguiar Soares Universidade Federal do Piauí Prof. ${ }^{a}$ Ma. Silvia Ap ${ }^{a}$ Medeiros Rodrigues Faculdade Sagrada Família Prof. ${ }^{a}$ Dr. $^{a}$ Silvia Gaia Universidade Tecnológica Federal do Paraná Prof. ${ }^{a}{ }^{D r}{ }^{a}$ Sueli de Fátima de Oliveira Miranda Santos Universidade Tecnológica Federal do Paraná Prof. ${ }^{a}$ Dr. ${ }^{a}$ Thaisa Rodrigues Instituto Federal de Santa Catarina 
๑ 2021 - AYA Editora - O conteúdo deste Livro foi enviado pelos autores para publicação de acesso aberto, sob os termos e condições da Licença de Atribuição Creative Commons 4.0 Internacional (CC BY 4.0). As ilustrações e demais informações contidas desta obra são integralmente de responsabilidade de seus autores.

E576 Engenharia de produção: novas fronteiras, soluções, problemas e desafios. / Alexandre Manoel dos Santos (organizador). -- Ponta Grossa: Aya, 2021. 113 p. -- ISBN: 978-65-8580-29-5

Inclui biografia

Inclui índice

Formato: PDF

Requisitos de sistema: Adobe Acrobat Reader.

Modo de acesso: World Wide Web.

DOI 10.47573/aya.88580.2.22

1. Engenharia de produção. 2. Reciclagem. 3. Ergonomia. 4. Cadeia de suprimentos. 5. Manutenção produtiva total. 6. Cervejarias. 7. Segurança do trabalho. 8. Equipamento de proteção individual. I. Santos, Alexandre Manoel dos II. Título

CDD: 658.5

Ficha catalográfica elaborada pela bibliotecária Bruna Cristina Bonini - CRB 9/1347

International Scientific Journals Publicações de Periódicos e Editora EIRELI

AYA Editora@

CNPJ: $\quad 36.140 .631 / 0001-53$

Fone: $\quad+55423086-3131$

E-mail: contato@ayaeditora.com.br

Site: https://ayaeditora.com.br

Endereço: Rua João Rabello Coutinho, 557

Ponta Grossa - Paraná - Brasil

84.071-150 


\section{Apresentação}

O modelo atual de nossa Sociedade global é sentido por nós de maneiras diversas. Em suas múltiplas dimensões, percebemos as grandes mudanças sociais que tem ocorrido nas últimas décadas e o quanto elas afetam as nossas noções de Modernidade e de Contemporaneidade. Ficamos surpresos com os impactos causados sobre nosso comportamento coletivo e institucional, espelhados -em nossa individualidade- por novos pensamentos, discursos e ações. Com certeza vivemos uma época em que a mútua influência nas relações entre Sociedade, Indivíduos e Sistemas de Suporte à Vida (Natureza como ela é), se faz cada vez mais potente. Essas relações, acopladas, induzem maior capacidade de nos adaptarmos às pressões ambientais decorrente destas mudanças. Penso que ser moderno é perceber o dinamismo do vetor de necessidades humanas em Sociedade e ser contemporâneo é perceber o impacto social de nossas ações individuais e institucionais ainda durante nossas vidas. A Modernidade e a Contemporaneidade são inescapáveis à efetiva participação na dimensão institucional de nossa Sociedade, que se torna mais complexa de se viver e entender. Estamos aprendendo a ver a realidade social como ela é e não como nós, individualmente, gostaríamos que ela fosse. Este é um processo de construção de conhecimentos, é histórico. Somos assim.

Nossa sociedade é efetivamente paradigmática: busca satisfazer o seu vetor de necessidades na forma contínua de entrega de Valor, produzindo elevação de qualidade de vida que se faz fluir para a maioria dos humanos no planeta. Desse paradigma, decorre a produção de produtos e serviços, em escala crescente, utilizando-se formas alternativas de energização dos processos e procedimentos, tanto aqueles inovadores quanto os tradicionais. A computação em nuvem e a aplicação de inteligência artificial levam-nos a perceber padrões de comportamentos sociais atual e necessidades emergentes que não eram antes reveláveis.

Vivemos um momento intenso de acontecimentos globalmente percebidos. A atual pandemia Covid-19, causada e potencializada pelas mutações do vírus Sars-Cov-2, as estratégias para desenvolver novos supridores e produtores de serviços e tecnologias -necessários para a colonização da Lua e Marte, por exemplo- tem oferecido uma "taxa de puxada" para novas expertises e competências a serem desenvolvidas em todos os países do planeta. É muito provável que daqui a vinte ou trinta anos não mais sejam produzidos veículos leves com motores à combustão. Trata-se de um esforço considerável da Humanidade para garantir a busca por maior Sustentabilidade dos processos de produção e de elevação de qualidade de Vida. Não estamos falando somente de sistemas de suporte à Vida, dos quais fazemos parte, neste planeta. Nossas noções de realidade e nossos comportamentos se modificam intensamente, de forma que nos tornamos mais sensíveis ao Valor das coisas e das relações construídas em nossa Sociedade.

Neste sentido, vale a pena ressaltar a importância da Engenharia para o processo de construção de um Mundo melhor. No âmbito da Engenharia de Produção, os processos de Tomadas de Decisões nas organizações assumem um papel fundamental para a consecução de estratégias corporativas, sejam elas públicas, privadas ou de caráter misto. A taxa de sucesso institucional, no cumprimento de seus contratos sociais, que é aumentada neste contexto, decorre do envolvimento de um número cada vez maior de jovens engenheiros, experientes ou nem tanto, efetivamente comprometidos com Ciência, Tecnologia e Educação. As organizações buscam por novas formas de obtenção de maior eficiência em seus processos, todas acopladas à mitigação 
de perdas e eliminação de desperdícios.

Mas também, no mesmo contexto, entende-se que a produção de elevação de qualidade de vida em Sociedade depende de aspectos normativos que precisam ser compreendidos para que valores humanos universais estejam presentes no projeto de construção do nosso porvir imediato. Para além da Ciência e Tecnologia, os engenheiros também são convidados a perceber a importância dos aspectos normativos, cujas dimensões são constituídas por Filosofia Política, por noções de ética, moral, Religião e Política Pública. Entender a importância das instituições em países que prezam por Liberdade, como o nosso Brasil, é fundamental nestes contextos. Busca-se aqui destacar a importância da Engenharia de Produção para os processos de construção de metodologias objetivando perseguir visões de Sustentabilidade para nossa Sociedade. Em termos práticos, estas essencialidades contextuais estão presentes em cada um dos capítulos que compõem o presente livro. Eu os apresento e os recomendo.

Caros leitores, desejo-lhes uma ótima leitura. 


\section{SUMÁRIO 01}

Compósitos de acrilonitrila-butadienoestipeno (ABS) recicladio Gom floras veggtais visando economia circular..... 8

Meire Noriko Hosoktawa

Karen ide Soura do Pradio

Amanda Pena Rodrigues Goelho

Ghristian Guello Barrios

Jane Maria Faulstich io Paiva

DOI: 10.47573/aya.88580.2.22.1

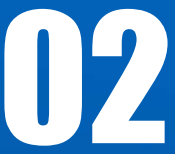

Gestão da Inovação, os desalifos do setor industrial para um padrão de classe mundial

Gezar Honorato

Franciseo Gristóvão Lourenço de Melo

DOI: 10.47573/aya.88580.2.22.2

03

Proposta para adequação e otimização do espaço físico de uma academia de ginástica por meio de uma análise ergonômica: Um estudo de caso ........ 42

Danielle de Cássia da Silva Malcher Lobato

Thiago Lohato Rodrigues

DOl: 10.47573/aya.88580.2.22.3 


\section{4}

A utilização do value stream mapping como ferramenta para reiução de desperilícios.

João tahnric Mota Luz

DOl: 10.47573/aya.88580.2.22.4

DS

Análise de eficiência da metodologia TPM aplicada em uma cervejaria com problemas na recravadeipa de latas ... 80

Oristiano Rilibas Fidolix

João Luiz Kovaleski

DOl: 10.47573/aya.88580.2.22.5

06

Gestão de riseos de segurança do trahalho: estudo de caso na empresa Daisyelle Bomfim Ilunes-MIE, Aracaju/SE....

ח

Samara Vaseoncolos ide Paula

Douglas Rafael Mendes Alves

Heloísa Thaís Rodrigues de Souza

Jeane Karrla de Mendonça Mota

Whiliams Alves de Azeveido

DOl: 10.47573/aya.88580.2.22.6

Organizador 


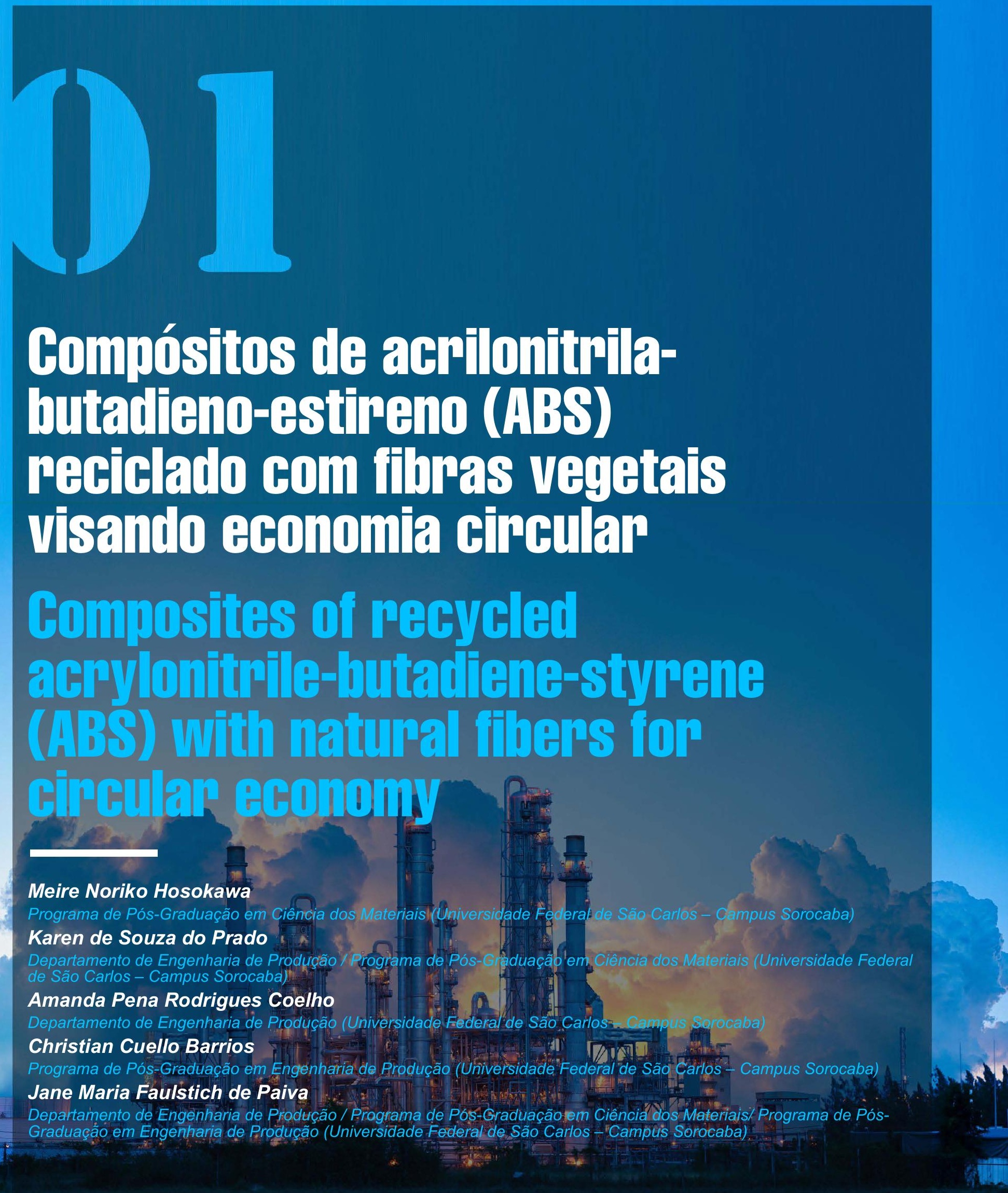

DOI: 10.47573/aya.88580.2.22.1 
O Brasil é um dos maiores produtores de resíduos de equipamentos elétricos e eletrônicos (REEE) do mundo. Dentre os polímeros presentes nos REEE, o terpolímero acrilonitrila-butadieno-estireno (ABS) se destaca devido à sua ampla utilização em monitores, telefones, impressoras e computadores. Neste contexto, ações que viabilizem a reinserção do ABS pós-consumo no ciclo produtivo por meio da reciclagem são importantes para promover a economia circular e minimizar os impactos ambientais, sociais e econômicos do seu descarte inadequado. Neste capítulo, foi realizada uma revisão bibliográfica sobre as propriedades, uso e reciclagem do ABS. Devido às propriedades mecânicas inferiores do ABS reciclado em relação ao material virgem, evidenciou-se a importância do desenvolvimento de compósitos, dentre os quais se destacam os com fibras vegetais. Por isto, também foi reportado neste capítulo o desenvolvimento de compósitos de ABS reciclado obtidos de REEE, usando tecidos de fibras de juta e algodão como fase dispersa. Apesar da incompatibilidade química entre as fases, verificou-se uma tendência de aumento na resistência à flexão do ABS reciclado com a incorporação dos tecidos de fibras vegetais. Os resultados reportados para os compósitos são promissores, principalmente, considerando o baixo custo das fibras vegetais em relação ao ABS, e sugerem uma oportunidade de reintroduzir o ABS reciclado na cadeia produtiva de diferentes setores com a melhoria das suas propriedades mecânicas. Dentre os setores que podem se beneficiar dos compósitos de ABS reciclado com fibras vegetais estão o eletroeletrônico e o automotivo.

Palavras-chave: polímero reciclado. fibra vegetal. compósito. reciclagem. economia circular.

\section{Alotrat}

Brazil is one of the highest producers of waste electrical and electronic equipment (WEEE) in the world. Among the polymers present in WEEE, the acrylonitrile-butadiene-styrene (ABS) terpolymer stands out due to its wide use in monitors, telephones, printers, and computers. In this scenario, actions that enable the reinsertion of post-consumer ABS into the production cycle through recycling are important to promote the circular economy and minimize the environmental, social, and economic impacts of its inadequate disposal. In this chapter, a literature review was made about the properties, use, and recycling of ABS. The relevance of developing composites based on recycled ABS was evidenced, mainly because of the inferior mechanical properties of recycled $A B S$ compared to the virgin material. In this sense, the incorporation of natural fibers may contribute to produce more sustainable materials with improved properties. For this reason, this chapter also reported the development of recycled ABS composites obtained from WEEE, using fabrics of jute and cotton fibers as a dispersed phase. Despite the chemical incompatibility between the phases, there was a tendency to increase the flexural strength of recycled ABS with the incorporation of vegetal fiber fabrics. The results reported for the composites are promising mainly considering the low cost of the natural fibers compared to ABS, as the improved mechanical properties of recycled ABS allow its reintroduction into the production chain of different sectors, such as electronics and automotive.

Keywords: recycled polymer. natural fiber. composite. recycling. circular economy. 


\section{INTRODUÇÃO}

Na última década, a preocupação com a gestão de resíduos sólidos têm sido crescente ao redor do mundo (ABRELPE, 2020). Os impactos ambientais, sociais e econômicos causados pelo descarte inadequado destes resíduos têm motivado a transição dos sistemas produtivos de um modelo linear para uma economia circular (STAHEL, 2016). Neste novo modelo de negócios, sistemas como a logística reversa vêm sendo implementados por diferentes setores como uma estratégia sustentável, capaz de promover a responsabilidade compartilhada entre produtores e consumidores pelo ciclo de vida dos produtos (ABRELPE, 2020; ISERNIA et al., 2019). Dentre estes setores, destaca-se o de equipamentos elétricos e eletrônicos, cujos resíduos podem conter substâncias potencialmente tóxicas (SINGH; SUMAN; KUMAR, 2020).

De acordo com o relatório publicado pela Global E-Waste Monitor em 2020 (FORTI et al., 2020), a geração mundial de resíduos de equipamentos elétricos e eletrônicos (REEE), também conhecidos como E-waste, alcançou o número recorde de 53,6 milhões de toneladas em 2019. Destes, apenas $17,4 \%$ foram reciclados. O Brasil ocupou a quinta posição entre os países com maior geração de REEE, com uma produção superior a 2,1 milhões de toneladas. Apesar de a logística reversa ser obrigatória no país desde 2020, alguns desafios ainda precisam ser superados para sua plena realização (ABRELPE, 2020; FORTI et al., 2020).

Os REEE são compostos por até 30\% de polímeros (TAURINO; POZZI; ZANASI, 2010), dentre os quais se destaca o Acrilonitrila-Butadieno-Estireno (ABS), usado para a fabricação de monitores, impressoras, telefones, computadores, fornos micro-ondas, entre outros equipamentos (BUEKENS; YANG, 2014). Sendo um dos polímeros mais utilizados em equipamentos elétricos e eletroeletrônicos, o ABS é um dos principais polímeros encontrados nos REEE (MARTI$\mathrm{NHO}$ et al., 2012). Portanto, vê-se a importância do estudo de sua reutilização e reciclagem, cujo interesse tem sido crescente principalmente nos últimos sete anos, como mostrado na Figura 1.

Figura 1 - Número de publicações sobre reciclagem de ABS proveniente de REEE nas últimas duas décadas (dados bienais)

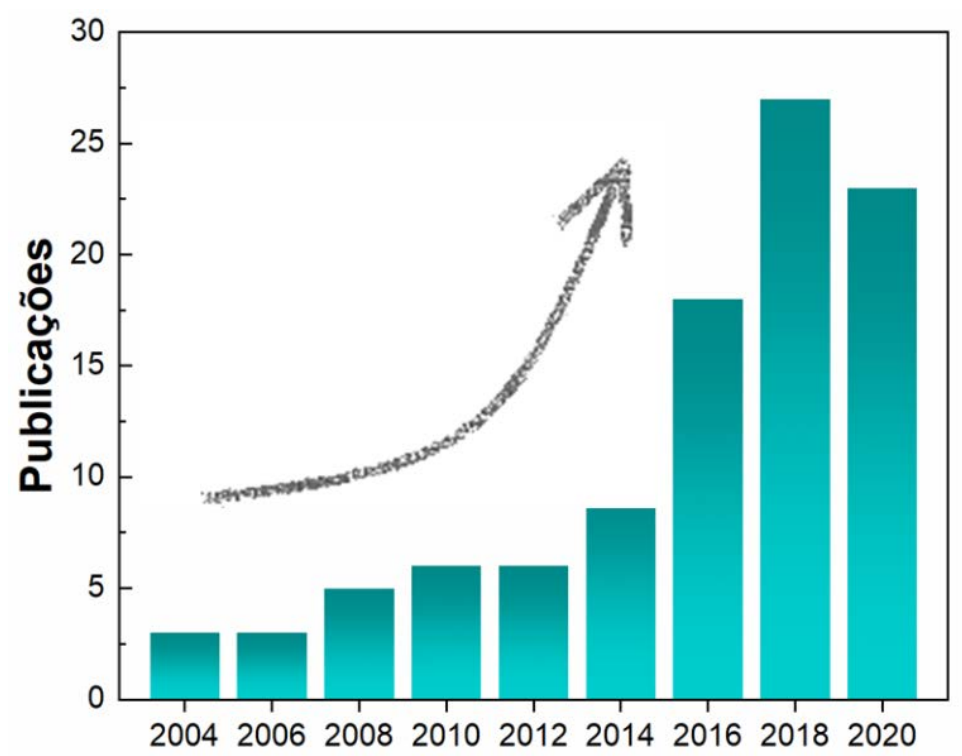

Ano

Fonte: Autoria própria (2021). Dados obtidos da base Web of Science em 10 de maio de 2021, usando as palavras-chave ("acrylonitrile-butadiene-styrene" OR "ABS") AND ("reycl*") AND" ("WEEE") 
Um dos problemas decorrentes do processo de reciclagem dos materiais poliméricos é a diminuição de suas propriedades mecânicas (BRENNAN; ISAAC; ARNOLD, 2002; SPINACÉ; DE PAOLI, 2005), o que faz com que polímeros reciclados como o ABS geralmente sejam usados em produtos com menor valor agregado. A fabricação de compósitos com matrizes poliméricas recicladas é uma alternativa para tentar resolver esta limitação, especialmente quando fibras vegetais são utilizadas visando à produção de compósitos sustentáveis para aplicações diversas (SANJAY et al., 2019). Por isso, este capítulo tem como objetivos: i) realizar uma revisão bibliográfica sobre as propriedades, uso e reciclagem do ABS, enfatizando a importância do desenvolvimento de compósitos de ABS reciclado com fibras vegetais; e II) reportar o desenvolvimento de compósitos de ABS reciclado obtidos de REEE, usando tecidos de fibras de juta e algodão como fase dispersa.

\section{REVISÃO BIBLIOGRÁFICA}

\section{Composição, propriedades e aplicações do ABS}

O ABS é um terpolímero formado pela polimerização dos monômeros acrilonitrila (15$35 \%$ ), butadieno (5-30\%) e estireno (40-60\%) como ilustrado na Figura 2, com proporções variadas dependendo da destinação do produto (MCKEEN, 2010). Cada monômero confere propriedades diferentes ao material; por exemplo, uma maior quantidade de acrilonitrila confere resistência química e térmica superiores ao ABS (THREEPOPNATKUL; TEPPINTA; SOMBATSOMPOP, 2011). De forma geral, entende-se que o ABS é formado por uma matriz de acrilonitrila e estireno (SAN), onde a fase elastomérica de butadieno está dispersa (BOLDIZAR; MÖLLER, 2003).

Figura 2 - Estrutura química do ABS

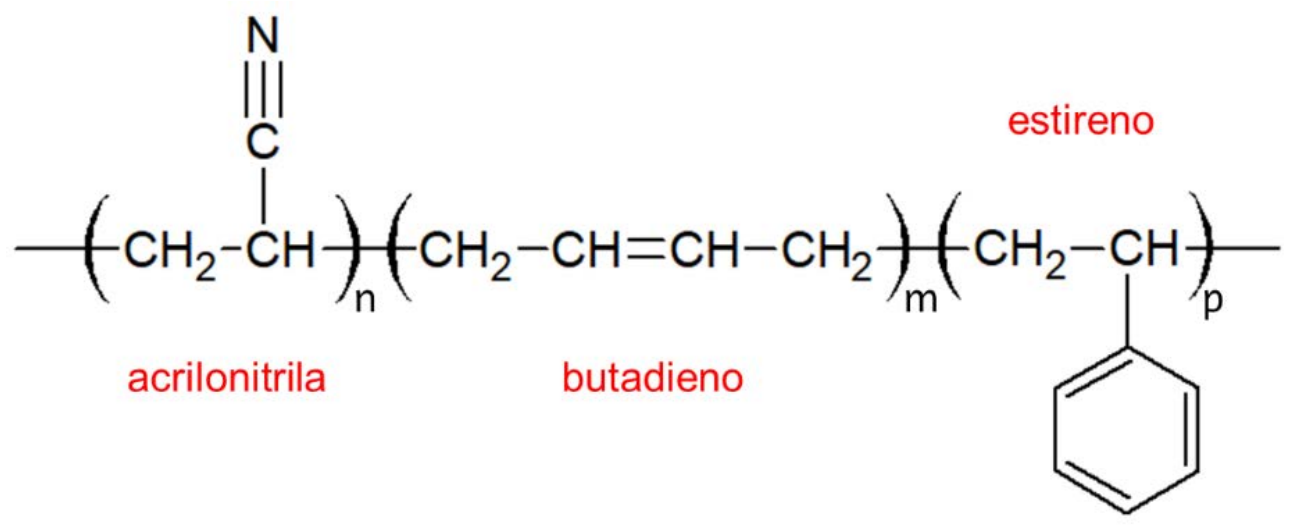

Fonte: Autoria própria (2021)

O ABS é considerado um polímero termoplástico de engenharia (BOLDIZAR; MÖLLER, 2003; SINGH; SUMAN; KUMAR, 2020). Assim, é capaz de amolecer e ser moldado de forma reversível quando submetido a altas temperaturas e/ou pressão. Como mencionado anteriormente, a resistência térmica do ABS depende de sua composição. A fase elastomérica de butadieno apresenta temperatura de transição vítrea em torno de $-50^{\circ} \mathrm{C}$, enquanto a fase de SAN apresenta transição vítrea a partir de $100^{\circ} \mathrm{C}$ (BLOM et al., 2006; POLLI et al., 2009). A degradação do ABS ocorre a partir de $325^{\circ} \mathrm{C}$, e pode levar a alterações nas propriedades mecânicas do polímero com a variação da temperatura (MOHD; ROSLAN; BABA, 2016; POLLI et al., 2009). Além 
da ampla faixa de temperatura de uso, o ABS também apresenta excelente processabilidade, boa resistência a abrasão e alta resistência ao impacto, que vai depender do teor de butadieno presente (BRAGA et al., 2019).

Devido às suas propriedades, o material apresenta ampla aplicação, com um foco maior para a utilização na indústria eletroeletrônica. Além da confecção de monitores, eletrodomésticos, telefones, computadores, o ABS também é utilizado na construção civil, em dispositivos médicos, em brinquedos e também indústria automobilística por possuir boa estabilidade dimensional (BRAGA et al., 2019; POLLI et al., 2009).

\section{Economia circular e a reciclagem do ABS}

Ao chegar ao final de sua vida útil, a destinação final mais ambientalmente adequada para o ABS presente nos REEE é a reciclagem. A reintrodução do ABS reciclado na cadeia produtiva contribui para a economia circular (FORD; FISHER, 2019). Como esquematizado na Figura 3, a economia circular surge como um sistema de produção alternativo ao modelo linear ainda amplamente empregado, no qual o início e o fim da cadeia produtiva não estão interligados.

A ideia de economia circular consiste justamente em conectar o fim ao início da cadeia produtiva, em um sistema de produção que viabiliza o uso de recursos em um ciclo fechado. Para isto, ao chegar ao final do seu ciclo de vida, o produto pode ser reutilizado ou passar pela logística reversa, na qual será redirecionado para uma fábrica adequada para uso como matéria-prima em um novo ciclo produtivo, o que geralmente ocorre por meio da reciclagem (BARROS et al., 2021; MENDES CAMPOLINA et al., 2017; STAHEL, 2016). No caso de resíduos poliméricos como o ABS, a economia circular evita a falta de recursos naturais pois minimiza a necessidade da síntese de novos polímeros a partir do petróleo (recurso não renovável), evita a liberação de substâncias tóxicas no meio ambiente, e promove um crescimento sustentável da economia (BRENNAN; ISAAC; ARNOLD, 2002; UNGER et al., 2017; WAGNER et al., 2019, 2020). 
Figura 3 - Comparação entre os modelos de economia linear e circular
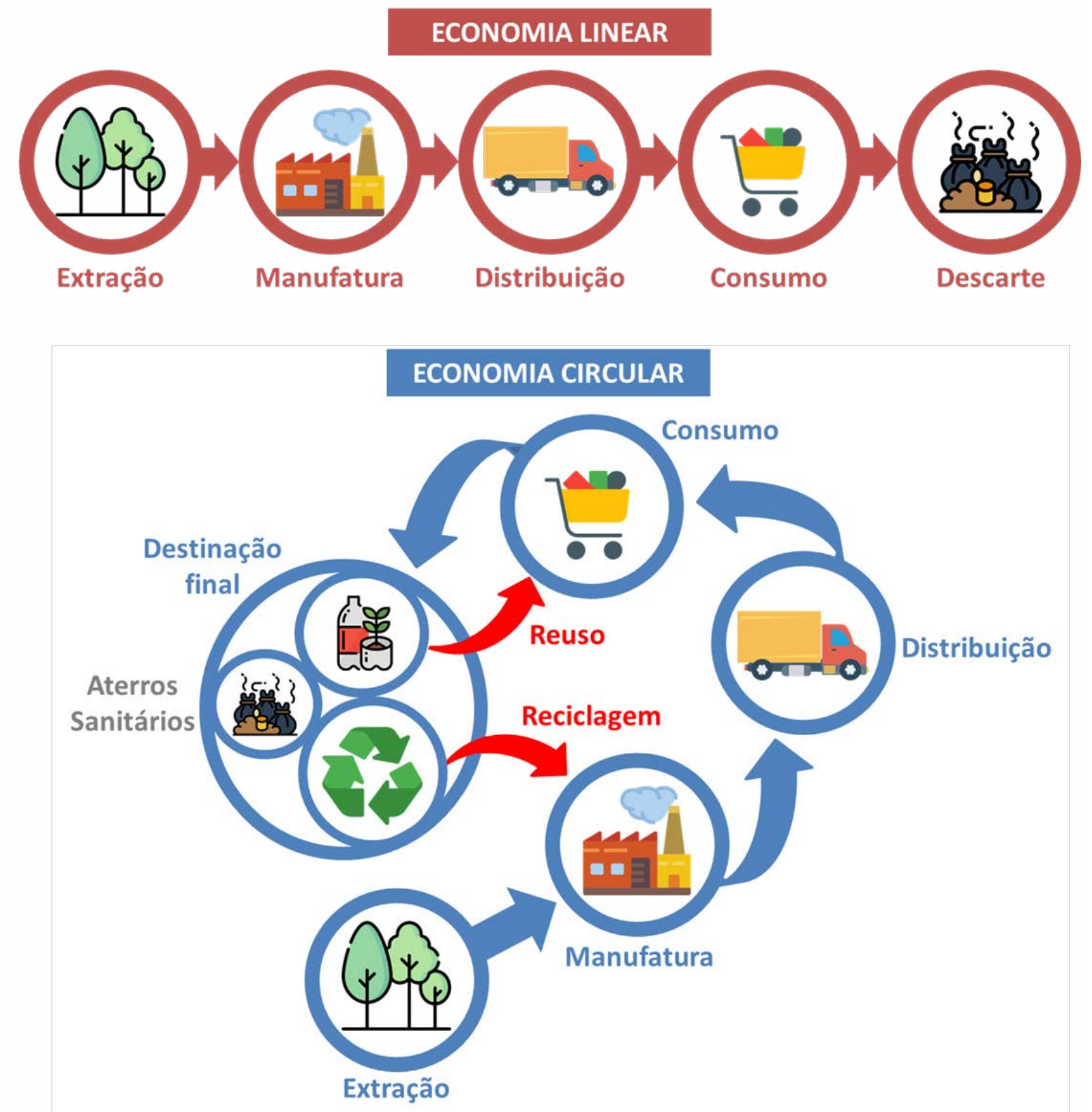

Fonte: Autoria própria (2021), ícones adaptados de Flaticon.com

Para a reciclagem do ABS proveniente dos REEE, primeiramente é necessária a desmontagem do equipamento eletroeletrônico e posterior separação dos diferentes tipos de materiais (metais, polímeros e/ou cerâmicas) (WAGNER et al., 2019). A etapa de separação é uma das mais complexas no caso dos REEE, devido ao grande número de materiais envolvidos na fabricação dos equipamentos elétricos e eletrônicos (DALRYMPLE et al., 2007; ONGONDO; WILLIAMS; CHERRETT, 2011). Após esse pré-tratamento, existem três opções principais para a reciclagem dos resíduos poliméricos dos REEE: mecânica, química ou energética (HIRAYAMA, 2015; WAGNER et al., 2019).

Na reciclagem química, o polímero passa por processos de despolimerização para obtenção de insumos que possam ser usados para a produção de produtos petroquímicos ou novos polímeros com propriedades similares ao material de partida. Na reciclagem energética, o alto poder calorifico dos polímeros é aproveitado por meio de incineração para aproveitamento do seu 
conteúdo energético na forma de calor, vapor ou eletricidade (AL-SALEM; LETTIERI; BAEYENS, 2009; SPINACÉ; DE PAOLI, 2005). Essas práticas vêm sendo adotadas principalmente em países desenvolvidos como o Japão; no Brasil, apesar dos avanços, a reciclagem mecânica ainda é o processo de reciclagem mais usado para resíduos poliméricos pós-industriais e pós-consumo (ABIPLAST, 2019; SPINACÉ; DE PAOLI, 2005). Nela, o material é reprocessado para a obtenção do polímero reciclado, geralmente na forma de grânulos (pellets) que se tornarão matérias-primas para novos produtos. As principais etapas da reciclagem mecânica são: moagem, lavagem, secagem, formulação, extrusão e granulação (AL-SALEM; LETTIERI; BAEYENS, 2009).

Embora a reciclagem seja estimulada no Brasil pela Política Nacional de Resíduos Sólidos (BRASIL, 2010), existem ainda limitações práticas que dificultam sua realização em larga escala. Um grande problema da reciclagem de polímeros, incluindo o $A B S$, é o custo da logística reversa (MENDES CAMPOLINA et al., 2017). Outra limitação para a ampla utilização de polímeros reciclados é que grande parte deles tem suas propriedades mecânicas reduzidas devido a processos de contaminação e degradação (SPINACÉ; DE PAOLI, 2005).

No caso do ABS, o butadieno é mais suscetível à degradação termooxidativa devido à presença da ligação dupla (Figura 1) (BLOM et al., 2006). Quando submetido a altas temperaturas, a oxidação do butadieno pode ocasionar dificuldade de adesão à matriz de acrilonitrila $e$ estireno, resultando em concentração de tensões e redução das propriedades mecânicas do polímero reciclado (BOLDIZAR; MÖLLER, 2003). Isto faz com que o ABS reciclado acabe sendo utilizado em produtos com aplicações de baixo valor agregado, ao invés de ser reintroduzido na produção dos equipamentos eletroeletrônicos.

\section{Compósitos de ABS reciclado}

A utilização de $A B S$ reciclado em compósitos é uma alternativa interessante para atenuar o problema da diminuição de propriedades mecânicas resultante do processo de reciclagem mecânica. Neste contexto, compósitos são definidos como materiais multifásicos que possuem propriedades relativas a todas as fases que os constituem, visando à obtenção da melhor combinação de propriedades (CALLISTER, 2007). Assim, os compósitos podem ser formados pela combinação de materiais com propriedades distintas (mecânicas, térmicas, entre outras), mas que podem se complementar desde que haja uma interação interfacial adequada entre as fases (LEE; KHALINA; LEE, 2021).

De forma geral, os compósitos são constituídos por uma fase contínua e uma ou mais fases dispersas. Enquanto a fase contínua, também chamada de matriz, é responsável pela unidade estrutural e aparência do compósito, a fase dispersa pode atuar como carga de enchimento, reforço, barreira, dentre outras funções. As propriedades dos compósitos dependem da proporção entre os constituintes, da interação entre eles, e do tipo de fase dispersa (CALLISTER, 2007; GIBSON, 1994; RABELLO, 2000). Dentre elas, destacam-se as fibras sintéticas ou naturais, que podem ser longas ou curtas, ou ainda organizadas em tecidos com diferentes tramas.

As fibras sintéticas mais utilizadas comercialmente em compósitos poliméricos são as fibras de carbono, fibras de aramida (poliaramida) e fibras de vidro, devido às suas excelentes propriedades mecânicas (CHINNASAMY et al., 2020). Em contrapartida, é crescente o interesse no uso de fibras naturais como carga dispersa para o desenvolvimento de compósitos poliméricos mais sustentáveis (VIGNESHWARAN et al., 2020). Dentre as vantagens da utilização de 
fibras naturais destacam-se sua baixa massa específica, o que possibilita a formação de compósitos mais leves ou a adição de mais camadas de suporte; menor abrasividade; não toxicidade; e sua biodegradabilidade. Adicionalmente, as fibras naturais geralmente apresentam baixo custo, são facilmente obtidas, possuem um menor consumo de energia em sua produção, e ainda são pouco utilizadas em escala industrial (NABI SAHEB; JOG, 1999).

Dentre as fibras naturais, destacam-se as fibras de origem vegetal ou fibras lignocelulósicas, que recebem essa denominação devido à sua composição majoritária: celulose, hemiceluloses e lignina. O teor de celulose, bem como as condições de plantio, armazenamento e cultivo, interferem diretamente nas propriedades das fibras vegetais e, consequentemente, nas propriedades dos compósitos poliméricos produzidos (SANJAY et al., 2019). A literatura reporta o uso de fibras vegetais de diversas fontes em compósitos com matriz de ABS: cânhamo (WÖTZEL; WIRTH; FLAKE, 1999), banana (KUSIĆ et al., 2020), abacaxi (THREEPOPNATKUL; KRACHANG; CHANIN KULSETTHANCHELEE, 2014), bambu (MA et al., 2012), polpa de dendê (BATENI et al., 2011), pupunha (LEÃO et al., 2012), palmeira (NEHER et al., 2016), sisal e kenaf (DUNNE; DESAI; SADIKU, 2017), coco, e outras (CHEN et al., 2015; MAZZANTI; MALAGUTTI; MOLLICA, 2019).

Dentre as fibras vegetais, destacam-se as fibras de algodão e juta. Ambas possuem baixo custo, são amplamente produzidas no Brasil e, por isso, possuem facilidade de compra no mercado nacional. Diversos trabalhos na literatura têm reportado propriedades promissoras para compósitos poliméricos produzidos com estas fibras devido à sua composição e propriedades, citados na Tabela 1 (FARUK et al., 2012; VIGNESHWARAN et al., 2020).

Tabela 1 - Composição e propriedades das fibras de algodão e juta

\begin{tabular}{|c|c|c|c|c|c|c|c|}
\hline \multirow[b]{2}{*}{ Fibra } & \multicolumn{3}{|c|}{ Composição } & \multicolumn{4}{|c|}{ Propriedades } \\
\hline & $\begin{array}{c}\text { Celulose } \\
(\%)\end{array}$ & $\begin{array}{c}\text { Hemi- } \\
\text { celulose } \\
(\%)\end{array}$ & $\begin{array}{l}\text { Lignina } \\
(\%)\end{array}$ & $\begin{array}{l}\text { Densidade } \\
\left(\mathrm{g} / \mathrm{m}^{3}\right)\end{array}$ & $\begin{array}{c}\text { Tensão } \\
\text { máxima } \\
\text { (MPa) }\end{array}$ & $\begin{array}{c}\text { Módulo } \\
\text { elástico } \\
\text { (GPa) }\end{array}$ & $\begin{array}{c}\text { Deformação } \\
(\%)\end{array}$ \\
\hline algodão & $83-91$ & 3 & - & 1,51 & 400 & 12 & $0,3-10$ \\
\hline juta & $61-72$ & $18-22$ & $12-13$ & $1,3-1,48$ & $393-800$ & $0,13-26,5$ & $1,16-1,80$ \\
\hline
\end{tabular}

Fonte: Adaptado de Vigneshwaran et al. (2020)

Apesar do grande potencial, ainda são poucos os estudos referentes ao desenvolvimento de compósitos de matriz de ABS reciclado com fibras vegetais (CAN, 2019; CHEN et al., 2015; SURYADI et al., 2017a, 2017b). Além disso, o uso de tecidos de fibras naturais como fase dispersa em compósitos de ABS reciclado ainda não foi amplamente explorado (HOSOKAWA, 2017). Por isso, este capítulo apresenta nas próximas seções o desenvolvimento de compósitos de $A B S$ reciclado com tecidos de fibras de algodão e juta com diferentes arquiteturas.

\section{PARTE EXPERIMENTAL}

ABS reciclado (rABS) proveniente de REEE (Sinctronics - Sorocaba, SP, Brasil), na forma de grânulos brancos (Figura 4a), foi utilizado como matriz polimérica. Como fase dispersa, foram selecionados três tipos de tecidos bidirecionais de fibras vegetais adquiridos no comércio nacional, cujas propriedades estão descritas na Tabela 2: i) um tecido de fibras de juta com trama simples (Figura 4b) - T1; ii) um tecido de fibras de juta com trama dupla (Figura 4c) - T2; e iii) 
um tecido híbrido composto por fibras de juta trama simples (orientado a $0^{\circ}$ ) e fibras de algodão trama simples (orientados a $90^{\circ}$ ) (Figura 4d) - T3.

Figura 4 - Fotografias de: (a) grânulos de rABS e tecidos (b) T1, (c) T2 e (d) T3
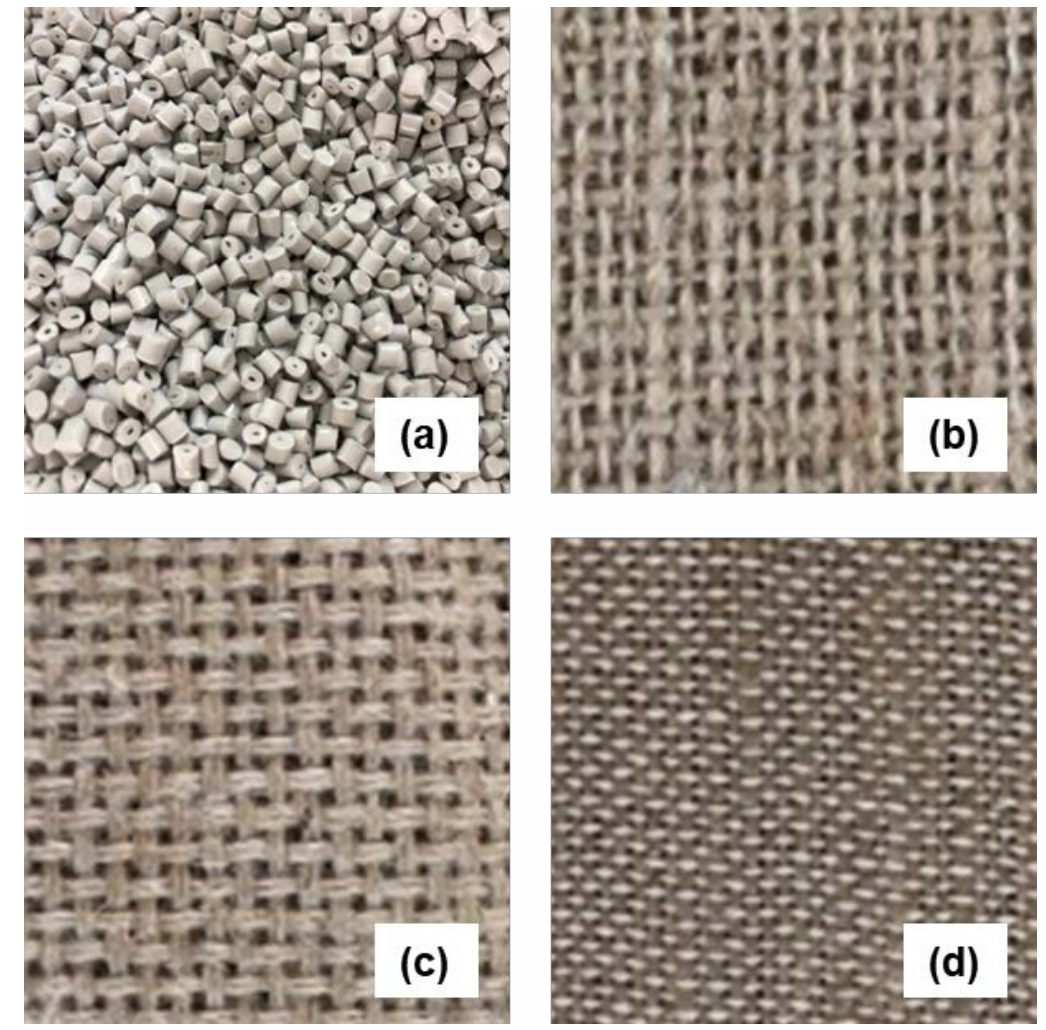

Fonte: Autoria própria (2021)

Para a confecção dos compósitos, os tecidos de fibras de juta foram cortados manualmente nas dimensões $160 \times 180 \mathrm{~mm}$. O rABS reciclado foi pesado em balança analítica, e metade da massa foi inserida em um molde de alumínio. Após, uma camada do tecido de fibras de juta foi inserida no molde, seguida do restante dos pellets de rABS.

Tabela 2 - Tipos de tecidos utilizados e suas especificações

\begin{tabular}{ccccc}
\hline Tecido & Composição & $\begin{array}{c}\text { Gramatura } \\
\left(\mathbf{g} / \mathbf{m}^{2}\right)\end{array}$ & $\begin{array}{c}\mathbf{N}^{\circ} \text { de cordões } \mathbf{0}^{\circ} \\
\text { (cordões/cm) }\end{array}$ & $\begin{array}{c}\mathbf{N}^{\circ} \text { de cordões } \mathbf{9 0}^{\circ} \\
\text { (cordões/cm) }\end{array}$ \\
\hline T1 & Juta (trama simples) & 365 & 4,3 & 4,5 \\
T2 & Juta (trama dupla) & 445 & 6,2 & 6,0 \\
T3 & Juta e algodão & 360 & 7,0 (juta) & 7,5 (algodão) \\
\hline
\end{tabular}

Fonte: Autoria própria (2021)

Os compósitos foram processados pelo método de compressão à quente em uma prensa hidráulica (Marconi MA098 A/E) a $240^{\circ} \mathrm{C}$ por 30 minutos. Durante os primeiros 10 minutos, o material foi aquecido sem aplicação de pressão de moldagem para a eliminação de quaisquer voláteis. Então, o material foi submetido a uma pressão de moldagem de $17 \mathrm{kgf} / \mathrm{cm}^{2}$, na mesma temperatura por 20 minutos. O molde permaneceu sob pressão até resfriar, quando as placas de $5 \mathrm{~mm}$ de espessura foram desmoldadas. A descrição das amostras está apresentada na Tabela 3. 
Tabela 3 - Composição das amostras moldadas

\begin{tabular}{cccc}
\hline Amostra & Composição & $\begin{array}{c}\text { Porcentagem em } \\
\text { massa de matriz } \\
(\%)\end{array}$ & $\begin{array}{c}\text { Porcentagem em } \\
\text { massa de fibra (\%) }\end{array}$ \\
\hline rABS & ABS reciclado sem reforço & 100,0 & - \\
rABS/T1 & ABS reciclado/ Tecido T1 & 94,7 & 5,3 \\
rABS/T2 & ABS reciclado/ Tecido T2 & 93,6 & 6,4 \\
rABS/T3 & ABS reciclado/ Tecido T3 & 94,7 & 5,3 \\
\hline
\end{tabular}

Fonte: Autoria própria (2021)

A avaliação das propriedades mecânicas dos compósitos desenvolvidos foi realizada por meio de ensaio de flexão do tipo três pontos, de acordo com a norma ASTM D790. As placas moldadas foram cortadas utilizando uma serra fita, resultando em 11 corpos de prova de cada composição, com dimensões 127 x 12,7 mm x 5,4 mm. Os ensaios de flexão foram realizados em máquina universal para ensaios mecânicos (EMIC DL10000) com uma célula de carga de 500 kgf, distância entre os apoios de $86,0 \mathrm{~mm}$ e velocidade de ensaio de 2,29 mm/ min.

\section{RESULTADOS E DISCUSSÃO}

Na Figura 5 são mostrados os aspectos dos corpos de prova após a realização dos ensaios de flexão. Com exceção de um corpo de prova do compósito rABS/T3 reforçado com tecido híbrido de juta e algodão, todos os demais corpos de prova submetidos ao ensaio de flexão sofreram fratura em local próximo a metade do seu comprimento.

Figura 5 - Fotografia dos corpos de prova após do ensaio de flexão: (a) rABS, (b) rABS/T1, (c) $\mathrm{rABS} / \mathrm{T} 2$, e (d) rABS/T3
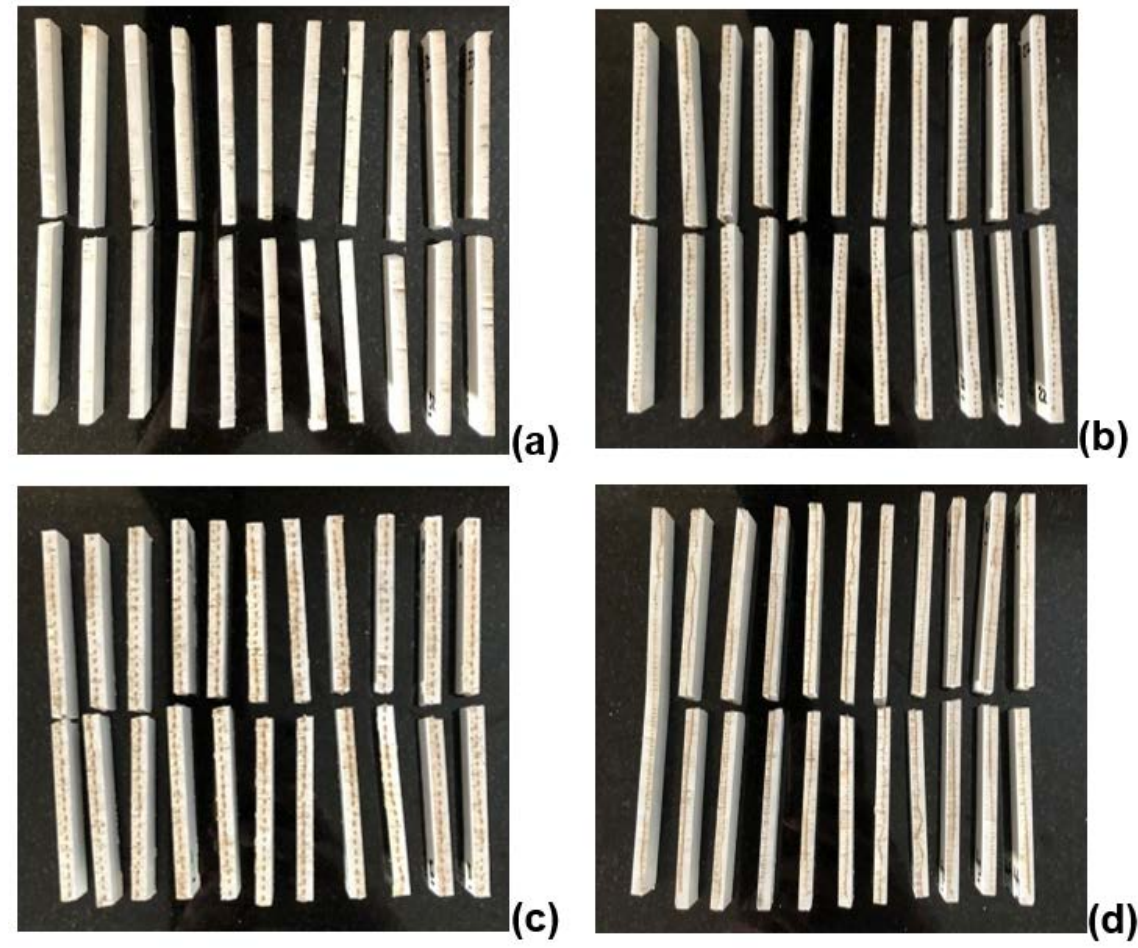

Fonte: Autoria própria (2021) 
Na Tabela 4 estão os valores médios das propriedades após os ensaios de flexão do rABS e dos compósitos produzidos com tecidos de fibras vegetais. É possível observar que a resistência à flexão do ABS reciclado sem reforço (rABS) foi de 54,0 $( \pm 6,7) \mathrm{MPa}$, valor quase $46 \%$ superior ao reportado por Budin et al. (2020), o qual obteve resistência a flexão de 37,1 MPa para o ABS reciclado (BUDIN et al., 2020). Variações nas propriedades mecânicas do ABS reciclado podem ser decorrentes dos parâmetros usados na reciclagem do ABS, capazes de promover diferentes graus de cisão nas cadeias poliméricas. Consequentemente, os polímeros com diferentes massas molares possuem quantidades distintas de grupos terminais que aumentam o volume livre e a mobilidade molecular, fazendo com que as cadeias poliméricas respondam às tensões de forma distintas (BUDIN et al., 2020).

Tabela 4 - Valores de resistência à flexão e módulo de elasticidade das amostras de rABS e seus compósitos com tecidos de fibras vegetais

\begin{tabular}{ccc}
\hline Amostra & Resistência à flexão (MPa) & Módulo de Elasticidade (MPa) \\
\hline rABS & $54,0 \pm 6,7$ & $2454 \pm 327$ \\
rABS/T1 & $61,6 \pm 6,7$ & $2827 \pm 283$ \\
rABS/T2 & $57,0 \pm 3,9$ & $2657 \pm 271$ \\
rABS/T3 & $62,9 \pm 5,0$ & $2747 \pm 142$ \\
\hline
\end{tabular}

Fonte: Autoria própria (2021)

Em relação aos compósitos produzidos, observa-se uma tendência de aumento nos valores de resistência à flexão e módulo de elasticidade dos compósitos contendo os tecidos de fibras vegetais, quando comparados ao ABS reciclado sem reforço ( $\mathrm{ABBS}$ ). Dentre os parâmetros que afetam a resistência à flexão de compósitos poliméricos reforçados com fibras vegetais estão o comprimento da fibra, sua razão de aspecto e o esquema de tecelagem (trama e urdume) usado na fabricação do tecido. No caso deste estudo, os tecidos eram bidirecionais, fazendo com que parte das fibras estivesse alinhada na direção do esforço enquanto a outra metade estivesse disposta transversalmente ao esforço. Consequentemente, neste esquema, pelo menos metade das fibras é capaz de transferir tensões de forma efetiva, resultando em melhora da resistência à flexão. A outra metade das fibras pode atuar como inclusões ou defeitos (CARVALHO; CAVALCANTI; CAVALVANTE, 2000). Além disso, o ABS reciclado sem reforço apresentou valores desvio padrão mais elevados que os compósitos tanto para a resistência a flexão quanto para o módulo de elasticidade, indicando que as fibras de reforço presentes nos compósitos moldados auxiliaram a aumentar a homogeneidade de amostras do polímero reciclado.

O compósito $\mathrm{rABS} / \mathrm{T} 2$ contendo o tecido de fibras de juta com trama dupla foi o que resultou em menor incremento das propriedades mecânicas dentre os três tecidos estudados. $\mathrm{O}$ maior número de cordões por centímetro do tecido com trama dupla (T2) em relação ao de trama simples (T1) pode resultar em uma distribuição insuficiente da matriz na superfície das fibras. Além disso, a baixa adesão entre as fibras de juta e a matriz polimérica, devido à incompatibilidade química entre as fases, pode contribuir na formação de vazios no compósito, que dificultam a transferência de tensões da matriz para a fase dispersa (LEE; KHALINA; LEE, 2021; VIJAYAKUMAR; PALANIKUMAR, 2020). Esta possibilidade de presença de vazios será, posteriormente, investigada por meio de microscopia eletrônica de varredura.

O maior valor de resistência à flexão $(62,9 \pm 5,0 \mathrm{MPa})$ foi observado para o compósito 
rABS/T3, contendo o tecido híbrido de juta e algodão. Apesar de o tecido T3 possuir a maior quantidade de cordões por centímetro, a presença das fibras de algodão pode ter auxiliado no aumento da resistência à flexão, já que seu teor de celulose (83-91\%) é significativamente maior que nas fibras de juta (61-72\%) (VIGNESHWARAN et al., 2020).

Estes resultados indicam que tanto o tipo de tecido quanto a sua composição influenciam na resistência a flexão dos compósitos de rABS reforçados com tecidos de fibras vegetais. Dentre os compósitos desenvolvidos, existe a tendência de que os tecidos de fibras de juta de trama simples e de fibras de juta com algodão sejam mais interessantes para serem utilizados como reforço em compósitos ABS reciclado.

Comparando os resultados obtidos neste estudo com os valores previamente reportados no trabalho de Hosokawa (2017), onde foi utilizado ABS reciclado como matriz e tecido de fibra de juta simples (gramatura de $270 \mathrm{~g} / \mathrm{m} 2$ ) como fase dispersa, observa-se que os resultados de resistência à flexão reportados (entre 57,4 e 61,2 MPa) são próximos aos obtidos no presente estudo, enquanto os valores de módulo de elasticidade (entre 2310 e $2585 \mathrm{MPa}$ ) são relativamente menores (HOSOKAWA, 2017). Isso pode estar associado à diferença na gramatura dos tecidos utilizados, uma vez que a gramatura dos tecidos utilizados no presente estudo foi de $365-445 \mathrm{~g} /$ m2. Além disso, as mudanças de lote, marca do tecido de reforço e materiais de origem vegetal podem ocasionar diferenças nos resultados. Assim, resultados relativamente diferentes podem ser encontrados apesar de materiais e métodos semelhantes.

A utilização de outros tipos de fibras vegetais também pode resultar em compósitos de rABS com propriedades mecânicas melhoradas. Em um artigo publicado por Ma et al. (2012), os autores reportaram o uso de fibras de bambu em compósitos com matriz de ABS. Os resultados foram superiores aos obtidos no presente trabalho, embora a adição de fibra vegetal tenha resultado em um ligeiro decréscimo na resistência à flexão do ABS (de 82,5 $\mathrm{MPa}$ para 78,1 $\mathrm{MPa}$ ) devido à incompatibilidade entre a matriz polimérica hidrofóbica e o reforço hidrofilico. Dentre as alternativas encontradas pelos autores para aumentar a compatibilidade entre as fases e, portanto, otimizar as propriedades mecânicas do compósito, estavam a realização de tratamento alcalino na fibra vegetal e utilização de agente acoplamento (MA et al., 2012).

Deste modo geral, considera-se que os resultados dos compósitos de ABS reciclado e fibras vegetais desenvolvidos neste estudo são promissores, pois apesar de apresentar discreto aumento nos valores das propriedades mecânicas, não apresentou diminuição, mesmo com a utilização de materiais com naturezas químicas diferentes. Tais resultados mostram que é possível a utilização de fibras vegetais para viabilizar a reinserção do ABS reciclado na cadeia produtiva por meio da fabricação de compósitos, de modo a impulsionar a implementação da economia circular.

\section{CONCLUSÕES}

Neste capítulo, evidenciou-se a relevância do desenvolvimento de compósitos de ABS reciclado com fibras vegetais como uma forma de contribuir para a economia circular. A tendência de aumento das propriedades mecânicas do ABS reciclado com a adição de tecidos de fibras de juta e algodão reportada neste estudo é promissora, mesmo com incompatibilidade química entre matriz e fase dispersa. Existem diversas opções para promover avanços na área, que pre- 
cisarão ser exploradas em trabalhos futuros. Dentre elas, estão: a) a melhoria da interação interfacial entre as fases, por exemplo, por meio do tratamento químico das fibras vegetais e/ou uso de agentes compatibilizantes e b) o uso de diferentes fibras vegetais. Sem dúvida, os compósitos desenvolvidos possuem grande potencial de ganho ambiental e econômico, com a possibilidade reinserção do $A B S$ reciclado na cadeia produtiva de equipamentos elétricos e eletrônicos e de outros setores.

\section{REFERENCIAS}

ABIPLAST. Perfil 2019Abiplast. Disponível em: <http://www.abiplast.org.br/publicacoes/perfil2019/>. Acesso em: 14 mai. 2021.

ABRELPE. Panorama dos Resíduos Sólidos no Brasil 2020. Disponível em: <https://abrelpe.org.br/ panorama-2020/>. Acesso em: 14 mai. 2021.

AL-SALEM, S. M.; LETTIERI, P.; BAEYENS, J. Recycling and recovery routes of plastic solid waste (PSW): A review. Waste Management, v. 29, n. 10, p. 2625-2643, 2009.

BARROS, M. V. et al. Circular economy as a driver to sustainable businesses. Cleaner Environmental Systems, v. 2, p. 100006, jun. 2021.

BATENI, F. et al. Performance of oil palm empty fruit bunch fibres coated with acrylonitrile butadiene styrene. Construction and Building Materials, v. 25, n. 4, p. 1824-1829, 2011.

BLOM, H. et al. Detection of degradation of ABS materials via DSC. Journal ofThermal Analysis and Calorimetry, v. 83, n. 1, p. 113-115, 2006.

BOLDIZAR, A.; MÖLLER, K. Degradation of ABS during repeated processing and accelerated ageing. Polymer Degradation and Stability, v. 81, n. 2, p. 359-366, 2003.

BRAGA, N. F. et al. Influence of compatibilizer and carbon nanotubes on mechanical, electrical, and barrier properties of PTT/ABS blends. Advanced Industrial and Engineering Polymer Research, v. 2, n. 3, p. 121-125, 2019.

BRASIL. Lei $n^{\circ}$ 12.305, de 2 de agosto de 2010. Institui a Política Nacional de Resíduos Sólidos; altera a Lei no 9.605, de 12 de fevereiro de 1998 e dá outras providências. Lex: Diário Oficial da União, Brasília, seção 1, mar./ago., 2. trim. 2010. Legislação Federal e marginalia.

BRENNAN, L. B.; ISAAC, D. H.; ARNOLD, J. C. Recycling of acrylonitrile-butadiene-styrene and highimpact polystyrene from waste computer equipment. Journal of Applied Polymer Science, v. 86, n. 3, p. 572-578, 2002.

BUDIN, S. et al. Investigation on mechanical properties of blend virgin and recycled acrylonitrilebutadiene-styrene (ABS) in injection molding. Key Engineering Materials, v. 833 KEM, n. March, p. 8-12, 2020.

BUEKENS, A.; YANG, J. Recycling of WEEE plastics: A review. Journal of Material Cycles and Waste Management, v. 16, n. 3, p. 415-434, 2014.

CALLISTER, W. D. Materials science and engineering: An Introduction. 7. ed. New York: John Wiley \& Sons, 2007.

CAN, Y. Sound insulation performance of short cotton fibre waste/recycled acrylonitrile butadiene styrene composites. Acta Physica Polonica A, v. 135, n. 4, p. 772-774, 2019.

CARVALHO, L. H.; CAVALCANTI, W. S.; CAVALVANTE, J. M. F. Influência da arquitetura do tecido nas propriedades de compósitos Poliéster/ tecido de Juta. In: CONGRESSO BRASILEIRO DE ENGENHARIA E CIÊNCIA DOS MATERIAIS, 14., 2000, São Pedro. Anais...São Pedro: 2000, p. 49101- 
49111.

CHEN, R. et al. Pithecellobium clypearia benth fiber/recycled acrylonitrile-butadiene-styrene (ABS) composites prepared in a vane extruder: Analysis of mechanical properties and morphology. Journal of Macromolecular Science, Part B: Physics, v. 54, n. 1, p. 1-16, 2015.

CHINNASAMY, V. et al. Characterization on thermal properties of glass fiber and kevlar fiber with modified epoxy hybrid composites. Journal of Materials Research and Technology, v. 9, n. 3, p. 31583167, 2020.

DALRYMPLE, I. et al. An integrated approach to electronic waste (WEEE) recycling. Circuit World, v. 33, n. 2, p. 52-58, 2007.

DUNNE, R.; DESAI, D.; SADIKU, R. Material characterization of blended sisal-kenaf composites with an ABS matrix. Applied Acoustics, v. 125, p. 184-193, out. 2017.

FARUK, O. et al. Biocomposites reinforced with natural fibers: 2000-2010. Progress in Polymer Science, v. 37, n. 11, p. 1552-1596, 2012.

FORD, P.; FISHER, J. Designing consumer electronic products for the circular economy using recycled Acrylonitrile Butadiene Styrene (ABS): A case study. Journal of Cleaner Production, v. 236, p. 117490, 2019.

FORTI, V. et al. The Global E-waste Monitor 2020: Quantities, flows and the circular economy potential. Disponível em: <http://ewastemonitor.info/>. Acesso em: 14 mai. 2021.

GIBSON, R. F. Principles of Composite Material Mechanics. St Louis: McGraw-Hill Inc., 1994.

HIRAYAMA, D. Reciclagem do copolímero acrilonitrila-butadieno-estireno e do poliestireno de alto impacto oriundos de rejeitos de equipamentos elétricos e eletrônicos na forma de blendas poliméricas. Lorena, 213 p., 2015. Tese (Doutorado) - Universidade de São Paulo.

HOSOKAWA, M. N. Aproveitamento do copolímero ABS reciclado na moldagem de compósitos com fibras de juta e avaliação de propriedades. Sorocaba, 84 p., 2017. Dissertação (Mestrado) Universidade Federal de São Carlos.

ISERNIA, R. et al. The reverse supply chain of the e-waste management processes in a circular economy framework: Evidence from Italy. Sustainability (Switzerland), v. 11, n. 8, p. 2430, 2019.

KUSIĆ, D. et al. Thermal and mechanical characterization of banana fiber reinforced composites for its application in injection molding. Materials, v. 13, n. 16, p. 3581, 2020.

LEÃO, A. L. et al. Panels produced from thermoplastic composites reinforced with peach palm fibers for use in the civil construction and furniture industry. Molecular Crystals and Liquid Crystals, v. 556, p. 246-253, 2012.

LEE, C. H.; KHALINA, A.; LEE, S. H. Importance of interfacial adhesion condition on characterization of plant-fiber-reinforced polymer composites: A review. Polymers, v. 13, n. 3, p. 1-22, 2021.

MA, L. et al. Effect of alkali treatment on structure and mechanical properties of acrylonitrile-butadienestyrene/bamboo fiber composites. Journal of Macromolecular Science, Part B: Physics, v. 51, n. 11, p. 2232-2244, 2012.

MARTINHO, G. et al. Composition of plastics from waste electrical and electronic equipment (WEEE) by direct sampling. Waste Management, v. 32, n. 6, p. 1213-1217, 2012.

MAZZANTI, V.; MALAGUTTI, L.; MOLLICA, F. FDM 3D printing of polymers containing natural fillers: A review of their mechanical properties. Polymers, v. 11, n. 7, p. 1094, 2019.

MCKEEN, L. W. Styrenic Plastics. In: MCKEEN, L. W. (Ed.). Fatigue \& Tribological Properties of Plastics \& Elastomers. 2 ed. William Andrew Publishing, 2010. p. 51-71. 
MENDES CAMPOLINA, J. et al. A study on the environmental aspects of WEEE plastic recycling in a Brazilian company. International Journal of Life Cycle Assessment, v. 22, n. 12, p. 1957-1968, 2017.

MOHD, A.; ROSLAN, A. A.; BABA, N. B. Effect of injection molding parameters on recycled ABS (r-ABS) mechanical properties. Indian Journal of Science and Technology, v. 9, n. 9, p. 1-6, 2016.

NABI SAHEB, D.; JOG, J. P. Natural fiber polymer composites: A review. Advances in Polymer Technology, v. 18, n. 4, p. 351-363, 1999.

NEHER, B. et al. Thermal properties of palm fiber and palm fiber-reinforced ABS composite. Journal of Thermal Analysis and Calorimetry, v. 124, n. 3, p. 1281-1289, 2016.

ONGONDO, F. O.; WILLIAMS, I. D.; CHERRETT, T. J. How are WEEE doing? A global review of the management of electrical and electronic wastes. Waste Management, v. 31, n. 4, p. 714-730, 2011.

POLLI, H. et al. Degradation behavior and kinetic study of ABS polymer. Journal of Thermal Analysis and Calorimetry, v. 95, n. 1, p. 131-134, 2009.

RABELLO, M. Aditivação de polímeros. São Paulo: Artiliber, 2000.

SANJAY, M. R. et al. A comprehensive review of techniques for natural fibers as reinforcement in composites: Preparation, processing and characterization. Carbohydrate Polymers, v. 207, n. October 2018, p. 108-121, 2019.

SINGH, P. K.; SUMAN, S. K.; KUMAR, M. Influence of Recycled Acrylonitrile Butadiene Styrene (ABS) on the Physical, Rheological and Mechanical Properties of Bitumen Binder. Transportation Research Procedia, v. 48, p. 3668-3677, 2020.

SPINACÉ, M. A. DA S.; DE PAOLI, M. A. A tecnologia da reciclagem de polímeros. Química Nova, v. 28, n. 1, p. 65-72, 2005.

STAHEL, W. R. The circular economy. Nature, v. 531, n. 7595, p. 435-438, 2016.

SURYADI, G. S. et al. Mechanical properties and surface free energy of oil palm empty fruit bunches fibre reinforced biocomposites as glass fibre substitution. Jurnal Teknologi, v. 79, n. 4, p. 97-105, 2017a.

SURYADI, G. S. et al. Surface free energy analysis of oil palm empty fruit bunches fiber reinforced biocomposites. IOP Conference Series: Earth and Environmental Science, v. 65, n. 1, 2017b.

TAURINO, R.; POZZI, P.; ZANASI, T. Facile characterization of polymer fractions from waste electrical and electronic equipment (WEEE) for mechanical recycling. Waste Management, v. 30, n. 12, p. 26012607, 2010.

THREEPOPNATKUL, P.; KRACHANG, T.; CHANIN KULSETTHANCHELEE. Phosphate derivative flame retardants on properties of pineapple leaf fiber/ABS composite. Polymers \& Polymer Composites, v. 22, n. 2014 , p. 591-597, 2014

THREEPOPNATKUL, P.; TEPPINTA, W.; SOMBATSOMPOP, N. Effect of co-monomer ratio in ABS and wood content on processing and properties in wood/ABS composites. Fibers and Polymers, v. 12, n. 8, p. 1007-1013, 2011.

UNGER, N. et al. The greenhouse gas benefit of recycling waste electrical and electronic equipment above the legal minimum requirement: An Austrian LCA case study. Journal of Cleaner Production, v. 164, p. 1635-1644, 2017.

VIGNESHWARAN, S. et al. Recent advancement in the natural fiber polymer composites: A comprehensive review. Journal of Cleaner Production, v. 277, p. 124109, 2020.

VIJAYAKUMAR, S.; PALANIKUMAR, K. Evaluation on mechanical properties of randomly oriented Caryota fiber reinforced polymer composites. Journal of Materials Research and Technology, v. 9, n. 4, p. 7915-7925, 2020. 
WAGNER, F. et al. Towards a more circular economy for WEEE plastics - Part A: Development of innovative recycling strategies. Waste Management, v. 100, p. 269-277, 2019a.

WAGNER, F. et al. Quality assessment of mixed plastic flakes from Waste Electrical and Electronic Equipment (WEEE) by spectroscopic techniques. Resources, Conservation and Recycling, v. 158, n. March, 2020.

WÖTZEL, K.; WIRTH, R.; FLAKE, M. Life cycle studies on hemp fibre reinforced components and ABS for automotive parts. Angewandte Makromolekulare Chemie, v. 272, n. 4763, p. 121-127, 1999.

\section{AGRADECIMENTOS}

Os autores agradecem à Coordenação de Aperfeiçoamento de Pessoal de Nível Superior (CAPES) pelo suporte financeiro (código de financiamento 001 e processo número 88887.464432/201900). Os autores também agradecem ao Sinctronics (Sorocaba-SP), e aos produtores dos ícones usados nos esquemas de economia circular e linear (Freepik, DinosoftLabs, Smashicons, Pixel perfect, Ultimateam e monkik), obtidos do site Flaticon.com. 


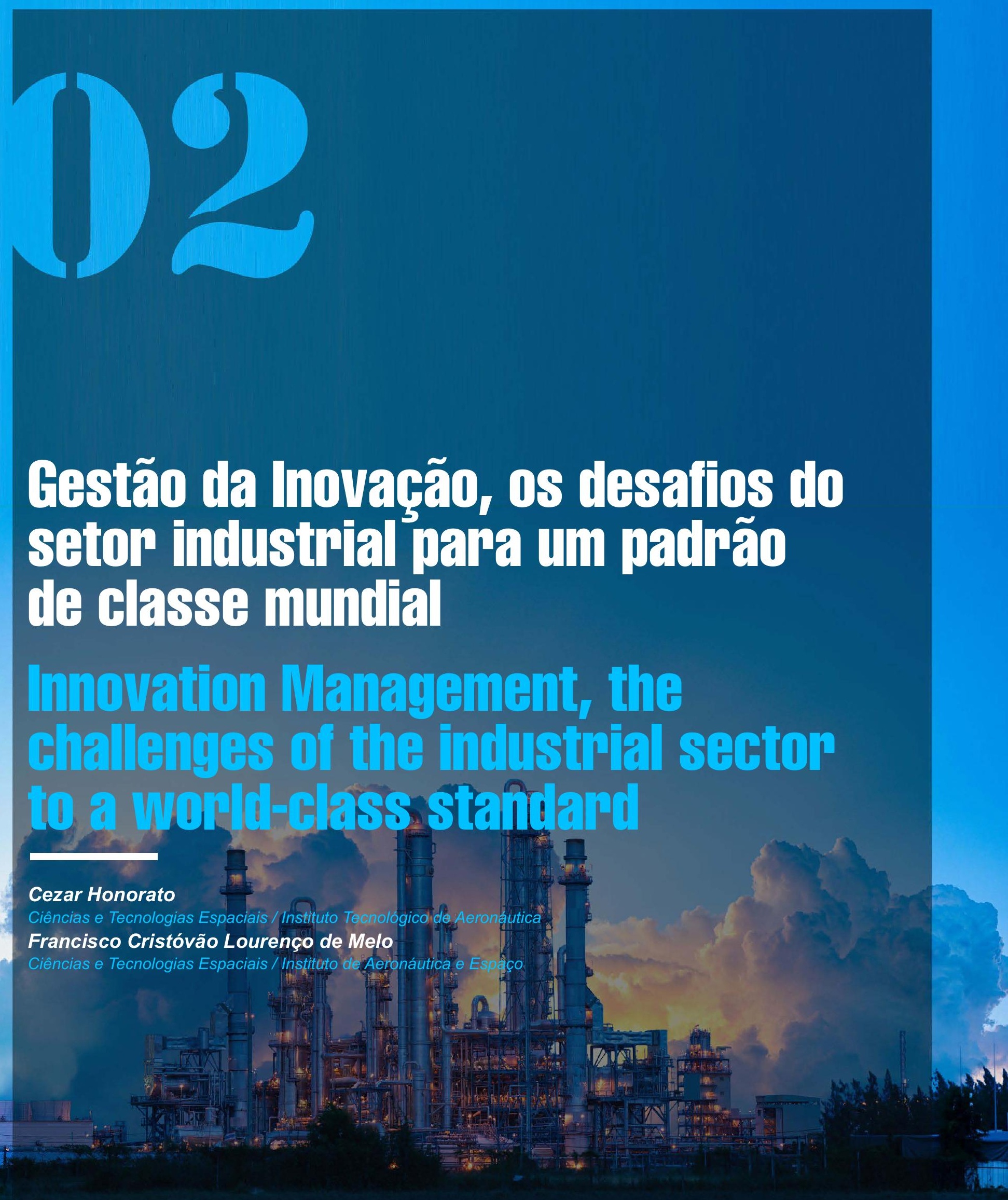

DOI: 10.47573/aya.88580.2.22.2 
À medida que a concorrência se baseia em batalhas de nível global, a inovação tornou-se essencial para que as organizações não apenas sejam líderes em seus mercados, mas também para aumentar a competitividade e, em particular, evitar o seu declínio, sendo vital o processo de gestão de inovação. O objetivo deste trabalho é apresentar um modelo de acumulação de capacidade tecnológica para gerenciamento de inovação, oferecendo referências desde o nível mais básico até o mais avançado para que as organizações possam atingir um padrão de classe mundial, também se comparar com outras e, por meio do planejamento, alcançar a excelência. Uma pesquisa foi aplicada ao diagnóstico de como os profissionais que atuam diretamente nos projetos de inovações em uma empresa de posicionamento global, líder em seu mercado, avaliam a gestão da inovação; a pesquisa mostrou que $51 \%$ dos pesquisados consideraram que a empresa estava em um nível avançado de competência tecnológica para gerenciamento de inovação, mas depois de repetir a pesquisa usando os critérios propostos neste estudo, apenas $8 \%$ mantiveram o nível avançado.

Palavras-chave: inovação. gestão da inovação. capacidade de inovação. acumulação tecnológica.

\section{Alistract}

As the competition is based on global level battles the innovation has become essential for organizations not only to be leaders in their markets, but also to increase competitiveness and, in particular, to avoid its decline, being vital have innovation management process. The aim of this research effort is to present a model of accumulation of technological capacity for innovation management, offering references from the most basic to the most advanced level so that organizations can reach a world class standard, also compare themselves with others and, through planning, achieving excellence. A research was applied to the diagnosis of how the professionals who act directly in the innovations projects in a global company, leader in their market, evaluate the management of the innovation; the survey showed that $51 \%$ of the researched considered that the company was at an advanced level of technological competence for innovation management, but after repeating the research using the criteria proposed in this study, only $8 \%$ maintained the advanced level.

Keywords: innovation. innovation management. innovation capability. technological accumulation. 


\section{INTRODUÇÃO}

A necessidade de maior assertividade no lançamento de produtos inovadores depende fundamentalmente de três fatores: o foco do produto, a análise externa (apoiada na análise de mercado) e o foco interno da empresa, esses três pilares são fundamentais para o sucesso do lançamento de novos produtos à medida que são disponibilizados no mercado.

Com a globalização, muitas empresas que estavam baseadas em um mercado não competitivo tiveram que se adaptar à competição baseada em níveis globais. Hoje em dia, é imprescindível que as inovações atinjam os objetivos planejados, já que um novo produto requer muita alocação de recursos, em áreas multidisciplinares como Marketing, Pesquisa e Desenvolvimento, manufatura, engenharia, logística e distribuição, em todas as etapas de um novo desenvolvimento a partir de a identificação de oportunidades, mapeamento de mercado, desenvolvimento de produtos, produção e distribuição.

De acordo com Rozenfeld e Amaral (2006), as principais forças que influenciam a busca competitiva por velocidade, eficiência e qualidade no desenvolvimento das inovações são: a crescente internacionalização dos mercados, o aumento da diversidade e variedade de produtos, a redução do ciclo de vida dos produtos no mercado, a mudança nos padrões de concorrência entre as organizações e as expectativas dos consumidores em relação à qualidade e à tecnologia.

O que faz as empresas serem competitivas é a sua capacidade de desenvolver e criar produtos, serviços, ou mesmo adequá-los às necessidades de seus clientes, ou novos processos de uma forma rápida a um custo competitivo.

Desta forma a inovação passa a ser encarada como uma espécie de necessidade premente; a habilidade de continuamente encontrar oportunidades para novos produtos e mercados e desenvolver processos mais eficientes para produzi-los é entendido como crucial pelas empresas (ROBERT, 1995).

Ismail, Malone e Geest (2015) expõem que muitas empresas estão satisfeitas com aquilo que funciona e, por isso, deixam de inovar; ressaltam que a sobrevivência de uma companhia depende da sua capacidade de se manter à frente da curva tecnológica e abraçar as mudanças a fim de estar, e permanecer, competitiva perante a concorrência, e por fim abordam que nenhuma empresa poderá acompanhar o ritmo de crescimento se não estiverem dispostas a realizar algo radicalmente novo.

Adicionalmente (Lee, 2019), que vivenciou os ecossistemas de inovação da China e nos Estados Unidos, especificamente no vale do Silício, aborda sob o prisma da competitividade que a clonagem generalizada, por meio do ataque de concorrentes imitadores além de forçar as empresas à inovar forjam a formação de empreendedores tenazes.

Contribuindo para essa discussão Bansal e Grewatsch (2019) entendem mais amplamente como obter inovações mais assertivas, de acordo com a visão dos autores, se as empresas quiserem desenvolver produtos verdadeiramente sustentáveis em vez de iniciar com as necessidades específicas de clientes e vendas no curto prazo devem ter como centro de suas abordagens a promoção do pensamento em longo prazo em torno das tendências sociais e ambientais que impactam nas empresas e na sociedade simultaneamente. Ao fazer isso, as empre- 
sas, não apenas antecipam as necessidades futuras dos clientes, mas também podem moldar ativamente o futuro, em vez de simplesmente reagir ao presente.

Entretanto, inovar sem agilidade é sinônimo de não captar as oportunidades detectadas, perda do protagonismo ou ser superado pela concorrência; Feitor, Kliemann e Cortimiglia (2005) ressaltam a importância da agilidade das empresas, pois concluem em seu estudo que o sucesso das organizações não depende exclusivamente do quanto elas conhecem do ambiente externo, mas de que maneira a empresa utiliza, alavanca seus recursos internos para antever e satisfazer as necessidades dos clientes e mercados.

De Negri e Salerno (2005) em pesquisa realizada com 72.000 empresas brasileiras em conjunto com o Instituto de Pesquisa Econômica Aplicada (IPEA) o qual teve a articulação inédita de banco de dados referente a indústria brasileira com o enfoque em inovações, padrões tecnológicos, desempenho e suas estratégias competitivas ao invés da tradicional visão de tamanho e setor demonstram que inovar e diferenciar produtos é extremamente benéfico para as empresas e seus funcionários; no estudo realizado as firmas foram alocadas em 3 categorias:

a) As que inovam e diferenciam produtos, são aquelas que realizaram inovação de produto para o mercado e obtiveram preço prêmio de $30 \%$ nas suas exportações quando comparadas com as demais exportadoras do mesmo produto, portanto, tendem a criar mais valor, compondo o segmento mais dinâmico, que tende a capturar parcela maior da renda gerada pela indústria;

b) As que são especializadas em produtos padronizados com alta produtividade, a sua estratégia competitiva impõe que o foco de sua atuação seja a redução de custos, em vez de criação de valor como na categoria anterior, tendem a ser atualizada quanto a características operacionais como fabricação, gestão da produção, gestão da qualidade e logística, que são imperativos para a sustentação de custos mais baixos, mas estão defasadas, relativamente à categoria anterior, no que se refere a outras armas da competição, como P\&D, marketing e gerenciamento de marcas;

c) As que não diferenciam e têm produtividade mais baixa, sendo as demais que não pertencem às categorias anteriores, na maior parte engloba empresas tipicamente não exportadoras, menores, que podem, inclusive, inovar, mas são menos eficientes nos mais variados sentidos, que se mostram capazes de captar espaços em mercados menos dinâmicos através de preços baixos e outras possíveis vantagens.

A tabela 1 demonstra alguns resultados do trabalho realizado, sendo que as empresas que inovam e diferenciam produtos, apesar de representar menor número (1,7\% do total), acumulam $25,9 \%$ do faturamento industrial sendo responsável por $13,2 \%$ do emprego gerado. Os dados demonstram que a escala de produção das firmas que inovam e diferenciam produtos é significativamente maior do que as demais categorias, faturamento médio destas empresas é de $\mathrm{R} \$ 135,5$ milhões, o que representa mais que cinco vezes o faturamento médio das empresas especializadas em produtos padronizados. Nas firmas que inovam e diferenciam produtos cada pessoa ocupada é responsável por $\mathrm{R} \$ 74,1$ mil de valor adicionado na produção representando $67,3 \%$ a mais que um trabalhador das firmas especializadas em produtos padronizados, que produz, em média, $\mathrm{R} \$ 44,3$ mil. A remuneração média é de $\mathrm{R} \$ 1.254,64$ e a escolaridade média de seus funcionários é de 9,13 anos, também com maior tempo de permanência no emprego de 54,09 meses quando comparada com as demais e por fim demonstrou que a inovação é 
positivamente correlacionada com a exportação em que o valor médio das firmas que inovam e diferenciam produtos é em média muito mais do que as demais firmas exportadoras.

Este estudo também demonstrou que, se as firmas forem exatamente iguais, exceto pelo fato de apresentarem estratégias competitivas diferentes, as que inovam e diferenciam produtos remuneram os empregados $23 \%$ a mais do que as que não diferenciam produtos e tem produtividade menor, e $11 \%$ a mais do que as especializadas em produtos padronizados.

Tabela 1 - Comparativo de indicadores das indústrias brasileiras segundo estratégias competitivas.

\begin{tabular}{|c|c|c|c|c|c|c|c|c|c|c|c|}
\hline Estratégia Competitiva & $\begin{array}{l}\text { Numero } \\
\text { de } \\
\text { firmas }\end{array}$ & $\begin{array}{l}\text { Participação no } \\
\text { faturamento da } \\
\text { Industria } \\
\text { (\%) }\end{array}$ & $\begin{array}{c}\text { Participação } \\
\text { no emprego } \\
(\%)\end{array}$ & $\begin{array}{c}\text { Faturamento } \\
\text { mé dio } \\
\text { (R\$ milhôes) }\end{array}$ & $\begin{array}{c}\text { Produtividade } \\
\text { do } \\
\text { trabalhador } \\
\text { (R\$ mil) }\end{array}$ & $\begin{array}{c}\text { Remuneração } \\
\text { média } \\
\text { (R\$̧/mês) }\end{array}$ & $\begin{array}{c}\text { Escolaridade } \\
\text { média } \\
\text { (anos) }\end{array}$ & $\begin{array}{c}\text { Tempo de } \\
\text { emprego } \\
\text { médio } \\
\text { (meses) }\end{array}$ & $\begin{array}{c}\text { Prêmio } \\
\text { Salarial } \\
(\%)\end{array}$ & $\begin{array}{c}\text { Valor médio } \\
\text { Exportações } \\
\text { US\$̦ } \\
\text { milhões }\end{array}$ & $\begin{array}{c}\text { Valor médio } \\
\text { Importações } \\
\text { US\$̦ } \\
\text { milhões }\end{array}$ \\
\hline Inovam e diferenciam produtos & $\begin{array}{r}1.199 \\
(1,7 \%) \\
\end{array}$ & 25,9 & 13,2 & 135,5 & 74,1 & $1.254,64$ & 9,13 & 54,09 & 23 & 11,4 & 12,01 \\
\hline Especializadas em produtos padronizados & ' $\begin{array}{r}15311 \\
(21,3 \%)\end{array}$ & 62,6 & 48,7 & 25,7 & 44,3 & 749,02 & 7,64 & 43,9 & 11 & 2,1 & 1,8 \\
\hline
\end{tabular}

Fonte: Adaptado de Negri e Salerno (2005).

\section{REFERENCIAL TEÓRICO}

\section{Conceitos de capacidade tecnológica}

Pesquisas bibliográficas demonstram os esforços realizados para o desenvolvimento de um modelo no qual as capacidades tecnológicas de uma empresa são categorizadas por funções.

Os modelos avaliados convergem, na teoria, que a acumulação se processa a partir das categorias mais simples para as mais complexas, sendo sempre acumulativa ao longo de sua existência. Esta métrica foi desenvolvida por Lall (1992), mais tarde refinada por Bell e Pavitt $(1993,1995)$ e finalmente adaptada por Figueiredo $(2005,2009)$, que desenvolveu estudos direcionados à indústria do setor de aço quanto à taxa de acumulação de capacidade tecnológica a qual foi fundamentada nas atividades que a empresa é capaz de realizar ao longo de sua existência, estas são identificadas em funções básicas com sete níveis de capacidades desde a mais simples até a mais complexa, denominada de inovadora.

Bell e Pavitt $(1993,1995)$ formularam uma definição ampla, segundo a qual a capacidade tecnológica incorpora os recursos necessários para conceber e gerenciar mudanças tecnológicas. Figueiredo (2005) complementa que, tais recursos se incorporam e acumulam aos indivíduos (como aptidões, conhecimentos e experiência) e aos sistemas organizacionais, de forma que para o autor existem quatro dimensões sobre o conceito: sistema físico, sistema organizacional, mentes dos indivíduos e, por fim, produtos e serviços.

A matriz de acumulação de capacidades tecnológicas é uma abordagem no nível das empresas que permite identificar os diversos setores tecnológicos da economia e a velocidade com que acumulam capacidades tecnológicas ao longo do tempo, bem como distinguir os setores e as empresas mais dinâmicas das mais lentas, e assim, programar medidas e incentivos diferenciados para os diferentes setores, com a finalidade de promover o desenvolvimento das 
capacidades tecnológicas, em países de industrialização tardia (FIGUEIREDO, 2005).

\section{Modelos de acumulação de capacidade tecnológica}

O modelo proposto por Lall (1992) foi à base para realizar uma avaliação do grau de complexidade das capacidades tecnológicas acumuladas das organizações. Foram desenvolvidos com três graus de complexidade segundo a formalidade e propósito dos esforços tecnológicos, considerando dimensões de investimento, produção e relacionamento com a economia:

a) Nível Básico - capacidades tecnológicas acumuladas por meio das rotinas básicas da atividade de produção, isto é, mecanismos by-doing. A capacitação é necessária para as empresas se manterem em funcionamento;

b) Nível Intermediário - capacidades tecnológicas construídas por meio de atividades ou esforços conduzidos deliberadamente. Essa capacitação habilita as empresas a aprimorarem a execução de melhoria da tecnologia em uso. Consiste na capacidade de encontrar soluções cujo desempenho deve ser superior;

c) Nível Avançado - capacidades tecnológicas em nível superior, no qual a empresa deverá não somente fazer melhor, mas, principalmente, fazer diferente, evoluir e/ou criar tecnologias.

Neste conceito, Lall (1992), possibilita distinguir capacidade operacional da capacidade inovativa. A capacidade operacional é considerada sinônima da expressão know-how, que indica que os conhecimentos e experiências são acumulados para usar tecnologias transferidas por outras empresas/setores/mercados; adquiridas por esforços by-doing, que constitui uma capacidade tecnológica de menor nível agregado de complexidade.

É compreendida como capacidade inovativa, cujo nível de complexidade é maior, como os conhecimentos, experiências e capacidades de entender os princípios da tecnologia, podendo ser considerada um sinônimo da expressão know-why (LALL, 1992).

A matriz de Lall (1992), apresentada na tabela 5, abrange a capacidade tecnológica e que foi construída segundo três grandes dimensões funcionais: capacidade de investimento, de produção e de ligação com outros agentes. As capacidades são segmentadas em três níveis de complexidades: básico, intermediário e avançado, sendo elas:

a) Capacidade de Investimento: Descreve as qualificações em planejar e executar investimento, considerando as análises e controles pré-investimento e as atividades de execução de projeto (LALL 1992, apud FLEURY e GALINNA, 2013);

b) Capacidade de produção: Relacionada com as qualificações básicas das operações de controle de qualidade, manutenção preventiva e assimilação de tecnologia de processo (LALL 1992, apud FLEURY e GALINNA, 2013);

c) Ligação com outros agentes: Relaciona as qualificações da empresa em se relacionar com agentes externos a fim de obter, trocar, transferir e desenvolver tecnologias (LALL 1992, apud FLEURY e GALINNA, 2013). 
Figura 1 - Matriz de Capacidades Tecnológicas de Lall

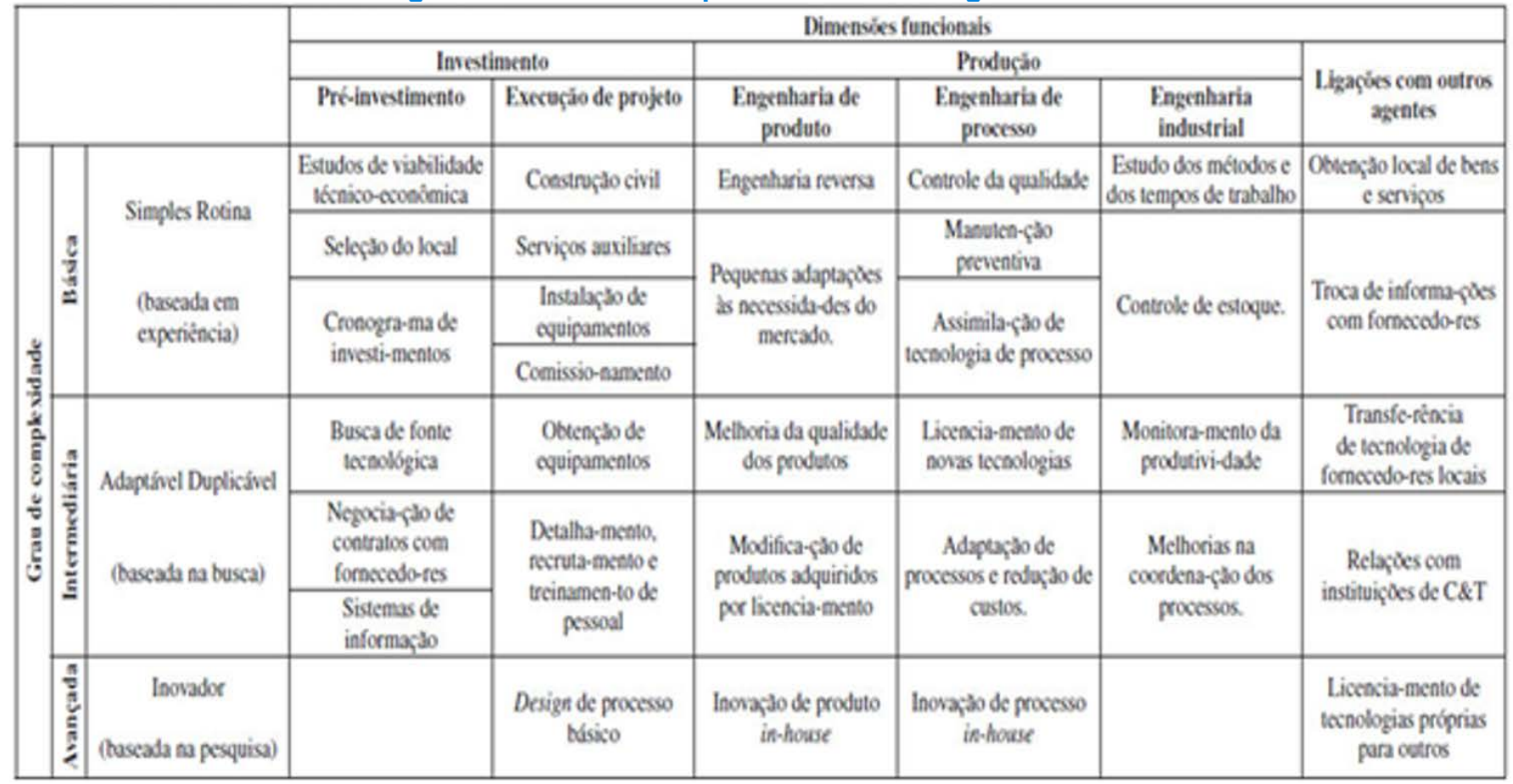

Fonte: Fleury e Galinna (2013)

No modelo desenvolvido por Bell (1997) o desenvolvimento da capacidade tecnológica das empresas ocorre num processo de acumulação ao longo dos anos em uma trajetória gradual de aquisição de novas capacidades tecnológicas, como demonstrado na Figura 2 que ilustra o modelo proposto; o autor divide os tipos de competência tecnológica em quatro níveis, sendo elas:

a) Competências para usar e operar tecnologias existentes, sendo o nível mais simples;

b) Competências para aprimoramento incremental dos produtos e processos e organizacional;

c) Competências para copiar, implementar e desenvolver as tecnologias existentes;

d) Competências para desenvolver e implementar novas tecnologias, sendo este o nível mais avançado.

Os degraus da escada mostram o nível de evolução para os tipos de competência tecnológica no decorrer dos anos, a qual vai se ampliando e acumulando até atingir um nível de amadurecimento representado pela curva identificada como "competência tecnologia acumulada" cuja referência é identifica pela linha "fronteira tecnológica internacional" (FIGUEIREDO, 2005). 


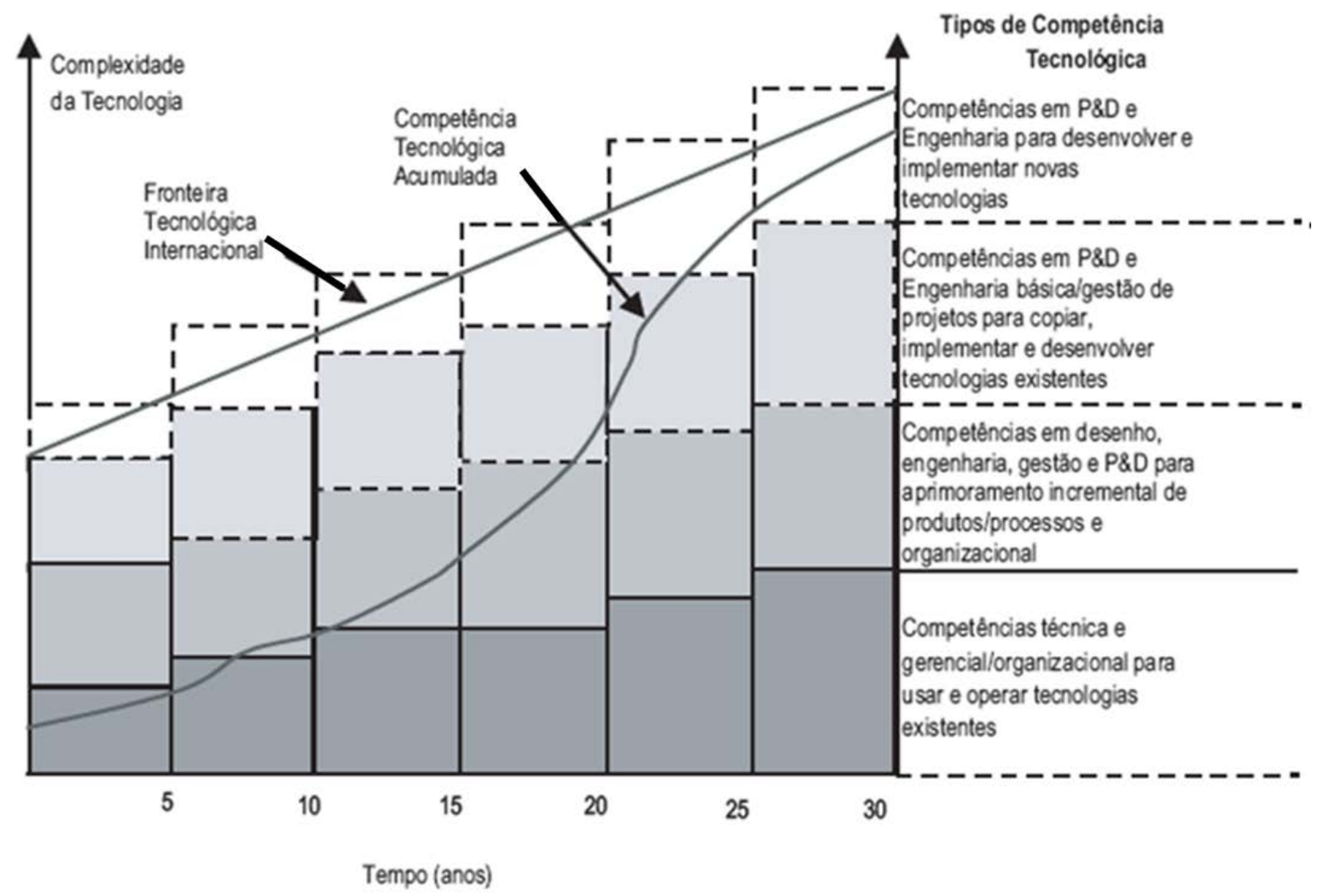

Fonte: Figueiredo (2005)

O modelo proposto por Figueiredo $(2005,2009)$ permite medir a acumulação de capacidade tecnológica baseada em atividades que a empresa é capaz de realizar ao longo de sua existência, sendo possível distinguir entre capacidades rotineiras - compreende a habilidade de usar ou operar determinada tecnologia, e capacidades inovadoras - habilidade de adaptar ou desenvolver novos processos de produção, sistemas organizacionais, produtos, equipamentos e projetos de engenharia, de forma a gerar e gerir a inovação tecnológica sendo referência mundial.

O modelo representado na tabela 6 é detalhado da seguinte forma: as colunas representam as capacidades tecnológicas por função, e as linhas, os níveis de dificuldade. As categorias expressam os níveis de capacidade, portanto, o tipo de atividade que a empresa é capaz de realizar por si mesmas em diferentes intervalos de tempos, sendo divido em sete níveis de capacidade tecnológica: Nível 1 Básico, Nível 2 Renovado, Nível 3 Extra básico, Nível 4 Pré-Intermediário, Nível 5 Intermediário, Nível 6 Intermediário Superior, Nível 7 Avançado. E as funções: 1) Investimento (Decisão e Controle sobre a planta e Engenharia de Projetos), 2) Processos e Organização da Produção, 3) Produtos e 4) Equipamentos.

O modelo de Figueiredo $(2005,2009)$ também diferenciou as capacidades tecnológicas de rotina das capacidades de inovação. As capacidades de rotina são responsáveis pelo dia a dia das empresas, portanto, por manter a operação, identificada na tabela 6 , os quadrantes na cor cinza. As capacidades de inovação referem-se às capacidades para criar, alterar ou melhorar os produtos, processo, equipamentos ou produtos da organização, estando os quadrantes identificados na cor branca. 
Neste modelo, os níveis de capacidade são acumulativos, o que significa que para estar num determinado nível deve existir o domínio dos requerimentos dos níveis anteriores. Este modelo não pressupõe uma sequência de evolução linear ou que as capacidades sejam construídas ao mesmo tempo e na mesma velocidade para as diferentes funções.

\section{METODOLOGIA}

O procedimento de pesquisa utilizado neste esforço de pesquisa pode ser dividido em cinco fases distintas conforme demonstrado na Figura 3. Uma fase inicial cria um entendimento completo nos campos de processo de desenvolvimento de produto por meio da pesquisa sistemática na literatura, visando uma estrutura de modelo que seja prática e aplicável à realidade das empresas industriais, a fase 01 de revisão bibliográfica é detalhada na figura 4.

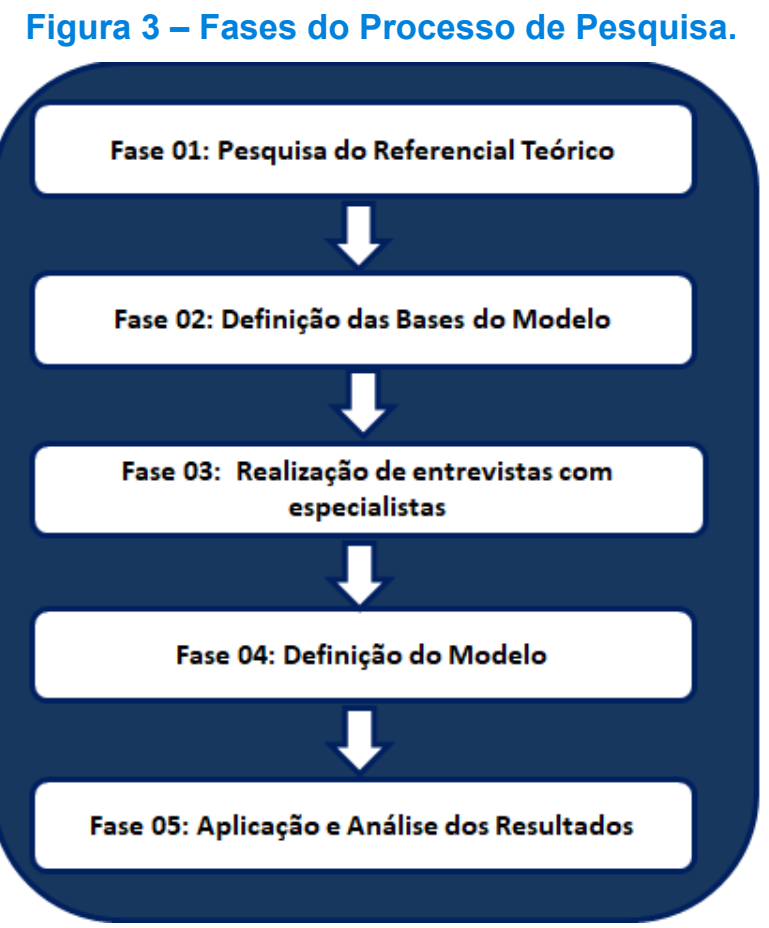

Fonte: Autoria própria (2021)

$\mathrm{Na}$ realização da extensa pesquisa bibliográfica foi utilizada como referência inicial as palavras-chave temáticas associadas a este trabalho: Inovação, Gestão da Inovação, Capacidade de inovação e Acumulação Tecnológica.

Para garantir a relevância acadêmica, limitamos a pesquisa bibliométrica deste trabaIho a disponibilizar os textos completos de artigos de periódicos revisados por pares, contendo bancos de dados on-line publicados nos últimos 5 anos (2015-2019) nas bases Web of Science, Scopus e base integrada de pesquisa do Instituto Tecnológico Aeronáutico, a figura 4 demonstra que foram encontrados quatrocentos e vinte e seis documentos, que foram revisados, entre artigos técnicos, pesquisas governamentais e, quando disponíveis, as citações mais relevantes e após análises realizadas obteve o ponto de partida, as referências bibliográficas utilizadas neste estudo, resultando em duzentos e trinta e quatro documentos. 
Figura 4 - Processo de Revisão de Literatura.

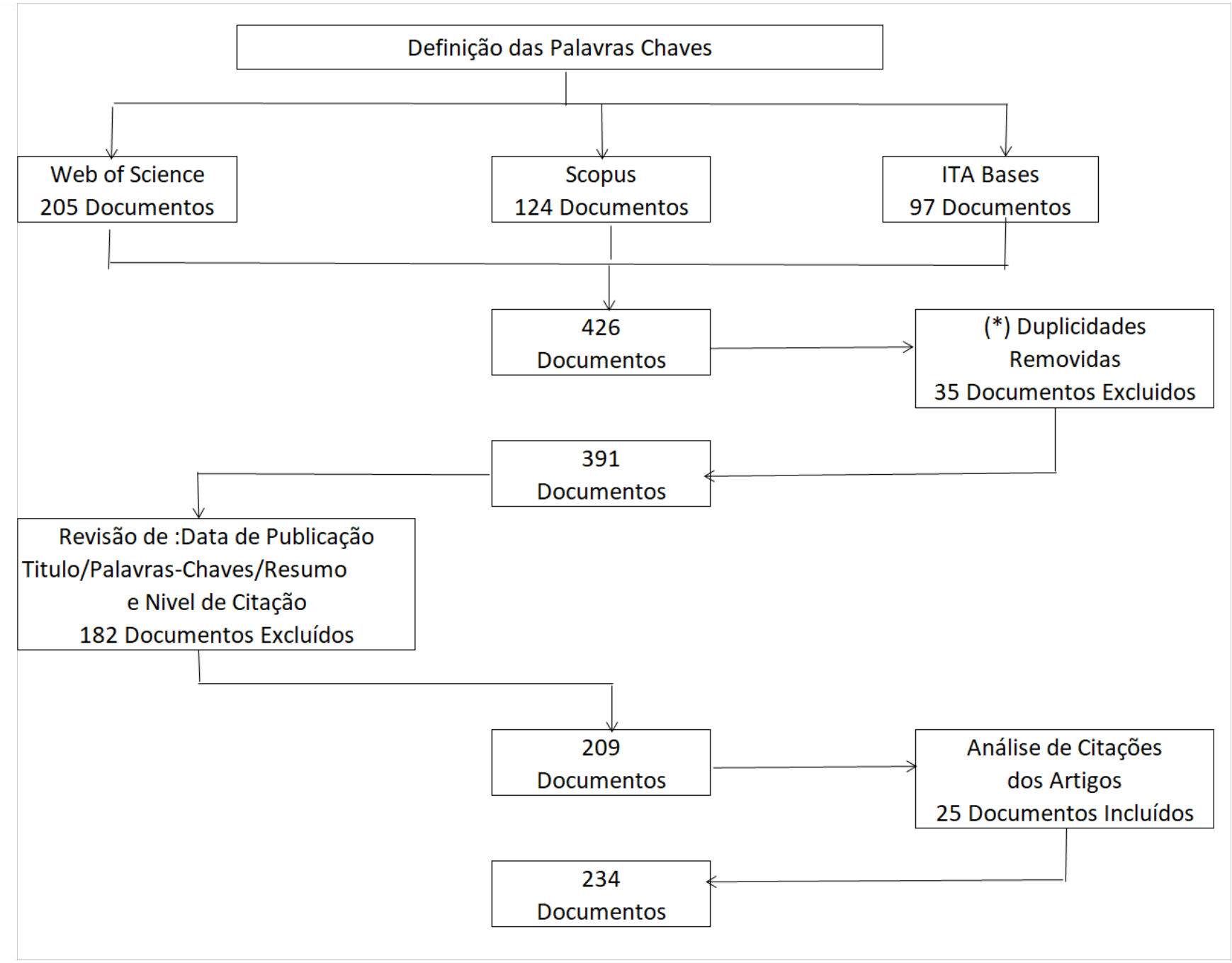

Fonte: Autoria própria (2020)

Devido ao tema deste esforço de pesquisa ser multidisciplinar a pesquisa do referencial teórico proporcionou a identificação das bases conceituais a serem utilizadas e que permearão em todo o trabalho que identifica a segunda fase. A terceira fase é marcada por um processo de entrevista com 15 profissionais que atuam, direta ou indiretamente, com processo de desenvolvimento de produto tais como: Engenharia, Qualidade, Pesquisa e Desenvolvimento, Gestão de Projetos, Suporte ao Cliente, Desenvolvimento de Fornecedores sob o enfoque de duas questões que envolvem os processos de desenvolvimento de produto diretamente nos projetos de inovação na prática: (i) As empresas falham em seus processos de inovação no que se refere ao setor industrial no desenvolvimento de produto, e/ou processo, por falta de capacidade ou mesmo em seus resultados; e (ii) As empresas não avaliam seus próprios recursos no processo de desenvolvimento de inovações que os impedem de executar qualquer ação coordenada.

A próxima etapa, quarta fase, é a definição do modelo que este trabalho preconiza o qual apresenta um modelo de acumulação tecnológica direcionado a gestão de inovação ancorados com a definição das entregas mínimas necessárias que caracterizam cada nível estabelecido, por fim, na quinta e última fase é aplicado por meio de estudo de caso numa empresa do setor industrial de presença global líder em seu segmento de atuação.

De acordo com o modelo proposto por Figueiredo (2003) com o objetivo de medir a acu- 
mulação de capacidade tecnológica baseada em atividades que a empresa é capaz de realizar ao longo de sua existência é preconizado neste trabalho o modelo de acumulação de capacidade para a função de gestão da inovação.

O modelo apresenta sete níveis cumulativos de capacidade de gestão da inovação, classificados de acordo com o nível de competência. Eles são: Nível 1: Básico, Nível 2: Renovado, Nível 3: Extra Básico, Nível 4: Pré-Intermediário, Nível 5: Intermediário, Nível 6: Alto Intermediário e Nível 7: Avançado.

A seguir é indicado o detalhamento do que se espera para cada nível de acordo com o modelo de acumulação de capacidade para a função de gestão da inovação proposto neste trabalho.

(1) Básico Rotina:

Sintetiza este nível a empresa que faz o lançamento da inovação sem análise de mercado, sem critérios, sem equipe estabelecida e sem controle das entregas.

Somente há um líder, não existindo uma equipe formalizada para desenvolvimento do projeto, que recebe ajuda por cooperação.

Existe a definição do escopo da inovação, representado pelo produto que deverá ser entregue, porém sem o detalhamento das especificações.

As iniciativas pulverizadas e com áreas de suportes dispersos sem ter análises de prioridade das atividades mais importantes assim como dos projetos mais relevantes.

(2) Básico Rotina Renovado:

Sintetiza este nível a empresa que faz o lançamento da inovação com análise de mercado baseado na experiência dos profissionais que nele atuam, portanto sem suporte de pesquisas.

Existe a definição e especificação clara do produto a ser entregue. Também há uma equipe multifuncional formalizada para cada inovação com responsabilidades definidas, entretanto não existe controle das entregas.

\section{(3) Extra básico Inovadores:}

Sintetiza este nível a empresa que identifica a necessidade da inovação com base em pesquisas qualitativas. É capaz de definir o escopo do projeto, mapeando as principais atividades como tempo, custo e os principais riscos envolvidos, também são definidos os indicadores que a inovação deverá entregar dando claridade as expectativas; consegue fazer uma priorização das inovações de acordo com as mais relevantes ao seu negócio através de métricas.

Possui estudo financeiro de viabilidade com indicadores claros que a inovação deva entregar depois do lançamento no mercado. Escopo detalhado e com as entregas acompanhadas através de um cronograma.

Realiza avaliação dos riscos referente ao desenvolvimento, produção e entrega do produto e através planejamento propõe ações de mitigação para os riscos mais relevantes. 


\section{(4) Pré-intermediário Inovadores:}

Sintetiza este nível a empresa que identifica a necessidade da inovação com base em pesquisas detalhadas quantitativas assim como consegue fazer uma priorização de acordo com as iniciativas as mais relevantes ao seu negócio através de critérios definidos comparando os recursos disponíveis com as inovações que entregarão os benefícios mais vantajosos à empresa.

Existe uma sistemática definida para a gestão da inovação, que contempla desde a geração da ideia até o lançamento no mercado e o cumpre de forma consistente.

Há detalhamento e especificação de todos os materiais utilizados (matéria prima e embalagem) assim como mapa de processo claramente estabelecido.

\section{(5) Intermediário Inovadores:}

Neste nível de capacidade são definidos critérios claros e objetivos para a aprovação da inovação estando alinhados com as metas do planejamento estratégico da empresa, no mínimo quanto a retorno financeiro, qualidade e atingimento do volume de vendas.

A sistemática da gestão da inovação envolve todo o ciclo da inovação contemplando desde geração da ideia até o lançamento no mercado e, posteriormente, análise de performance do produto no mercado até um ano após o seu lançamento. Existe uma sistemática clara de governança para a gestão do portfólio de projetos de inovação.

É realizado o levantamento das competências necessárias a fim de desenvolvê-las, ou aprimorá-las para suportar a entrega da inovação.

Análise e controle de qualidade de todos os materiais utilizados para a produção do produto (embalagem e matéria prima) ou através garantia de qualidade enviada pelo fornecedor para todos os lotes de materiais. Avaliação da qualidade por atributos dos produtos produzidos, estabelecidos somente no final do processo produtivo.

\section{(6) Intermediário Superior Inovadores:}

Sintetiza este nível a empresa que faz a gestão da inovação de forma sistêmica com métricas claras e com a mensuração dos resultados, porém não existe o atingimento consistente da performance dos indicadores planejados, no mínimo, quanto à qualidade, retorno financeiro $\mathrm{e}$ atingimento do volume de vendas.

Estabelecimento do procedimento de controle estatístico ao longo do processo de montagem ou produtivo com avaliação de qualidade por atributos através de itens de controle e itens de verificação, entretanto não existe um plano para que variações sistêmicas ou pontuais possam ser detectadas e corrigidas nas suas causas fundamentais.

\section{(7) Avançado inovadores:}

Faz a gestão de forma consistente em todas as inovações da firma com a mensuração e atingimento dos resultados que foram planejados antes do lançamento, no mínimo quanto à qualidade, retorno financeiro e atingimento do volume de vendas após um ano do produto entrar no mercado. As inovações que não tiveram a performance desejada têm através de metodologia 
robusta a identificação das causas raízes e juntamente com a análise dos registros das lições aprendidas para que as melhorias possam ser incorporadas nas inovações futuras.

Garantir amplamente o atingimento proposto dos índices de qualidade e de satisfação dos consumidores estabelecidos dentro da firma através da metodologia de melhoria continua composto por planos consistentes, como por exemplo, o ciclo PDCA, utilizando ferramentas de análise tendo com o foco as variações de processo, produto fora de especificação e reclamações de consumidores das inovações colocados no mercado suportado pelos stakeholders internos e, quando necessário, externos como, por exemplo, fornecedores.

A figura 5 apresenta uma síntese dos requerimentos propostos por nível de competência de acordo com a visão ampla de gestão da inovação de acordo com as recomendações indicadas neste trabalho.

Figura 5 - Resumo dos requerimentos propostos por nível de competência para a gestão da inovação.

\begin{tabular}{|c|c|c|c|c|c|c|c|}
\hline Requerimentos / Nivel de competencia Tecnológica & Básico & $\begin{array}{c}\text { Básico } \\
\text { Renovado }\end{array}$ & $\begin{array}{l}\text { Extra } \\
\text { Básico }\end{array}$ & Pré-Inter. & Intermediário & $\begin{array}{l}\text { Intermediário } \\
\text { Super } \\
\text { Inovadores }\end{array}$ & Avançado \\
\hline & Nivel 1 & Nivel 2 & Nivel 3 & Nivel 4 & Nivel 5 & Nivel 6 & Nivel 7 \\
\hline Ter designado uml lider para cada inovaçăo & $\mathrm{X}$ & $\mathrm{X}$ & $\mathrm{X}$ & $\mathrm{X}$ & $\mathrm{X}$ & $\mathrm{X}$ & $\mathrm{X}$ \\
\hline Definiçāo de escopo & $\mathrm{X}$ & $\mathrm{X}$ & $\mathrm{X}$ & $\mathrm{X}$ & $\mathrm{X}$ & $\mathrm{X}$ & $\mathrm{X}$ \\
\hline Have defined specifications for innovation products & & $\mathrm{X}$ & $\mathrm{X}$ & $\mathrm{X}$ & $\mathrm{X}$ & $\mathrm{X}$ & $\mathrm{X}$ \\
\hline Realizar analise de Mercado & & $\mathrm{X}$ & $\mathrm{X}$ & $\mathrm{X}$ & $\mathrm{X}$ & $\mathrm{X}$ & $\mathrm{X}$ \\
\hline Equipe estabelecida com foco na inovação (multifumcional) & & $\mathrm{X}$ & $\mathrm{X}$ & $\mathrm{X}$ & $\mathrm{X}$ & $\mathrm{X}$ & $\mathrm{X}$ \\
\hline Priorização das inovaçōes de forma subjetiva & & $\mathrm{X}$ & $\mathrm{X}$ & $\mathrm{X}$ & $\mathrm{X}$ & $\mathrm{X}$ & $\mathrm{X}$ \\
\hline Análise de Mercado e/ pesquisas qualitativas & & & $\mathrm{X}$ & $\mathrm{X}$ & $\mathrm{X}$ & $\mathrm{X}$ & $\mathrm{X}$ \\
\hline Definiçäo das atividades criticas - cronograma & & & $\mathbf{X}$ & $\mathrm{X}$ & $\mathrm{X}$ & $\mathrm{X}$ & $\mathrm{X}$ \\
\hline Definição de planejamento de custos do projeto & & & $\mathbf{X}$ & $\mathrm{X}$ & $\mathrm{X}$ & $\mathrm{X}$ & $\mathrm{X}$ \\
\hline Definição de métricas das entregas da inovação & & & $\mathbf{X}$ & $\mathrm{X}$ & $\mathrm{X}$ & $\mathrm{X}$ & $\mathrm{X}$ \\
\hline Priorizaçāo das inovaçōes coml criterios tecnicos & & & $\mathbf{X}$ & $\mathrm{X}$ & $\mathrm{X}$ & $\mathrm{X}$ & $\mathrm{X}$ \\
\hline $\begin{array}{l}\text { Avaliação/ Mïtigaçăo dos riscos: desenvolvimento /produção e } \\
\text { entrega da inovação }\end{array}$ & & & $\mathbf{X}$ & $\mathrm{X}$ & $\mathrm{X}$ & $\mathrm{X}$ & $\mathrm{X}$ \\
\hline Analise de Mercado $\mathrm{d} /$ pesquisas quantitativas & & & & $\mathbf{X}$ & $\mathrm{X}$ & $\mathrm{X}$ & $\mathrm{X}$ \\
\hline Processo de gestāo de inovação definido & & & & $\mathbf{X}$ & $\mathrm{X}$ & $\mathrm{X}$ & $\mathrm{X}$ \\
\hline $\begin{array}{l}\text { Priorizaçäo das inovaçōes mais relevantes ao negócio avaliando } \\
\text { recursos disponiveis x beneficios }\end{array}$ & & & & $\mathbf{X}$ & $\mathrm{X}$ & $\mathrm{X}$ & $\mathrm{X}$ \\
\hline Especificação de todos os materiais utilizados na inovação & & & & $\mathbf{X}$ & $\mathrm{X}$ & $\mathrm{X}$ & $\mathrm{X}$ \\
\hline Mapa de processo estabelecido & & & & $\mathbf{X}$ & $\mathrm{X}$ & $\mathrm{X}$ & $\mathrm{X}$ \\
\hline $\begin{array}{l}\text { Targets da Inovação alinhados com o desdobramento de metas do } \\
\text { planejamento estratégico }\end{array}$ & & & & & $\mathbf{X}$ & $\mathrm{X}$ & $\mathrm{X}$ \\
\hline $\begin{array}{l}\text { Sistemática de gestão da inovação contemipla desde a geração de } \\
\text { idéia ate o produto no mercado }\end{array}$ & & & & & $\mathbf{X}$ & $\mathrm{X}$ & $\mathrm{X}$ \\
\hline Avaliação pós lançamento & & & & & $\mathbf{X}$ & $\mathrm{X}$ & $\mathrm{X}$ \\
\hline $\begin{array}{l}\text { Identificar e melhorar as competências para garantir a entrega da } \\
\text { inovação }\end{array}$ & & & & & $\mathbf{X}$ & $\mathrm{X}$ & $\mathrm{X}$ \\
\hline $\begin{array}{l}\text { Analise e controle de qualidade das especificaçōes de todos os } \\
\text { materiais utilizados }\end{array}$ & & & & & $\mathbf{X}$ & $\mathrm{X}$ & $\mathrm{X}$ \\
\hline $\begin{array}{l}\text { Avaliação da qualidade dos produtos fabricados através de } \\
\text { atributos somente no final do processo produtivo }\end{array}$ & & & & & $\mathbf{X}$ & $\mathrm{X}$ & $\mathrm{X}$ \\
\hline $\begin{array}{l}\text { Realiza a mensuração dos resultados das inovaçōes: qualidade dos } \\
\text { produtos, retomo financeiro e vendas }\end{array}$ & & & & & & $\mathbf{X}$ & $\mathrm{X}$ \\
\hline $\begin{array}{l}\text { Avaliação da qualidade por atributos durante o processo de } \\
\text { fabricaçäo/montagem com itens de controle e de verificaçăo }\end{array}$ & & & & & & $\mathbf{X}$ & $\mathrm{X}$ \\
\hline $\begin{array}{l}\text { Processo de controle estatistico ao longo do processo de } \\
\text { fabricaçäo/montagemi dos itens de controle criticos }\end{array}$ & & & & & & $\mathbf{X}$ & $\mathrm{X}$ \\
\hline $\begin{array}{l}\text { Atingimento das metricas propostas para as inovaçōes quanto a } \\
\text { qualidade / financeiro e vendas }\end{array}$ & & & & & & & $\mathbf{X}$ \\
\hline Identificaçāo das causas raizes das falhas ocomidas & & & & & & & $\mathbf{X}$ \\
\hline $\begin{array}{l}\text { Analise de variação de processo, produtos fora de especificação e } \\
\text { reclamaçöes de consmmidores das inovaçōes com as açöes de } \\
\text { contingencia }\end{array}$ & & & & & & & $\mathbf{X}$ \\
\hline $\begin{array}{l}\text { Registro de liçōes aprendidas e melhorias propostas para os } \\
\text { projetos futuros }\end{array}$ & & & & & & & $\mathbf{X}$ \\
\hline
\end{tabular}

Fonte: Autoria própria (2021) 


\section{ESTUDO DE CASO}

Estabelecido o modelo de acumulação de capacidade para a função de gestão da inovação, será aplicada uma pesquisa exploratória para diagnosticar como os profissionais da empresa líder em seu mercado e que atuam diretamente nas inovações avaliam a gestão da inovação.

Serão fornecidas referências para que os participantes se autoavaliem, devido ao sigilo e ao objetivo de ter maior objetividade nas respostas, não será solicitado o nome do participante e a empresa é identificada como "empresa $\beta$ ", o que é uma empresa global do setor industrial presente no Brasil e em mais de 60 países em todos os continentes.

A amostra foi selecionada para acessibilidade entre 40 profissionais, que atuam diretamente nos projetos de inovação da "empresa $\beta$ ", após cálculo com nível de confiança de $95 \%$, erro amostral de $5 \%$ atingiu número mínimo de 37 participantes. nas áreas: Pesquisa e Desenvolvimento, planejamento estratégico, engenharia e tecnologia, planejamento de demanda, planejamento de qualidade, manufatura e inovação; sendo a "empresa $\beta$ " uma empresa multinacional com forte presença na América Latina, os participantes estão distribuídos em países como no Brasil, Argentina, México, Colômbia e os perfis dos participantes são apresentados na figura 6 de acordo com a área de trabalho.

Figura 6 - Distribuição dos participantes da pesquisa por área de atuação

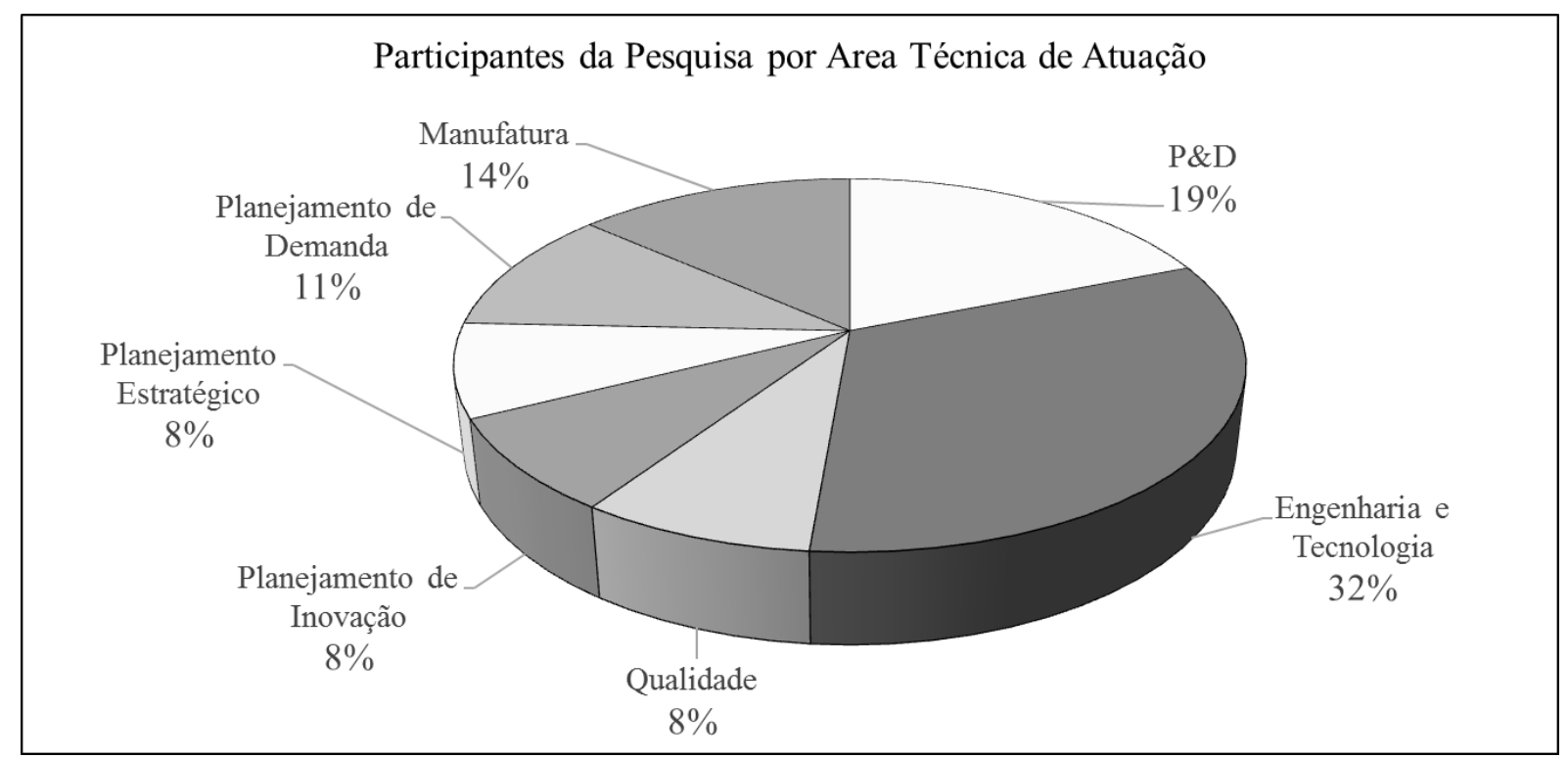

Fonte: Autoria própria (2021)

Para garantir a compreensão dos participantes da interpretação das questões elaboradas, bem como dos termos técnicos utilizados, foi realizado um pré-teste, ou seja, a validação do questionário com a aplicação prévia em um pequeno grupo de participantes para enviar a pesquisa para todos os participantes.

O instrumento de pesquisa consiste em avaliar em qual nível de acumulação tecnológica da gestão da inovação a empresa foi avaliada de acordo com a visão e experiência de cada profissional que atua diretamente em inovações por meio da escala likert avaliada em 1 (não existe), 2 (nível básico) , 3 (nível pré-intermediário), 4 (nível intermediário) e 5 (nível avançado).

A pesquisa foi repetida utilizando o conceito proposto neste artigo de acordo com o nível de competência desde o nível 1 como básico até o nível 7 como avançado. 
Para correlacionar a primeira avaliação realizada no nível de gestão da inovação com os critérios que foram propostos neste artigo foi feita a tabela 2 na qual propõe a correlação dos critérios de forma a poder comparar os resultados da pesquisa, portanto, analisar a gestão da inovação em prismas diferentes.

Tabela 2 - Correlação de critérios entre as autoavaliações realizadas.

\begin{tabular}{|l|l|}
\hline $\begin{array}{l}\text { Critérios utilizados na } \\
1^{\circ} \text { questão da avaliação }\end{array}$ & $\begin{array}{l}\text { Critérios utilizados na } 6^{\circ} \text { questão da avaliação de acordo com a matriz de } \\
\text { competencia tecnológica para a gestão da inovação indicados neste trabalho }\end{array}$ \\
\hline (1) Não Existe & \\
\hline (2) Básico & Básico (nivel 1) / Renovado (nivel 2) / Extra Básico (nivel 3) \\
\hline (3) Pré-Intermediário & Pré-Intermediário (nível 4) \\
\hline (4) Intermediário & Intermediário (nível 5)/Intermediário Super Inovadores (nível 6) \\
\hline (5) Avançado & Avançado Inovadores (nível 7) \\
\hline
\end{tabular}

Fonte: Autoria própria (2021)

Com a finalidade de identificar a percepção dos participantes em relação a cada uma das questões, inicia-se a apresentação dos dados analisando cada uma das questões abordadas isoladamente e no final será realizada uma análise com o cruzamento da primeira e última questão, colocadas nesta posição de forma intencional, a fim de avaliar sobre prismas diferentes o mesmo aspecto da gestão da inovação.

Na figura 7 poderá ser visualizado o comparativo entre as duas avaliações, sendo a primeira de acordo a experiência e os próprios critérios que avaliador acredita que empresa " $\beta$ " se encontrava e a segunda avaliação sob o prisma da matriz de competência tecnológica para a gestão da inovação indicadas neste trabalho.

Figura 7 - Comparativo das autoavaliações da Gestão de Inovação

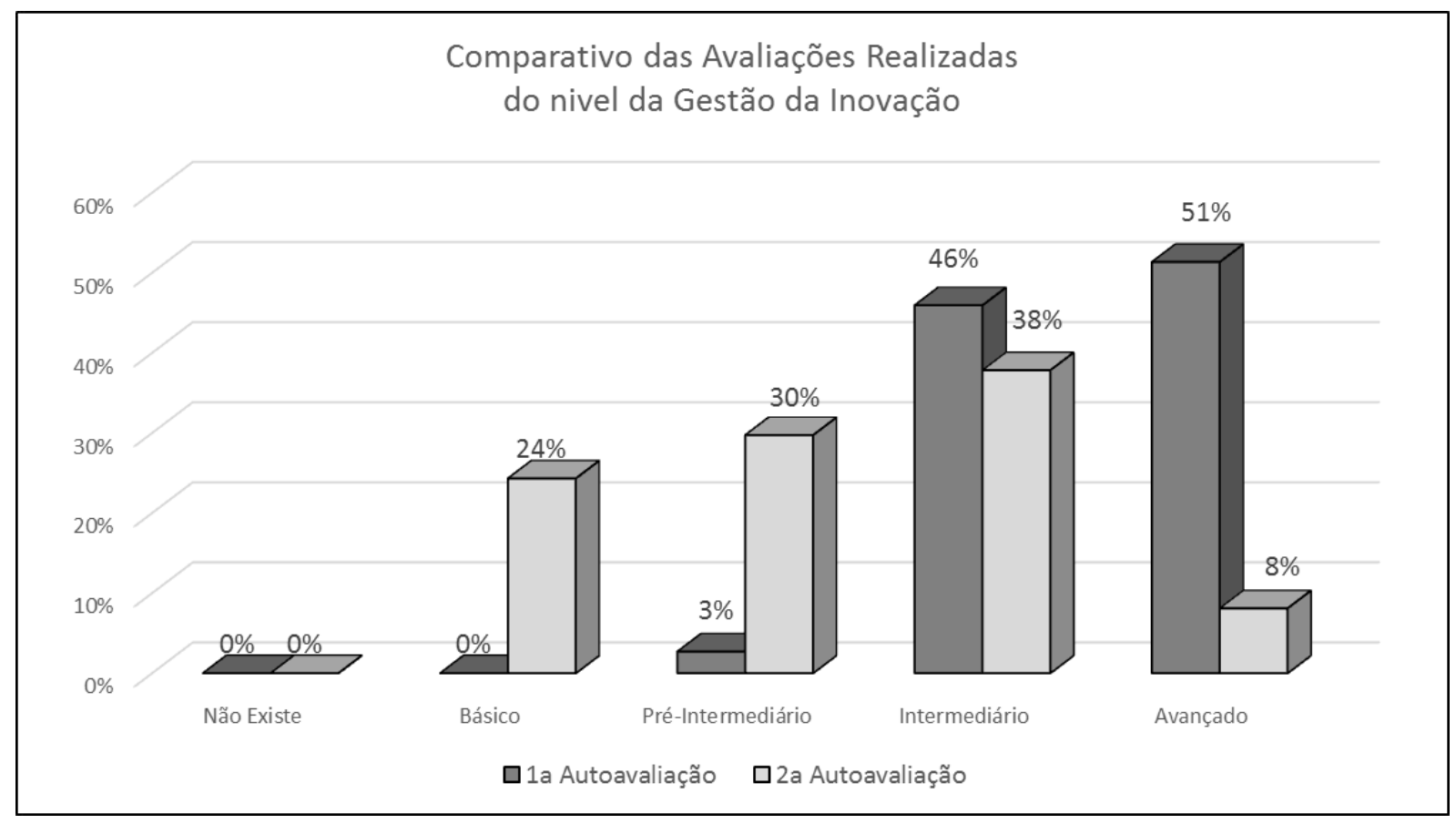

Fonte: Autoria própria (2021)

Percebe-se que houve uma diminuição significativa quanto à avaliação do nível avançado da gestão da inovação o qual passou de $51 \%$ dos participantes para, somente, $8 \%$ do total dos avaliados; o nível intermediário de $46 \%$ para $38 \%$, por outro lado evidenciou um aumento do 
nível pré-intermediário de 3\% para 30\% e, surpreendentemente, o nível básico que não apareceu na $1^{\text {a }}$ avaliação obteve o resultado de $24 \%$ do total dos pesquisados.

A pesquisa demonstrou que os profissionais que avaliaram que a empresa estava no nível avançado da gestão de inovação ao se deparar com critérios mais claros reavaliaram seus posicionamentos com um menor nível de competência, sendo que na $1^{\text {a }}$ pesquisa obteve $97 \%$ dos pesquisados entenderam que a empresa se encontrava no nível intermediário ou acima e posteriormente foi de $46 \%$ dos pesquisados.

Ao analisar detalhadamente os resultados percebeu que de todos os profissionais que alteraram suas autoavaliações em que $32 \%$ regrediram para, somente, o nível anterior, desta forma, alteraram de nível avançado para intermediário, intermediário para pré-intermediário ou de pré-intermediário para básico e que $68 \%$ dos entrevistados alteraram para, no mínimo, dois níveis anteriores; destes $56 \%$ dos entrevistados regrediram em dois níveis anteriores e $12 \%$ regrediram em três níveis, desta forma, é evidenciado pela pesquisa em questão que, existe demasiada subjetividade ao avaliar a gestão de inovação de uma organização.

\section{CONCLUSÃO}

A partir do objetivo colocado no foco deste trabalho de medir a acumulação de capacidade tecnológica (TC) eliminando a subjetividade que existe atualmente a partir das atividades que a empresa é capaz de realizar ao longo de sua existência foi proposto o modelo de acumulação de capacidade para a gestão da inovação. . O modelo sugere níveis cumulativos de capacidade de gestão da inovação do nível mais básico (nível 01) ao mais avançado (nível 07); com uma visão ampla da gestão da inovação a empresa tem neste nível não se restringe a ter um processo de inovação estabelecido, mas sim tem métricas claras, governança estabelecida, resultados de projetos de inovação alcançados e falhas que podem acontecer serão analisadas sob o processo de causa raiz e implementação das melhorias identificadas no próximo dos projetos de inovação.

Essas considerações associadas à pesquisa realizada nos permitem elaborar as conclusões deste trabalho em que os conceitos de gestão da inovação são amplamente conhecidos pela "empresa $\beta$ "; de acordo com a pesquisa, $76 \%$ dos respondentes acreditam que é extremamente importante seguir uma metodologia para o desenvolvimento de inovações e 54\% como extremamente relevante que a aplicação da metodologia suporte o sucesso das inovações. Apenas sua adoção não tende a representar vantagens competitivas, mas requisitos básicos de sobrevivência no cenário atual, porém, uma definição clara de entregas em cada etapa, governança clara, agilidade na execução e o benefício das lições aprendidas proporcionam vantagem competitiva.

A necessidade de aplicar uma metodologia de gestão de projetos de inovação, como requisito básico para a continuidade do negócio, não significa facilidade e simplicidade na implementação, requer muita disciplina, foco e determinação para evitar atalhos, muitas vezes propostos, e não fornecer resultados consistentes. Muitas empresas falham com consequências drásticas para os negócios; a pesquisa realizada mostrou que embora a empresa "empresa $\beta$ " compreendesse a importância de ter um sistema de gestão definido para a obtenção dos resultados, que, no entanto, a aplicação prática da metodologia e ferramentas propostas pela própria empresa em todos os projetos teve um adesão $5 \%$ e a grande maioria, representada por $59 \%$ 
dos respondentes, relatou que aplicou apenas parcialmente as ferramentas em seus projetos.

Com a utilização do modelo proposto de acumulação de capacidade tecnológica para a gestão da inovação, foi realizada uma aplicação prática através da pesquisa a fim de se ter um diagnóstico de como os profissionais que atuam diretamente no ambiente de inovação avaliam a empresa "empresa $\beta$ "; a pesquisa mostrou que $51 \%$ dos respondentes identificaram que a empresa estava no nível avançado e nenhum dos participantes avaliou que a empresa estava no nível básico, após receber os critérios propostos neste trabalho e repetir a pesquisa apenas $8 \%$ permaneceram no um nível avançado. Na primeira pesquisa, $97 \%$ dos respondentes entendiam que a empresa estava no nível intermediário ou superior e posteriormente esse número era de apenas $46 \%$ dos respondentes, ou seja, mais de $50 \%$ de redução; a pesquisa mostrou que a subjetividade e a falta de critérios para avaliar e qualificar a gestão da inovação no nível avançado faz com que os profissionais que trabalham com as inovações superestimam o nível de capacitação de suas empresas, sendo a matriz de competência tecnológica proposta para a inovação. a gestão fornece critérios para uma avaliação que permite comparações entre empresas e setores industriais, abrindo a oportunidade para a construção de benchmarking da capacidade de gestão da inovação.

\section{REFERÊNCIAS}

BANSAL, P.; GREWATSCH, S. (2019). The unsustainable truth about the stage-gate new product innovation process. Innovation Organization \& Management, 21(4), 487-571. Disponível em: https://doi. org/10.1080/14479338.2019.1684205. Acesso em: 09 ago. 2020.

BELL, M.; PAVITT, K. Technological accumulation and industrial growth: contrast between developed and developing countries. Industrial Corporates Change, v.2., n. 2, p.157-210, 1993. Disponível em: https://doi.org/10.1093/icc/2.2.157.Acesso em: 18 jul.2020.

BELL, M.; PAVITT, K. The development of technological capabilities. In: HAQUE, I. U. (ed). Trade, technology and international competitiveness. Washington, DC: World Bank, 1995. p. 69-102(EDI development studies).

BELL, M. Overheads and notes on lectures and seminars. 1997. Dissertação (Mestrado), Universidade de Sussex, Brighton.

DE NEGRI, J.A.; SALERNO, M.S. Inovações, padrões tecnológicos e desempenho das firmas industriais brasileiras, 1.ed. Brasília: IPEA, 2005.

FEITOR, C. D. C.; KLIEMANN, N.; CORTIMIGLIA, M. N. Competências essenciais: uma análise da importância das capacidades organizacionais na busca de vantagens competitivas. In. SIMPÓSIO DE ENGENHARIA DE PRODUÇÃO, 2005, Bauru. Anais[...] Bauru: UNESP, 2005. p.50-58.

FIGUEIREDO, P. N. Gestão da inovação: conceitos, métricas e experiências de empresas no Brasil. Rio de Janeiro: LTC, 2009.

FIGUEIREDO, P. N. Acumulação tecnológica e inovação industrial: conceitos, mensuração e evidências no Brasil. São Paulo em Perspectiva, v.19, n.1, p.54-69, mar. 2005. Disponível em: https://doi. org/10.1590/S0102-88392005000100005.Acesso em: 19 ago. 2020

FLEURY, A.; GALLINA, R. A capacidade tecnológica na empresa: a função da Tecnologia Industrial Básica (TIB). Revista Gestão e Produção. v.20, n.2 p. 405-418, 2013.Disponível em: https://doi. org/10.1590/S0104-530X2013000200011. Acesso em: 23 ago.2020.

ISMAIL, S.; MALONE, M. S.; GEEST, Y. V. Organizações exponenciais: por que elas são 10 vezes melhores, mais rápidas e mais baratas que a sua (e o que fazer a respeito). São Paulo: HSM, 2015. 
LALL, S. Technological capability and industrialization. World Development, v.20, n.2, p. 165-186, 1992. Disponível em: https://doi.org/10.1016/0305-750X(92)90097-F.Acesso em: 23 set. 2020.

LEE, K. F. Inteligência Artificial: como os robôs estão mudando o mundo, a forma como amamos, nos comunicamos e vivemos. 1 ed. Rio de Janeiro. Globo Livros, 2019.

ROBERT, M. Product innovation strategy pure and simple: how winning companies outpace their competitor. Boston: McGraw-Hill, 1995.174p.

ROZENFELD, H.; AMARAL, D.C. Gestão de desenvolvimento de produtos: uma referência para a melhoria de processo. São Paulo: Saraiva, 2006. 


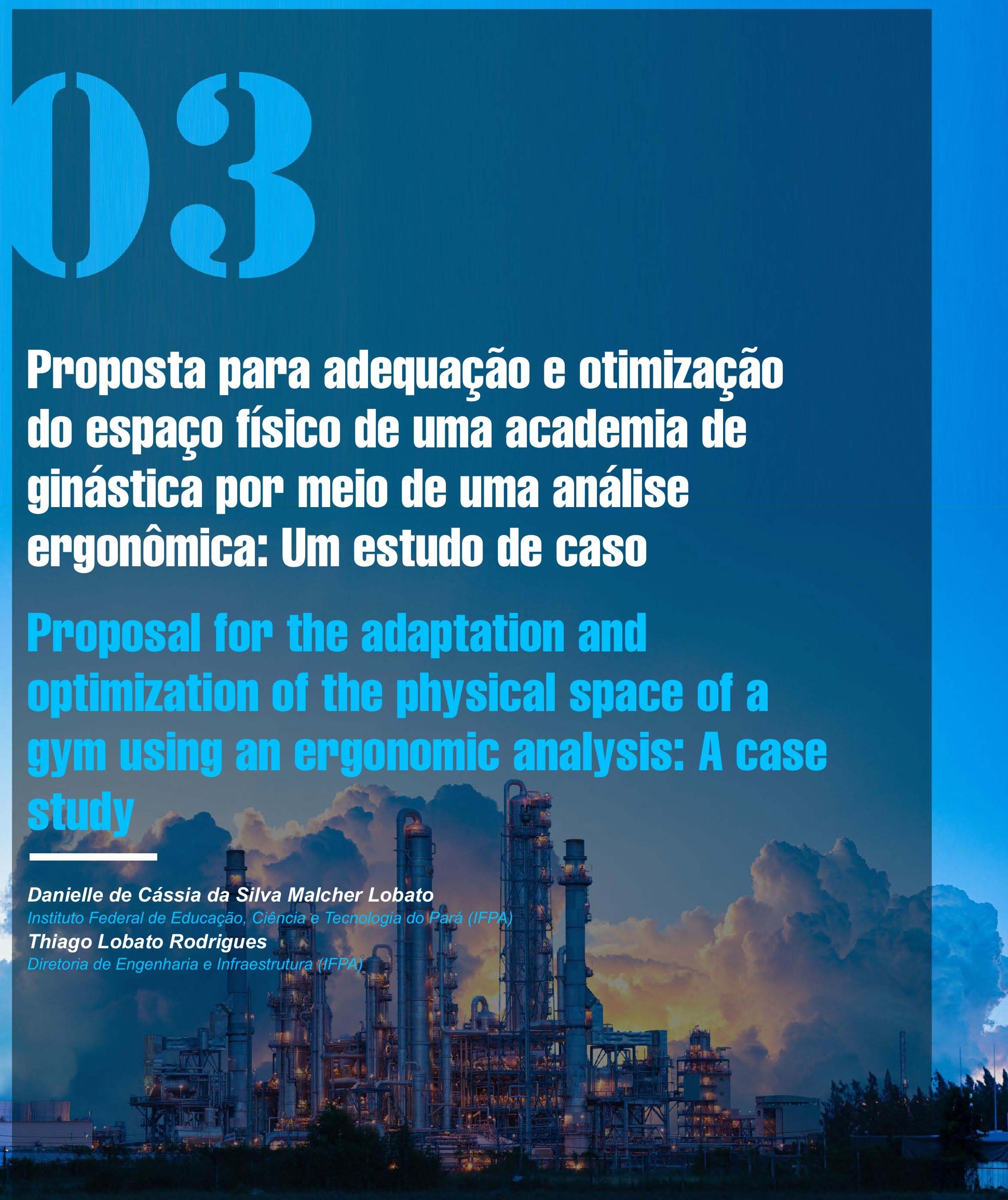

DOI: 10.47573/aya.88580.2.22.3 
Este trabalho apresenta uma análise ergonômica utilizando conceitos de arranjo físico industrial realizada em uma academia de ginásticas de pequeno porte localizada na cidade de Belém, Estado do Pará. O empreendimento possui um layout elaborado de maneira empírica e sem o devido embasamento científico, o que pode causar a insatisfação de seus clientes. Esta análise tem como objetivo geral elaborar sugestões que visem harmonizar e otimizar o espaço físico desta empresa, buscando, de maneira mais específica, adequar a disposição de seus pesos livres, otimizar a utilização de seu espaço físico e apresentar uma proposta de layout criada a partir de embasamentos científicos. Este trabalho foi realizado em diferentes etapas, cumpridos todos seus objetivos a partir de uma metodologia moldada, principalmente, com referências de Abrantes (2004), Couto (1995), Mendes (2010) e Slack, Chambers e Johnston (2002), que possibilitou a proposição mudanças que objetivam sanar e/ou reduzir os problemas apresentados pela academia e, a partir da implementação dessas, espera-se que a mesma consiga prestar um serviço de maior qualidade a seus clientes.

Palavras-chave: ergonomia. levantamento manual de cargas. espaço físico. layout.

\section{Alistract}

This work presents an ergonomic analysis using concepts of industrial physical arrangement carried out in a small gymnasium located in the city of Belém, State of Pará. The project has an empirically elaborated layout and without the proper scientific basis, which can cause the dissatisfaction of your customers. This analysis has as general objective to elaborate suggestions that aim to harmonize and optimize the physical space of this company, seeking, in a more specific way, to adapt the disposition of its free weights, optimize the use of its physical space and present a layout proposal created from scientific basis. This work was carried out in different stages, fulfilling all its objectives based on a molded methodology, mainly, with references from Abrantes (2004), Couto (1995), Mendes (2010) and Slack, Chambers and Johnston (2002), which made it possible the proposition changes that aim to remedy and / or reduce the problems presented by the academy and, from the implementation of these, it is expected that it will be able to provide a higher quality service to its customers.

Keywords: ergonomics. manual lifting load. physical space. layout. 


\section{INTRODUÇÃO}

A partir dos anos 90, de acordo com o Serviço Brasileiro de Apoio às Micro e Pequenas Empresas (Sebrae), houve uma consciência maior por parte da população acerca de temas relacionados a saúde e qualidade de vida, com isso a procura por academias de ginastica ganhou mais visibilidade e importância, alavancando o aumento do número desse tipo de estabelecimento no Brasil.

A revista Você $\mathrm{RH}$ publicou que o Brasil é o segundo país do mundo em número de academias, perdendo apenas para os Estados Unidos. Segundo a IHRSA (Associação Internacional de Fomento ao Universo de Saúde e Exercícios), elucidou a citada publicação, existem, mais de 34.500 academias de ginástica atuando no mercado fitness brasileiro, que movimenta cerca de 2 bilhões de dólares anuais.

A prática regular de atividades físicas, de forma geral, proporciona ganhos de qualidade de vida a seus praticantes, auxiliando na manutenção da boa postura, no controle de peso, melhorando o sistema cardiorrespiratório, a mobilidade, a flexibilidade e a autoestima, além de prevenir algumas doenças e proporcionar sensação de bem-estar e alívio do estresse (TAHARA; SCHWARTS; SILVA, 2003).

Desta feita, para se manter nesse mercado tão competitivo, as academias de ginástica, por atuarem diretamente com o público alvo interessado na prática de atividades físicas, devem adotar técnicas e procedimentos que objetivem melhorar a qualidade de vida de seus clientes, de modo a elevar o valor percebido por esses em relação aos serviços oferecidos, elevando o nível de satisfação, cativando e fidelizando a clientela a partir da prestação de serviços de alta qualidade.

Embora já se encontrem consolidadas no mercado brasileiro grandes redes de academias de ginásticas, Campos (apud Silva, 2010) afirma que esse mercado é pulverizado e constituído, essencialmente, por operadores individuais de micro e pequenas empresas, com mínima estrutura gerencial, assim, depreende-se que empresas com baixo poder de investimento lutam para se manter em um mercado acirrado e desbalanceado no prisma econômico.

Levando tal fato em consideração, este estudo concentra-se em uma microempresa que atua no "mercado fitness", uma academia de ginástica localizada no centro da cidade de Belém no Estado do Pará, e busca, a partir de uma análise ergonômica utilizando conceitos de arranjo físico industrial, propor melhorias que demandem nenhum ou pouco investimento, com a finalidade de se criar um ambiente mais seguro para os clientes da academia e que, ao mesmo tempo, sejam compatíveis com a realidade financeira dessa.

\section{OBJETIVOS}

\section{Objetivo geral}

Harmonizar e otimizar o espaço físico de uma academia de ginástica. 


\section{Objetivos específicos}

- Adequar a disposição dos pesos livres;

- Otimizar a utilização do espaço físico da academia;

- Propor novo layout que contemple todas as medidas ergonômicas necessárias para sanar e/ou reduzir os problemas enfrentados pela academia neste aspecto.

\section{ESTUDO DE CASO}

\section{Caracterização da empresa}

\section{Características gerais}

A academia de ginástica estudada se localiza em uma região central de grande circulação da cidade de Belém, Estado do Pará, em um bairro de classe média alta caracterizado como residencial e comercial, onde desde 2003 oferece três serviços distintos, musculação, ginástica e artes marciais (muay thai e kung-fu), a seu público alvo formado por jovens e adultos de ambos os sexos e de classe média.

O empreendimento é considerado de pequeno porte, contando, além da gerente, com apenas 10 colaboradores, dentre os quais 7 são professores, 2 são recepcionistas e 1 responsável pelos serviços gerais. A academia possui uma área igual a $239,32 \mathrm{~m}^{2}$, dessa, porém, apenas $117,79 \mathrm{~m}^{2}$ são utilizados para a prática da musculação, principal atividade da empresa, realizada por cerca de $90 \%$ de seus 254 clientes, e alvo desse estudo.

\section{Espaço físico}

No horário de pico, entre 18 e $22 \mathrm{H}$, é notório que a superlotação incomoda os clientes, pois gera cruzamentos de fluxo de pessoas e a formação de filas para utilizar os aparelhos, tornando a prática de exercícios físicos algo estressante. Tal observação, levantou a hipótese de que a área utilizada para a prestação do serviço musculação seja insuficiente, ou seja, não é capaz de acomodar os 24 aparelhos e os clientes de forma adequada, principalmente, no citado horário.

A proposição exposta foi confirmada pelo questionário (apêndice $A$ ) aplicado a $30 \%$ dos clientes da academia, onde $47 \%$ destes afirmaram que o maior problema do estabelecimento é justamente seu inadequado espaço físico. Além disso, $36 \%$ dos entrevistados asseguram que a academia disponibiliza poucos aparelhos aos seus clientes. $O$ gráfico 1 ilustra essa situação: 
Gráfico 1 - Principais problemas enfrentados pela academia

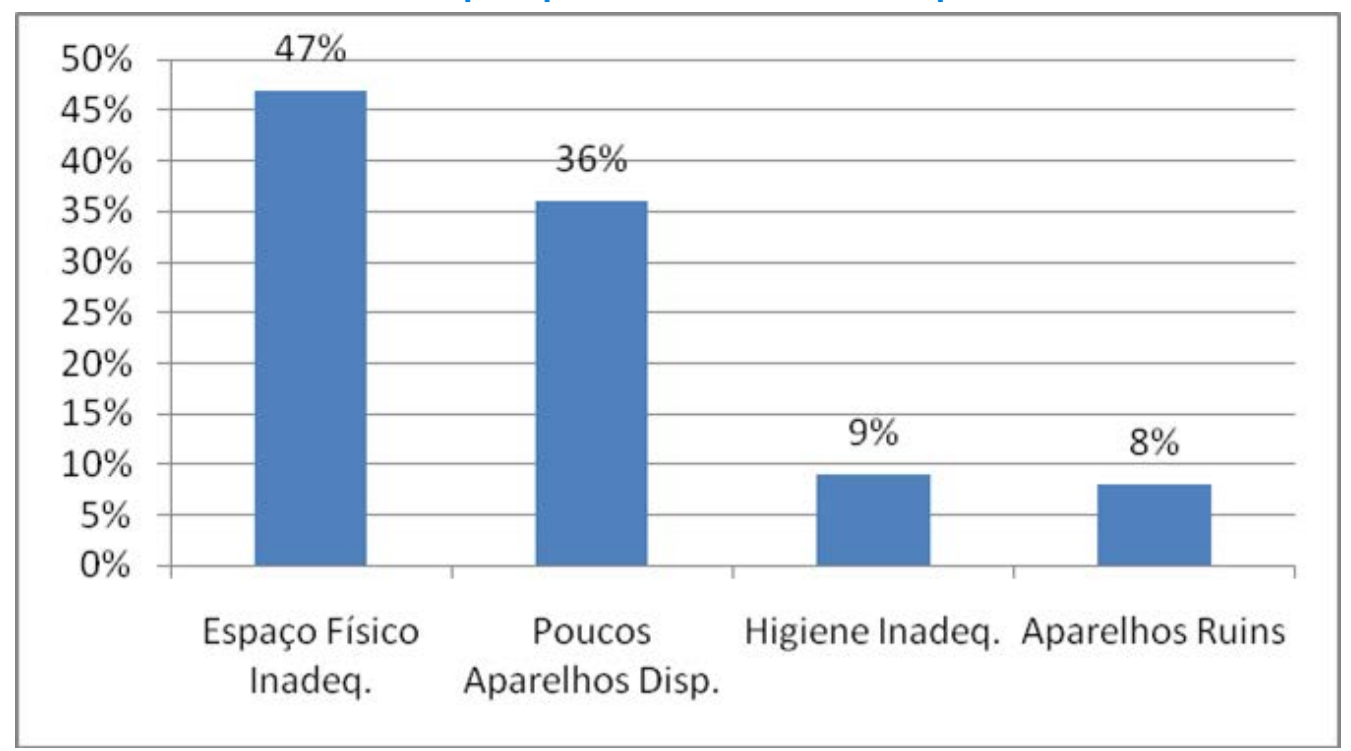

Fonte: Questionário aplicado pelos autores

O supracitado questionário apontou, também, que $67 \%$ dos entrevistados acreditam passar mais tempo que o desejado na academia para cumprir sua sequência de exercícios. $O$ gráfico 2 ilustra bem essa problemática, apontando os principais motivos para essa lentidão segundo os clientes:

Gráfico 2 - Principais motivos para a lentidão da prestação do serviço

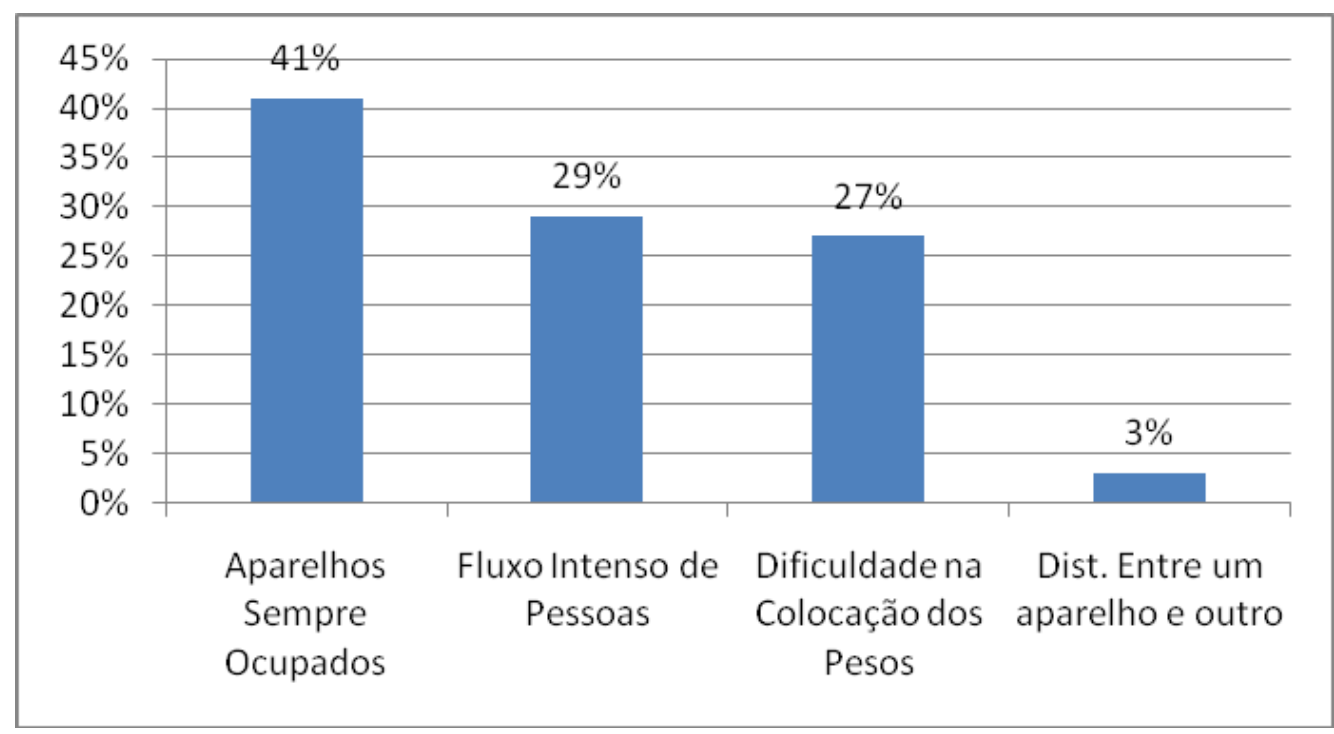

Fonte: Questionário aplicado pelos autores

Com esses dados em mãos, analisou-se que as principais causas de lentidão são consequências diretas dos três fatores anteriormente citados: espaço físico inadequado (responsável pela dificuldade de se manipular os pesos), poucos aparelhos (responsável pela ocupação quase constante dos aparelhos) e superlotação (responsável pelo grande fluxo de pessoas na sala de musculação). 
Após conversa informal com a gerente da academia, constatou-se que o layout utilizado foi concebido sem a elaboração de nenhum projeto específico, ou seja, esse foi elaborado de maneira empírica e sem algum embasamento científico, sendo que o único aspecto levado em consideração foi a área definida para ser utilizada como sala de musculação, que possui 117,79 $m^{2}$.

Por conta da falta de um projeto, o layout não apresenta uma arrumação lógica, ou seja, aparelhos para diferentes grupos de músculos e que não possuem nenhuma ou possuem pouca ligação se encontram próximos uns dos outros, e aparelhos e acessórios complementares se encontram afastados, o que levantou a hipótese de que tal situação gera dificuldades para os clientes no momento da execução de sua sequência de exercícios. Esse fato foi comprovado pelo questionário, onde $85 \%$ dos clientes afirmaram que possuem dificuldades para executar seus treinos:

Gráfico 3 - Grau de dificuldade para execução dos treinos

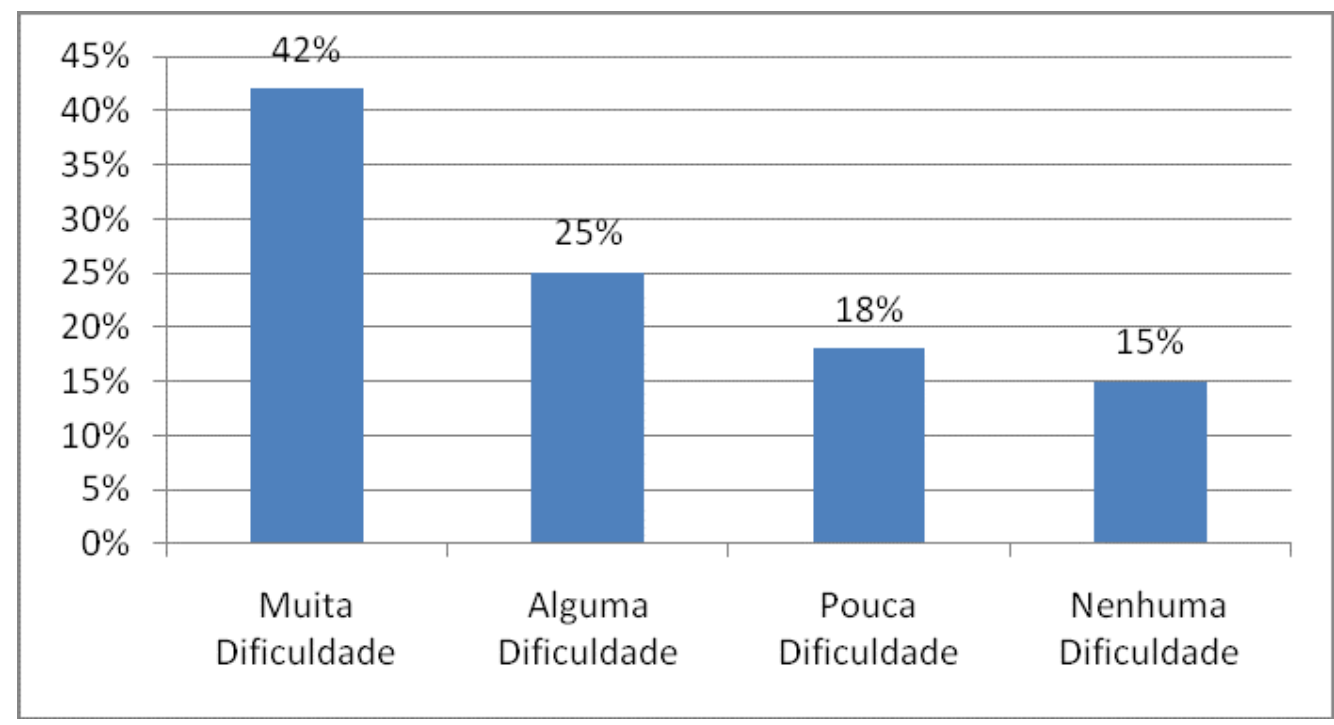

Fonte: Questionário aplicado pelos autores

\section{Anilhas e halteres}

As anilhas possuem pesos que variam $1 \mathrm{Kg}$ a $25 \mathrm{Kg}$, e são comportadas em uma estante, as mais leves nos pontos mais elevados e as mais pesadas nos pontos mais baixos, bem próximos ao chão. Os halteres, por sua vez, possuem pesos que variam de $1 \mathrm{Kg}$ a $10 \mathrm{Kg}$ e não possuem uma estante específica para serem organizados, sendo dispostos diretamente no chão.

Destarte, levantou-se a hipótese de que os clientes da academia sentiam dificuldades em manipular os chamados pesos livres, isso se deveria, entre outros motivos, principalmente pelo fato dos mesmos serem dispostos de maneira aparentemente equivocada, mais especificamente, muito próximos ao chão, forçando os alunos a promoverem um esforço extra no momento de se exercitar, o que poderia pôr em risco a saúde dos mesmos.

O mesmo questionário anteriormente citado comprovou essa proposição, já que $73 \%$ dos clientes afirmam possuir dificuldade em manipular os pesos livres, e os principais motivos para tal são mostrados no gráfico 4: 
Gráfico 4 - Principais motivos de dificuldade de manipulação dos pesos livres

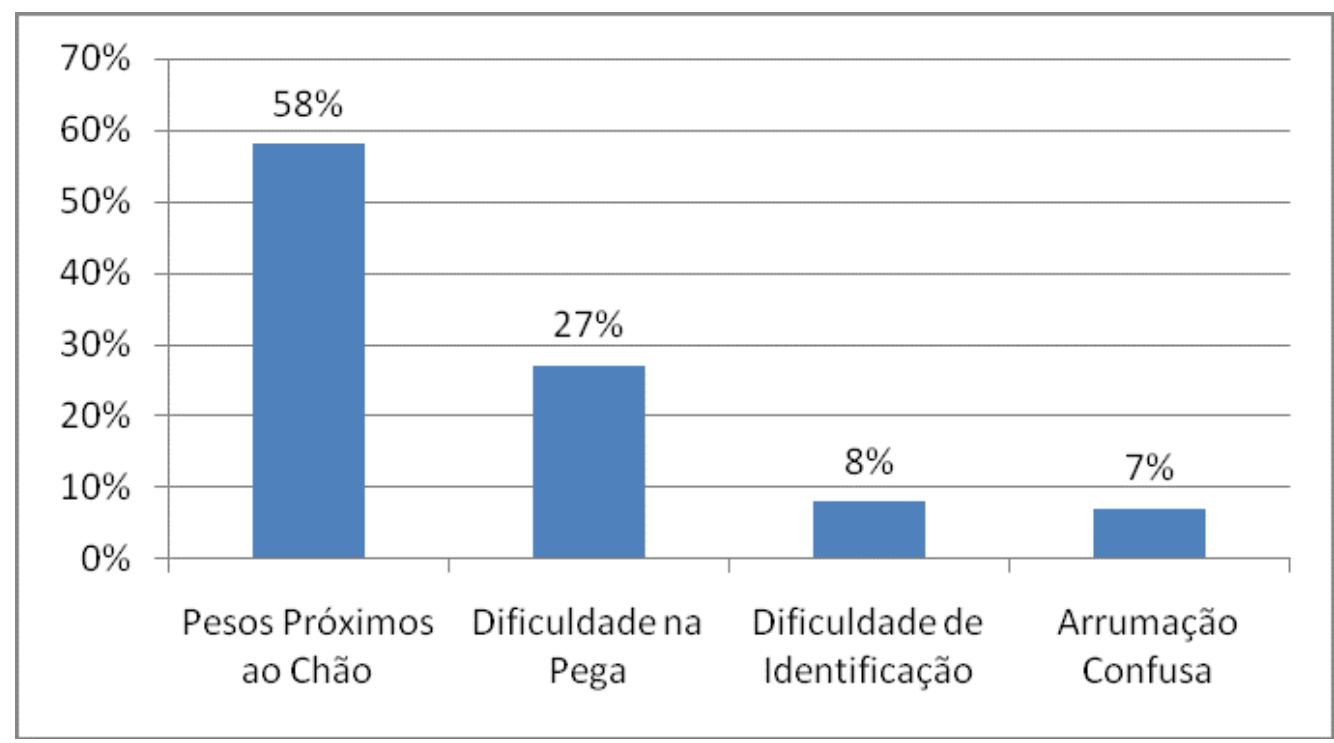

Fonte: Questionário aplicado pelos autores

Como é possível de se observar no gráfico, a segunda causa mais apontada pelos alunos é a dificuldade na pega, ou seja, a dificuldade de se apanhar esses pesos livres, entretanto, tal causa pode ser considerada uma consequência daquela mais votada, fato que contribui para aumentar a dificuldade para se apanhar esses acessórios.

\section{PROBLEMAS ENCONTRADOS}

Ao analisar a caracterização da academia e os dados colhidos através do questionário aplicado aos seus clientes, foi possível identificar os principais problemas que a impedem de prestar seus serviços de maneira mais eficaz e correta:

I. Área utilizada insuficiente para a prestação do serviço musculação;

II. Poucos aparelhos disponíveis e consequente formação de filas, em especial, no horário de pico;

III. Layout erroneamente arranjado;

IV. Pesos livres dispostos de maneira incorreta, mais especificamente, anilhas e halteres.

\section{PROPOSTAS PARA SOLUÇÃO DOS PROBLEMAS ENCONTRADOS}

\section{Problema I: Área Utilizada Insuficiente para a Prestação do Serviço Musculação}

Para solucionar este problema, foi proposta a expansão da sala de musculação, fazendo a mesma englobar uma das duas salas existentes no segundo andar, no caso, a sala de ginástica. Assim, a sala de artes marciais passaria a ser utilizada não apenas para esse fim, mas também para as aulas de ginástica. Esta medida é plausível uma vez que estas salas nunca são utilizadas simultaneamente, ou seja, aulas de ginástica nunca ocorrem no mesmo horário das 
aulas de artes marciais. A figura 1 elucida essa proposta:

Figura 1 - Disposição atual e proposta

\section{Disposição atual:}

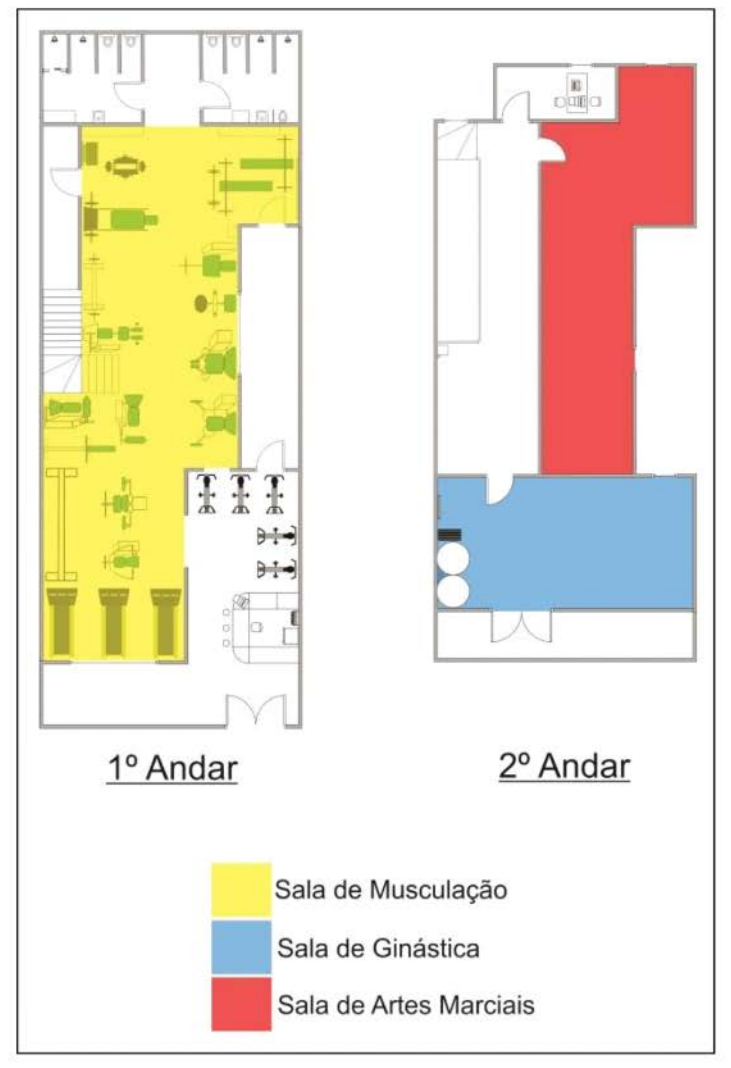

\section{Disposição proposta:}

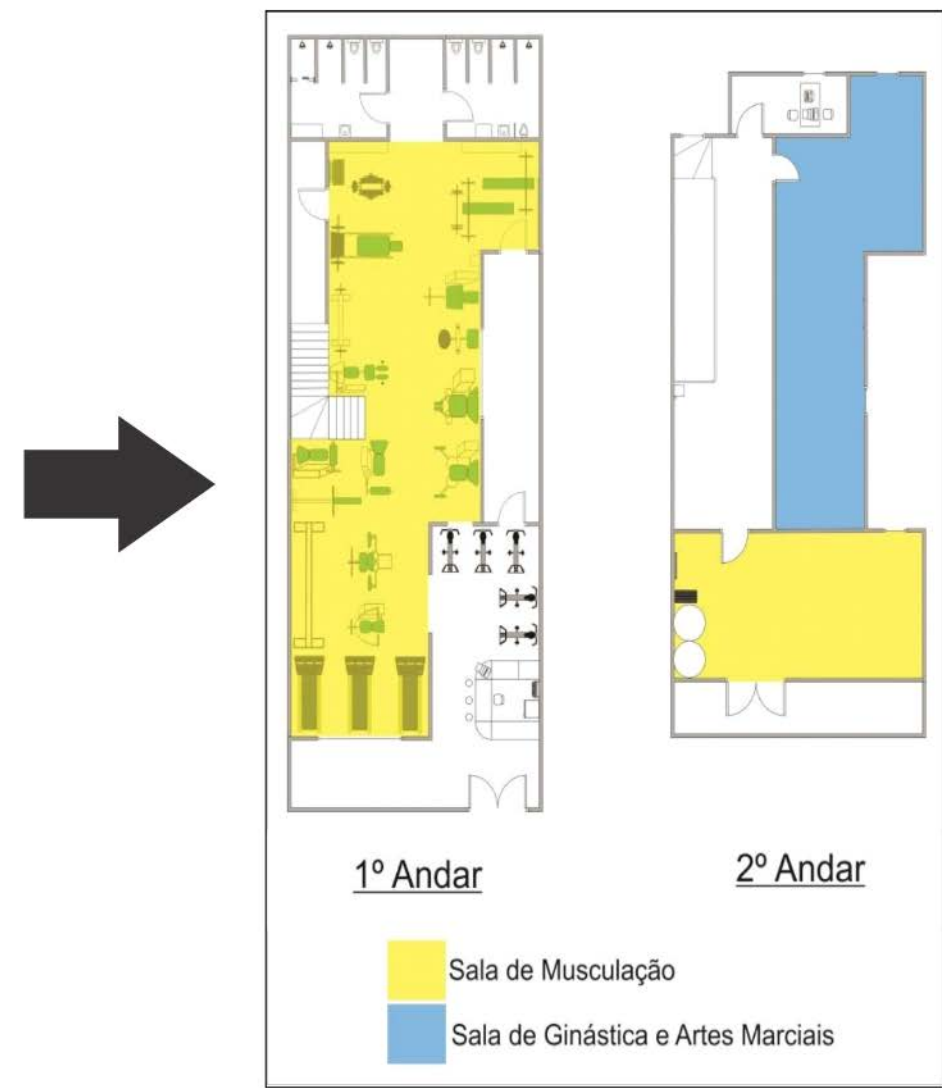

Fonte: Autoria própria

Esta alteração faria a sala de musculação expandir de $117,79 \mathrm{~m}^{2}$ para $150,02 \mathrm{~m}^{2}$, possibilitando a dispersão dos aparelhos no $1^{\circ}$ andar, uma vez que alguns deles, agora, poderão ser alocados no segundo andar, na antiga sala de ginástica.

Problema II: Poucos aparelhos disponíveis e consequente formação de filas

Caso seja implantada a proposta explicada no item anterior, a academia passará a ter um espaço físico capaz de comportar mais aparelhos, logo, para solucionar o Problema II, propõe-se que sejam comprados novos aparelhos e que estes sejam alocados utilizando-se este "espaço extra".

Frente a isso, para que essa aquisição não seja feita de forma aleatória, o questionário passado para os clientes da academia abordou esse tema, questionando-os acerca de qual aparelho deveria ter a sua quantidade aumentada, os resultados obtidos foram plotados no gráfico 5 : 
Gráfico 5 - Aparelhos que necessitam ter sua quantidade aumentada

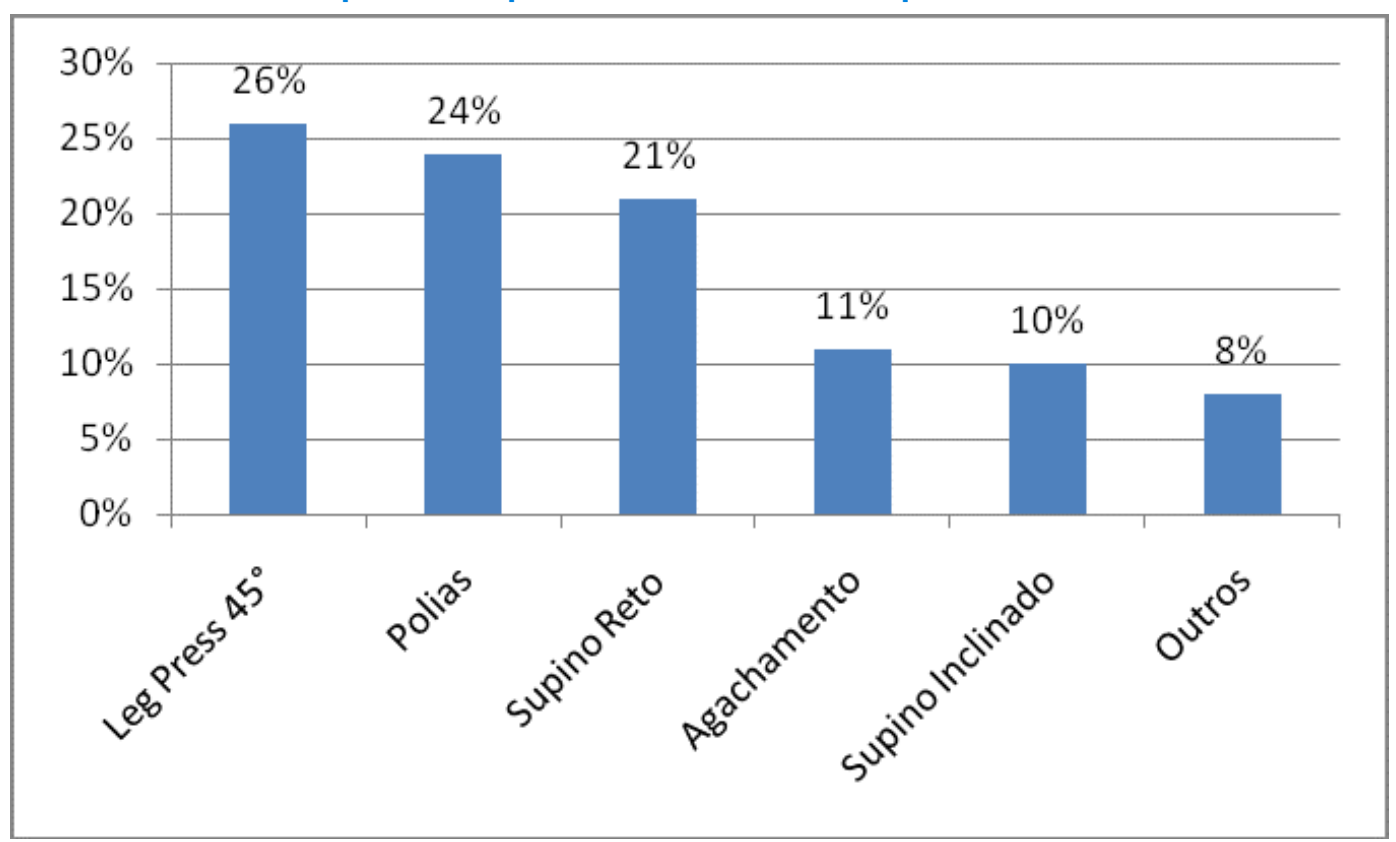

Fonte: Questionário aplicado pelos autores

O ideal seria adquirir mais um exemplar de cada aparelho, porém, isto não seria possível uma vez que o espaço físico da academia não suportaria tal quantidade de aparelhos em seu interior, mesmo com a expansão. Então, para solucionar e/ou reduzir este problema, a proposta é fazer a aquisição de mais uma unidade dos três aparelhos mais citados nas respostas dos clientes: Leg press $45^{\circ}$, polias e supino reto.

Entretanto, esses investimentos não garantirão a eliminação das filas no interior da academia na sua totalidade, isto dependerá da demanda que tais aparelhos terão durante determinado período do dia, o que se pode supor é que, provavelmente, o tempo de espera pra utilizar esses aparelhos reduzirá, porém, ainda assim, 71\% dos clientes entrevistados terão seus anseios supridos.

\section{Problema III: Layout Erroneamente Arranjado}

Com o objetivo de sanar esse problema, seguindo a metodologia de Muther (apud ABRANTES, 2004), propõe-se a mudança do atual layout, de acordo com as seguintes etapas:

\section{Localização}

Considerando que a proposta feita no item 5.1 seja posta em prática, a área que será utilizada para o planejamento do novo layout é de 150,02 m² e, como não haverá transferência de tecnologia neste planejamento, ou seja, os aparelhos serão os mesmos já utilizados, não foi necessária uma análise dos aspectos antropométricos dos usuários, uma vez que estes apareIhos são ajustáveis de acordo com o biotipo de cada aluno. Portanto, independente de altura, envergadura, peso, etc., qualquer pessoa pode usar tais equipamentos de maneira plena.

\section{Arranjo físico geral}

Para a elaboração desta etapa, primeiramente foi realizada uma entrevista informal com os professores e com a administração da academia. Nesta, foi relatado que os treinos são ela- 
borados sempre em três etapas ( $\mathrm{A}, \mathrm{B}$ e $\mathrm{C}$ ), agrupando os grupos musculares (peitoral, braços, costas, ombro e pernas) de acordo com o quadro 1 :

Quadro 1 - Esquema de trinos

\begin{tabular}{|c|c|c|c|c|c|c|}
\hline \multirow{2}{*}{ Treino } & \multicolumn{5}{|c|}{ Grupos Musculares Trabalhados } \\
\cline { 2 - 6 } & \multirow{2}{*}{ Peitoral } & \multicolumn{2}{|c|}{ Braços } & \multirow{2}{*}{ Costas } & Ombros & Pernas \\
\cline { 3 - 6 } & & Bíceps & Tríceps & & & \\
\hline A & $\mathbf{X}$ & & $\mathbf{X}$ & & & \\
\hline B & & $\mathbf{X}$ & & $\mathbf{X}$ & & \\
\hline C & & & & & $\mathbf{X}$ & $\mathbf{X}$ \\
\hline
\end{tabular}

Fonte: Autoria própria

Desta forma, optou-se por dividir a área a ser utilizada em três subáreas, sendo uma (Área 1) para alocar os aparelhos utilizados para exercitar os músculos do peitoral, outra (Área 2) para aqueles que exercitam os músculos do braço, das costas e do ombro e a última (Área 3) para os que trabalham os músculos da perna, de acordo com a figura 2 :

Figura 2 - Arranjo físico geral

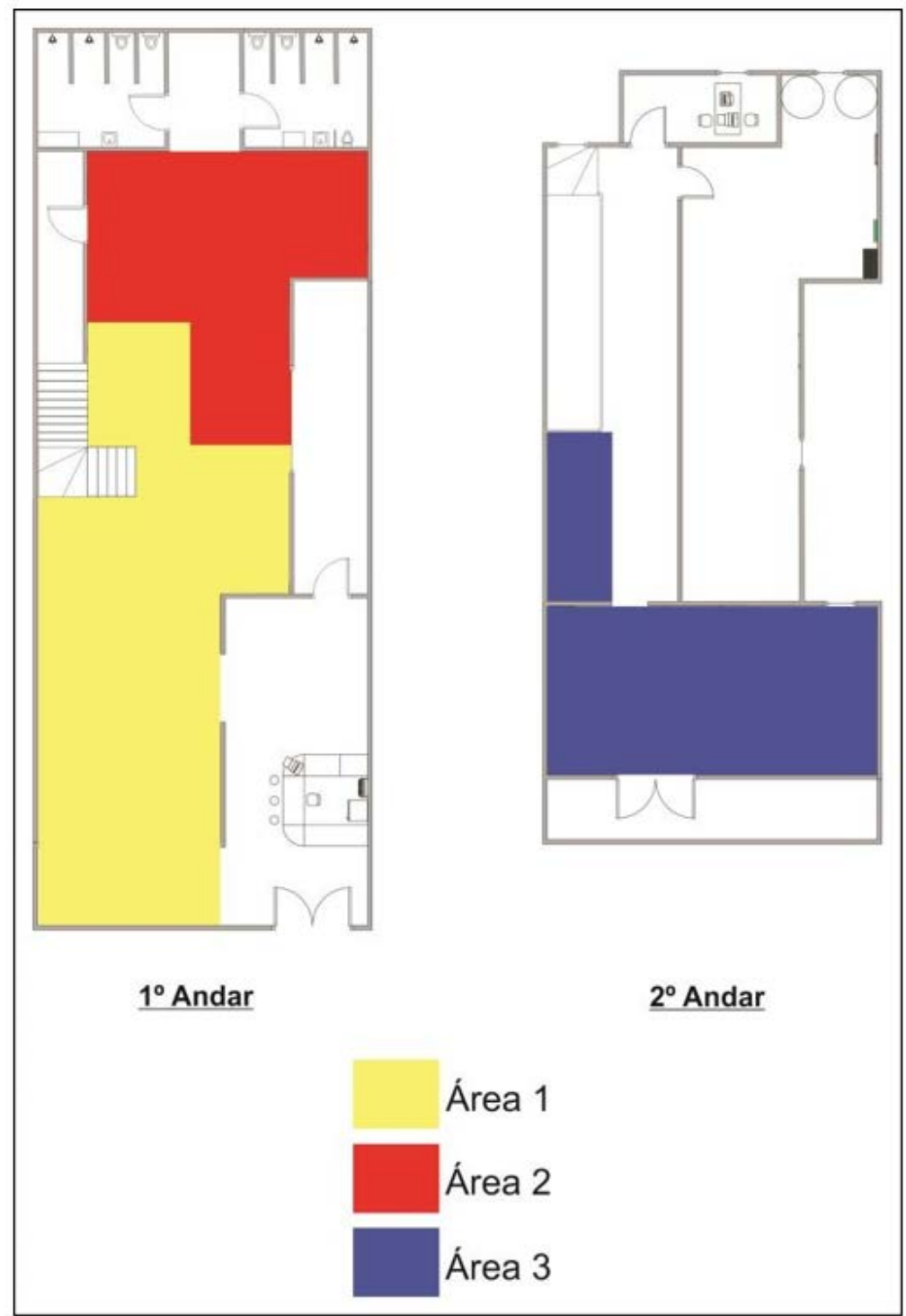

Fonte: Autoria própria 
Como mostra a figura acima, a Área 1 encontra-se próxima a Área 2 devido a grande inter-relação que ocorre entre elas. Isso acontece pelo fato de que os aparelhos designados para estas áreas são complementares, ou seja, são sempre utilizados em conjunto durante a execução do treino $\mathrm{A}$, que trabalha os músculos do peitoral e dos braços (tríceps), portanto, estas duas áreas devem fazer fronteira de modo a aumentar o rendimento das mesmas, além de oferecer maior conforto aos clientes, uma vez que os mesmos não mais precisarão realizar grandes deslocamentos para cumprir seus treinos.

Em relação ao treino $B$, este poderá ser realizado apenas na Área 2, haja vista que os aparelhos necessários para seu desenvolvimento, aqueles que trabalham os bíceps, serão dispostos nesse espaço. Por fim, o treino $\mathrm{C}$, que requisita os aparelhos que trabalham os músculos dos ombros e das pernas, deverá ser efetuado se utilizando as áreas 2 e 3.

Neste caso, percebe-se uma falsa ineficácia devido ao fato destas duas áreas não fazerem fronteira, porém, o deslocamento que os clientes deverão realizar entre uma área e outra não será problemático, uma vez que este será efetuado apenas uma vez e sem o transporte de cargas, haja vista que os alunos primeiro farão os exercícios para os ombros (na Área 2) e depois os para as pernas (na Área 3) ou vice e versa, sem a necessidade de retornarem para a área inicial.

Deste modo, de acordo com os conceitos de Slack, Chambers e Johnston (2002), este novo layout se caracterizará como um arranjo físico por processo, já que nele os aparelhos de musculação (equipamentos) que exercem funções e tarefas semelhantes serão agrupados próximos uns aos outros, e o que se deslocará serão os clientes (materiais em transformação) pelos diferentes treinos (processos) garantindo uma maior flexibilidade, taxa de uso dos aparelhos e menor vulnerabilidade às paradas.

\section{Arranjo físico detalhado}

Após a conclusão das duas etapas anteriores, foi possível a elaboração de um novo layout para a academia, alocando cada aparelho da maneira mais coerente possível, já incluindo os equipamentos sugeridos para compra, visando tornar as instalações da academia mais dinâmicas, proporcionando aos clientes mais liberdade de movimentos. Este novo layout é representado pela figura 3 : 
Layout atual:

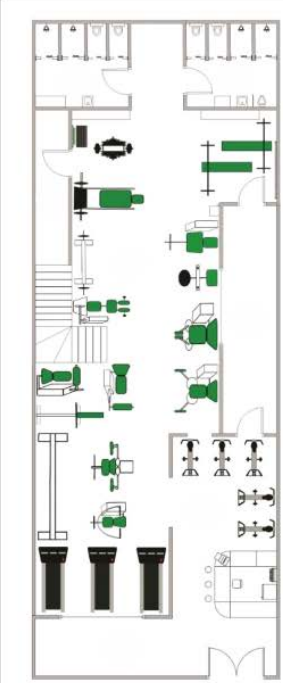

$\underline{1^{\circ} \text { Andar }}$

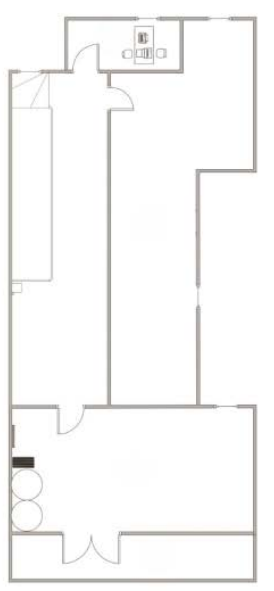

$\underline{2^{\circ} \text { Andar }}$
Layout proposto:

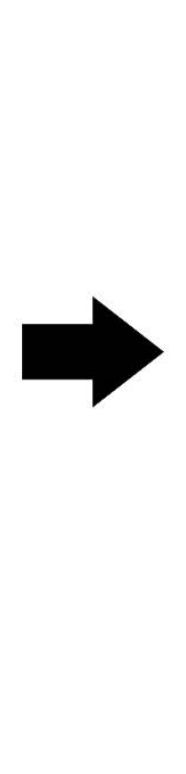

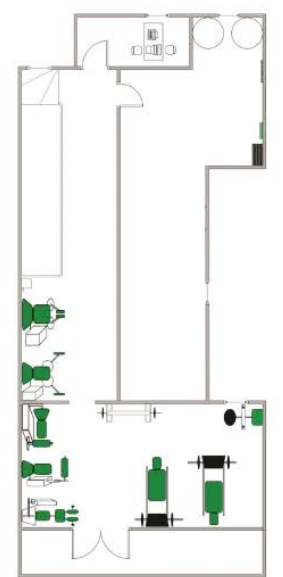

$2^{\circ}$ Andar

Fonte: Autoria própria

Nesta nova proposta de layout já foram implementadas todas as sugestões feitas anteriormente, como: ampliação da sala de musculação, rearranjo dos pesos livres através de novas estantes (será mostrado nos itens a seguir), inclusão dos novos aparelhos sugeridos para compra e arranjo do espaço físico por processo, a partir da criação de 3 subáreas (Área 1, Área 2 e Área 3).

Além dessas implementações, conseguiu-se adequar ergonomicamente o espaço considerando o padrão para espaçamentos de corredores propostos por Neufert (1976), que afirma que corredores para a circulação de uma pessoa deve possuir $0,90 \mathrm{~m}$ de largura e aqueles onde duas pessoas possam circular, uma largura de 1,15 m.

\section{Implementação}

Esta etapa do processo de criação do novo layout não é objetivo deste trabalho.

\section{ProblemalV:Pesoslivres dispostos de maneiraincorreta, mais especificamente, anilhas e halteres}

Apesar das respostas e conclusões explicitadas no item 3.1.4, buscou-se uma outra maneira de comprovar a existência do Problema IV, desta vez, utilizando os critérios de avaliação do National Institute for Ocupational Safety and Health (NIOSH) de levantamento manual de cargas, ensinado por Abrantes (2004), Couto (1995) e Mendes (2010).

A partir das fórmulas matemáticas desenvolvidas por esta instituição, foi possível comprovar matematicamente o problema em questão, estando os resultados de Limite de Peso Recomendado (LPR) e Índice de Levantamento (IL) obtidos para cada anilha e halter, levando-se em consideração o maior Fator Multiplicador de Distância (DM), que é o espaço percorrido pela carga ao ser transportada, encontram-se expostos nas tabelas 1 e 2 : 
Tabela 1 - LPR e IL atual para as anilhas

\begin{tabular}{c|c|c|c|c|c|c|c|c|c}
\hline Pesos (Kg) & CC & HM & VM & DM & FM & AM & CM & LPR & IL \\
\hline 1 & 23,00 & 0,74 & 0,95 & 0,84 & 1,00 & 0,71 & 1,00 & 9,58 & $\mathbf{0 , 1 0}$ \\
2 & 23,00 & 0,63 & 0,99 & 0,84 & 1,00 & 0,71 & 1,00 & 8,45 & $\mathbf{0 , 2 4}$ \\
3 & 23,00 & 0,56 & 0,96 & 0,84 & 1,00 & 0,71 & 1,00 & 7,28 & $\mathbf{0 , 4 1}$ \\
5 & 23,00 & 0,74 & 0,95 & 0,84 & 1,00 & 0,71 & 1,00 & 9,58 & $\mathbf{0 , 5 2}$ \\
10 & 23,00 & 0,56 & 0,96 & 0,84 & 1,00 & 0,71 & 1,00 & 7,28 & $\mathbf{1 , 3 7}$ \\
15 & 23,00 & 0,50 & 0,86 & 0,84 & 1,00 & 0,71 & 1,00 & 5,89 & $\mathbf{2 , 5 5}$ \\
20 & 23,00 & 0,52 & 0,90 & 0,84 & 1,00 & 0,71 & 1,00 & 6,49 & 3,08 \\
25 & 23,00 & 0,52 & 0,90 & 0,84 & 1,00 & 0,71 & 1,00 & 6,49 & 3,85 \\
\hline
\end{tabular}

Fonte: Autoria própria

Tabela 2 - LPR e IL atual para os halteres

\begin{tabular}{c|c|c|c|c|c|c|c|c|c}
\hline Pesos (Kg) & CC & HM & VM & DM & FM & AM & CM & LPR & IL \\
\hline 1 & 23,00 & 0,45 & 0,78 & 0,83 & 1,00 & 0,57 & 1,00 & 3,81 & $\mathbf{0 , 2 6}$ \\
2 & 23,00 & 0,45 & 0,78 & 0,83 & 1,00 & 0,57 & 1,00 & 3,81 & $\mathbf{0 , 5 2}$ \\
3 & 23,00 & 0,45 & 0,78 & 0,83 & 1,00 & 0,57 & 1,00 & 3,81 & $\mathbf{0 , 7 9}$ \\
4 & 23,00 & 0,45 & 0,78 & 0,83 & 1,00 & 0,57 & 1,00 & 3,81 & $\mathbf{1 , 0 5}$ \\
5 & 23,00 & 0,45 & 0,78 & 0,83 & 1,00 & 0,57 & 1,00 & 3,81 & $\mathbf{1 , 3 1}$ \\
6 & 23,00 & 0,45 & 0,78 & 0,83 & 1,00 & 0,57 & 1,00 & 3,81 & $\mathbf{1 , 5 7}$ \\
7 & 23,00 & 0,45 & 0,78 & 0,83 & 1,00 & 0,57 & 1,00 & 3,81 & $\mathbf{1 , 8 4}$ \\
8 & 23,00 & 0,45 & 0,78 & 0,83 & 1,00 & 0,57 & 1,00 & 3,81 & $\mathbf{2 , 1 0}$ \\
9 & 23,00 & 0,45 & 0,78 & 0,83 & 1,00 & 0,57 & 1,00 & 3,81 & $\mathbf{2 , 3 6}$ \\
10 & 23,00 & 0,45 & 0,78 & 0,83 & 1,00 & 0,57 & 1,00 & 3,81 & $\mathbf{2 , 6 2}$ \\
\hline
\end{tabular}

Fonte: Autoria própria

Para se traduzir os resultados obtidos, recorreu-se ao quadro de interpretação dos valores dos de IL:

Quadro 2 - Interpretação dos valores de IL

\begin{tabular}{|c|c|c|}
\hline IL & Nível de Risco & Tipo de Intervenção \\
\hline$\leq 1$ & $\begin{array}{c}\text { Ausência de } \\
\text { Risco }\end{array}$ & $\begin{array}{c}\text { Nã necessária } \\
\text { intervenção }\end{array}$ \\
\hline$\geq 1.1$ e $\leq 2.9$ & $\begin{array}{c}\text { Risco para } \\
\text { alguns } \\
\text { operadores }\end{array}$ & Engenharia/organização \\
\hline$>3$ & $\begin{array}{c}\text { Risco para a } \\
\text { Maioria dos } \\
\text { Operadores }\end{array}$ & Engenharia \\
\hline
\end{tabular}

Fonte: MENDES (2010)

Assim, pode-se verificar que o IL das anilhas de $10 \mathrm{Kg}, 15 \mathrm{Kg}, 20 \mathrm{Kg}$ e $25 \mathrm{Kg}$, e dos halteres de $5 \mathrm{Kg}$ a $10 \mathrm{Kg}$ apresentam incompatibilidade com os critérios NIOSH, portanto, apresentam riscos aos clientes e necessitam sofrer intervenções.

Deste modo, as anilhas de $10 \mathrm{Kg}$ e $15 \mathrm{Kg}$ e os halteres de $5 \mathrm{Kg}$ a $10 \mathrm{Kg}$, que possuem IL entre 1.1 e 2.9, oferecem riscos para alguns clientes e necessitam de uma intervenção por meio 
de engenharia e/ou organização. Por outro lado, de maneira mais grave, as anilhas de $20 \mathrm{Kg}$ e $25 \mathrm{Kg}$ possuem IL maior que $3 \mathrm{e}$, por isso, oferecem riscos para a maioria dos clientes e necessitam sofrer uma intervenção por meio de engenharia.

Para solucionar este problema e adequar a academia aos critérios NIOSH de levantamento manual de cargas, propõem-se a reorganização destes pesos livres. Acerca das anilhas, estas poderão ser reorganizadas na mesma estante já existente, porém, com outra configuração e em três novas estantes (que deverão ser adquiridas) que, como mostrado no layout proposto acima, se localizarão próximas aos aparelhos abastecidos por elas, no caso, os supinos retos e inclinado. A figura 8 ilustra essa nova organização:

Figura 4 - Disposição proposta para as anilhas

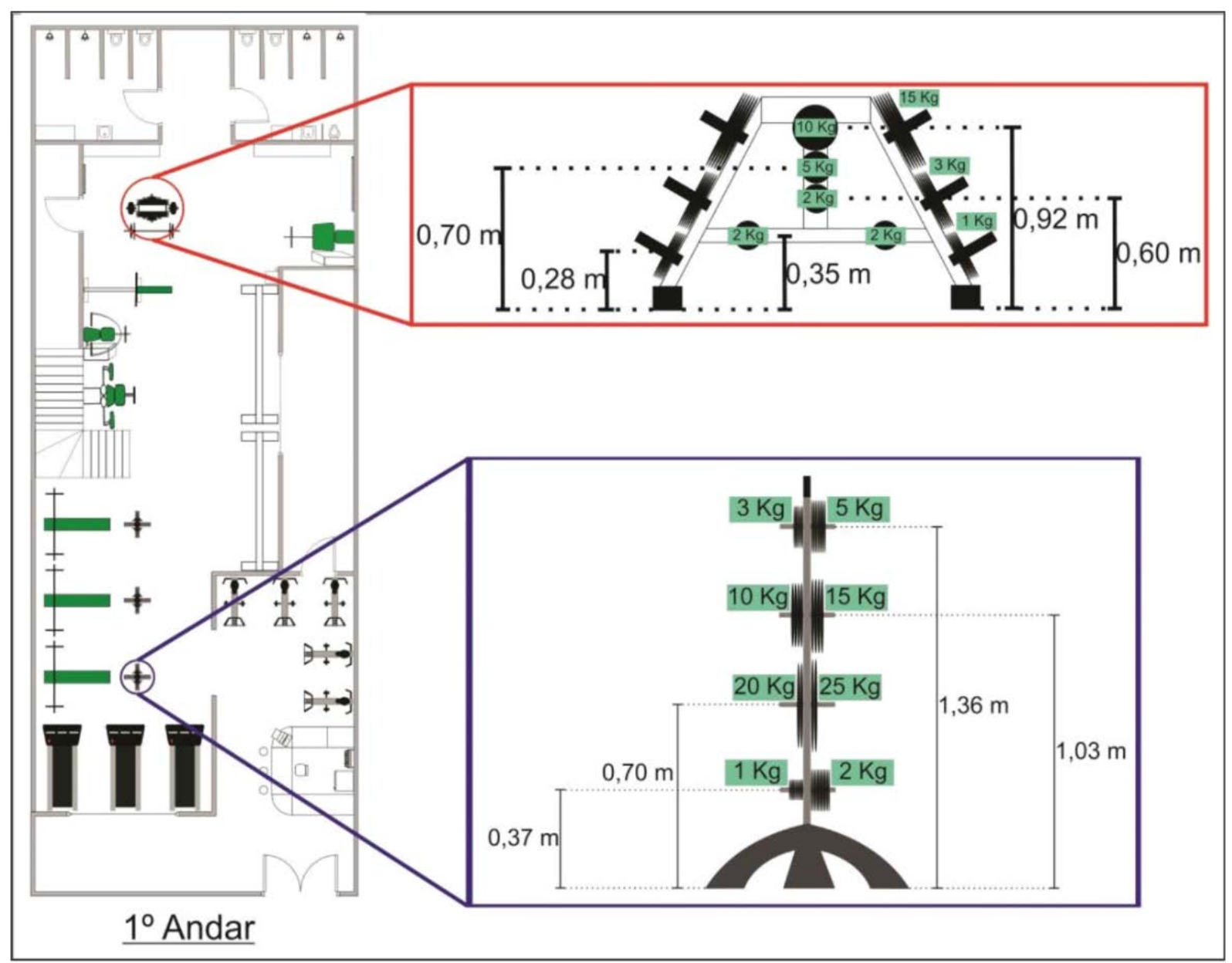

Fonte: Autoria própria

Com este novo cenário, os cálculos de LPR e IL foram refeitos levando em consideração o maior DM e os resultados expostos na tabela 3: 
Tabela 3 - LPR e IL obtido com as propostas sugeridas para as anilhas

\begin{tabular}{c|c|c|c|c|c|c|c|c|c}
\hline Pesos (Kg) & CC & HM & VM & DM & FM & AM & CM & LPR & IL \\
\hline 1 & 23,00 & 1,04 & 0,89 & 0,96 & 1,00 & 1,00 & 1,00 & 20,39 & $\mathbf{0 , 0 5}$ \\
2 & 23,00 & 1,04 & 0,89 & 0,96 & 1,00 & 1,00 & 1,00 & 20,39 & $\mathbf{0 , 1 0}$ \\
3 & 23,00 & 1,67 & 0,82 & 0,96 & 1,00 & 1,00 & 1,00 & 30,09 & $\mathbf{0 , 1 0}$ \\
5 & 23,00 & 1,67 & 0,82 & 0,96 & 1,00 & 1,00 & 1,00 & 30,09 & $\mathbf{0 , 1 7}$ \\
10 & 23,00 & 1,39 & 0,78 & 0,96 & 1,00 & 1,00 & 1,00 & 23,97 & $\mathbf{0 , 4 2}$ \\
15 & 23,00 & 1,39 & 0,78 & 0,96 & 1,00 & 1,00 & 1,00 & 23,97 & $\mathbf{0 , 6 3}$ \\
20 & 23,00 & 1,19 & 0,99 & 0,96 & 1,00 & 1,00 & 1,00 & 25,91 & $\mathbf{0 , 7 7}$ \\
25 & 23,00 & 1,19 & 0,99 & 0,96 & 1,00 & 1,00 & 1,00 & 25,91 & $\mathbf{0 , 9 6}$ \\
\hline
\end{tabular}

Fonte: Autoria própria

Como mostra a tabela, todas as anilhas com esta nova configuração passarão a possuir IL menor que 1, comprovando a melhora que essa alteração na arrumação das mesmas proporcionará ao ambiente da academia, visto que os critérios $\mathrm{NIOSH}$, dessa maneira, passarão a ser respeitados.

Em relação aos halteres, para estes poderá ser adquirida uma nova estante fixa para parede, onde os mesmos serão dispostos adequadamente de modo a se ajustarem aos critérios $\mathrm{NIOSH}$, de acordo com a figura 5 :

Figura 5 - Disposição proposta para os halteres

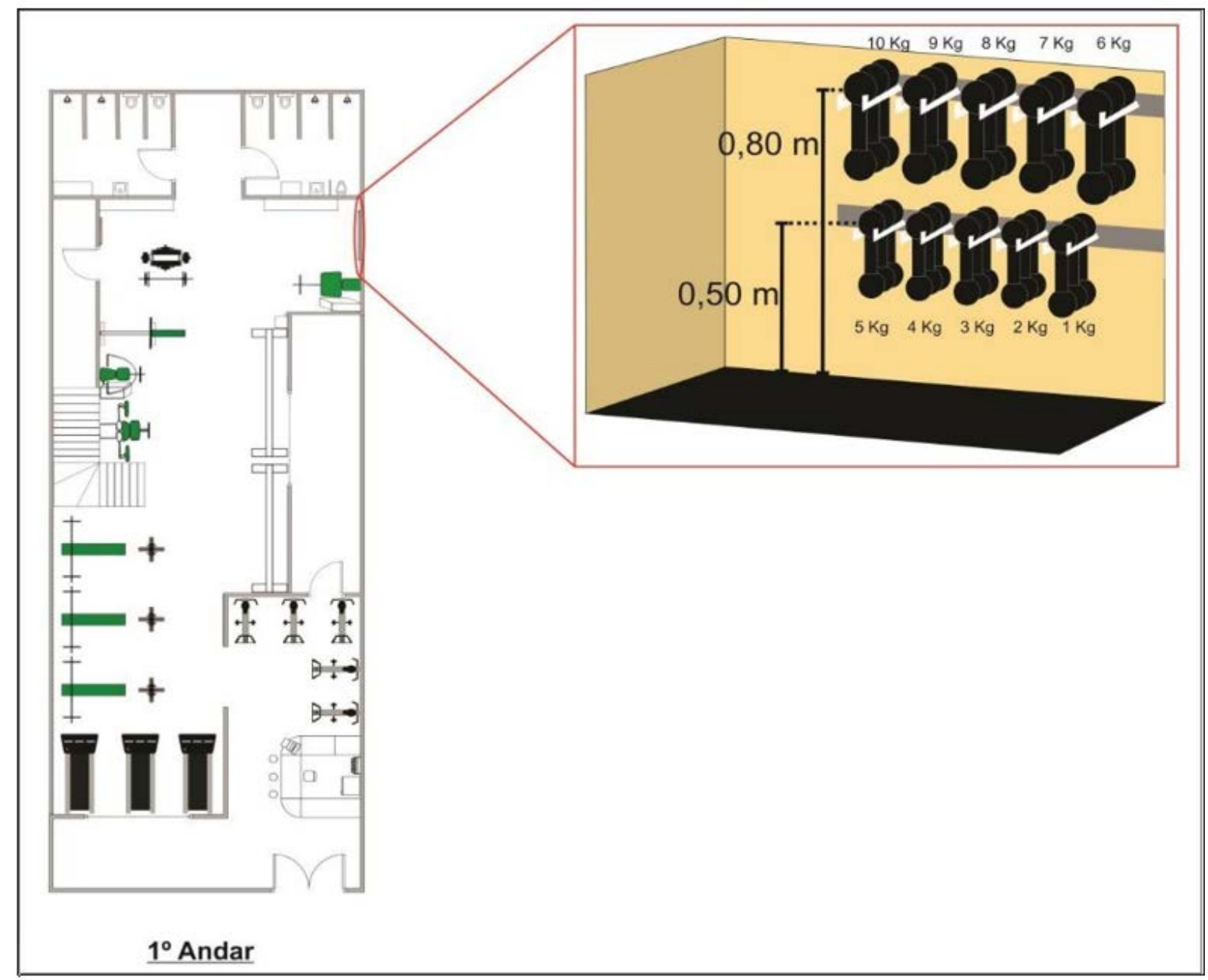


Com este novo panorama, os cálculos de LPR e IL para os halteres foram refeitos e os resultados mostrados na tabela 4 :

Tabela 4 - LPR e IL obtido com as propostas sugeridas para os halteres

\begin{tabular}{c|c|c|c|c|c|c|c|c|c}
\hline Pesos (Kg) & CC & HM & VM & DM & FM & AM & CM & LPR & IL \\
\hline 1 & 23,00 & 1,25 & 0,93 & 0,85 & 1,00 & 0,71 & 1,00 & 16,09 & $\mathbf{0 , 0 6}$ \\
2 & 23,00 & 1,25 & 0,93 & 0,85 & 1,00 & 0,71 & 1,00 & 16,09 & $\mathbf{0 , 1 2}$ \\
3 & 23,00 & 1,25 & 0,93 & 0,85 & 1,00 & 0,71 & 1,00 & 16,09 & $\mathbf{0 , 1 9}$ \\
4 & 23,00 & 1,25 & 0,93 & 0,85 & 1,00 & 0,71 & 1,00 & 16,09 & $\mathbf{0 , 2 5}$ \\
5 & 23,00 & 1,25 & 0,93 & 0,85 & 1,00 & 0,71 & 1,00 & 16,09 & $\mathbf{0 , 3 1}$ \\
6 & 23,00 & 1,67 & 0,99 & 0,85 & 1,00 & 0,71 & 1,00 & 22,85 & $\mathbf{0 , 2 6}$ \\
7 & 23,00 & 1,67 & 0,99 & 0,85 & 1,00 & 0,71 & 1,00 & 22,85 & $\mathbf{0 , 3 1}$ \\
8 & 23,00 & 1,67 & 0,99 & 0,85 & 1,00 & 0,71 & 1,00 & 22,85 & $\mathbf{0 , 3 5}$ \\
9 & 23,00 & 1,67 & 0,99 & 0,85 & 1,00 & 0,71 & 1,00 & 22,85 & $\mathbf{0 , 3 9}$ \\
10 & 23,00 & 1,67 & 0,99 & 0,85 & 1,00 & 0,71 & 1,00 & $\mathbf{2 2 , 8 5}$ & $\mathbf{0 , 4 4}$ \\
\hline
\end{tabular}

Fonte: Autoria própria

Como se pode observar na tabela, com este novo arranjo todos os halteres passarão a possuir IL menor que 1, adequando-se, dessa forma, aos critérios do National Institute for Ocupational Safety and Health de levantamento manual de cargas, o que colaborará de maneira expressiva para a harmonização do ambiente interno da academia.

\section{CONSIDERAÇÕES FINAIS}

A ergonomia é um aspecto comum no cotidiano de qualquer cidadão, tendo suas aplicações presentes em todos ambientes contemplados pelos mesmos. Por esse motivo, a preocupação com os aspectos ergonômicos deve estar presente em qualquer tipo de organização, seja ela uma grande indústria ou uma pequena empresa prestadora serviços, como é o caso da academia analisada neste estudo.

Porém, ainda existem poucos estudos que tratem este tema neste tipo de empreendimento, fato este que demonstra a relevância deste estudo. Pensar em ergonomia no ambiente de uma academia de ginástica é algo assaz conveniente e importante, visto que nele pessoas realizam vários tipos de movimentos (exercícios) associados à manipulação de cargas (pesos) e, se mal executados, podem gerar danos à saúde dessas pessoas.

O estudo realizado pôde atestar e comprovar falhas na prestação do serviço musculação na academia estudada, equívocos esses que causam transtornos, constrangimentos e dificuldades aos seus clientes. Tais disparates fazem com que a qualidade do serviço interno chegue a níveis baixos, reduzindo o valor percebido pelos clientes, podendo deixá-los insatisfeitos de modo a procurar o concorrente que consiga atender às suas expectativas, fato que geraria um decrescimento na lucratividade da empresa.

O gráfico 6, plotado com dados colhidos por meio do questionário aplicado aos clientes, explicita os principais motivos que os levam a frequentar a academia: 
Gráfico 6 - Principais motivos para se frequentar a academia

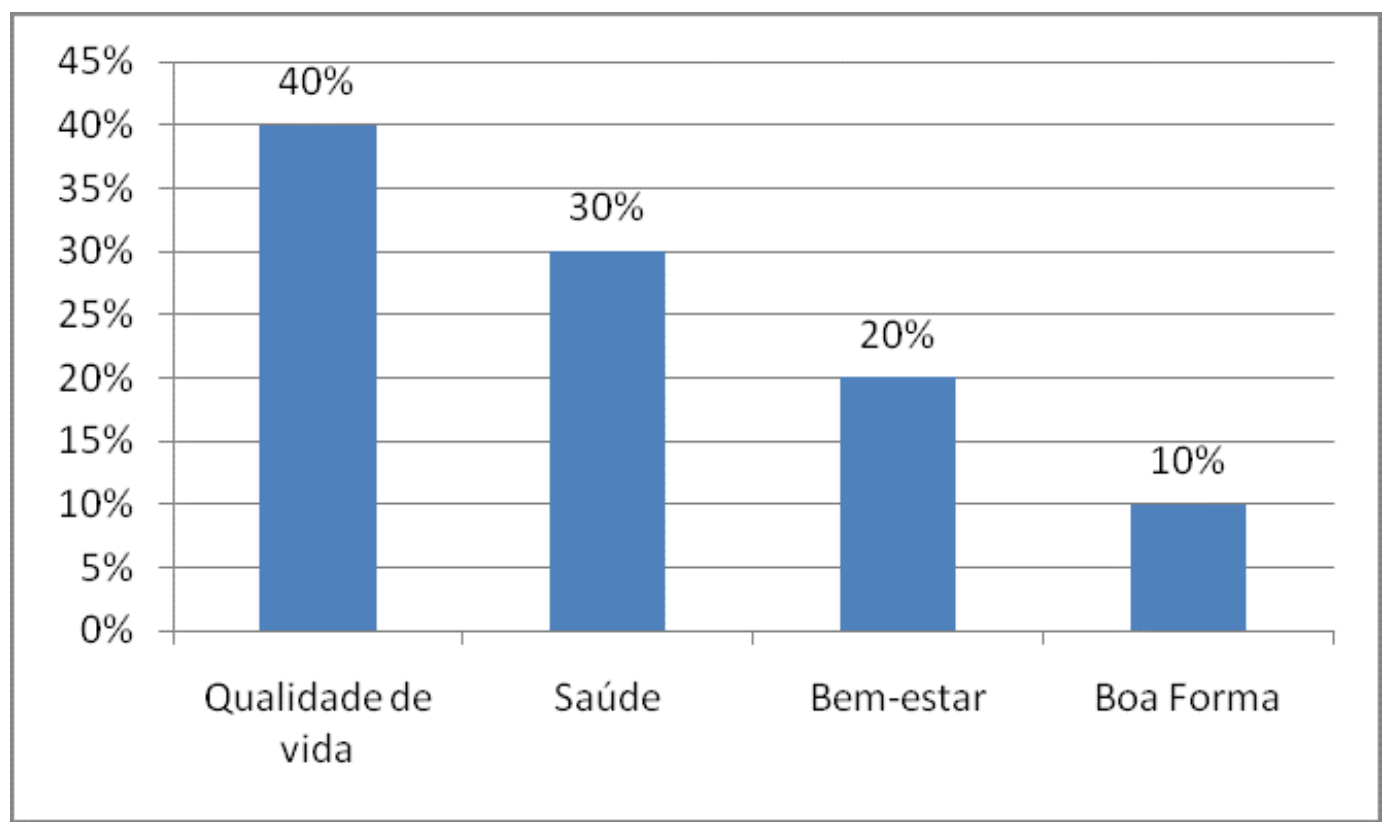

Logo, para que a academia consiga atender o principal desejo de seus clientes (qualidade de vida) promovendo, assim, sua satisfação, algumas medidas precisarão ser tomadas. Tais medidas foram propostas e minuciosamente explicadas neste estudo e os resultados esperados a partir de suas implantações expostos em detalhes.

Este trabalho atingiu todos os seus objetivos específicos e, como isso, foi possível, também, cumprir o objetivo geral: harmonizar e otimizar o espaço físico de uma academia de ginástica.

\section{REFERÊNCIAS}

ABRANTES, A. Atualidades em ergonomia: logística, movimentação de materiais, engenharia industrial e escritórios. São Paulo: IMAM, 2004.

COUTO, H. Ergonomia aplicada ao trabalho: o manual da máquina humana. Belo Horizonte: Ergo Editora, 1995.

DI DOMENICO, M. Onda fiteness movimenta US\$ 2 bi no Brasil e só cresce. Veja como aproveitar. Você RH, São Paulo, dez. 2020. Disponível em: https://vocerh.abril.com.br/mercado-vagas/ondafitness-movimenta-us2-bi-no-brasil-e-so-cresce-veja-como-aproveitar/\#: :text=Hoje $\% 2 \mathrm{C} \% 20 \mathrm{a} \% 20$ ind \%C3\%BAstria\%20de\%20atividades,mais\%20lucram\%20com\%20o\%20fitness.. Acesso em: 20 abr. 2021.

MENDES, O. Manipulação Manual de Cargas: equação de NIOSH. [S.I.: s.n., 2010].

NEUFERT, E. Arte de Projetar em arquitetura: princípios, normas e prescrições sobre construções, instalações, distribuição e programa de necessidades, dimensões de edifícios, locais e utensílios. 5. Ed. São Paulo: Gustavo Gil do Brasil, 1976.

SEBRAE. Como montar uma academia de ginástica. Disponível em: https://www.sebrae.com.br/sites/ PortalSebrae/ideias/como-montar-uma-academia-de-ginastica,80387a51b9105410VgnVCM1000003b74 010aRCRD. Acesso em: 29 abr. 2021.

SILVA, D. Sobre as questões administrativas, de marketing e de mercado: um estudo na área fitness. Campinas, 79 p., 2010. TCC (Graduação) - Universidade Estadual de Campinas. 
SLACK, N.; CHAMBERS, S.; JOHNSTON, R. Administração da Produção. São Paulo: Atlas, 2002.

TAHARA, A.; SCHWARTZ, G.; SILVA, K. Aderência e manutenção da prática de exercícios em academia. Revista de Ciência e Movimento, Brasília, v. 11, n. 4, p. 7-12, out./dez. 2003.

\section{APÊNDICE A - QUESTIONÁRIO}

1. O que the motiva a frequentar a academia?

( ) Qualidade de vida ( ) Saúde ( ) Bem estar ( ) Outros

2. Qual o maior problema que a academia possui?

( ) Espaço físico inadequado ( ) Poucos aparelhos disponíveis ( ) Higiene inadequada ( ) Aparelhos ruins

3. Você demora mais tempo que o desejado para cumprir seu treino? Se sim, por qual motivo?

( ) Aparelhos sempre ocupados ( ) Fluxo Intenso de Pessoas ( ) Dificuldade na Colocação dos Pesos ( ) Distância entre um aparelho e outro ( ) Outros

4. Qual aparelho da academia você acha que deveria ter sua quantidade aumentada?

( ) Leg press 45 ( ) Polias ( ) Supino reto ( ) Pulley ( ) Voador ( ) Extensora ( ) Flexora ( ) Supino Máquina ( ) Adutora ( ) Abdutora ( ) Panturrilha ( ) Glúteo

5. Você possui dificuldades para manipular os pesos livres? Se sim, por qual motivo?

( ) Pesos próximos ao chão ( ) Dificuldade na pega ( ) Dificuldade de identificação ( ) Arrumação confusa ( ) Outros

6. Você acha que a disposição dos aparelhos dentro da academia dificulta seu treino?

( ) Muita dificuldade ( ) Alguma dificuldade ( ) Pouca dificuldade ( ) Nenhuma dificuldade 


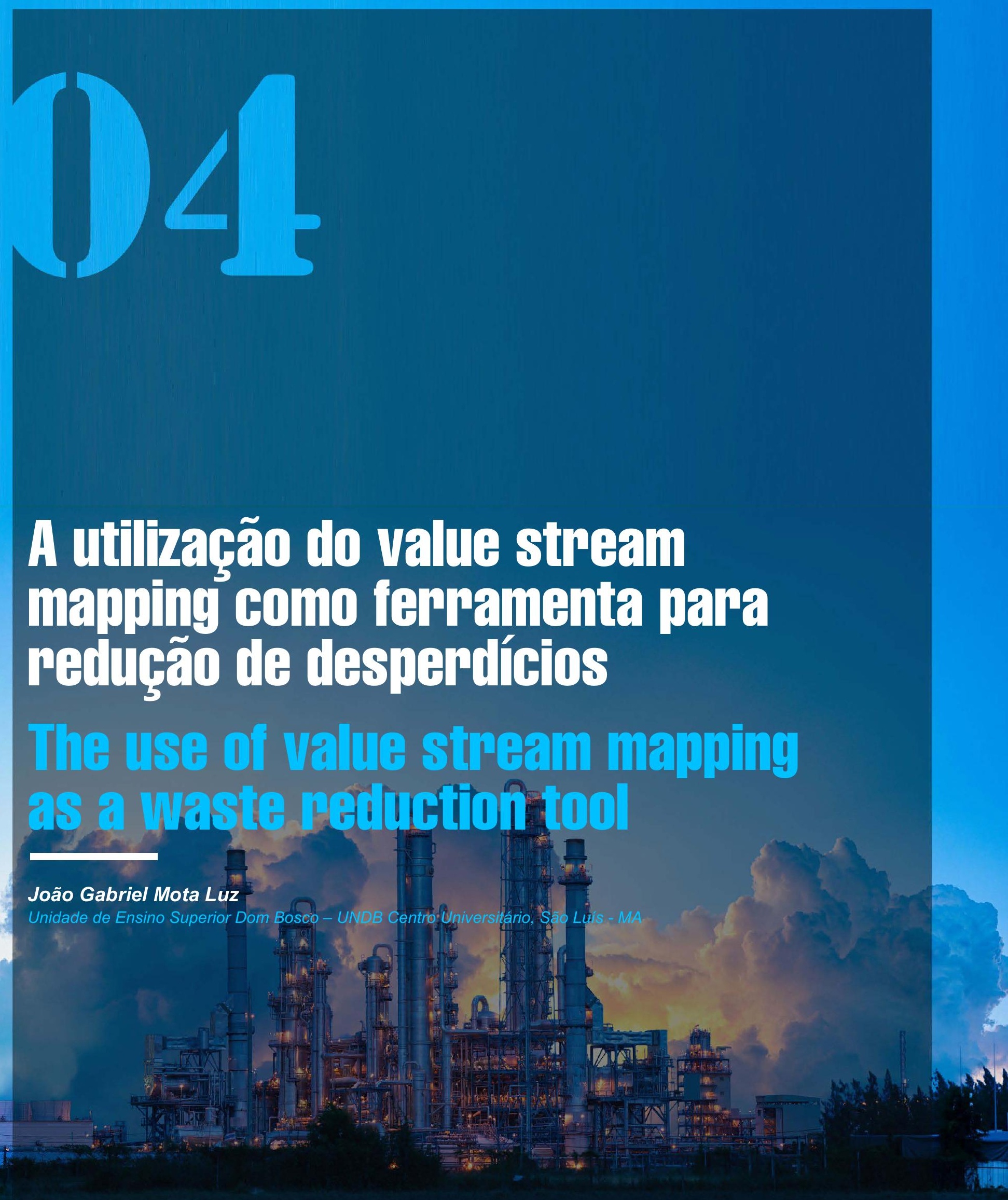

DOI: 10.47573/aya.88580.2.22.4 
Este artigo apresenta uma proposta de aplicação do pensamento enxuto dentro da cadeia de suprimentos de uma empresa de moagem de trigo, onde o foco foi na identificação e redução de desperdícios através do mapeamento do fluxo de valor. O principal objetivo deste trabalho é propor, através de um estudo de caso, uma abordagem enxuta para a cadeia de suprimentos desde o recebimento de matéria-prima até a expedição dos produtos acabados. Inicialmente foi feita uma revisão bibliográfica acerca do pensamento enxuto, bem como as principais ferramentas e metodologias empregadas. Em seguida foi realizada uma pesquisa de campo em uma empresa de moagem de trigo onde foram analisadas a rotina e os métodos de produção e expedição. Foram coletados todos os dados pertinentes para a elaboração dos mapas de fluxo de valor através de observação, aferição, entrevistas e análise de relatórios. A partir deste estudo foi entendido que a redução de desperdícios é um fator importante para o aumento da margem de lucro de uma empresa, bem como para elevar a qualidade dos processos e, por conseguinte do produto acabado. Este trabalho comprova que é possível abordar de maneira enxuta a cadeia de suprimentos de uma empresa de moagem de trigo.

Palavras-chave: pensamento enxuto. fluxo de valor. cadeia de suprimentos. desperdício. moagem de trigo.

\section{Alistract}

This paper presents a proposal of the application of lean manufacturing within the supply chain of a wheat milling company, in which the focus will be on identifying and reducing waste means of the value stream mapping. The main objective of this paper is to propose, through a case study, a lean approach to the supply chain from the receipt of raw material to the dispatch of finished products. Initially a literature review was made about lean thinking, as well as the main tools and methodologies employed. Then a field research was carried out at a wheat milling company where the routine and the methods of production and shipping were analyzed. All data, pertinent to the elaboration of value stream maps were collected for the elaboration through observation, measurement, interviews and report analysis. From this study it can be understood that the reduction of wastes is an important factor for the profit margin in a company, as well as to raise the quality of the processes and, consequently, of goods. This monography proves that it is possible to approach the supply chain of a wheat milling company in a lean way.

Keywords: lean thinking. value stream. supply chain. waste. wheat milling. 


\section{INTRODUÇÃO}

Mapear o fluxo de valor de uma empresa significa traçar toda a cadeia de valor de um produto ou família de produtos desde a recepção da matéria-prima até a expedição dos bens acabados para os clientes.

Conforme afirma Kuhlang, et al. (2012) o value stream mapping ${ }^{1}$ (VSM) é uma ferramenta de melhoria de processos, ou seja, trata-se de um instrumento que permite a visualização de oportunidades de melhoria onde os gargalos e focos de desperdícios são identificados, analisados e seus efeitos eliminados ou reduzidos durante a aplicação do plano de melhoria fundamentada no VSM futuro.

O cumprimento do plano de melhoria geralmente resulta na otimização da cadeia de suprimentos deixando-a mais enxuta, reduzindo desperdícios em seus três fluxos fundamentais. De forma geral, uma cadeia de suprimentos pode ser caracterizada a partir da identificação de três fluxos entre os agentes: o fluxo produtivo, o fluxo de recursos e o fluxo de informações (ARBAGE, 2004, p.31).

Desta maneira é possível ressaltar que a otimização da cadeia de suprimentos, através da melhoria dos processos, traz vários benefícios para as empresas, como por exemplo a redução de custos e de desperdícios através da aplicação de um sistema de produção puxado orientado pelo takt time ${ }^{2}$ da organização.

Foram investigadas e detalhadas também perdas relacionadas aos sete desperdícios com o objetivo de otimizar os três fluxos citados acima. A eliminação de gargalos e de tudo o que não agrega valor no ponto de vista do cliente são fundamentais para a redução do lead time ${ }^{3}$.

Embasando-se no conceito de Ohno (1997) de que toda e qualquer atividade que não agregue valor na visão do cliente é considerada desperdício, este artigo busca responder a seguinte questão: como o mapeamento do fluxo de valor como ferramenta para redução dos desperdícios pode otimizar a cadeia de valor de uma empresa de moagem de trigo?

Partindo desta problemática entende-se que por hipótese o lean thinking ${ }^{4}$ como uma filosofia de gestão tem condições garantir que as melhorias implementadas sejam mantidas de forma sustentável, bem como incentivar uma política de melhoria contínua dentro da organização. Também seria possível a criação de um fluxo contínuo, sincronizado e integrado entre os três fluxos fundamentais.

\section{LEAN THINKING, DEFINIÇÃO DE VALOR E OS 7 DESPERDÍCIOS}

Para entender o conceito e as particularidades do VSM é necessário compreender os conceitos de desperdício e de gestão enxuta. $O$ lean manufacturing ${ }^{5}$ é uma filosofia de gestão enxuta é baseada no Sistema Toyota de Produção (STP) e fundamentada pelos conceitos de valor, fluxo contínuo e desperdícios, onde o principal objetivo é oferecer produtos e serviços de

\footnotetext{
1 Mapeamento do fluxo de valor

2 Tempo de ritmo

3 Tempo total desde a recepção até a expedição para o cliente

4 Pensamento enxuto

5 Produção enxuta
} 
qualidade para seus clientes.

Lean thinking starts with the customer and the definition of value. Therefore, as a manufacturing process is a vehicle to deliver value (a product) to a customer, the principles of lean thinking should be applicable to the processes within that industry (MELTON, 2005, p. 664$)^{6}$.

Este modelo de gestão possui uma gama de ferramentas que funcionam como sua base e pilares que sustentam sua estrutura de forma que os fluxos produtivo, logístico e informativo estejam sempre em sincronia para que não ocorram longos tempos de espera para descarga e coleta de material, longos setups ${ }^{7}$ de produção e excessos de estoque de produto acabado e de matéria-prima, entretanto o foco não deve ser nas ferramentas e sim na construção de uma cultura organizacional que funcione de forma orgânica e integre todos os setores e colaboradores.

O lean manufacturing possui um campo de aplicação amplo, podendo ser utilizado na área da saúde, logística, manufatura, construção, tecnologia e prestação de serviços em qualquer tipo de empresa, na empresa toda e em qualquer tipo de processo.

Shingo (1996) explica que o Just-in-time ${ }^{8}$ (JIT) é uma ferramenta utilizada para produzir exatamente a quantidade demandada no tempo exato em que se precisa. O sistema de produção puxado tem como principal finalidade a criação de um fluxo de valor contínuo, ou seja, sem paradas onde tudo que é produzido é demandado pelo cliente.

\section{Os 7 desperdícios}

A redução dos desperdícios é um ponto chave dentro do STP, onde através da eliminação destas perdas é possível elevar a qualidade do produto e reduzir os custos de fabricação. Deste modo o STP defende que a Muda $^{9}$ deve ser completamente eliminada, admitindo apenas aqueles processos que são necessários para o funcionamento da empresa mantendo um fluxo de valor enxuto.

Any activity in a process, which does not add value to the customer, is called waste. Sometimes the waste is a necessary part of the process and adds value to the company and this cannot be eliminated, e.g., financial controls (MELTON, 2005) ${ }^{10}$.

Deste modo o STP defende que a Muda deve ser completamente eliminada, admitindo apenas aqueles processos que são necessários para o funcionamento da empresa mantendo um fluxo de valor enxuto.

6 O pensamento enxuto começa com o cliente e a definição de valor. Por esta razão, como o processo produtivo é um veículo para entregar valor (um produto) para um cliente, os princípios do lean thinking devem ser aplicáveis nos processos dentro da indústria (MELTON, 2005, p. 664, tradução livre)

7 Tempos de troca

8 No momento certo

9 Desperdício

10 Qualquer atividade em um processo a qual não agrega valor para o cliente é chamado 'desperdício'. Algumas vezes o desperdício é uma parte necessária do processo e agrega valor para a empresa e não pode ser eliminado, por exemplo, controle financeiro (MELTON, 2005, p. 665, tradução livre). 
Quadro 1 - Os sete tipos de desperdício

\begin{tabular}{|c|c|c|c|}
\hline $\begin{array}{c}\text { Tipo de des- } \\
\text { perdício }\end{array}$ & Descrição & Dentro do processo industrial & Sintomas \\
\hline $\begin{array}{l}\text { Superprodu- } \\
\text { ção }\end{array}$ & $\begin{array}{l}\text { Produto feito para ne- } \\
\text { nhum cliente em espe- } \\
\text { cífico; Desenvolvimento } \\
\text { de um produto, proces- } \\
\text { so ou uma melhoria de } \\
\text { produção para nenhum } \\
\text { valor adicional. }\end{array}$ & $\begin{array}{l}\text { Grandes lotes e processos produ- } \\
\text { ção contínua em larga escala; } \\
\text { Desenvolvimento de rotas de pro- } \\
\text { dução alternativas que não são } \\
\text { utilizadas ou o desenvolvimen- } \\
\text { to de processos que não auxiliam } \\
\text { o gargalo. }\end{array}$ & $\begin{array}{l}\text { A extensão do espaço do armazém } \\
\text { necessária e utilizada; Desenvolvi- } \\
\text { mento e organização da produção } \\
\text { desequilibrada; } \\
\text { Um processo com muitas mudan- } \\
\text { ças; } \\
\text { Altos custos com engenharia e tem- } \\
\text { po associados a modificações. }\end{array}$ \\
\hline Espera & $\begin{array}{l}\text { Pessoas, equipamen- } \\
\text { tos ou produtos que } \\
\text { esperam para serem } \\
\text { processados não agre- } \\
\text { gam nenhum valor para } \\
\text { o cliente. }\end{array}$ & $\begin{array}{l}\text { Tanques de armazenamento atu- } \\
\text { ando como amortecedores de } \\
\text { produtos em processo de fabrica- } \\
\text { ção. }\end{array}$ & $\begin{array}{l}\text { A grande quantidade de "trabalho } \\
\text { em progresso" retido no processo } \\
\text { de fabricação frequentemente vis- } \\
\text { tos em "pilhas de inventário" em tor- } \\
\text { no da área de fabricação. }\end{array}$ \\
\hline Transporte & $\begin{array}{l}\text { Mover o produto para } \\
\text { vários locais; } \\
\text { Enquanto o produto } \\
\text { está em movimento ele } \\
\text { não pode ser proces- } \\
\text { sado, ou seja, não está } \\
\text { agregando valor para o } \\
\text { cliente. }\end{array}$ & $\begin{array}{l}\text { A matéria-prima é encontrada em } \\
\text { diferentes locais e transportada } \\
\text { para uma área onde um volume } \\
\text { intermediário é feito; } \\
\text { Embalagem para uso dos clientes } \\
\text { pode estar em uma área separa- } \\
\text { do. }\end{array}$ & $\begin{array}{l}\text { Movimento de pallets de produtos } \\
\text { intermediários ao redor das áreas } \\
\text { ou entre elas; } \\
\text { Grande armazenamento de mate- } \\
\text { riais e contínuo transporte de ma- } \\
\text { teriais intermediários para dentro e } \\
\text { para fora da área ao invés de pro- } \\
\text { duto acabado. }\end{array}$ \\
\hline $\begin{array}{l}\text { Inventário } \\
\text { desnecessário }\end{array}$ & $\begin{array}{l}\text { Estoque de matéria-pri- } \\
\text { ma, produtos intermedi- } \\
\text { ários, produtos acaba- } \\
\text { dos, entre outros. Tudo } \\
\text { isso é dinheiro parado. }\end{array}$ & $\begin{array}{l}\text { Economicamente grandes bate- } \\
\text { ladas de matéria-prima são com- } \\
\text { pradas para grandes campanhas } \\
\text { de produção e ficam estaciona- } \\
\text { das nos armazéns por longos pe- } \\
\text { ríodos. } \\
\end{array}$ & $\begin{array}{l}\text { Grandes estoques amortecedores } \\
\text { dentro de uma instalação produtiva } \\
\text { e; } \\
\text { Úma grande armazenagem na } \\
\text { área; financeiramente visto como } \\
\text { um grande uso de capital de giro. }\end{array}$ \\
\hline $\begin{array}{l}\text { Processamen- } \\
\text { to inadequado }\end{array}$ & $\begin{array}{l}\text { Quando um processo } \\
\text { em particular que serve } \\
\text { de base para outro não } \\
\text { agrega valor ao produ- } \\
\text { to; }\end{array}$ & $\begin{array}{l}\text { Uma abordagem cuidadosa para } \\
\text { a produção de unidade de ope- } \\
\text { ração pode estender o tempo } \\
\text { de processamento e pode incluir } \\
\text { mais etapas, como retenção ou } \\
\text { testes, os quais não agregam va- } \\
\text { lor. }\end{array}$ & $\begin{array}{l}\text { O estágio de reação é tipicamente } \\
\text { concluído em minutos ainda que o } \\
\text { processamento continue por horas } \\
\text { ou dias; } \\
\text { Controle em processos que nunca } \\
\text { apresentaram falhas. }\end{array}$ \\
\hline $\begin{array}{l}\text { Movimenta- } \\
\text { ção }\end{array}$ & $\begin{array}{l}\text { Enquanto eles estive- } \\
\text { rem em movimento não } \\
\text { podem dar suporte aos } \\
\text { processos de produção. }\end{array}$ & $\begin{array}{l}\text { Pessoas transportando amostras } \\
\text { ou documentos; Pessoas neces- } \\
\text { sárias para mover produtos em } \\
\text { processamento para dentro e } \\
\text { para fora dos armazéns. }\end{array}$ & $\begin{array}{l}\text { Grandes times de operadores se } \\
\text { movimentando para dentro e para } \\
\text { fora da fábrica, mas com pouca ati- } \\
\text { vidade dentro da unidade fabril. }\end{array}$ \\
\hline Defeitos & $\begin{array}{l}\text { Erros durante os pro- } \\
\text { cessos exigem retraba- } \\
\text { lho e trabalho extra. }\end{array}$ & $\begin{array}{l}\text { Materiais fora da especificação; } \\
\text { grupo de documentos incomple- } \\
\text { tos; } \\
\text { Dados e entrada de dados incor- } \\
\text { retos. }\end{array}$ & $\begin{array}{l}\text { Ordens perdidas ou atrasadas; } \\
\text { Horas extras excessivas; } \\
\text { Aumento dos custos operacionais. }\end{array}$ \\
\hline
\end{tabular}

Fonte: Adaptado pelo autor de Melton, 2005

Entretanto a eliminação das perdas também atua sobre os custos de produção e operação de forma que seja possível obter uma maior margem de lucro obedecendo a contraposição de não custo feita por Shingo (1996) em relação à fórmula:

$$
\text { Custos }+ \text { Lucro }=\text { Preço }
$$

Afirmando que para aumentar a o lucro não era necessário aumentar o preço de seus produtos e sim reduzir os custos através da eliminação de perdas proveniente dos processos.

$$
\text { Preço-Custos }=\text { Lucro }
$$

Desta forma aumentar o preço de seus produtos não é uma alternativa, haja vista que o 
preço é ditado pelo mercado e deve ser alterado apenas para acompanhá-lo, logo para aumentar sua margem de lucro a Muda deve ser eliminada. Cada tipo de perda apresenta características únicas e sintomas próprios que facilitam sua identificação.

\title{
Value stream mapping
}

Baseada nos conceitos de valor, fluxo de valor, desperdício e fluxo contínuo, a ferramenta conhecida como VSM é utilizada para mapear toda a cadeia de valor da organização identificando o lead time, takt time, tempo de ciclo para cada etapa do processo, o número de operadores ou equipes por etapa, o volume do estoque intermediário e sua dimensão em dias, número de turnos, bem como os fluxos de operações e informações desde o recebimento da matéria-prima até a entrega para o cliente final.

É elaborado um mapa do estado atual, o qual reflete as condições atuais de operação e coloca em evidência os gargalos e oportunidades de melhoria. Com base nessas informações é elaborado o mapa do estado futuro, o qual apresenta as melhorias nos processos a serem aplicadas.

\begin{abstract}
O mapeamento do fluxo de valor é uma ferramenta que utiliza papel e lápis e o ajuda a enxergar e entender o fluxo de material e de informação na medida em que o produto segue o fluxo de valor. O que queremos dizer por mapeamento do fluxo de valor é simples: siga a trilha da produção de um produto, desde o consumidor até o fornecedor, e cuidadosamente desenhe uma representação visual de cada processo no fluxo de material e informação. Então, formule um conjunto de questões chave e desenhe um mapa do "estado futuro" de como o valor deveria fluir (ROTHER e SHOOK, 2007).
\end{abstract}

A utilização dessa ferramenta auxilia não apenas na identificação do fluxo de valor, mas também a visualização da Muda e dos processos individuais e em conjunto como um processo orgânico, desta forma torna mais fácil as tomadas de decisão para melhoria do processo.

Para que seja possível a leitura do mapa de forma simples, existem alguns símbolos que podem ser utilizados em sua montagem, embora não exista um padrão rígido a ser seguido permitindo que a empresa crie sua simbologia própria para o desenho do VSM.

Imagem 1 - Legenda de símbolos

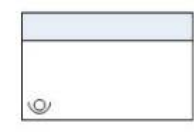

Caixa de processos

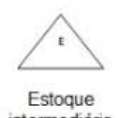

Estoque
intermediário

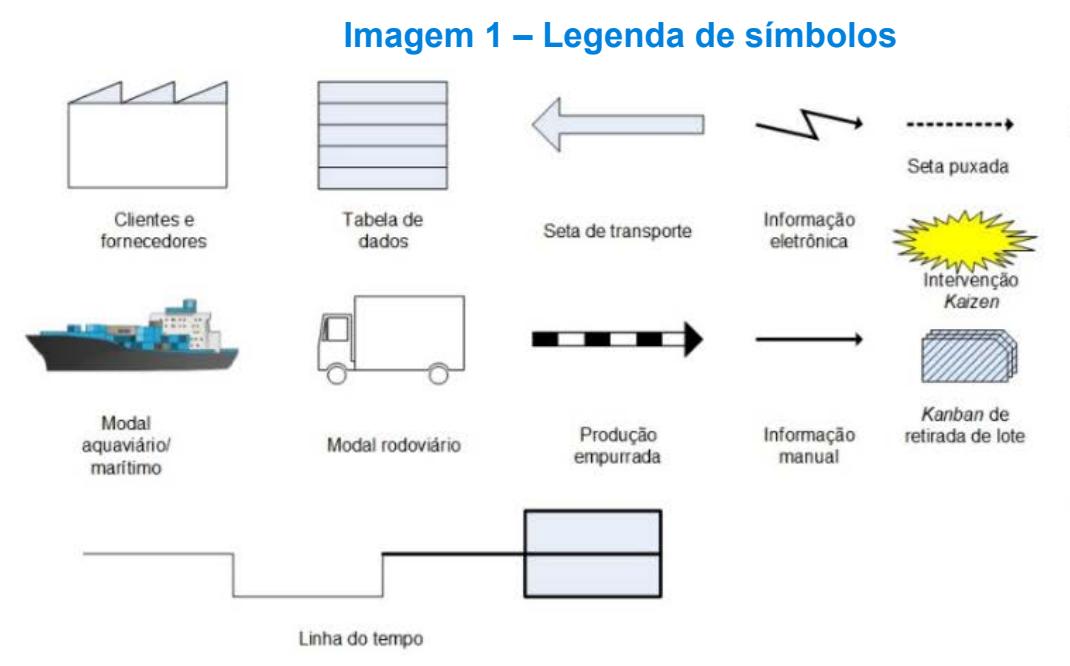

Fonte: Elaborado pelo autor

O grupo de símbolos adotados como padrão e utilizados neste trabalho estão apresentados na Imagem 1. 


\section{METODOLOGIA}

O estudo de caso foi realizado em uma empresa que atua no ramo alimentício por meio da moagem de trigo. Devido ao sigilo de informações a empresa citada não terá sua localização declarada, bem como a marca de seus produtos e será chamada de Empresa $\mathrm{X}$ pelo autor.

A Empresa $\mathrm{X}$ atua de maneira ativa em todo o país e possuí um portfólio de produtos muito conhecidos e consumidos em todas as regiões nacionais. Entre seus produtos estão as farinhas para panificação e para uso doméstico, as farinhas integrais para panificação e uso doméstico, misturas para bolo e farinhas com fermento.

A coleta de dados foi realizada por meio de levantamento junto ao moinho de trigo através da observação e mapeamento dos processos e atividades diárias, leitura de relatórios gerados relacionados à produtividade das operações, acompanhamento de indicadores estipulados para um melhor controle de rendimento e entrevista com colaboradores. Também foram utilizados literaturas específicas, bibliografias, teses e artigos.

Dados quantitativos foram analisados através de tabelas e gráficos e dados qualitativos serão descritos em quadros e texto corrido. Com as informações obtidas será possível elaborar o mapeamento do fluxo de valor do estado atual que servirá como base para a proposta de meIhoria do sistema que será apresentada através do mapeamento do estado futuro considerando todas as mudanças internas nos processos para a elaboração de uma cadeia de valor enxuta.

A coleta de dados no local de estudo foi autorizada por intermédio de um ofício entregue à empresa e assinado pelo responsável pela área a ser estudada. Informações consideradas sigilosas não foram agregadas ao trabalho, respeitando a particularidade informativa. A confidencialidade deve ser respeitada para que as partes interessadas não sejam lesadas e possam usufruir das atividades realizadas em prol da construção deste trabalho.

\section{RESULTADOS E DISCUSSÕES}

Neste capítulo apresenta-se o funcionamento de uma empresa de moagem de trigo, tendo como objeto de estudo a Empresa X.

Detalham-se os resultados obtidos através do acompanhamento dos fluxos logístico, produtivo e de informação na produção da família de produtos destinados à panificação e uso doméstico, sendo estes a farinha doméstica sem fermento de $1 \mathrm{~kg}$ e as farinhas para panificação de $25 \mathrm{~kg}$ e $50 \mathrm{~kg}$ através do fluxograma de processos e dos mapeamentos do fluxo de valor dos estados atual e futuro.

\section{Moagem de trigo}

Na moagem industrial de trigo a qualidade da matéria-prima é muito importante e influencia diretamente na confiabilidade do produto final, entretanto mesmo com insumos de alto padrão não é possível garantir a qualidade total do bem-acabado sem um processo de produção efetivo.

Dentro de uma empresa de moagem de trigo existem grandes pacotes de processos para a produção da farinha e seus derivados, onde os mesmos podem ser caracterizados como 
recepção, limpeza, moagem, envase e expedição.

De acordo com Guarienti (1996) o processo de moagem de trigo consiste na separação do grão em três produtos sendo eles o farelo, gérmen e endosperma (farinha). Onde o primeiro e o segundo são vendidos como ração e o último é misturado a alguns aditivos para a fabricação dos produtos que encontramos nos supermercados e utilizado na produção de diversos produtos para panificação e também para uso doméstico, sendo o elemento fundamental na produção de pães, bolos, biscoitos bem como outros tipos de produtos

\section{VSM do estado atual}

Através da utilização da ferramenta conhecida como Genchi Gembutsu11 pode-se visualizar as operações do gemba ${ }^{12} \mathrm{e}$ identificar os gargalos existentes dentro de um processo produtivo tornando mais fácil a elaboração do VSM do estado atual.

Após a montagem e análise do VSM do estado atual as oportunidades de melhoria identificadas foram exploradas no desenvolvimento do mapeamento do estado futuro. Como afirmam Rother e Shook (2007) um dos maiores benefícios do mapeamento do fluxo de valor é a possibilidade de atingir as causas raízes dos problemas encontrados, o que permite aplicar ações corretivas ao invés de apenas corrigir os sintomas.

Desta forma é mais simples diagnosticar as principais perdas dentro do sistema, afim de classificar as atividades executadas como as que agregam valor no ponto de vista do cliente, as que não agregam valor, no entanto são necessárias e por fim as que não agregam valor e podem ser eliminadas.

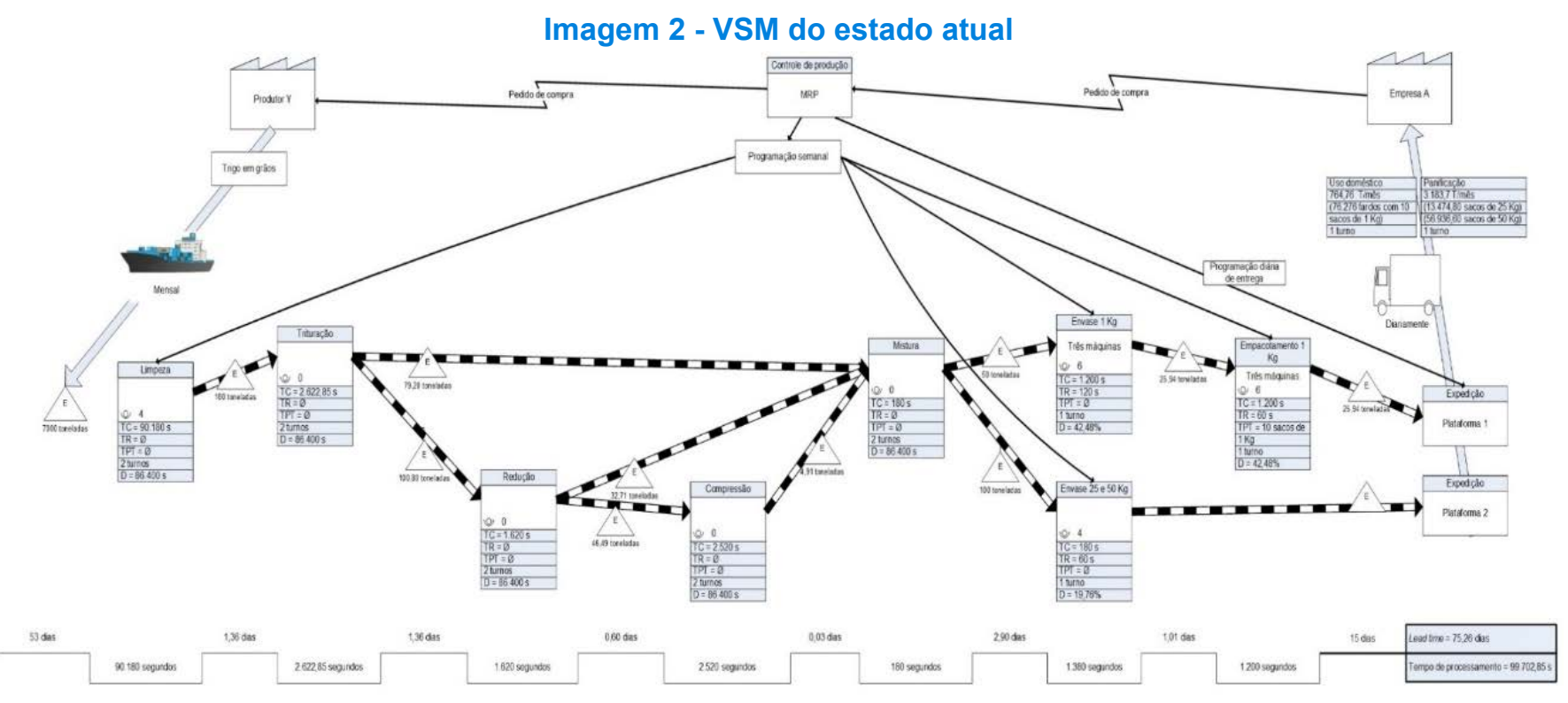

Fonte: Elaborado pelo autor

O mapa de fluxo de valor apresentado na Imagem 2 foi desenhado a partir dos dados coletados na Empresa X, apresenta o lead time em dias e o tempo total de processamentos em segundos, bem como todos os estoques intermediários e fluxos de informações. Devido ao sigilo de informações não foram revelados nomes de clientes e fornecedores. 
Através da análise dos relatórios de produção e expedição foi possível perceber que as demandas mensais dos produtos estudados não sofreram grandes variações no último semestre.

Foram analisados relatórios de avarias e devoluções construídos por vendedores e analistas foram encontrados grandes desperdícios por produtos defeituosos referentes aos produtos expedidos, entretanto a Empresa $X$ não mantinha arquivados dados concretos sobre os motivos das devoluções e avarias.

Gráfico 1 - Panificação 25 kg: devoluções em toneladas

\section{FARINHA PARA PANIFICAÇÃO 25 KG}

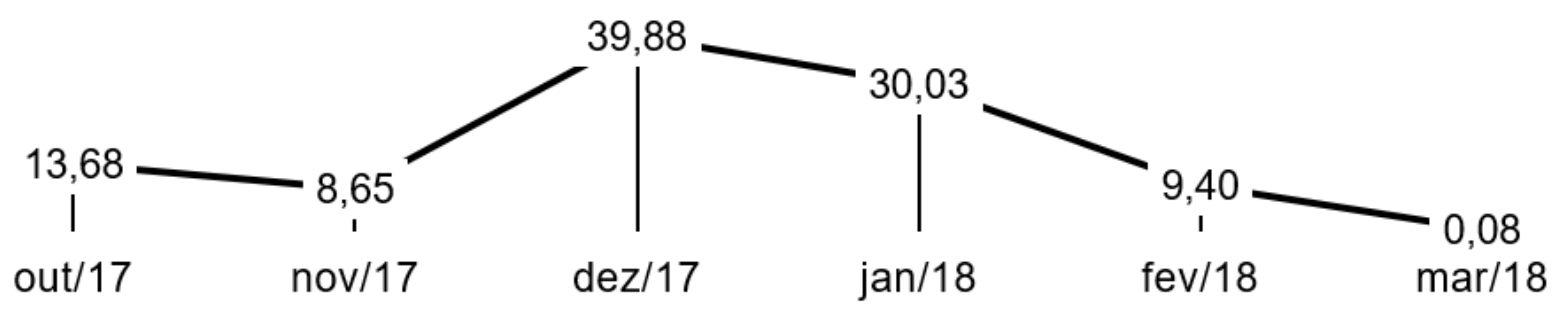

Fonte: Elaborado pelo autor

Os Gráficos 1 e 2 apresentam as devoluções referentes a farinha de trigo para panificação, onde nos últimos seis meses foram devolvidos em média 16,95 toneladas equivalentes a 678 sacos de $25 \mathrm{~kg}$ e 38,42 Ton proporcionais a 768,40 sacos de $50 \mathrm{~kg}$ por mês. Baseando-se no preço médio das mercadorias esta perda custou para a Empresa X em média $\mathrm{R} \$ 121.814,00$ por mês.

Gráfico 2 - Panificação 50 kg: devoluções em toneladas

\section{FARINHA PARA PANIFICAÇÃO 50 KG}

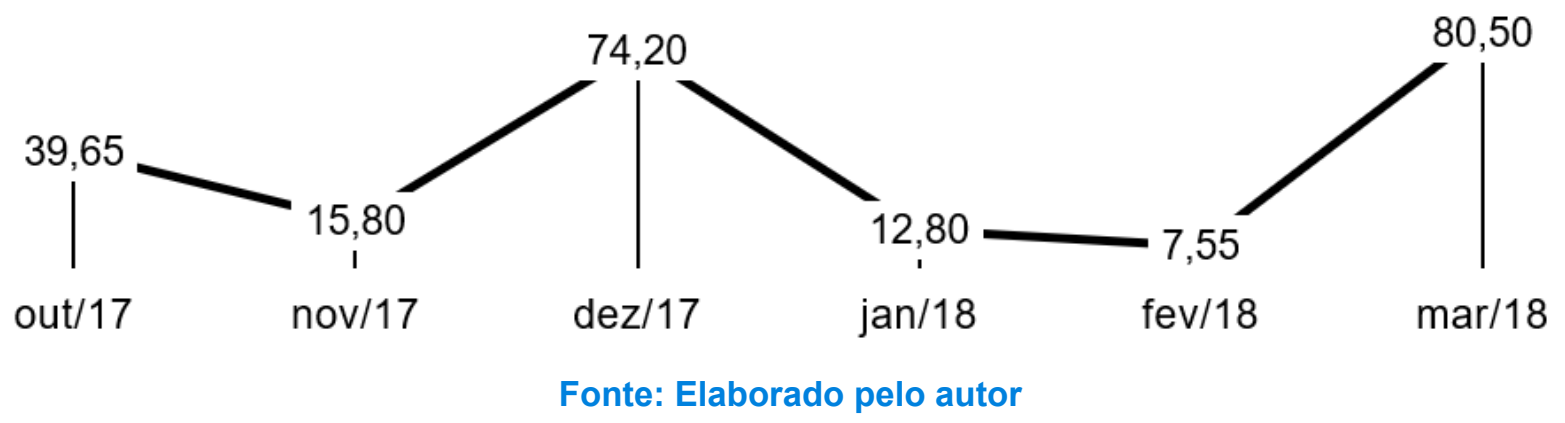

Entretanto os meses com maiores perdas podem ser observados nos gráficos respectivamente nos meses de dezembro, onde as devoluções atingiram 39,88 toneladas iguais a $1.595,2$ sacos de $25 \mathrm{~kg}$ que custam em média $\mathrm{R} \$ 87.736,00$ e março, onde a quantidade devolvida foi de 80,50 Ton análogas a 1.610 sacos de $50 \mathrm{~kg}$ que custam em média $\mathrm{R} \$ 177.100,00$.

O Gráfico 3 expressa as devoluções referente a farinha para uso doméstico onde a média de devoluções nos últimos seis meses foi de 8 Ton equivalentes à 800 fardos ou 8.000 sacos de $1 \mathrm{~kg}$ cujo custo médio é proporcional a $\mathrm{R} \$ 20.000,00$. 


\section{FARINHA PARA USO DOMÉSTICO 1 KG}

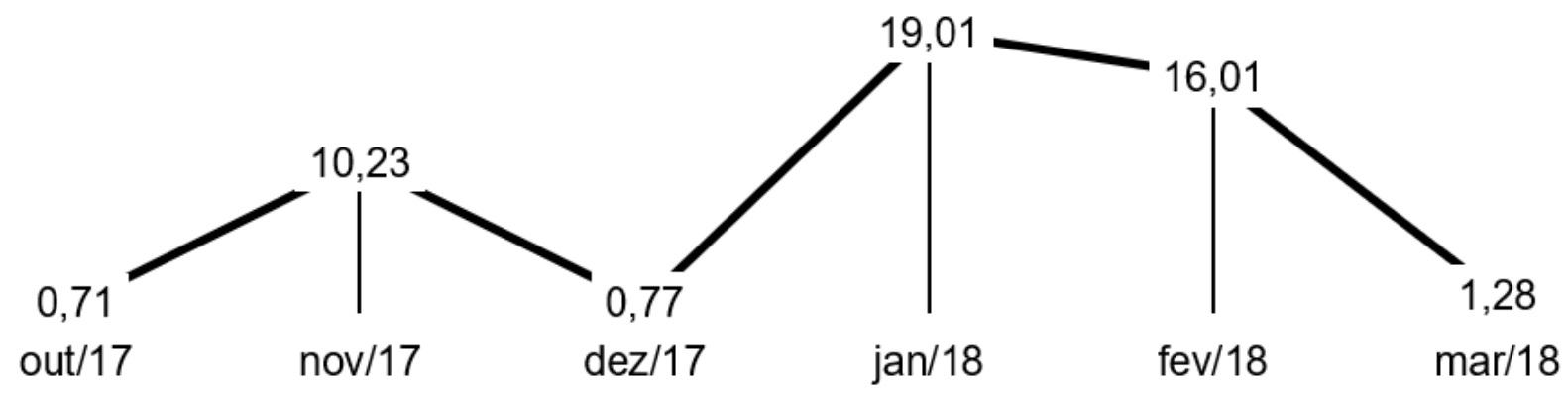

Fonte: Elaborado pelo autor

Entretanto o mês de janeiro apresentou mais do que o dobro da média de devolução dos últimos seis meses, apresentando 19,01 Ton proporcionais a 1.901 fardos ou 19.010 sacos cujo custo baseado no preço médio é equivalente a $\mathrm{R} \$ 47.525,00$.

Gráfico 4 - Pareto: causas de produtos defeituosos

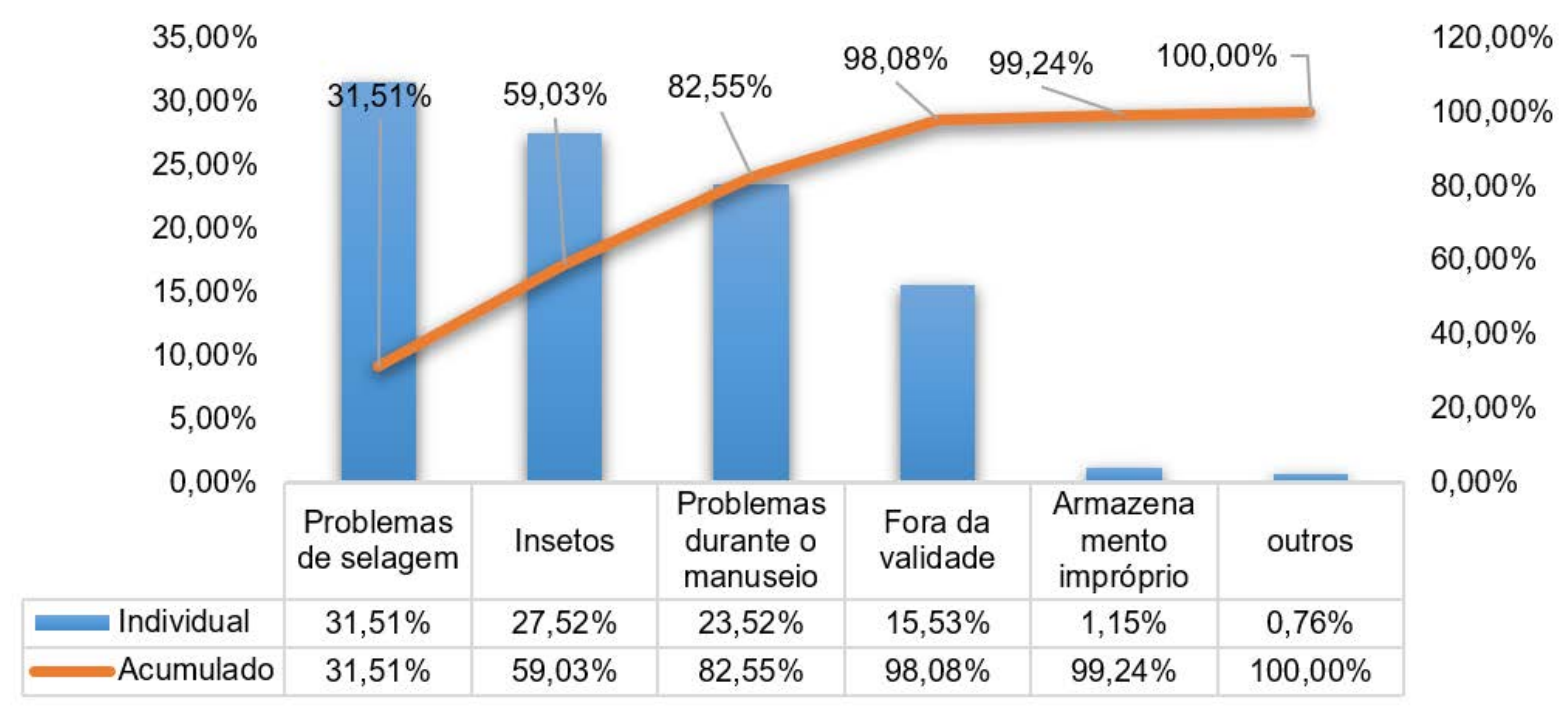

Fonte: Elaborado pelo autor

Por intermédio de entrevistas com alguns dos promotores de vendas da família de produtos estudada, foi possível criar o Gráfico 4 que apresenta os maiores problemas encontrados em produtos defeituosos, onde mais de $80 \%$ das devoluções e avarias são causadas por selagem ineficaz das embalagens, insetos e manuseio incorreto da mercadoria.

Estes problemas encontrados acarretam na quebra da confiança no relacionamento com os clientes que buscam por produtos de qualidade e acabam por se deparar com embalagens abertas ou resíduos indesejados como cascas e insetos.

Ao visualizar os Gráficos 5 e 6 nota-se a grande diferença entre as quantidades demandadas da farinha para panificação em embalagens de 25 e 50 kg. 


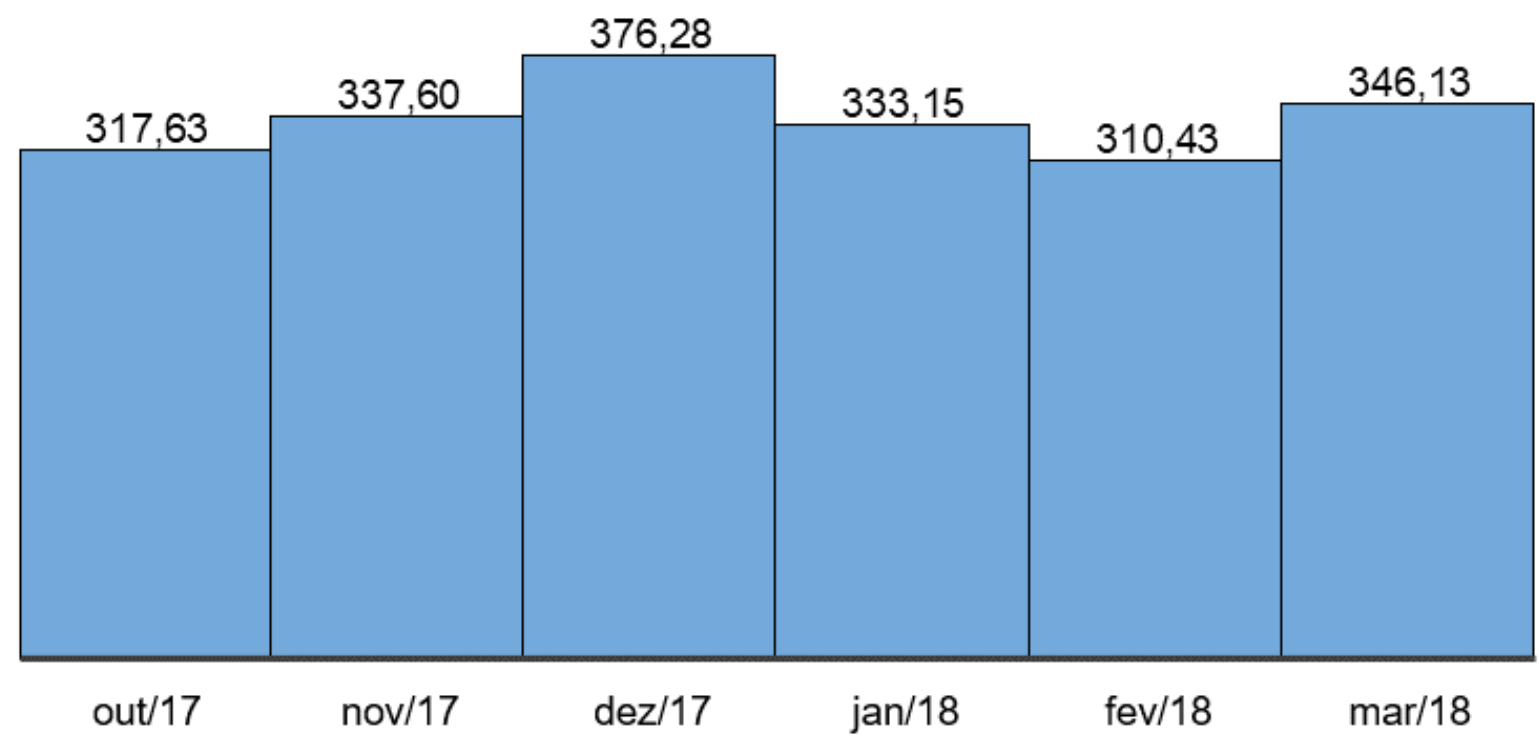

Fonte: Elaborado pelo autor

Foi calculada uma média mensal de 336,87 Ton equivalente a $13.474,80$ sacos de 25 $\mathrm{kg}$, enquanto a média mensal atingida de sacos de $50 \mathrm{~kg}$ foi de $2.846,83$ Ton, proporcionais a $56.936,60$ sacos expedidos por mês nos últimos seis meses.

Gráfico 6 - Histograma panificação 50 kg: expedição em toneladas

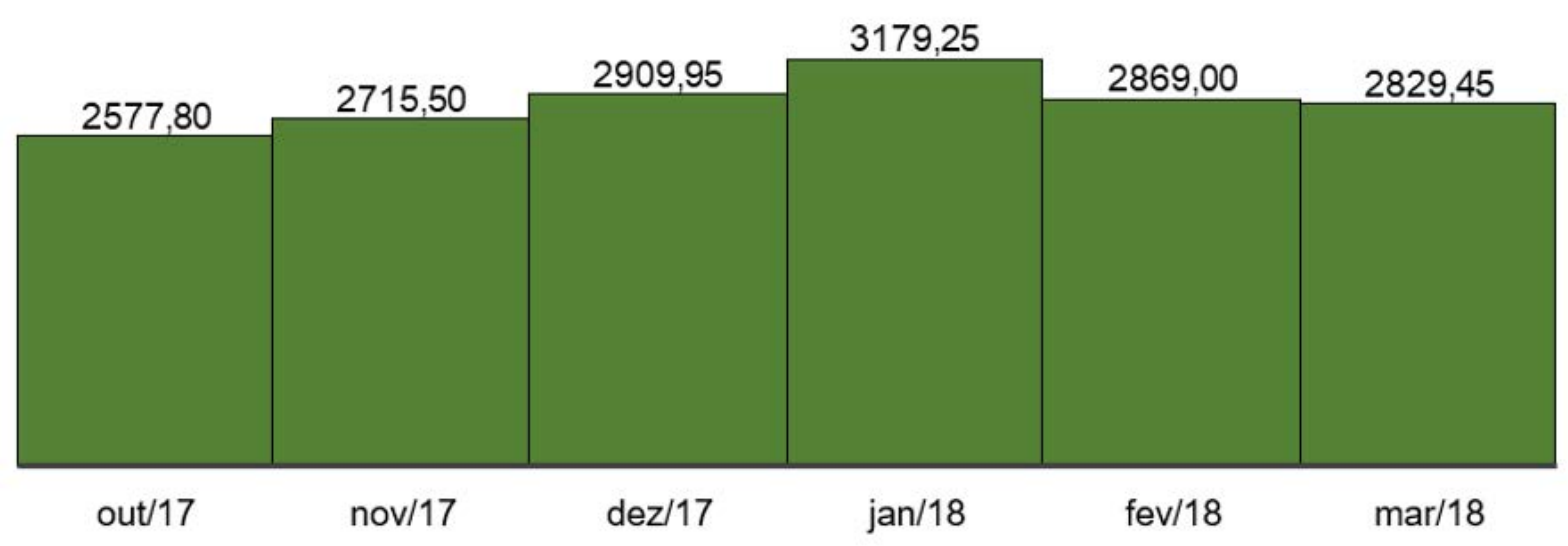

Fonte: Elaborado pelo autor

A farinha para uso doméstico também apresenta uma quantidade demandada com pouca variação, como apresentado no Gráfico 7 , onde a quantidade média expedida por mês nesse período foi de 764,76 Ton, equivalentes a 764.760 sacos de $1 \mathrm{~kg}$ ou 76.476 fardos com $10 \mathrm{~kg}$. Isso significa que a Empresa $X$ necessita evitar perdas para que não haja demanda reprimida $e$ aumento de custos. 


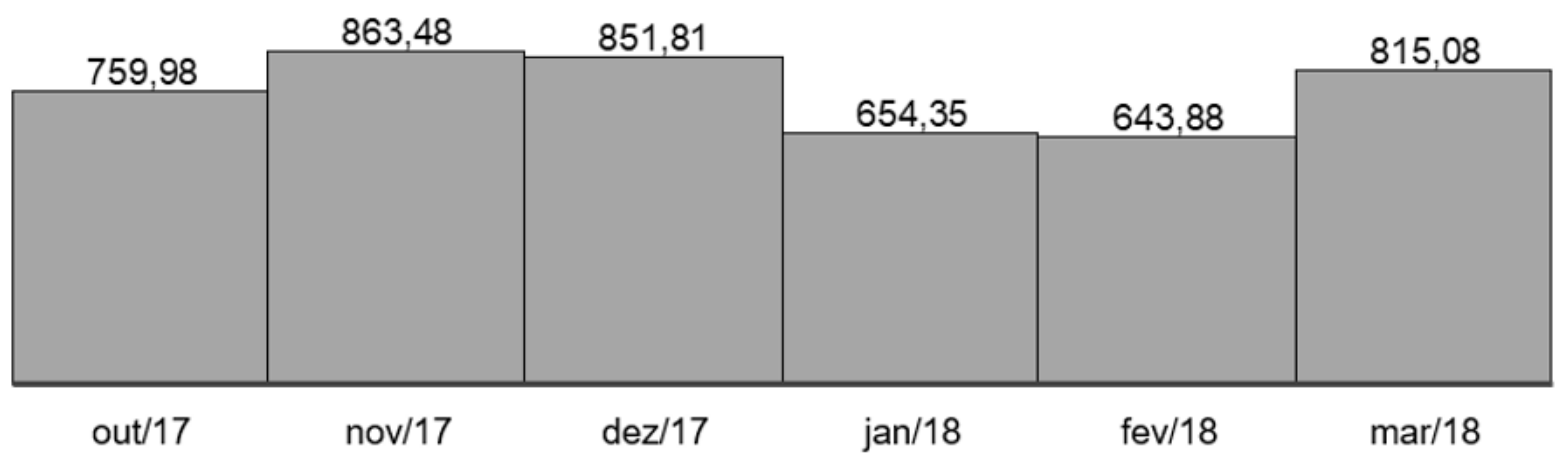

Fonte: Elaborado pelo autor

Por não possuir uma área destinada exclusivamente ao estoque de farinha envasadas em embalagens de $1 \mathrm{~kg}$, esses produtos são paletizados e amontoados ao lado da linha produtiva. Isto pode ser classificado como desperdício por inventário desnecessário ou estoque indevido.

Esses estoques são frequentemente transportados entre os andares da instalação com a ajuda de paleteiras hidráulicas para liberação de espaço, caracterizando o desperdício por transporte.

\section{VSM do estado futuro}

Após a montagem e análise do VSM do estado atual as oportunidades de melhoria identificadas foram exploradas no desenvolvimento do mapeamento do estado futuro, apresentado na Imagem 3. Como afirmam Rother e Shook (2007) um dos maiores benefícios do mapeamento do fluxo de valor é a possibilidade de atingir as causas raízes dos problemas encontrados, o que permite aplicar ações corretivas ao invés de apenas corrigir os sintomas.

Durante a moagem não há desperdício por transporte, pois existe um sistema de filtros pneumáticos que são utilizados para aspirar impurezas e para transportar os grãos entre as etapas de produção, de maneira rápida e prática, não necessitando da intervenção humana e reduzindo a quase zero os estoques intermediários nessas etapas. Devido a isto foram analisados apenas os processos de envase e a expedição. 


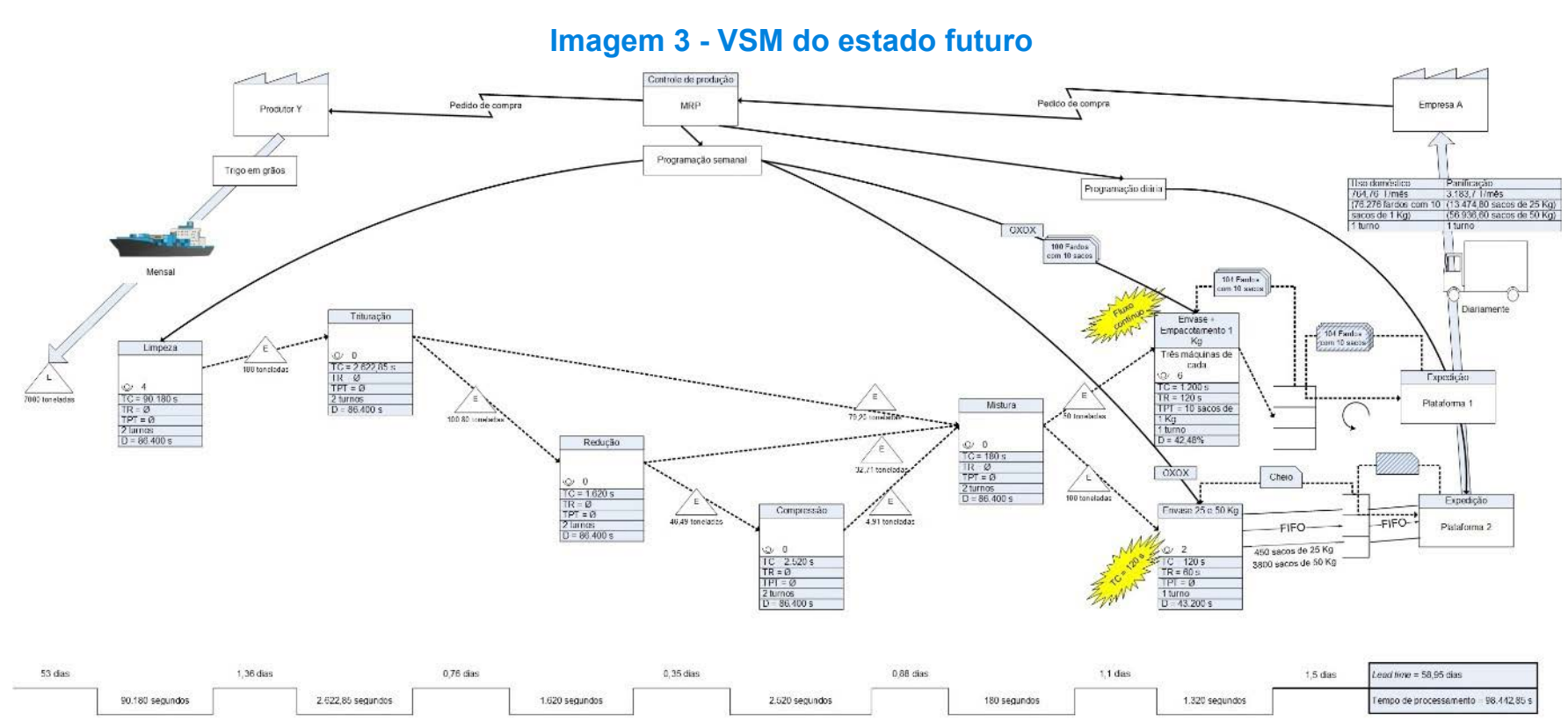

Fonte: Elaborado pelo autor

Para a elaboração do o VSM do estado futuro foi necessário primeiramente calcular o takt time da Empresa X. Esta opera em regime 24/7, ou seja, produz de domingo a domingo durante 24 horas. As equipes de moagem se revezam em turnos de 12 horas, com intervalo de 2 horas para almoço, onde após o expediente de trabalho o colaborador tem 36 horas de folga, enquanto as equipes de envase e expedição trabalham em somente um turno de 12 horas e apenas de segunda a sexta-feira. As trocas de turno duram em média 10 minutos.

São realizados diálogos diários de segurança (DDS) antes de cada turno com duração média de 15 minutos. Todas as segundas-feiras o primeiro turno do dia para e é efetuada a limpeza de máquinas e pisos, bem como manutenções preventivas.

Durante o processo de limpeza, para manter o nível de qualidade, os grãos devem ser umidificados e devem repousar durante 24 horas, por consequência disto esta etapa não foi analisada haja vista que não há como reduzir o tempo de descanso do trigo. Porém, tendo em vista que o processo de moagem apresenta uma disponibilidade de 168 horas semanais enquanto o envase e expedição apenas 60 horas semanais foi entendido que as equipes de moagem e de envase devem trabalham em ritmos diferentes para que seja possível sincronizar os fluxos de produção.

Foi percebido que por funcionar como um fluxo contínuo onde os grãos são tratados como um fluido dentro das tubulações de transporte pneumático, o processo de moagem atende ao takt time não havendo necessidades de alterações em seus tempos de ciclo.

Já as equipes de envase e expedição trabalham sob o seguinte tempo de ritmo:

- Tempo semanal total disponível para produção $=216.000 \mathrm{~s}$;

- $\quad$ DDS semanal = $4.500 \mathrm{~s}$;

- Manutenção e limpeza = $43.200 \mathrm{~s}$;

- Intervalo semanal para almoço $=50.400 \mathrm{~s}$;

- Tempo semanal de troca de turno $=\varnothing$;

- Demanda semanal $=921,3069$ Ton.

Através dos dados acima tem-se: 


$$
\text { Takt time envase e expedição }=\frac{216000 \mathrm{~s}-(4500-43200-50400)}{921,3069}
$$

Takt time envase $=127,97 \mathrm{~s}$

Efetuando o comparativo entre o takt time de envase com os tempos de ciclo dos processos foi possível perceber que os tempos de ciclo estão acima do ritmo encontrado. Isso significa que atualmente Empresa $X$ precisa produzir e manter um pulmão de estoque elevado para garantir que a sua demanda não seja reprimida devido aos longos tempos de processamento. Este tipo de atitude gera desperdícios por superprodução antecipada, estoques indevidos e transporte de produto acabado.

Entretanto é importante ressaltar que existem três máquinas para envase e três empacotadeiras destinadas a produção de farinha para uso doméstico de $1 \mathrm{~kg}$ onde o tempo de ciclo de cada uma é de $1.200 \mathrm{~s} / \mathrm{T}$ apresentando capacidade para atender a demanda se trabalharem ao mesmo tempo.

Realizando um comparativo entre os mapas do estado atual e futuro é possível perceber que houve uma redução de 16,31 dias no lead time e de 1.260 segundos no tempo de processamento.

É possível visualizar que durante o mapeamento do estado futuro foi proposta a união dos processos de envase e empacotamento da farinha para uso doméstico de $1 \mathrm{~kg}$ onde o processo cliente não precisaria aguardar o envase de um lote inteiro para então começar a empacotar.

Imagem 4 - Melhorias em fluxo contínuo

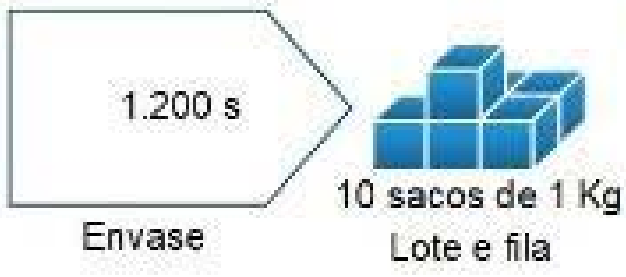

Lote e fila

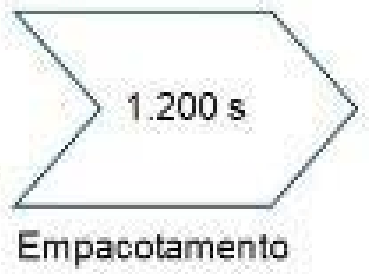

Empacotamento

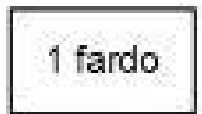

Lote

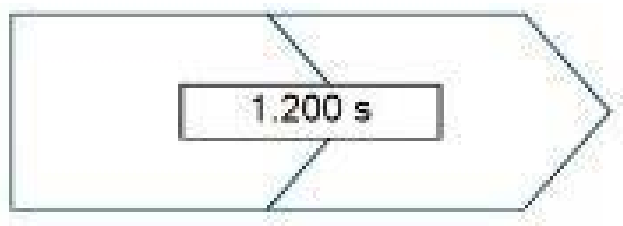

Envase + empacotamento

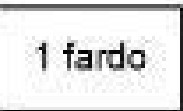

Lote

Fonte: Elaborado pelo autor

A Imagem 4 representa ilustrativamente de maneira mais clara como através da produção em fluxo contínuo seria possível envasar e empacotar continuamente alterando apenas o layout de produção. Em decorrência disso haveria a redução do tempo de processamento pela metade passando de 2.400 segundos para 1.200 segundos. 
Desta maneira o tempo de espera para a produção de um lote com 10 sacos seria eliminada e ao invés de dois tempos de processamento haveria apenas um, otimizando a produção.

Foi proposta a delimitação de uma área para instalação de supermercados para farinha de uso doméstico de $1 \mathrm{~kg}$ que, auxiliada pela utilização de kanbans de produção e de retirada, reduziria o volume de estoque e ditaria o ritmo de produção onde seria produzido apenas o necessário para repor a quantidade puxada pela expedição.

Este supermercado seria dimensionado de maneira que armazenasse apenas o estoque necessário para um dia e meio, haja vista que produtos são expedidos diariamente. O estoque seria o suficiente para suprir a demanda diária, bem como flutuações inesperadas sem que sejam produzidos produtos em excesso, eliminando os desperdícios relacionados superprodução por antecipação e estoques indevidos.

Os desperdícios relativos ao transporte deste produto entre os andares das instalações serão reduzidos com a implantação do sistema de supermercados auxiliados por kanbans, entretanto por se tratar de uma atividade que muitas vezes se torna necessária não seria completamente eliminada.

Com isso, é possível sanar os retrabalhos provenientes da execução desta tarefa através da padronização da organização dos fardos de $10 \mathrm{~kg}$ nos pallets de forma que seja feita uma amarração com uma base de 13 fardos em uma altura de segurança de oito andares onde cada andar é sobreposto por outro em sentido oposto, como apresentado pela Imagem 5.

A utilização de chapatex a cada três andares garante uma maior estabilidade e reduz as quedas de materiais e, por conseguinte os retrabalhos por remontagem.

O transporte seria mais seguro, menos demorado e necessitaria de apenas um operador por pallet ao invés de dois. Este tipo de paletização é amplamente utilizado e pode ser visto em muitos supermercados que atuam no mercado de atacado.

\section{Imagem 5 - Paletização de fardos de $10 \mathrm{~kg}$}

Vista Superior

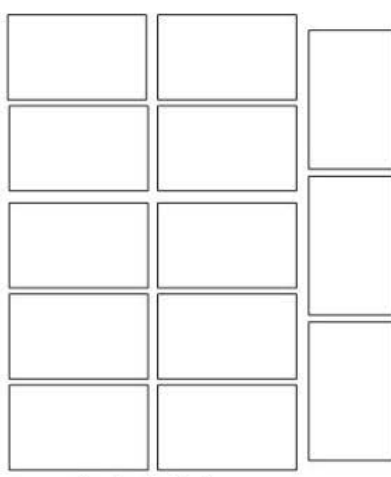

Andar inferior

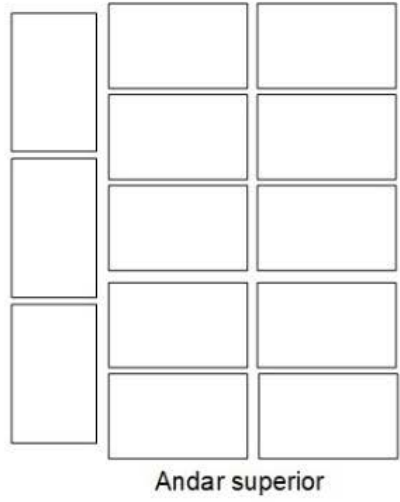

Fonte: Elaborado pelo autor

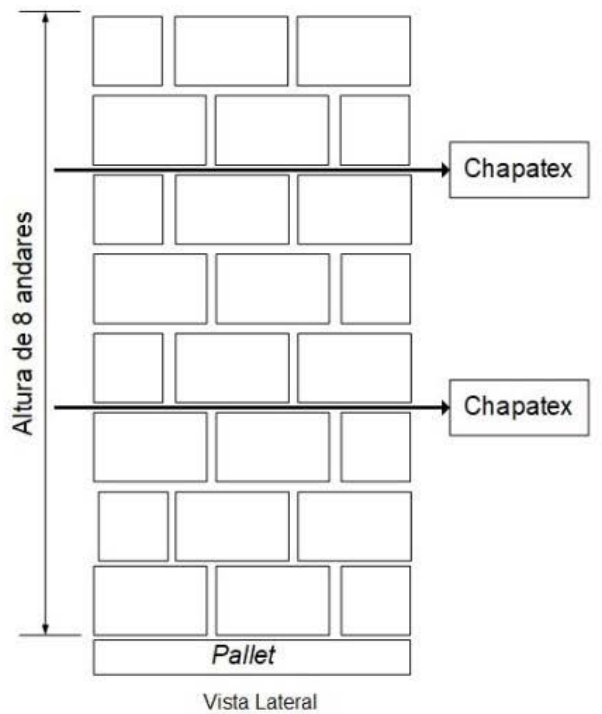

Foi proposto também que o tempo de ciclo do envase da farinha para panificação de 
25 e $50 \mathrm{~kg}$ fosse reduzido para 120 segundos para que possa estar alinhado com o takt time e não haja sobrecarga de trabalho, haja vista que o equipamento de envase opera em velocidade menor a de sua capacidade. É importante também que ocorra o nivelamento de produção de maneira que não haja superprodução por antecipação por parte de nenhum dos produtos.

Outro ponto importante é que este nivelamento ocorra levando em conta a programação de expedição para que um produto não seja produzido e expedido logo em seguida enquanto ainda existe estoque de produto acabado. Desta forma foi atribuído um sistema onde o primeiro produto a sair da linha produtiva é o produto a ser expedido do supermercado de produtos acabados conhecido também como first in first out ${ }^{13}$ (FIFO).

Esta retirada seria auxiliada por uma adaptação do kanban de retirada na área de expedição ilustrada na, onde os primeiros a entrar devem ser os primeiros a sair e a reposição deve ser orientada a medida em que os produtos nas áreas demarcadas são puxados para expedição de modo que a sincronia de nivelamento produza sempre o produto que não está sendo expedido e o ponto de reposição seja orientado pela área vermelha.

Imagem 6 - Layout de supermercado: 25 e $50 \mathrm{~kg}$

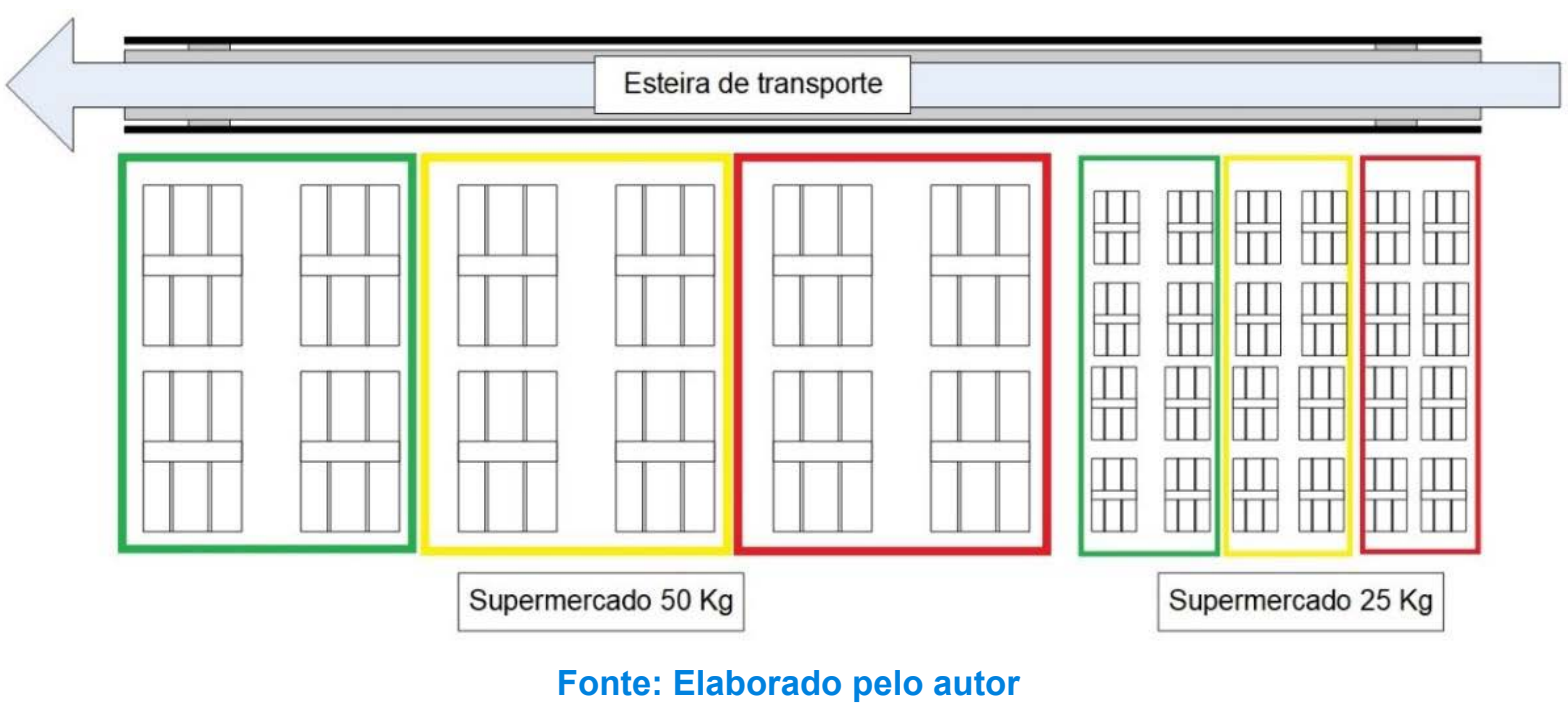

Os problemas de manuseio ocorrem durante o carregamento dos caminhões na expedição dos produtos acabados. Os colaboradores que manuseiam o produto sem o devido cuidado acabam por danificá-lo e isto acarreta em devoluções e avarias onde o cliente se sente lesado e não aceita receber o produto fora de suas especificações.

Este problema pode ser sanado através da conscientização e da padronização do trabalho, de maneira que todos os colaboradores possam manusear os materiais do mesmo modo, reduzindo o grau de risco e garantindo a integridade dos bens. A Empresa X deve perceber a melhor forma de abordar e supervisionar seus colaboradores para que possa ter êxito na eliminação desta perda.

Já os insetos são oriundos dos longos períodos de estocagem. Através da implementação de um sistema puxado, este tipo de desperdício será sanado naturalmente devido a redução dos tamanhos e dos tempos de armazenagem dos estoques, entretanto alguns cuidados devem ser tomados na armazenagem, como por exemplo guardar em local seco e arejado e protegido da luz sol. 
Os problemas de selagem são provenientes da falta de comunicação entre os colaboradores. Alguns operadores operam as máquinas de envase habilitadas em configurações específicas enquanto outros colaboradores preferem quando as máquinas estão ajustadas de maneira diferente.

Por se tratar de três equipes que trabalham a cada três dias em turnos de 12 horas existe uma lacuna na comunicação. Os operadores começam a trabalhar e só percebem que as configurações das máquinas não estão de acordo com seu modo de trabalho após a identificação de defeitos nos produtos acabados, o que muitas vezes demora para acontecer.

Através do trabalho padronizado, é possível definir as configurações a serem utilizadas por todos os operadores das máquinas de envase. Desta maneira os problemas de selagem seriam reduzidos drasticamente e o controle de qualidade seria mais eficiente.

Através da eliminação destes desperdícios relacionados aos produtos defeituosos, compostos por problemas de selagem, insetos e problemas durante o manuseio, aproximadamente $80 \%$ dos problemas seriam solucionados. Isso que significa que em um comparativo com o valor médio perdido devido às devoluções $R$ \$ 113.451,20 seriam poupados por mês, contribuindo para o aumento do lucro da Empresa $X$ através da redução dos custos com avarias.

Uma vez eliminados os desperdícios podem voltar a aparecer se não houver uma melhoria contínua nos processos, haja vista que os colaboradores e a alta gerência podem se acostumar com o cenário se não forem cuidadosos.

\section{CONSIDERAÇÕES FINAIS}

Durante o desenvolvimento deste trabalho monográfico foi solucionado o problema de estudo de forma que a aplicação do sistema de produção puxado, apoiado por uma cultura organizacional enxuta, é um fator importante para garantir a manutenibilidade dos fluxos contínuos em toda a cadeia de suprimentos.

É possível criar um fluxo contínuo e sincronizado entre os fluxos produtivo logístico e de informação, onde entregas menores e mais frequentes eliminam perdas relacionadas à espera e sobrecargas produtivas.

Os objetivos da pesquisa foram integralmente alcançados, haja vista que foi possível entender o TPS, não apenas como um modelo de gestão, mas também como uma filosofia que compõe uma cultura organizacional onde os colaboradores são os principais agentes de mudança.

Foi possível também desenvolver os mapeamentos do fluxo de valor dos estados atual e futuro, os quais possibilitaram a visualização gráfica das oportunidades de melhoria, bem como das mudanças propostas.

Através da análise dos dados foi possível projetar em valores monetários a redução de custos relacionados aos desperdícios por produtos defeituosos. Foi possível também propor meIhorias para perdas relacionadas a transporte de materiais e retrabalho.

Por fim este trabalho concluiu que através da utilização do VSM como ferramenta para 
eliminação de desperdícios é possível abordar de maneira enxuta a cadeia de suprimentos de uma empresa de moagem de trigo.

\section{REFERÊNCIAS}

ARBAGE, Alessandro Porporatti. Custos de transação e seu impacto na formação e gestão da cadeia de suprimentos: estudo de caso em estruturas de governança híbridas do sistema agroalimentar no Rio Grande do Sul. 2004. 280 f. Tese (Doutorado) - Curso de Administração, Universidade Federal do Rio Grande do Sul, Porto Alegre, 2004. Disponível em: http://www.lume.ufrgs.br/bitstream/ handle/10183/4871/000416579.pdf?sequence=1. Acesso em: 20 fev. 2018.

GUARIENTI, Eliana Maria (Ed.). Qualidade industrial de trigo. 2. ed. Passo Fundo:

Embrapa, 1996. 36 p. Disponível em: https://www.infoteca.cnptia.embrapa.br/bitstream/doc/849741/1/ CNPTDOC.2796.pdf. Acesso em: 17 mar. 2018.

KUHLANG, Peter et al. Utilizing a process management approach to standardize the application of value stream mapping. Brazilian journal of operations \& production management. Vienna, p. 89-102. 09 nov. 2011. Disponível em: https://bjopm.emnuvens.com.br/bjopm/article/view/V8N2A5/V8N2A5 . Acesso em: 05 nov. 2017.

MELTON, T.. The benefits of lean manufacturing what lean thinking has to offer the process industries. Chemical engineering research and design. Chester, p. 662-673. jun. 2005. Disponível em http://www.sciencedirect.com/science/article/pii/S0263876205727465 . Acesso em 15 set. 2017.

OHNO, Taiichi. O sistema de produção Toyota - além da produção em larga escala. Porto Alegre: Bookman, 1997. Tradução de: Cristina Schumacher.

ROTHER, Mike; SHOOK, John. Aprendendo a enxergar: mapeando o fluxo de valor para agregar valor e eliminar o desperdício: manual de trabalho de uma ferramenta enxuta. São Paulo: Lean Institute Brasil, 2007. 102 p. Disponível em: https://pt.slideshare.net/diegobiondo37/aprendendo-a-enxergar . Acesso em: 27 fev. 2018.

SHINGO, Shigeo. O sistema de produção Toyota do ponto de vista da engenharia de produção. Porto Alegre: Bookman, 1996. Tradução de: Eduardo Schaan. 


\section{ANEXOS}

Anexo 1 - VSM do estado atual

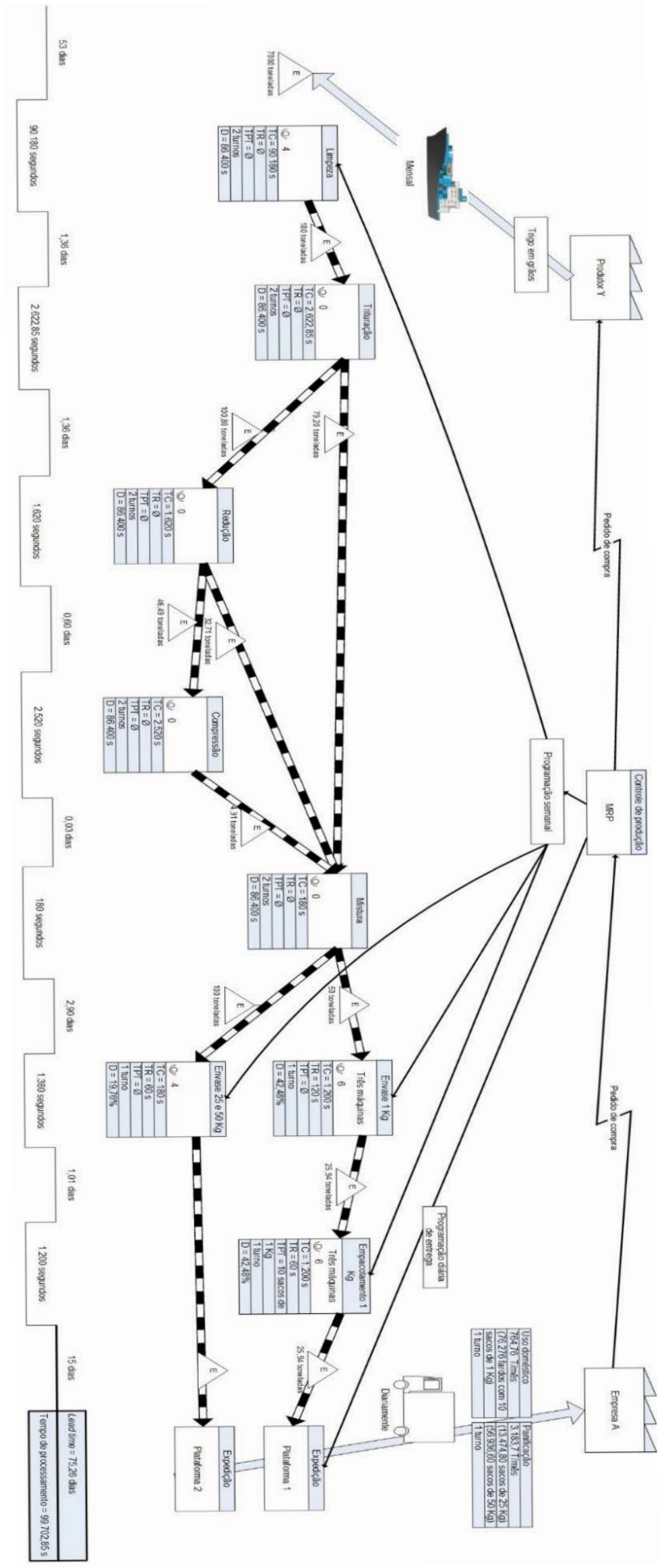

Fonte: Elaborado pelo autor 


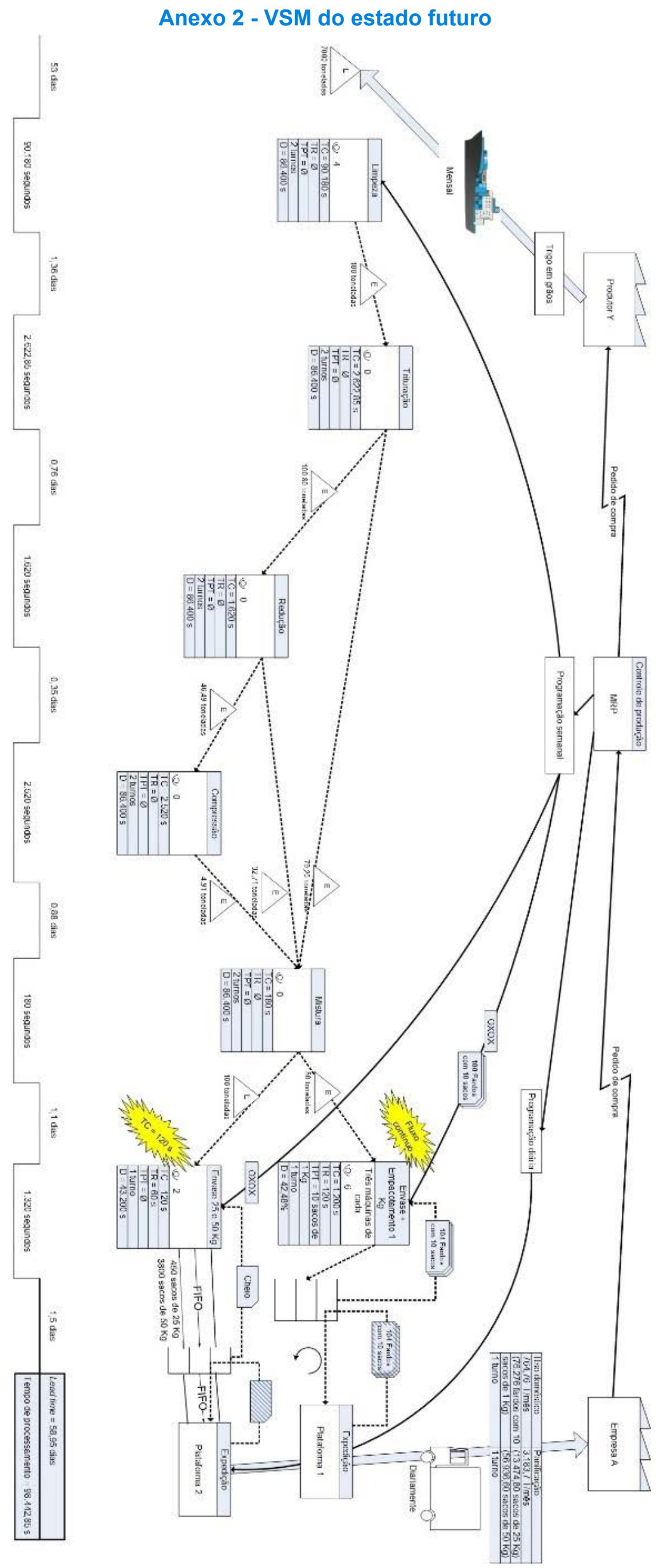

Fonte: Elaborado pelo autor 


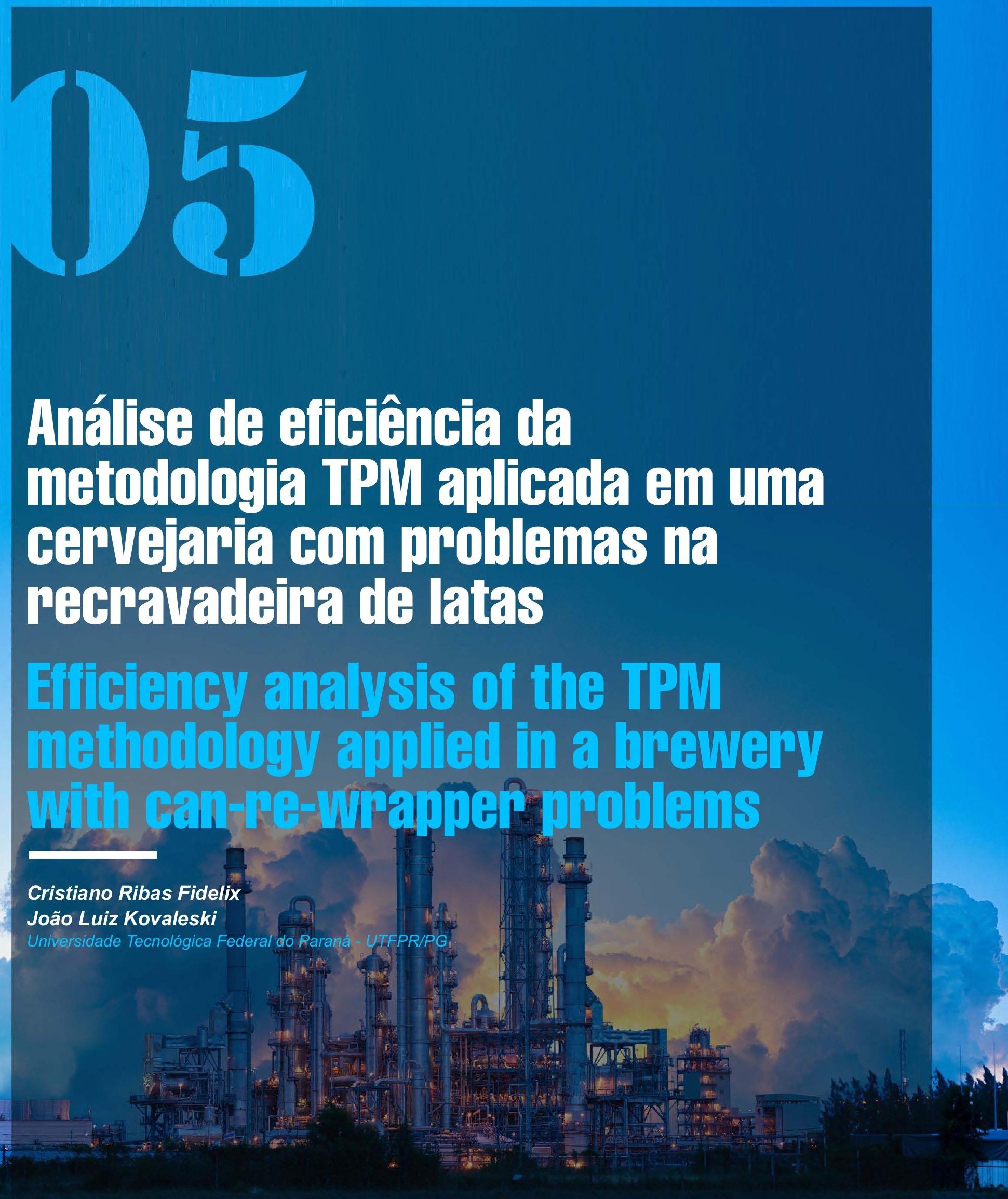

DOI: 10.47573/aya.88580.2.22.5 
A Total Productive Maintenance - TPM (Manutenção Produtiva Total) é um instrumento altamente eficaz para as empresas que buscam soluções e técnicas capazes de manter seus padrões produtivos em evolução e com alta qualidade, diante de um mercado infinitamente competitivo e agressivo. Neste cenário, a busca constante pela melhoria contínua, aperfeiçoamento produtivo e capacitação periódica de colaboradores são situações indispensáveis para o desenvolvimento das organizações. Logo então, a Total Productive Maintenance oferece ferramentas que contribuem efetivamente no êxito destes resultados. Assim, este trabalho objetivou a análise da eficiência da metodologia TPM na resolução de uma falha na recravadeira de latas na cervejaria em estudo. Os resultados obtidos foram a aplicação de métodos de manutenção mais eficientes e uma melhora plausível nos índices produtivos do setor.

Palavras-chave: TPM. manutenção autônoma. recravadeira. cervejaria.

\section{Alistragt}

Total Productive Maintenance - TPM (Total Productive Maintenance) is a highly effective tool for companies seeking solutions and techniques capable of keeping their production standards evolving and of high quality in the face of an infinitely competitive and aggressive market. In this scenario, the constant search for continuous improvement, productive improvement and periodic training of employees are indispensable situations for the development of organizations. Thereafter, Total Productive Maintenance offers tools that effectively contribute to the success of these results. Thus, this work aimed to analyze the efficiency of the TPM methodology in solving a failure in the can rewrapper in the brewery under study. The results obtained were the application of more eficiente maintenance methods and a plausible improvement in the productive indexes of the sector.

Keywords: TPM. self employed maintenance. brewery. 


\section{INTRODUÇÃO}

Conforme os dados do setor cervejeiro nacional (CERVBRASIL, 2019), a indústria cervejeira, da agricultura ao varejo, está ligada de maneira direta com o progresso e o desenvolvimento do Brasil. Este segmento é responsável por 2\% do PIB e emprega cerca de 2,7 milhões de pessoas ao ano no país. Em termos tributários, ela recolhe cerca de $\mathrm{R} \$ 21$ bilhões de tributos e paga cerca de $R \$ 21$ bilhões anuais em salários aos seus colaboradores.

Neste mercado consolidado, as fábricas estão em constante expansão de suas plantas, investindo em equipamentos altamente tecnológicos, promovendo o aumento de suas produções e qualidade de seus produtos e serviços, a fim de manter seu espaço no setor.

Como nos diz Falconi (1999), um produto ou serviço de qualidade é aquele que atende perfeitamente, de forma confiável, de forma acessível, de forma segura e no tempo certo às necessidades do cliente. Em outros termos, é o comprometimento da indústria em garantir a máxima qualidade de seu produto. Conforme Martins e Laugeni (2015), ser competitivo é ter condições de concorrer com um ou mais fabricantes e fornecedores de um produto ou serviço em um determinado mercado.

Para manter a excelência e qualidade da produção, a busca pela melhoria contínua é fundamental. As indústrias precisam garantir que seus equipamentos operem com alta eficiência, baixo índice de perdas e treinamento constante de seus colaboradores. Estas condições estão inseridas na filosofia da Total Productive Maintenance (TPM), uma metodologia fundamental para as cervejarias, cujos resultados dependem diretamente de produções de larga escala.

Este artigo teve como base de pesquisa a aplicação da Total Productive Maintenance (TPM) na resolução de uma falha recorrente da recravadeira de latas, responsável pelos baixos índices de rendimento produtivo do setor, evidenciando assim os resultados obtidos, em uma cervejaria multinacional de grande porte, cuja identidade permanecerá resguardada. Esta pesquisa tem caráter qualitativo.

\section{FUNDAMENTAÇÃO TEÓRICA}

\section{Metodologia TPM}

A Total Productive Maintenance (TPM) é uma aplicação direcionada da melhoria contínua, focada no aumento expressivo da qualificação competitiva e potencial dos processos, por intermédio de progressões estratégicas da empresa. É uma ferramenta de gerenciamento que ataca as causas de perdas seqüenciais, de modo a aperfeiçoar constantemente o sistema organizacional da empresa, tanto na qualificação de pessoal quanto no aumento da autonomia de equipamentos dos processos industriais, garantindo assim, a qualidade dos produtos e serviços ofertados.

Segundo Takahashi e Osada (1993):

A Manutenção Produtiva Total ou TPM - Total Productive Maintenance - se estabelece como sendo as atividades de manutenção produtiva com participação de todos os funcionários da empresa - está entre os métodos mais eficazes para transformar uma fábrica em uma operação com gerenciamento orientado para o equipamento, coerente com as 
mudanças da sociedade contemporânea.

Inicialmente, a condição para que aconteça a mudança é que todos os colaboradores, incluindo a alta gerência e supervisores, estejam atentos a todos os detalhes da fábrica, sejam equipamentos, sensores, máquinas, dispositivos etc., admitindo a importância do gerenciamento do equipamento em questão, mantendo sua integridade, pois conforme Takahashi e Osada (1993), a confiabilidade, a segurança, a manutenção e as características operacionais da fábrica são os elementos decisivos para a qualidade, quantidade e custo. Então, a tecnologia inovadora deve ser implementada nas operações de manufatura de modo dinâmico, entretanto, não se pode deixar despercebido alguns detalhes essenciais:

a) Não investir em equipamentos desnecessários;

b) Utilizar ao máximo os equipamentos existentes;

c) Melhorar a taxa de utilização do equipamento para produção;

d) Garantir a qualidade do produto, através do uso do equipamento;

e) Reduzir a mão-de-obra de baixo custo, através da melhoria dos equipamentos.

f) Reduzir os custos de energia e materiais adquiridos, através de inovações no equipamento e melhorias dos métodos de sua utilização.

Todas essas tarefas são fundamentais para a reestruturação da empresa, como resposta aos desafios futuros. Vale ressaltar que elas precisam ser realizadas com a participação de todos os funcionários.

As atividades que a TPM estabelecidas por Takahashi e Osada (1993) são:

a) Investir e melhorar máquinas, matrizes, dispositivos e acessórios, de modo que sejam confiáveis, seguros e de fácil manutenção, e explorar meios para padronizar essas técnicas;

b) Determinar como oferecer e garantir a qualidade do produto através do uso de máquinas, dispositivos e acessórios, e treinar todo o pessoal nessas técnicas;

c) Aprender como melhorar a eficiência da operação e como maximizar sua durabilidade;

d) Descobrir como despertar o interesse dos operadores e educá-los para que cuidem das máquinas da fábrica.

A TPM sugere a criação de pequenos grupos de trabalho formados de maneira estratégica, seguindo o regimento da metodologia, respeitando as particularidades de cada instituição, com os níveis de hierarquia sendo levados em consideração, onde cada grupo seja subdividido em outros dois grupos, no mínimo, e que o grupo com mais integrantes pertença à classe inferior.

Com a divisão dos grupos, estes devem se instalar dentre os 8 pilares que regem a filosofia da Total Productive Maintenance (figura 1), cada qual com suas funções organizadas e bem definidas. 


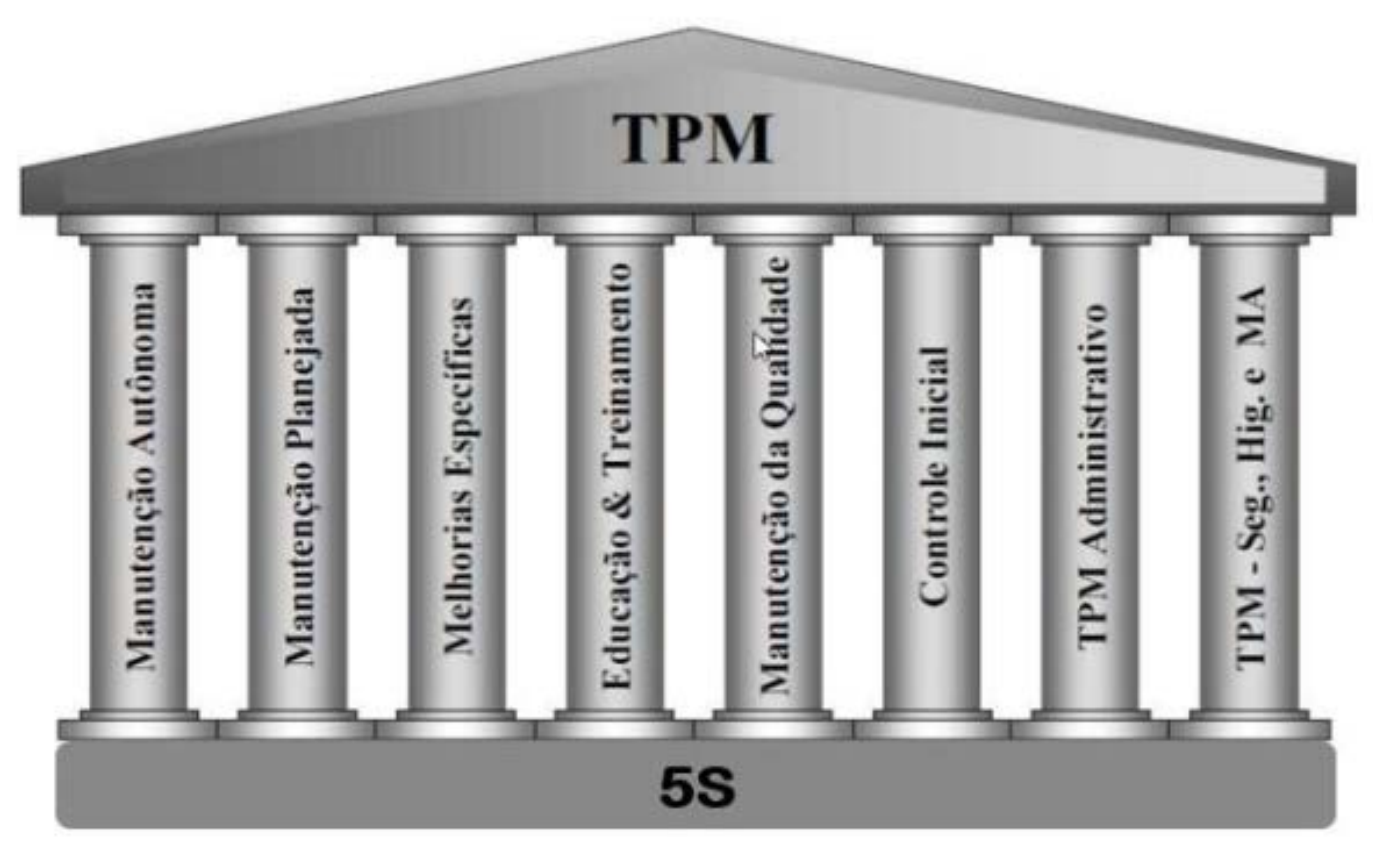

Fonte: Amaral (2013)

A cervejaria analisada aplica em sua planta seis pilares da TPM, sendo eles: Manutenção Autônoma; Manutenção Planejada; Melhorias Específicas; Educação e Treinamento; Manutenção da Qualidade; Segurança, Higiene e Meio Ambiente.

\section{Conceito $5 \mathrm{~S}$}

As primeiras aplicações do conceito 5S se deram no Japão, país de sua origem.

Como visto na figura 1 , o $5 \mathrm{~S}$ está na base de todos os pilares que regem a metodologia TPM. Tal conceito tem como objetivo a mudança comportamental das pessoas em relação ao ambiente, a fim de torná-lo mais organizado, compacto, limpo, livre de excessos. Está ligado diretamente à gestão da qualidade das empresas.

\section{METODOLOGIA}

\section{Problema raiz}

Esta pesquisa discorre de uma situação pontual recorrente de um processo produtivo, onde se verifica as técnicas padronizadas e estudo dos indicadores em uma observação sistêmica (TEIXEIRA, 2005).

Segundo os indicativos da Auditoria Interna de Qualidade, supervisionada remotamente pela fábrica matriz da cervejaria analisada, alocada na Europa, estes vinham apontando perdas importantes de extrato de cerveja em uma linha de latas, gerando assim infortúnios nas entregas de produto, descartes indesejados de materiais produtivos, tempo ocioso de processo e por fim, elevados prejuízos econômicos. 
Inúmeras quebras de equipamentos por motivos de desgaste, a falta de planejamento e execução de manutenções periódicas, dentre outros fatores, geram prejuízos quanto à pontualidade de entrega de produtos, resultando em mão-de-obra parada e altos custos para reparação e troca de peças dos equipamentos. Os técnicos de produção, operadores de máquinas, pessoal de manutenção, estagiários e o supervisor de departamento foram designados para a composição do Time TPM, e estes passaram por um treinamento específico àquela situação, a fim de garantir a qualidade e o bom êxito da operação.

O desenvolvimento das atividades desta pesquisa se deu pelo acompanhamento desde a análise dos dados, passando pela observação dos efeitos da metodologia TPM sobre a falha encontrada e apreciação dos resultados.

Com as características evidenciadas do problema, a coordenação da metodologia TPM em consonância com a alta gerência, se estabeleceu a abertura do time TPM na enchedora de latas, com foco exclusivo na recravadeira de tampas, segundo os passos do Pilar da Manutenção Autônoma.

O cronograma deste grupo foi o seguinte:

a) Abertura do Time TPM Manutenção Autônoma;

b) Aplicação do conceito $5 \mathrm{~S}$ e etiquetagem de anomalias;

c) Análise das condições do equipamento;

d) Auditorias de eficiência do Time TPM;

e) Fechamento do time e resultados.

Os dados apontados pela auditoria externa indicavam perdas de extrato na linha produtiva na faixa de $4,5 \%$ a $4,9 \%$, impactando negativamente em torno de $12 \%$ nos índices produtivos em relação ao envasamento como um todo.

A análise destes índices fez com que as primeiras ações fossem tomadas, na busca pelas causas das perdas e identificação delas.

Foram encontradas as seguintes situações:

a) Set-up: As perdas ocorrem no ato da troca de produtos, em razão do mau posicionamento da altura das válvulas de enchimento, ocasionando quedas e travamento de latas nas correias transportadoras, resultando em paradas de produção para limpeza de refugos gerados dentro da enchedora;

b) Falta de Lubrificação nos tapetes de transporte: os bicos de lubrificantes dos tapetes de transportes, em sua maioria, encontram-se entupidos, gerando quedas de latas na entrada da enchedora;

c) Latas refugadas: Estas perdas derivam de latas com enchimento inferior ao designado por padrão, ou seja, latas com baixo volume de extrato em seu interior;

d) Checkmat: Análise do nível de enchimento das latas por meio de raio-x, com alto índice de reprovação de latas por nível de extrato baixo;

e) Vazamento de cerveja pela tampa da lata;

f) Problemas recorrentes com a Recravadeira: responsável pelo elevado índice de per- 
das, resultando em vazamentos de cerveja pela tampa da lata.

\section{Processo de Recravação das latas de Alumínio}

Como nos diz Farias (1990), recravação é a operação responsável pela junção da tampa ao corpo da lata. Esta junção, estruturalmente, consiste em três espessuras do material da tampa, e duas espessuras do material do corpo, juntamente com o vedante, donde resulta um fechamento hermético. Em outros termos, recravação consiste no dobramento das bordas da região superior das latas, com encaixe arredondado e rebaixado na circunferência da tampa. A proteção do alimento contido na lata é garantida quanto a recravadeira realiza o fechamento hermético de modo eficaz. Isto garante com que o produto seja mantido íntegro nos processos de pasteurização, resfriamento, transporte e armazenamento. Logo, a recravação possibilita a vedação entre o produto envasado com o meio externo, a fim de evitar a contaminação do produto, garantindo a estabilidade e vida útil da cerveja. Uma recravação bem dimensionada distingue uma boa lata daquela que apresenta ou que estejam na eminência de um vazamento.

Outros fatores modificadores dos padrões estabelecidos ocorrem de maneira inevitável nos processos, como a recravadeira com características de trabalho particulares, temperatura de trabalho, condições mecânicas da máquina e a folha de flandres que se refere à dureza e espessura do material.

Figura 2 - Seção transversal da recravação em lata de alumínio

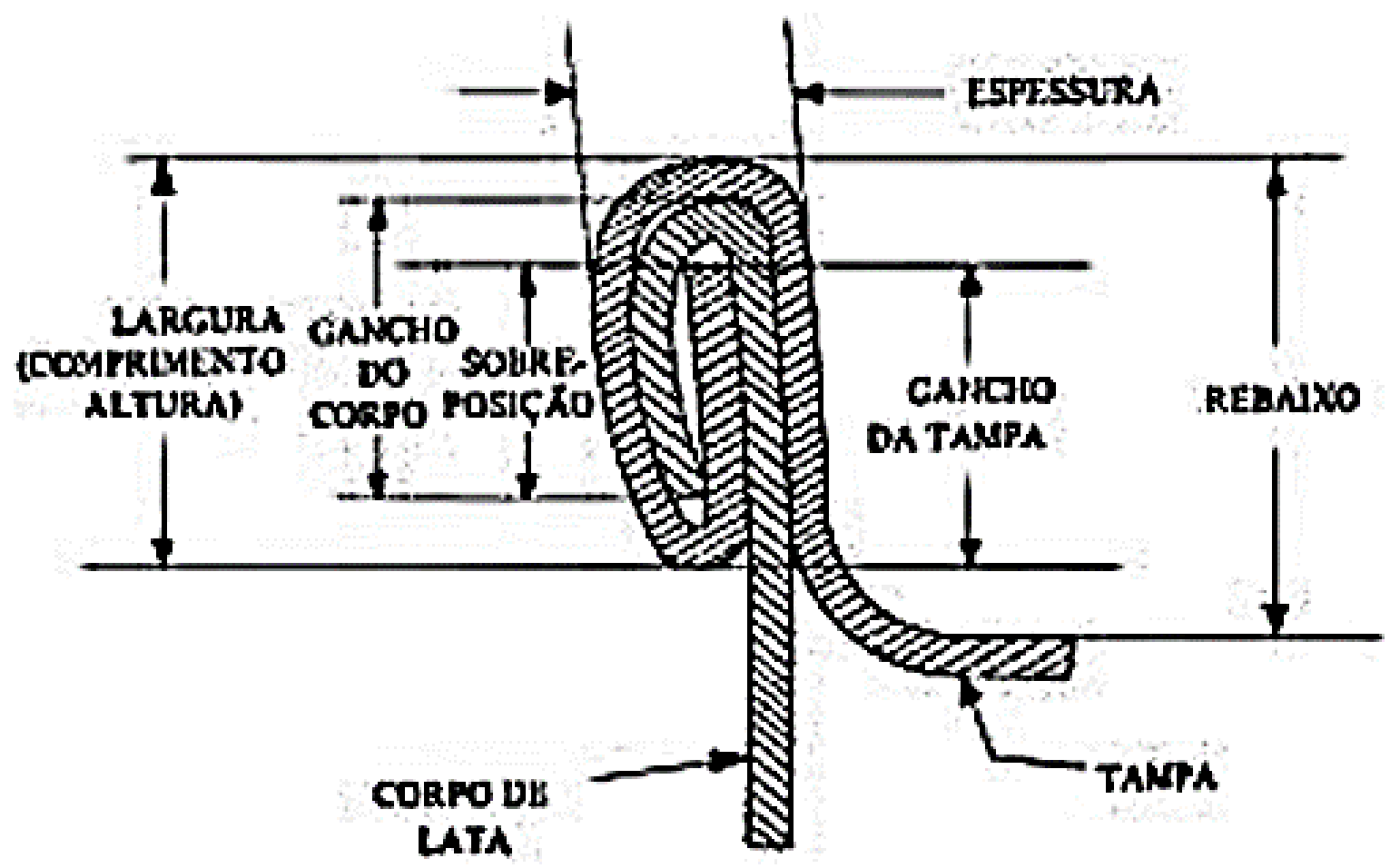

Fonte: Soler (1999) 


\section{Ações do time de AM - Manutenção Autônoma}

Com o Time TPM estruturado, com as funções de cada integrante delegadas e a área de atuação definida, os trabalhos são iniciados. O tempo para execução das atividades e conclusão é de três meses. O fabricante estimula o time, dispondo de suporte técnico e financeiro, sendo todos os recursos criteriosamente auditados antes e durante a execução de todos os passos pertinentes à manutenção autônoma.

O primeiro dia de trabalho é denominado como o "Dia D", data em que os integrantes do time realizam uma limpeza em toda a área, inclusive nos equipamentos e máquinas, pois em um ambiente organizado e limpo facilita consideravelmente a detecção de defeitos e problemas. Neste contexto, aplicam-se os conceitos do programa 5S na área, visando sempre a melhoria contínua e para assim restabelecer as condições básicas na área crítica. Finalizada esta etapa, os integrantes iniciam o processo de etiquetagem, que é a identificação dos problemas encontrados, sendo etiquetas verdes para problemas de natureza técnica, elétrica, hidráulica, pneumática etc.; etiquetas azuis para ambientes geradores de sujeiras; etiquetas vermelhas para os pontos onde se evidenciam riscos de segurança; e etiquetas amarelas para ambientes inacessíveis ou de difícil acesso. Nelas estão as descrições do problema, ações a serem tomadas, período para execução da atividade requerida e observações.

As etiquetas são priorizadas de acordo com a sua gravidade. Estas etiquetas são contabilizadas pelo líder do time, que acompanhará junto ao responsável a sua solução.

Dois quadros são colocados na área e permanecem durante os três meses de trabalho, um apresentando informações como indicadores de eficiência, planejamento e controle, política interna da empresa e os objetivos a serem alcançados pelo time. No outro quadro estão dispostas as etiquetas de anomalias. A cada duas semanas, o time passa por auditorias internas onde se verifica o desenvolvimento dos trabalhos e a eficiência da equipe.

\section{Resolução do problema de recravação}

Para buscar as causas raízes do problema de maior impacto que era da recravadeira, o time realizou inspeções de análise interna e externa nas latas em coletas amostrais. Na análise interna, foi realizada a abertura da recravação para a obtenção de importantes características como a qualidade da recravação, a verificação da presença de defeitos e de modo especial, a uniformidade do processo. Na análise externa foi feita uma inspeção visual na busca por algum defeito recorrente, onde acontece também a coleta das medidas externas com a utilização de instrumentos específicos.

Dentre os dados observados estão: a espessura da lata e da tampa, dimensão do enganchamento entre a lata e a tampa, profundidade do rebaixo, sobreposição e o enrugamento. Tem-se o percentual de sobreposição, fator importante na determinação da qualidade da recravação, que é dada pela função do comprimento da recravação, dos ganchos da lata e tampa e da espessura da chapa metálica. Uma sobreposição de $45 \%$ já se torna aceitável, desde que a recravação esteja apertada de modo suficiente. 
O valor é obtido pela seguinte equação:

$$
S=\frac{\mathrm{GC}+\mathrm{GT}+1,1 * \mathrm{ET}-\mathrm{HT}}{\mathrm{HT}-2,2 * \mathrm{ET}-1,1 * \mathrm{EC}} * 100
$$

Onde: S = sobreposição; GT = comprimento do gancho da tampa; GC = comprimento do gancho do corpo; ET = espessura da folha da tampa; HT = altura ou comprimento da recravação e EC = espessura da folha do corpo.

Outro índice calculado para verificar a qualidade do fechamento da tampa é o índice de compactação, onde:

$$
C=\frac{3 * \mathrm{ET}+2 * \mathrm{EC}}{\mathrm{ER}} * 100
$$

Para efeito de análise:

Se C > 85\%, então a recravação está muito boa;

Se $75 \leq \mathrm{C} \leq 85 \%$, então a recravação está boa;

Se C $<75 \%$, então a recravação está sujeita a vazamento.

Fonte: Soler (1999).

As coletas de amostras foram retiradas logo na saída da recravadeira, durante um turno em condições de produção eficiente, com mínimas paradas operacionais. Foram coletadas no início de operação da enchedora e "restarts" programados com esta finalidade; e durante o processo produtivo recorrente, foram coletadas a cada 30 minutos. Um comportamento periódico instigante foi observado durante a análise dos resultados. O índice de compactação apresentou variações grosseiras em momentos específicos da produção.

O primeiro ponto ocorria ao iniciar a enchedora, logo nas primeiras latas do processo em que estas apresentaram índice de compactação sempre abaixo dos $75 \%$ esperados, gerando refugos em quantidades elevadas. O segundo ponto, durante a produção já em estabilidade, observou-se que acorriam problemas na recravação de modo sistemático, ou seja, falhas periódicas durante a produção, mas com impacto menor.

A média do índice de compactação da recravação no início da enchedora era de $61 \%$, e na etapa de estabilidade produtiva, $71 \%$.

Detalhes da manutenção e reparos do equipamento não foram colocados nesta pesquisa em razão da preservação da identidade da empresa em análise.

Os manutentores foram acionados para averiguar as condições da recravadeira. Em uma análise visual, a dinâmica da máquina se apresentava estável. Logo após a abertura da máquina, se detectou diversas anomalias, componentes em eminência de quebra, material biológico depositado em componentes de atuação pelas más condições de vedações, problemas de folga na estrela de transporte, componente este que encaminha a lata para receber a tampa de maneira sincronizada, elos da correia transportadora com folgas, ocasionando declives, interferindo na sincronia das latas no ato de tamponamento. 
Abaixo segue o gráfico com o comportamento dos índices de compactação já estabilizados, com uma média de $76 \%$ de eficiência, garantindo assim um fechamento hermético satisfatório.

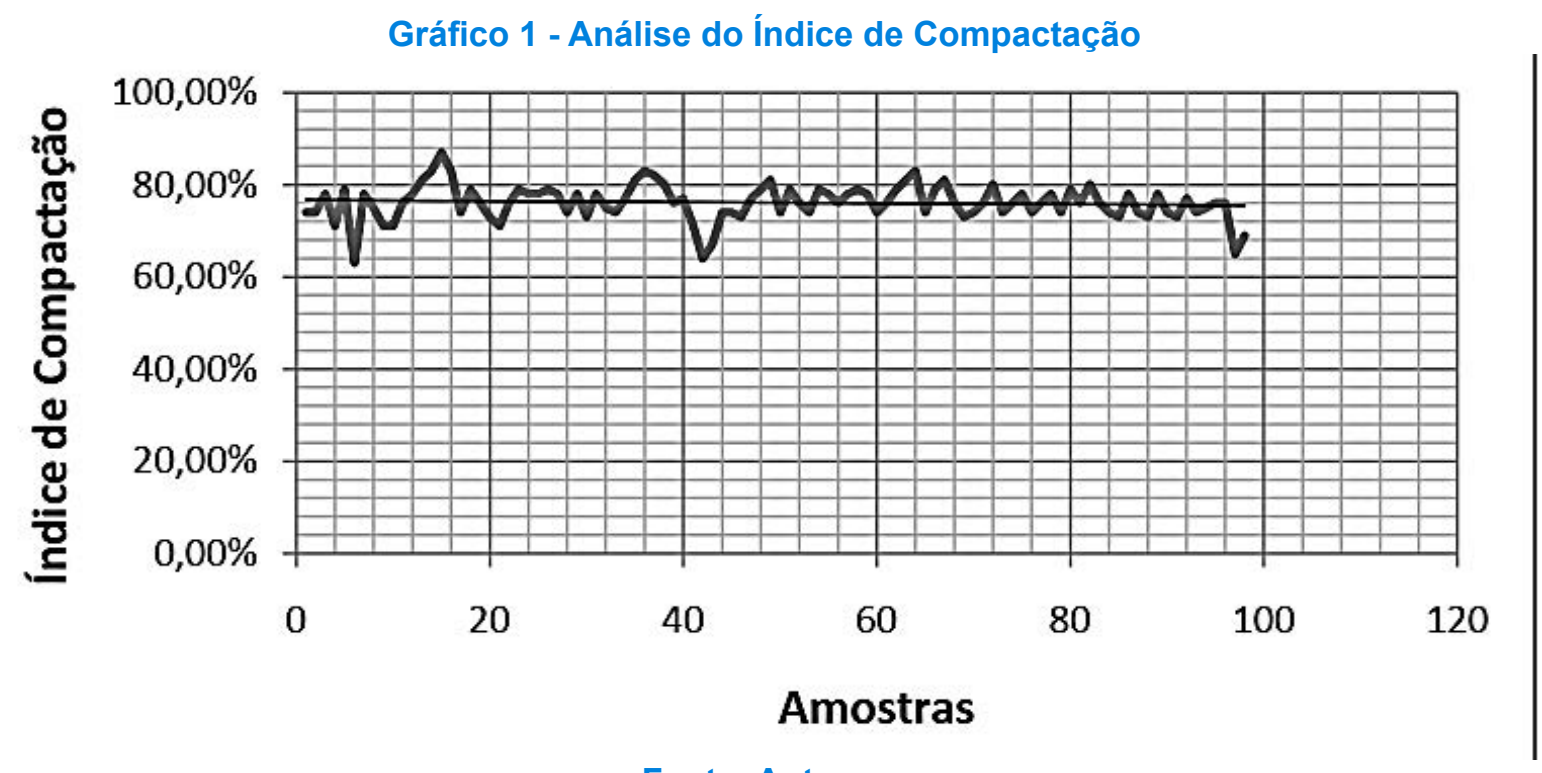

Fonte: Autores

\section{CONCLUSÃO}

Os dados apontados pela auditoria externa da cervejaria, após a conclusão com êxito do Time TPM segundo o Pilar de Manutenção Autônoma, mostraram a redução de perda de cerveja na enchedora por falhas na recravadeira foi de $4,6 \%$ para expressivo $0,8 \%$, conforme o gráfico 2 .

Gráfico 2 - Redução das perdas de cerveja na enchedora de latas

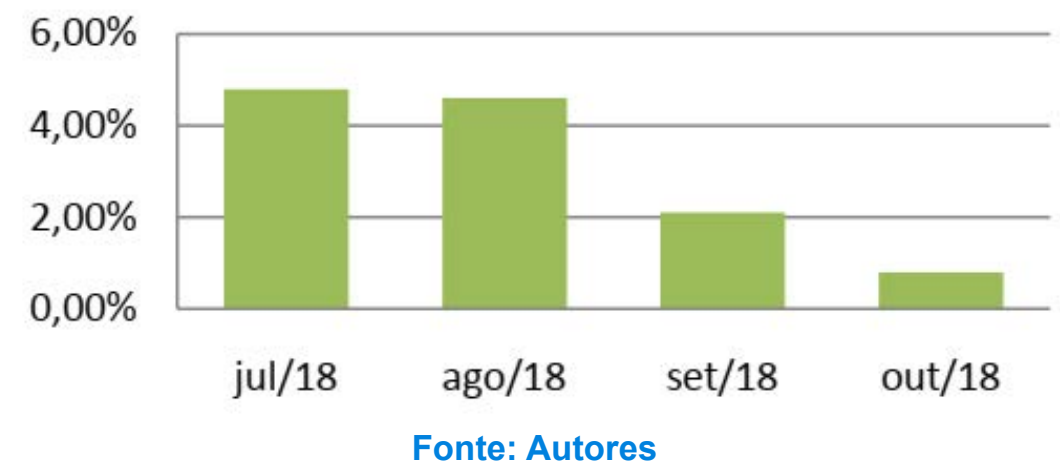

O percentual de fechamento de etiquetas de anomalias apresentado foi de $95 \%$, ou seja, grande parte das falhas identificadas pelo time durante o "Dia D" foram resolvidas.

Após a correção de todos estes problemas, foi instaurado o método de análise de degradação para esta máquina, cujo objetivo será de acompanhar de maneira periódica a necessidade de troca de componentes e as condições de operação da recravadeira.

Sendo assim, a metodologia TPM se mostrou altamente eficaz na obtenção de resultados positivos, no que se refere à melhoria contínua dos processos, equipamentos, gestão de pessoas e de modo especial, na redução de perdas da cervejaria analisada. 


\section{REFERÊNCIAS}

AMARAL, Paulo. TPM - Manutenção Produtiva Total. Curitiba, Fevereiro 2013. Disponível em: <http:// pauloamaral.blog.br/tpm-manutencao-produtiva-total/>. Acesso em: 01 ago. 2019.

CERVEJA, Associação Brasileira da Indústria da. Dados do setor cervejeiro nacional. 2019. Disponível em: <http://www.cervbrasil.org.br/novo_site/dados-do-setor/>. Acesso em: 01 ago. 2019.

FALCONI, Vicente Campos. TQC - Controle da Qualidade Total (no estilo japonês). Belo Horizonte: Editora de Desenvolvimento Gerencial, 1999.

FARIA, E.V.; DANTAS, S.T.; SOLER, R.M.; ANJOS, V.D.A.; ARDITO, E.F.G. Controle de qualidade de embalagens metálicas para alimentos. Campinas. CETE/ITAL, 1990. 228p.

JIPM. Apostila IMC. Curso de Facilitadores TPM. São Paulo: IMC Internacional, 2000.

MARTINS, P.G.; LAUGENI, F.P. Administração da Produção. 3.ed. São Paulo: Saraiva, 2015.

SOLER, Roger Maciel. Avaliação do desempenho de latas micro-recravadas para alimentos termoprocessados. 1999. $77 \mathrm{f}$. Tese (Doutorado) - Curso de Doutorado em Tecnologia de Alimentos, Unicamp, Campinas-sp, 1999.

TAKAHASHI, Yoshikazu; OSADA, Takashi. Manutenção Produtiva Total: TPM. 3. ed. São Paulo: Iman, 1993. 322 p. Tradução do Japonês: TPM - Zenin Sankano Setsubishiko Manajimento. 

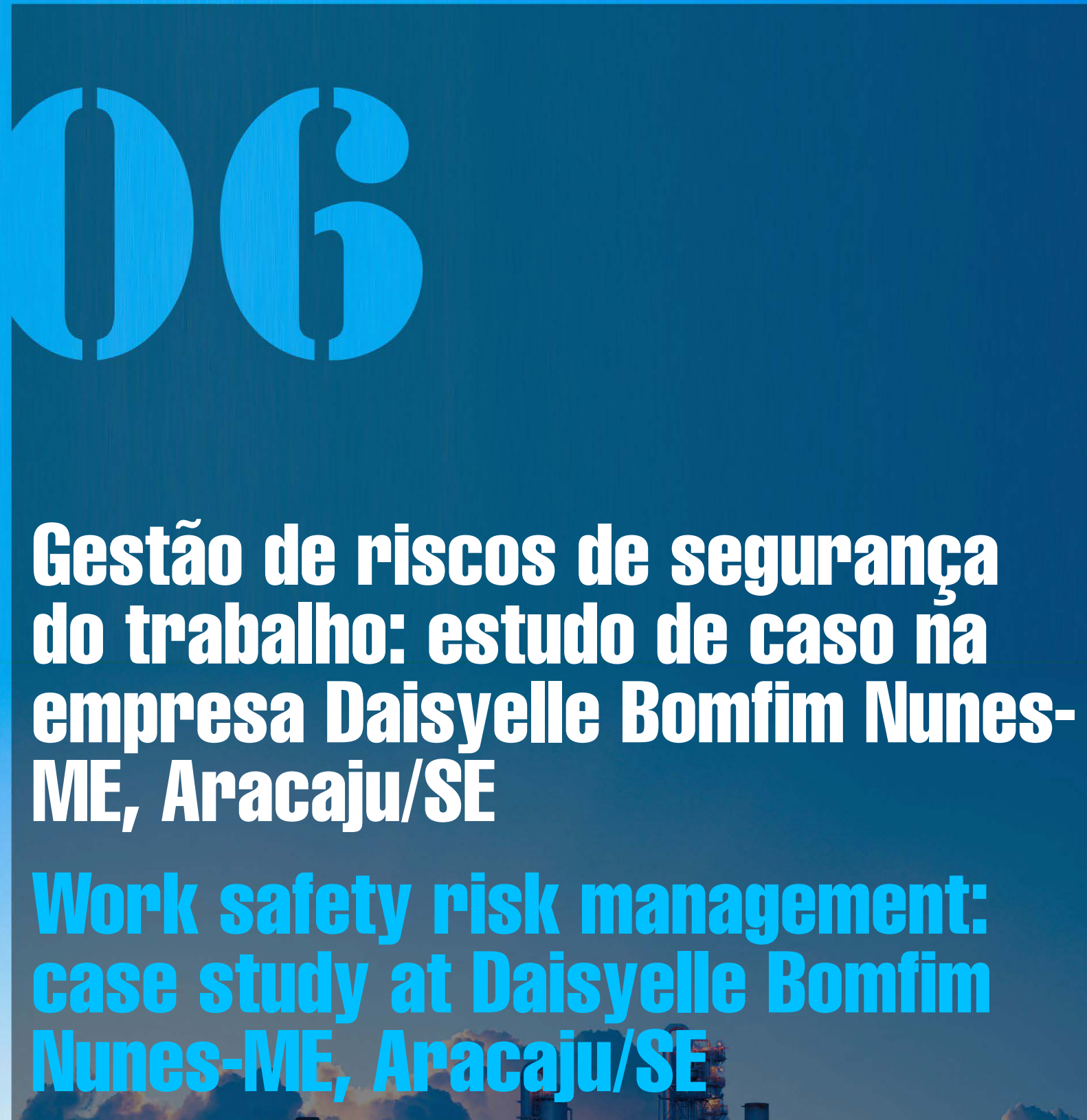

Samara Vasconcelos de Paula Engenheira de Produção. E-mail: samal Douglas Rafael Mendes Alves

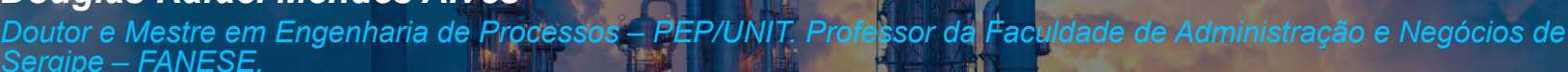
Heloísa Thaís Rodrigues de Souza

Pós Doutora, Doutora e Mestre em Desenvolvimento e Meio Ámbiente - PRODEL Pesquisa em Geoecologia e Planejamento Territofial-GEOPLAN/UFS/CNRq. Professsora da Faculdade de Administração e

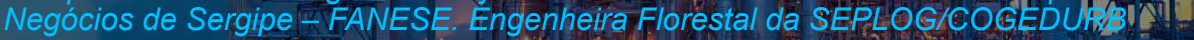
Jeane Karla de Mendonça Mota Doutorada e Mestre em Engenharia Agricola UFCG. Professora dä Fä́cullade de Administração e Negócios de Sergipe FANESE.

\section{Williams Alves de Azevedo}

Pós-graduado em Engenharia de Produção e em Engenhariăl de Segurançâdo Trabalho. Professor da Faculdade de Administração e Negócios de Sergipe 
A gestão de riscos é utilizada dentro das organizações de forma estratégica para que possa prevenir riscos que estão ligados a uma determinada atividade. A fim de servir como objeto de estudo da gestão de riscos, foi pesquisada a empresa Daysielle Bomfim Nunes- ME localizada em Aracaju/SE. Areferente empresa produz artefatos de pré-moldados e realiza prestação de serviços para Prefeitura Municipal de Aracaju. Este estudo teve como objetivo geral: adequar a gestão de riscos de segurança do trabalho na empresa em estudo, sendo uma pesquisa qualiquantitativa de cunho descritiva e explicativa. Diante do exposto, foram utilizadas as seguintes ferramentas da qualidade: fluxograma, Diagrama de Ishikawa, Questionário semiestruturado, Mapa de Riscos, $5 \mathrm{~W} 2 \mathrm{H}$ e 5S. Foram observadas falhas nas condições gerais do ambiente de trabalho, tais como: falta de sinalização, falta de conscientização ao uso de EPIs, manuseio incorreto de cargas, falta de limpeza e organização do ambiente de trabalho e falta de EPCs. Os resultados mostraram que o tratamento destes riscos poderá gerar benefícios para a organização. Com a pesquisa realizada, verificou-se que a empresa não está de acordo com a legislação, por conta dos riscos que apresenta para saúde e segurança dos colaboradores. Sendo assim, foram apresentadas soluções, tais como: elaboração do PPRA, colocar o EPC em locais que há necessidade de avisar sobre o risco que aquele ambiente ofereça utilização de EPI, dentre outras sugestões para a empresa, a fim de obter uma melhor qualidade de trabalho e garantir a saúde e o bem-estar do trabalhador.

Palavras-chave: gerenciamento. mapeamento. NRs. riscos.

\section{Alistrat}

Risk management is used within organizations strategically so that it can prevent risks that are linked to a particular activity. In order to serve as an object of study of risk management, the company Daysielle Bomfim Nunes- ME, located in Aracaju / SE, was researched. The referred company produces precast artifacts and provides services to the Municipality of Aracaju. This study had as its general objective: to adapt the management of occupational safety risks in the company under study, being a qualitative and quantitative research of a descriptive and explanatory nature. In view of the above, the following quality tools were used: flowchart, Ishikawa diagram, semi-structured questionnaire, risk map, 5W2H and 5S. Failures were observed in the general conditions of the work environment, such as: lack of signage, lack of awareness of the use of PPE, incorrect handling of loads, lack of cleanliness and organization of the work environment and lack of EPCs. The results showed that the treatment of these risks can generate benefits for the organization. With the research carried out, it was found that the company does not comply with the legislation, due to the risks it presents to the health and safety of employees. Therefore, solutions were presented, such as: elaboration of the PPRA, placing the EPC in places that need to warn about the risk that that environment may offer the use of PPE, among other suggestions for the company, in order to obtain a better quality of work and guarantee the health and wellbeing of the worker.

Keywords: management. mapping. NRs. scratchs. 


\section{INTRODUÇÃO}

Uma empresa, por menor que ela seja, necessita ter uma gestão das normas de segurança que possa mensurar o seu grau de risco, a fim de garantir a saúde e a integridade física dos colaboradores. A segurança de trabalho é fundamental para os colaboradores e para a organização, pois manter um ambiente laboral sem oferecer riscos traz um grau de confiabilidade muito elevado para a empresa.

No Brasil, as normas que fornecem informações sobre procedimentos obrigatórios relacionados à segurança e medicina do trabalho são conhecidas como Normas Regulamentadoras (NRs). A empresa que não cumpre as obrigações estabelecidas pelas NRs, pode ser penalizada com multas, embargos ou interdições.

De acordo com Moraes (2017), a Norma Regulamentadora 17 tem como objetivo proporcionar aos trabalhadores parâmetros que possibilite que o trabalho se adapte as condições de trabalho às particularidades psicofisiológicas dos trabalhadores, proporcionando conforto, segurança ao trabalhador, para que ele possa ter um desempenho eficiente em suas tarefas.

Portanto, a partir da conscientização dos riscos de acidente no local de trabalho, é possível realizar as atividades com segurança. Manter os locais de perigo sinalizados é fundamental, pois assim acidentes indesejados serão evitados. A utilização de medidas protetivas tais como Equipamentos de Proteção Individual (EPIs) também é importante, pois pode evitar danos à saúde dos trabalhadores. Além do risco de acidente há outros riscos tais como: risco físico, químico, biológico e ergonômico.

Conforme Costa e Barrozo (2005), os riscos físicos são aqueles que geram ruídos, quando há um aumento excessivo na temperatura do ambiente, quando o local de trabalho oferece alto nível de radiações, dentre outros. Os riscos químicos são quando o ambiente está exposto a gases tóxicos, excesso de poeira, fumos, dentre outros que pode ser de fácil absorção pelas vias respiratórias dos trabalhadores e de quem está em volta do local. Quanto aos riscos biológicos são aqueles que são relacionados a bactérias, fungos, vírus, parasitas, dentre outros.

Os riscos ergonômicos também podem afetar a saúde do colaborador. Pode-se citar como riscos ergonômicos as seguintes situações: postura inadequada na execução de tarefas, locais pouco iluminados, altos níveis de ruídos e ambientes com altas temperaturas. Estes podem causar acidentes por lesões e esforços repetitivos e outras patologias. Diante disso é fundamental ter uma gestão de riscos numa empresa visando prevenir acidentes e doenças ocupacionais.

A empresa na qual se realizou a presente pesquisa foi a Daisyelle Bomfim Nunes-ME, fundada em outubro de 2011, e encontra-se localizada no município de Aracaju/Sergipe. Exerce como atividade principal a prestação de serviços para a Prefeitura Municipal de Aracaju, através de obras em construção de casas e praças e na construção de pré-moldados. Através de uma análise no ambiente, foi verificado que a empresa em questão apresenta riscos operacionais, como: a mesma não possui mapas setoriais de riscos, não tem placas sinalizadoras, e em determinados setores o ambiente não apresenta uma segurança adequada para os trabalhadores.

Diante do exposto, surge a questão: Como melhorar a gestão de risco de segurança do trabalho na empresa Daisyelle Bomfim Nunes-ME? 
Portanto, esta pesquisa possui como objetivo geral adequar a gestão de risco de segurança do trabalho na empresa Daisyelle Bomfim Nunes-ME, Aracaju/SE. Como objetivos específicos foram definidos: mapear as atividades desenvolvidas no ambiente operacional da empresa; avaliar o ambiente de trabalhado sob aspectos dos riscos oferecidos à saúde e segurança do trabalhador como foco para o risco de acidente, estabelecer um plano de ações para fornecimento de medidas de proteção de acidentes de trabalho e propor melhoria para promover a qualidade dentro da organização.

Verifica-se que toda empresa necessita ter uma gestão de riscos para que possa ajudar na prevenção de ameaças que o ambiente de trabalho oferece, e para auxiliar no desenvolvimento de ações que possam minimizar tais riscos. A gestão de riscos é importante, pois ajuda a minimizar os impactos dos acidentes e protege a organização de possíveis existências de situações indesejadas.

\section{PROCEDIMENTOS METODOLÓGICOS}

\section{Abordagem Metodológica}

O procedimento adotado na empresa Daysielle Bomfim Nunes- ME foi estudo de caso, pois foi feito um estudo no local relacionado às práticas de segurança de trabalho adotadas pela empresa.

\section{Quanto aos objetivos ou fins}

O referente estudo teve como princípio os métodos de pesquisa descritiva e explicativa, pois a pesquisa consiste em mapear dados da empresa, levantamento de dados que inclui a caracterização dos problemas que a empresa possui. Elaborou-se a partir desse princípio, procurando através das pesquisas, buscar se aprofundar ao máximo em relação ao tema estudado, levantando questionamentos relevantes ao problema, para colher informações importantes na solução do mesmo.

\section{Quanto ao objeto ou meios}

Foi realizada uma pesquisa bibliográfica de dados correlatos ao estudo tais como: ergonomia, análise de risco, Normas Regulamentadoras, saúde ocupacional dentre outros. Tais pesquisas bibliográficas foram realizadas mediante pesquisa e leitura de artigos científicos, livros, teses, dissertações e monografias que trabalham sobre a temática desta pesquisa.

O estudo desenvolvido na empresa Daysielle Bomfim Nunes-ME foi do tipo pesquisa de campo. Primeiramente iniciaram-se os trabalhos com uma observação prévia do local de estudo e, em seguida, foram realizadas entrevistas e aplicação de questionários semiestruturados com os colaboradores para responderem a respeito do problema observado na empresa. Sendo assim, foram realizadas três entrevistas e questionários semiestruturadas (com um colaborador do setor de produção, com dono e a gerente da organização). Com isso, realizaram-se as observações in loco em horários pré-selecionados de acordo com a disponibilidade dos envolvidos. 


\section{Quanto ao tratamento dos dados}

Para o estudo realizado na empresa, o método usado foi o qualiquantitativo, no qual foram levantados dados por meio de entrevista com sugestões para melhoria no ambiente de trabalho.

\section{Instrumentos de Pesquisa}

O tipo de instrumento de pesquisa utilizado na elaboração da presente pesquisa foi, a princípio, uma observação pessoal e, em seguida, uma entrevista onde foram selecionados alguns colaboradores, o proprietário da empresa e a supervisora.

Utilizaram-se, portanto, neste trabalho, trabalhos de campos, aplicação de um questionário semiestruturado junto aos colaboradores do setor de produção e do setor administrativo e entrevista, com um roteiro de questões relacionadas à saúde ergonômica dos mesmos, condições de uso dos EPIs e EPCs, condições ergonômicas e condições do ambiente de trabalho.

Na pesquisa realizada foram coletados dados qualitativos através de registros fotográficos, entrevista com os colaboradores e observações do ambiente de trabalho no período de 21 de fevereiro a 26 de abril de 2019.

\section{Unidade, Universo e Amostra da Pesquisa}

De acordo com Segundo Ubirajara (2016, p. 130) apud Santos (2020, p. 31), o local exato onde a investigação foi realizada é conceituada de unidade. A unidade de pesquisa foi a empresa Daysielle Bomfim Nunes-Me, uma organização de pequeno porte e que produz artefatos de pré-moldados. Os tipos de pré-moldados fabricados são vigas para portas e janelas, blocos, cobogós, calhas, meio fio, bancos de praças, anéis de foça, pergolados e estaca para cerca. A empresa está distribuída em 3 setores que são: escritório, refeitório e setor de produção.

Diante do exposto, por ser uma empresa de pequeno porte do ramo de construção e apresentar riscos, esta precisa promover um ambiente propício para que seus colaboradores possam trabalhar com segurança sem comprometer sua saúde.

Sendo assim, na empresa em estudo, constam em geral, quatorze (14) funcionários, os quais são o universo da pesquisa. A amostra da pesquisa corresponde a três colaboradores registrados na empresa no setor pesquisado, os quais relataram sobre as condições inadequadas no ambiente de trabalho.

\section{Ferramentas da Qualidade}

A presente pesquisa aborda sobre riscos encontrados na empresa em estudo e com isso fez-se necessário à utilização de ferramentas da qualidade para que pudesse atingir os objetivos propostos no estudo. Portanto, as ferramentas utilizadas no presente trabalho para melhoria da empresa são descritas abaixo.

\section{Fluxograma}

Conforme Barros e Bonafini (2014), o fluxograma relata a sequência e comunicação 
entre os processos. No fluxograma existem símbolos que são padronizados, e este processo é necessário para que qualquer pessoa que tenha o conhecimento das simbologias possa ser capaz de compreender o funcionamento de processo. No momento da elaboração de um fluxograma, o mesmo deve ser claro e objetivo, e não apenas algo que possa ficar só exposto para o cumprimento de normas. O fluxograma é importante, pois ele poderá facilitar em determinados processos da empresa.

\section{Diagrama de Ishikawa}

Conforme Barros e Bonafini (2014, p. 39), "[...] o Diagrama de Ishikawa é usado para identificar a relação entre as causas e os efeitos de um processo, buscando-se as circunstâncias e analisando aquilo que se convencionou chamar de Ms." Diante do exposto, nota-se a importância de se utilizar essa ferramenta no presente estudo, uma vez que, por meio dela, é possível obter resultados sobre a diminuição dos riscos, chegando diretamente na raiz do problema observado dentro da empresa, quanto a falta de inspeção para monitorar as situações geradoras.

\section{Mapa de Riscos}

Conforme Costa e Barrozo (2005), o mapa de riscos é uma análise qualitativa dos riscos reais no ambiente de trabalho. É exibido em forma de gráfico por meio de cores e círculos em proporções desiguais de acordo com o ambiente que se foi analisado. Esse ambiente pode ser um ponto específico ou a empresa por completa.

No mapa de riscos, pode-se avaliar os tipos de agentes, os riscos existentes e suas respectivas cores e o grau em relação ao tamanho do círculo. A cor vermelha indica que o tipo de agente é o químico: poeiras, fumos, névoas, neblina. Já a cor verde corresponde ao tipo de agente físico e está relacionada a: ruídos, calor, frio, umidade, radiações ionizantes ou não. A cor marrom indica agente químico biológico e tem como exemplo: fungos, vírus, parasitas, bactérias, protozoários, insetos. A cor amarela está associada ao agente ergonômico e tem como exemplo: levantamento e transporte manual de peso, repetitividade, ritmo excessivo. Por fim, a cor azul indica agente do tipo acidentes ou mecânicos e correspondem a arranjo físico e iluminação inadequada, incêndio e explosão, eletricidade, etc.

Diante do exposto, foi elaborado o mapa de risco da empresa em questão, pois o mesmo serviu para avaliar o ambiente de trabalho que apresentar os riscos à saúde e segurança dos trabalhadores da Daysielle Bomfim Nunes.

\section{$5 \mathrm{~W} 2 \mathrm{H}$}

De acordo com Seleme e Stadler (2012), a ferramenta 5W2H representa a aplicação de perguntas que foram elaboradas na língua inglesa e que se iniciam com as letras $\mathrm{W}$ e $\mathrm{H}$. Essas perguntas têm como finalidade gerar respostas que resolvam os problemas e que organizem as ideias no momento em que estejam solucionando os problemas. Conforme os problemas observados na empresa de estudo, notou-se uma necessidade da aplicação do 5W2H para poder organizar e colocar em prática um plano de ação para melhoria dos riscos observados. 
A ferramenta $5 \mathrm{~S}$ tem como objetivo criar uma disciplina nas organizações para uma melhoria na qualidade de vida, e com ela identificar problemas, levando a empresa a um elevado grau de desempenho. Conforme a observação da empresa em estudo, foi verificado que a empresa precisava de uma ferramenta que ajudasse na mudança de hábitos das pessoas envolvidas na organização, pois não só bastaria uma mudança no ambiente físico, todos precisavam passar por essa transformação, para poder ter êxito.

\section{ANÁLISE DE RESULTADOS}

\section{Mapeamento das Atividades Desenvolvidas no Ambiente Operacional da Empresa}

Para avaliar as condições gerais de trabalho e os possíveis riscos existentes no ambiente, foi feito um mapeamento das atividades desenvolvidas pelo colaborador desde a solicitação de pedido realizado pelo cliente até a entrega do produto, conforme fluxograma apresentado na Figura 1.

Figura 1 - Fluxograma da empresa desde o início da chegada da matéria prima até a entrega do pedido

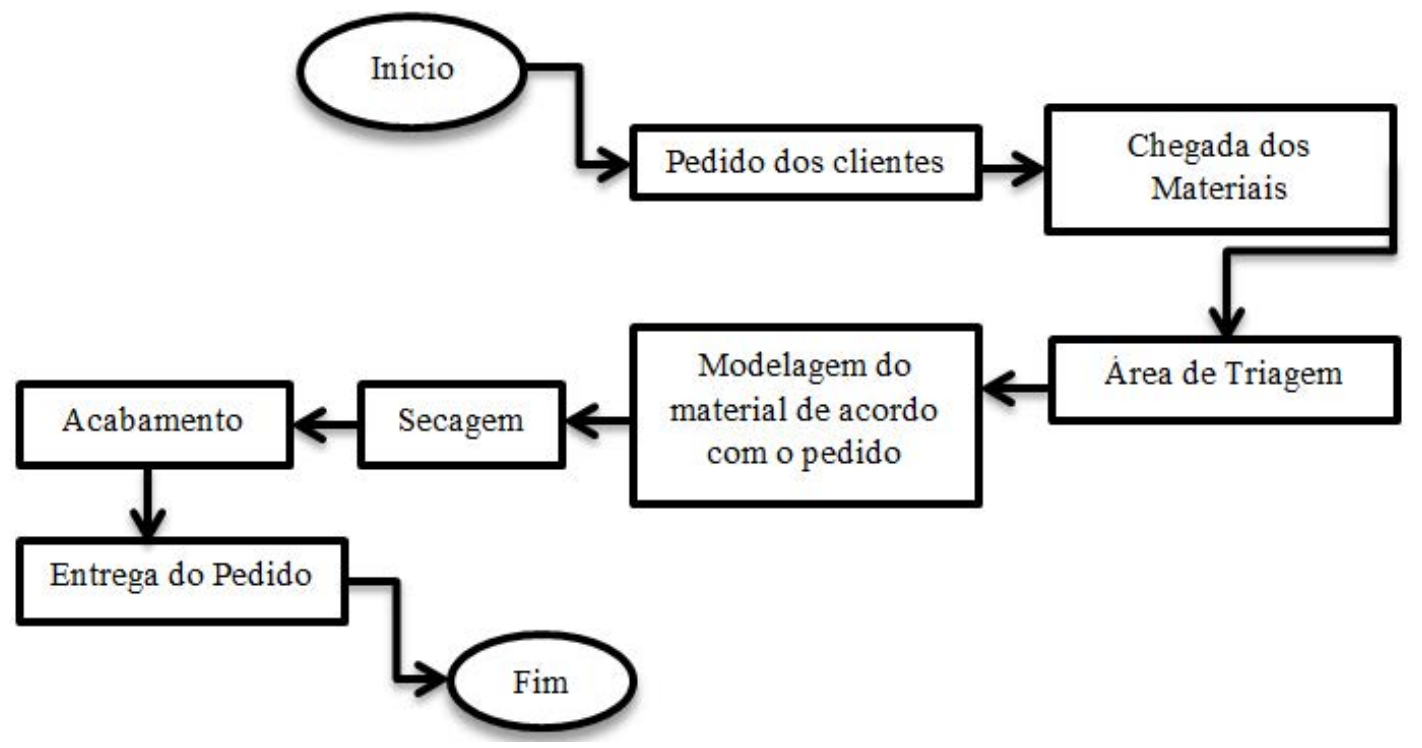

Fonte: Autor (2021)

O processo de produção inicia com a chegada do material na empresa, logo após a solicitação de compra realizada pelo cliente. Nesta etapa os colaboradores realizam o transporte e descarga manual do material. Na execução desta tarefa foi observado esforço físico demasiado realizado por meio do levantamento de cargas excessivas. Na fase de preparação dos concretos, após passar pela separação dos materiais, os colaboradores manipulam os componentes da mistura através de auxílio de máquinas, tais como as betoneiras. Nesta prática foi observado que o colaborador fica em pé por longos períodos, além de realizar movimentos repetitivos de agachamento (Figura 2). 
Figura 2 - Execução de atividades na fase de manipulação dos componentes

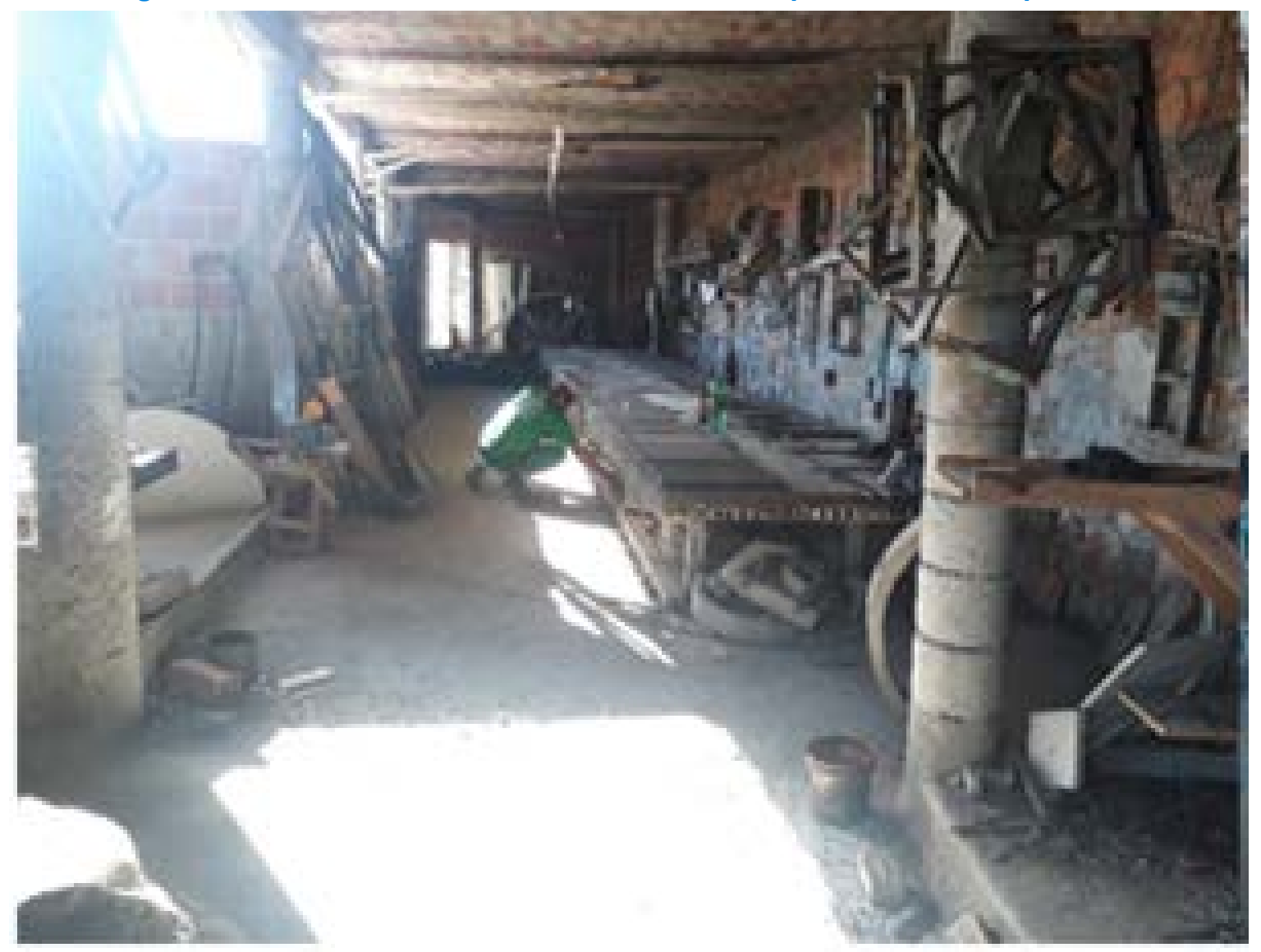

Fonte: Autor (2021)

A etapa seguinte consistiu na modelagem do material. Quando o concreto está pronto, deve-se modelar o material, conforme o pedido do cliente. Na execução desta tarefa, nota-se que as bancadas não possuem altura compatível com o tipo de serviço realizado, a qual pode ser mais bem visualizada na Figura 3. Observa-se ainda a falta de utilização de equipamentos de proteção tais como: óculos protetores, protetor auricular, capacete e máscara.

Figura 3 - Posto de trabalho na etapa de modelagem de material

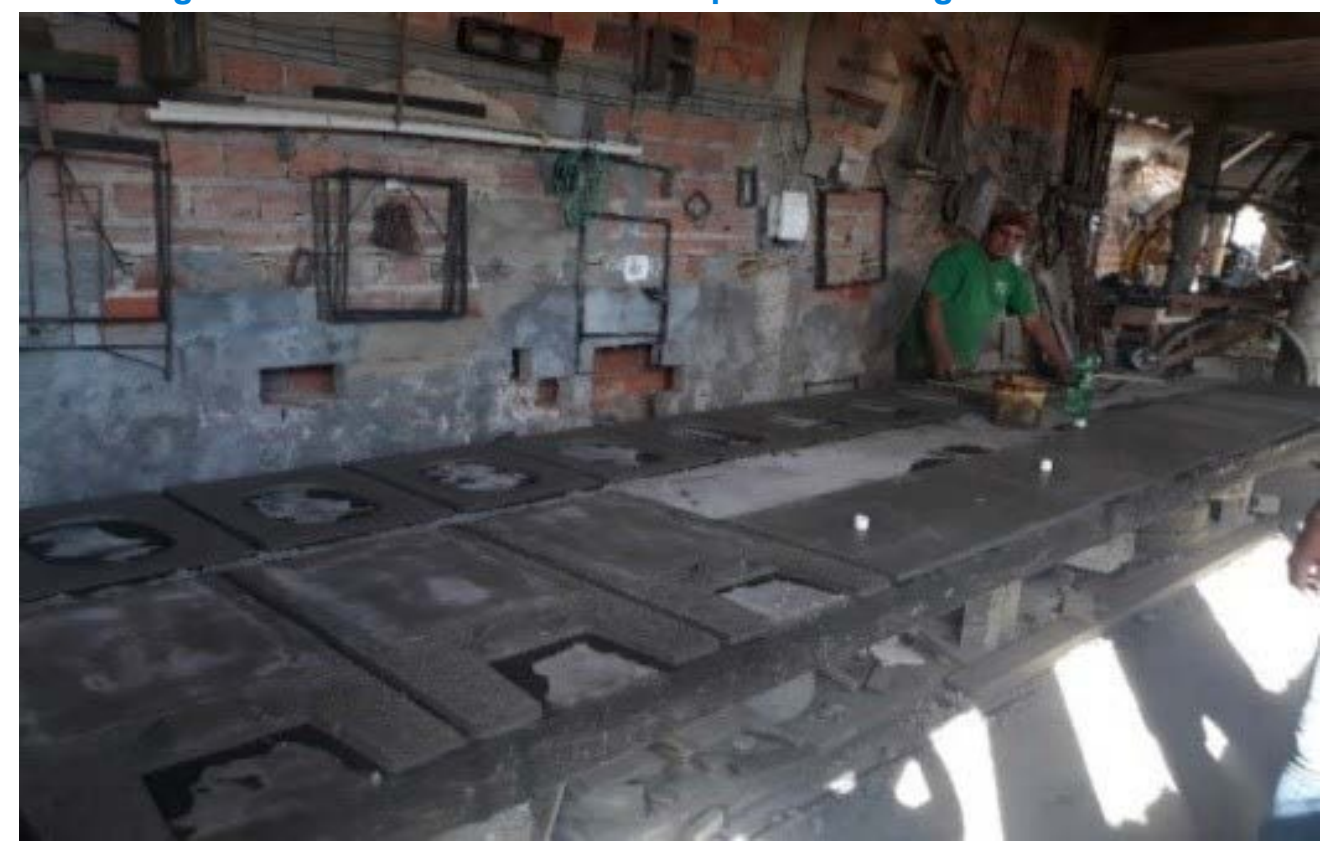

Fonte: Autor (2021) 
Na etapa de secagem, os pré-moldados são levados para uma área ao ar livre para acelerar o processo de cura do concreto. A Figura 4 apresenta as condições de desorganização do ambiente de trabalho o que dificulta a movimentação de pessoas no local.

Figura 4 - Ambiente do posto de trabalho
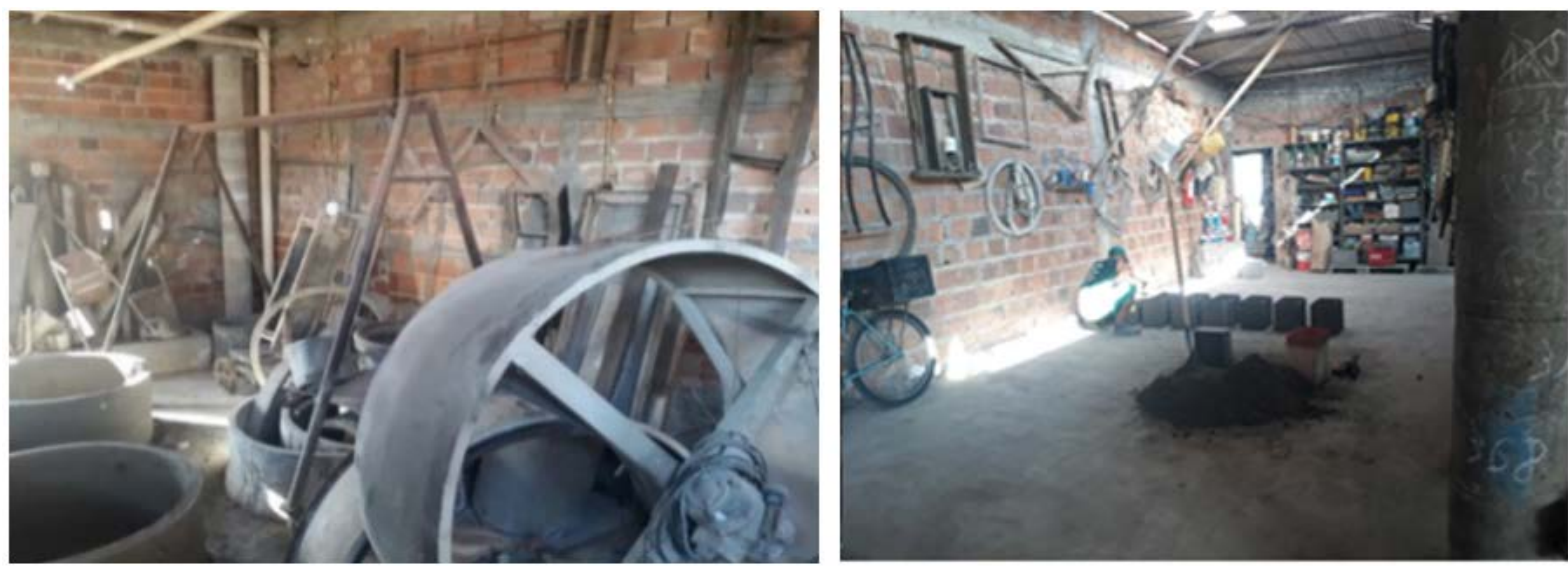

Fonte: Autor (2021)

Em seguida, na fase de acabamento, os pré-moldados passam por um processo de inspeção onde são removidas as imperfeições da peça para então finalizar a confecção. A última etapa consiste na entrega de pedido, realizada ao término do acabamento. Esses pedidos são levados por caminhões para seus destinos. No entanto, há clientes que fazem a retirada das peças no próprio estabelecimento.

As condições sanitárias e de conforto também são aspectos que devem ser abordados durante a realização das atividades de produção. A Figura 5 mostra as áreas destinadas as instalações sanitárias e refeitórios. Pode-se observar que a limpeza é precária, embora haja arejamento e boa iluminação nos referidos ambientes.

Vale salientar que a cozinha não possui mesas e assentos em número correspondente ao de usuários e o banheiro não possui as dimensões apropriadas, tão pouco lavatórios. Além disso, o refeitório não está instalado em local apropriado estando próximo das instalações sanitárias.

Figura 5 - Condições sanitárias e de conforto inadequadas

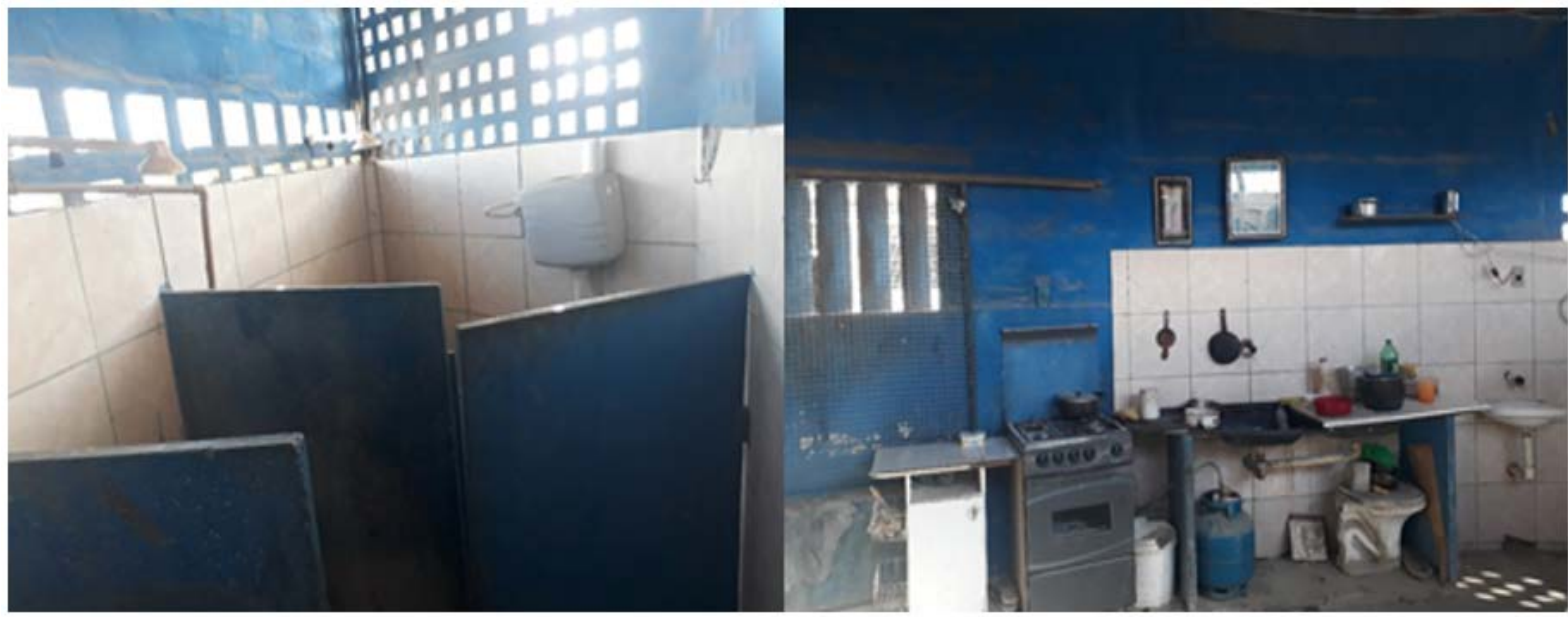

Fonte: Autor (2021) 
É importante ressaltar que não foram observados no local extintores de incêndio, mapa de risco e placas de sinalização. Conforme a observação feita na empresa, foi notado que a empresa tem uma carência de EPC e ausência de utilização de EPIs nos funcionários que estavam realizando seus serviços nos setores. Diante dessa situação, foi investigado o porquê dessa ausência, chegando a uma conclusão que os EPIs são fornecidos para cada colaborador, porém não há uma fiscalização para monitorar o uso adequado do mesmo.

\section{Avaliação do Ambiente de Trabalho - Diagrama de Ishikawa}

A presente ferramenta tem o objetivo de indicar a relação entre o efeito e as causas que contribuem para a sua ocorrência. A Figura 6 mostra o diagrama de Ishikawa com base nos riscos que foram observados na empresa estudada.

Figura 6 - Diagrama de Ishikawa construído a partir das observações realizadas na empresa

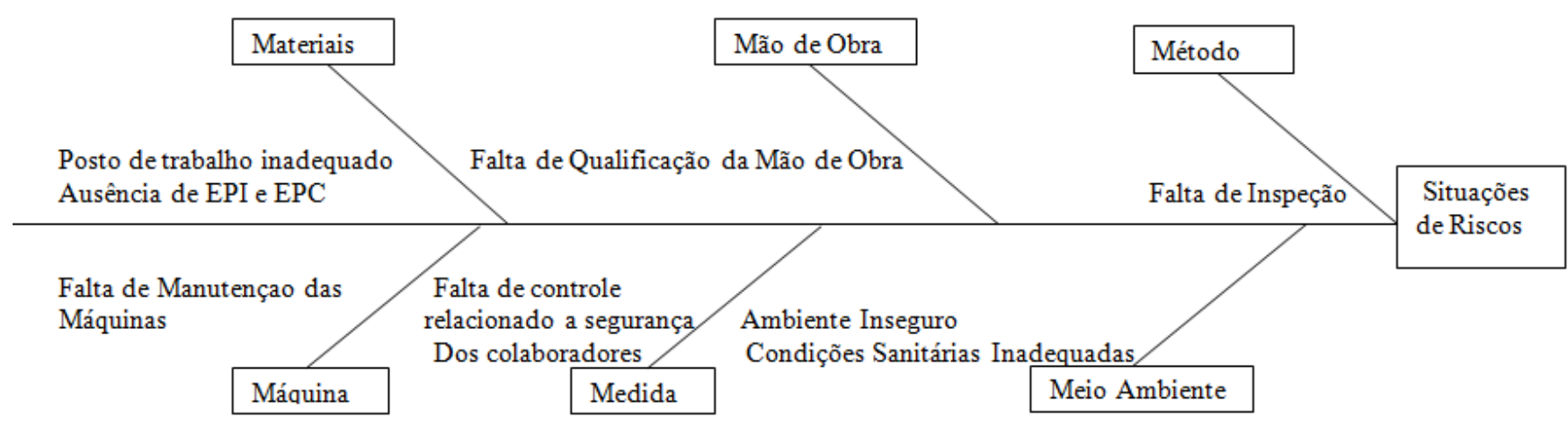

Fonte: Autor (2021)

Para avaliar os problemas identificados no ambiente de trabalhos, as seguintes categorias foram classificadas para relacionar às causas que contribuíram para a sua ocorrência.

1) Material: esta categoria está relacionada à desorganização do material no posto de trabalho. Como citado anteriormente, a empresa não possui um ambiente que ofereça aos seus colaboradores um posto de trabalho adequado, comprometendo a saúde e a integridade dos colaboradores.

2) Máquina: esse grupo está relacionado à falta de manutenção dos equipamentos, quando um equipamento não tem uma manutenção oferece riscos a saúde dos trabalhadores, evitar esse tipo de situação é indispensável, as máquinas precisam sempre passarem por manutenções.

3) Medida: o ambiente em estudo não tem um controle quando se trata da saúde dos trabalhadores, essa falha poderá levar a empresa a situações indesejadas, como funcionários doentes e acidentados.

4) Mão de obra: A ausência de EPI e EPC oferece riscos para o trabalhador, como por exemplo um aumento nos riscos de acidentes no trabalho, pois a ausência desse equipamento pode aumentar as chances de uma lesão e no progresso de doenças geradas por atividades que oferecem perigos, impacto na saúde.

5) Método: a falta de inspeção no ambiente de trabalho gera risco para a saúde do colaborador e para quem estiver ao seu redor. $O$ espaço físico pode se tornar um risco se não tiver uma 
inspeção periódica, pois se não houver conformidade, como por exemplo, inspeção do posto de trabalho, utilização dos EPIs e EPC, condições sanitárias, ergonômicas, inspeção dos maquinários, pode trazer riscos à saúde do trabalhador.

6) Meio Ambiente: não oferece boas condições higiênicas, assim, os colaboradores podem adquirir enfermidades e patologias.

Diante do diagrama de Ishikawa, podem-se verificar na empresa falhas relacionadas à saúde e segurança dos colaboradores da empresa. Pode-se observar também que a empresa possui falhas na estrutura do ambiente, provocando assim riscos físicos para todos envolvidos na organização.

\section{Questionário Semiestruturado}

Mediante a aplicação de entrevistas e questionários semiestruturado com 3 colaboradores do setor de produção e do setor administrativo, verificou-se que $100 \%$ dos colaboradores responderam que com mudança ou adaptação física no ambiente de trabalho haverá uma redução dos riscos para os colaboradores, dos 3 colaboradores entrevistados, todos afirmam que é necessária essa mudança.

Através do questionário aplicado com os 3 funcionários, foi observado que $33,3 \%$ dos entrevistados relatam que o grau de risco da empresa é alto, 33,3\% dizem que o risco é médio e $33,3 \%$ falam que o nível do risco é moderado.

Gráfico 1 - De acordo com a atividade que exerce qual o grau de risco da empresa

\section{Considerando a atividade que exerce, qual o grau de risco da empresa?}

3 respostas

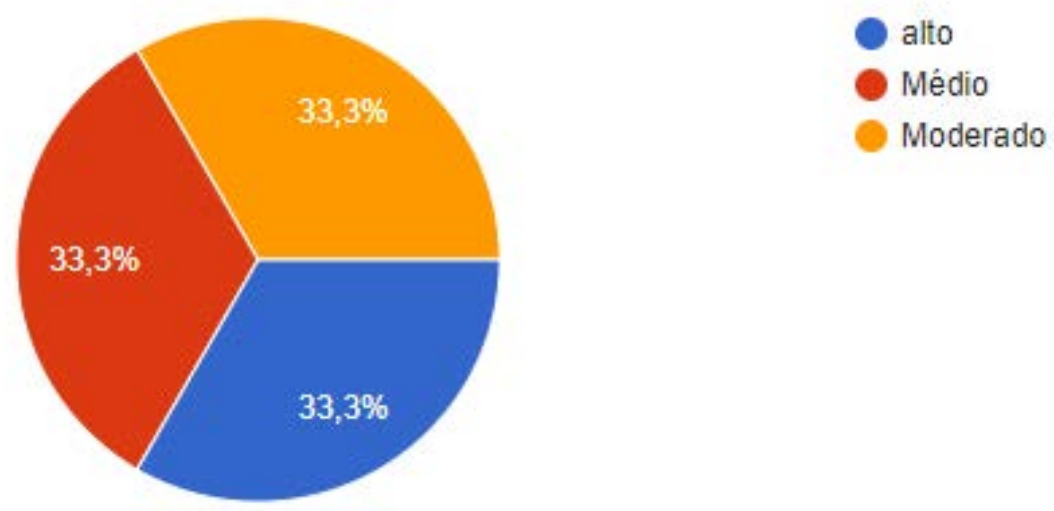

Fonte: Autor (2021)

De acordo com o questionário aplicado aos colaboradores, verificou-se que $100 \%$ das respostas apontam que há risco em que o colaborador está exposto, tais como: agentes químicos que está relacionado a exposição dos funcionários a poeira; agentes físicos, como: ruídos e calor; riscos ergonômicos, tais como: levantamento e transporte manual de peso e repetitividade; e riscos de acidentes, tal como: mau arranjo físico.

Conforme a aplicação do questionário semiestruturado, notou-se que $100 \%$ das respos- 
tas apontam que a empresa não possui mapa setorial de riscos e nem placas sinalizadoras.

\section{Mapa de Risco}

Foi elaborado um mapa de riscos e através desse mapa pode-se verificar que os principais riscos são os riscos mecânicos que se encontram no setor de produção, no setor de entrada de caminhões onde tem a carga e descarga de materiais e na cozinha, todos foram considerados como riscos elevados.

Em sequência aos riscos elevados encontrados, nota-se que existem riscos ergonômicos, químicos e físicos nos setores de produção, no setor de entrada de caminhões onde há carga e descarga de materiais e no banheiro onde foram encontrados riscos biológicos.

No setor administrativo, pode-se observar riscos pequenos químicos e físicos, pois por ser perto do setor de produção o mesmo recebe pequenos impactos desses riscos. Já na cozinha, há também um pequeno impacto dos riscos químicos, físico e biológicos, assim como no banheiro onde existe a presença desses pequenos impactos relacionados aos riscos químicos, mecânicos e físico.

Esses riscos são representados por círculos e cores. O círculo menor corresponde a riscos pequenos, o círculo médio corresponde aos médios riscos e o círculo maior representa a riscos elevados.

Os riscos também são classificados de acordo com as seguintes cores: amarelo (risco ergonômico), vermelho (risco químico), verde (risco físico), marrom (risco biológico), e azul (risco mecânico). Essas descrições estão representadas na Figura 7, que corresponde ao mapa de riscos da empresa.

Figura 7 - Mapa de Riscos - Daysielle Bomfim Nunes-ME

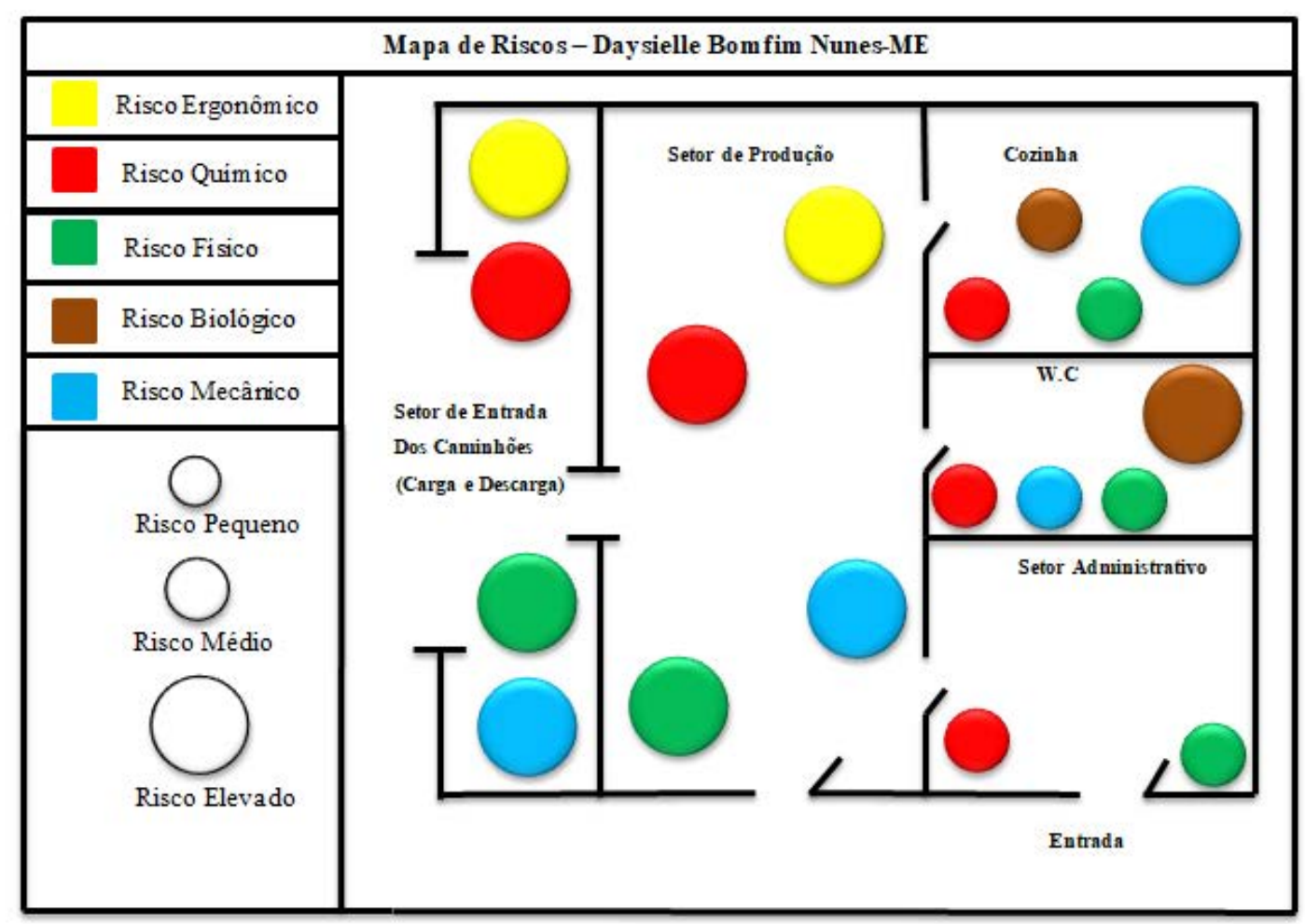

Fonte: Autor (2021) 
Diante do exposto verificou-se a importância de realizar o mapa de risco na empresa pesquisada, uma vez que a mesma não possui mapa de riscos e de acordo com as normatizações vigente a NR 5 faz-se necessário se ter o mapa de riscos para referente atividade realizada pela empresa.

\section{Elaboração de Plano de Ação}

A fim de minimizar os possíveis riscos que podem gerar acidentes e/ou enfermidades, ações foram sugeridas com o auxílio da ferramenta da qualidade $5 \mathrm{~W} 2 \mathrm{H}$. Esta ferramenta tem grande importância para uma empresa, pois com ela é possível elaborar um planejamento mais adequado sobre um determinado objetivo.

$\mathrm{Na}$ aplicação do 5W2H (Quadro 2) é possível verificar outras ações que podem ser tomadas tais como: elaboração do PPRA, utilização de EPls, compra de EPCs, melhoria das condições higiênicas e sanitárias, colocar funcionários para inspeção, colocar bancos para que os trabalhadores que executam suas tarefas em pé possam ter um descanso durante as pausas, oferecer treinamentos e instruções de como manusear cargas altas, colocar extintores de incêndio, colocar mapas que indiquem os riscos de todos os setores e melhorar o layout da empresa. Essas melhorias ajudam a empresa a ter progresso em relação a este assunto que influencia no desempenho da organização.

A elaboração do Programa de Prevenção de Riscos Ambientais (PPRA) é uma boa opção para a referente empresa em questão, pois esse documento apresenta os riscos e as medidas protetivas para cada risco sob aspecto de um profissional qualificado. Até o momento desta pesquisa, a empresa não detém de um PPRA.

Trabalhadores que ficam muito tempo em pé fazendo o preparo de concretos precisam de assentos em locais que possam utilizar nos momentos de pausas. Com essa ação, os trabaIhadores poderiam executar suas tarefas de forma menos cansativas e não afetaria tanto a sua saúde.

De acordo com Barsano e Barbosa (2012), são considerados riscos ambientais de caráter obrigatório para constar no PPRA os riscos físico, químico e biológico, que em função de sua natureza, concentração ou intensidade e tempo de exposição, são capazes de causar danos à saúde do trabalhador. pode-se notar que há a presença desses riscos para os colaboradores, como foi observado ao longo do trabalho realizado na empresa.

Para colaboradores que executam suas tarefas com levantamento de cargas em excesso, é preciso que a empresa ofereça treinamentos e instruções para esses colaboradores, pois conforme a NR 17, item 17.2.2, não é permitido o transporte manual de cargas, por um trabaIhador cujo peso seja suscetível de comprometer sua saúde ou sua segurança (para homens o peso máximo é de $60 \mathrm{~kg}$ ).

Para a melhoria da empresa é preciso implementar os programas de segurança, visto que a empresa necessita do programa para que possa auxiliar na gestão de riscos que o ambiente de trabalho oferece aos colaboradores. É preciso uma reestruturação do layout e no ambiente de trabalho, como foi visto na elaboração do 5W2H. Nota-se também uma desordem no ambiente, favorecendo acidentes de trabalho. 
É necessário à implementação das ferramentas da qualidade que é de grande importância para a empresa, pois elas auxiliam a melhorar o gerenciamento dos processos de segurança. O treinamento de profissionais é fundamental, pois eles estarão capacitados para identificar problemas dentro da empresa, e ajudar o gestor em dificuldades que a empresa esteja passando, assim como diminuiria o índice de acidentes decorrentes do trabalho.

A aplicação do 5W2H na empresa em estudo teve uma grande importância, devido a possibilidade de organizar todas as ações que levasse a empresa a uma melhoria no aspecto de segurança para os colaboradores. 


\begin{tabular}{|c|c|c|c|c|c|c|}
\hline 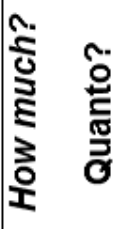 & $\begin{array}{l}8 \\
8 \\
0 \\
0 \\
0 \\
\oplus\end{array}$ & $\begin{array}{l}8 \\
8 \\
8 \\
0 \\
0\end{array}$ & $\begin{array}{l}8 \\
8 \\
8 \\
0 \\
0 \\
0\end{array}$ & $\begin{array}{l}8 \\
\delta \\
\delta \\
i \\
\text { i } \\
\text { ه }\end{array}$ & 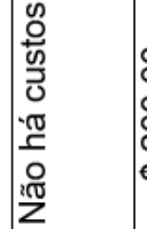 & 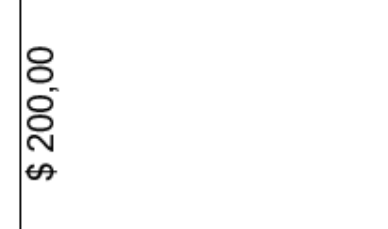 \\
\hline 递 & 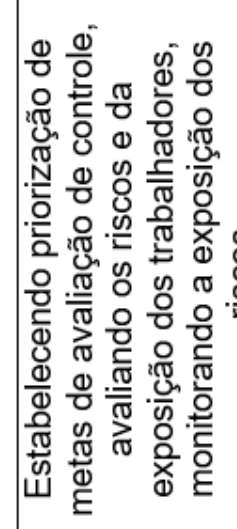 & 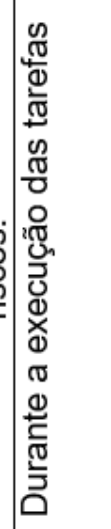 & 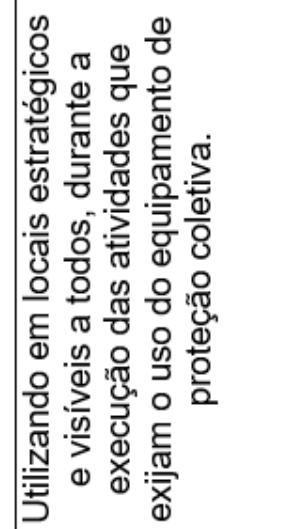 & 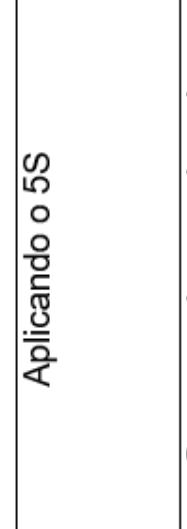 & 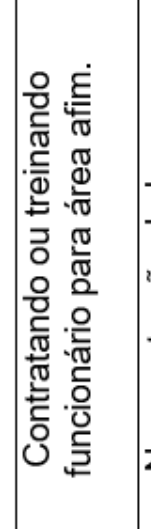 & 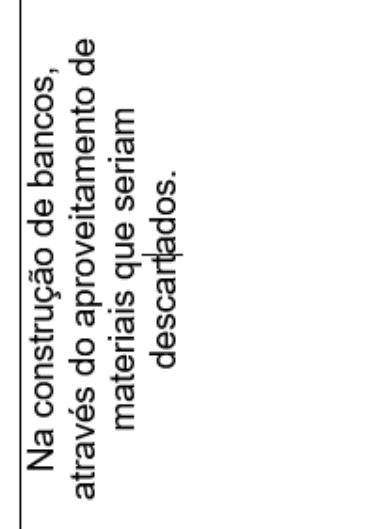 \\
\hline 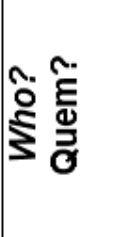 & 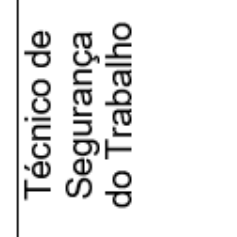 & 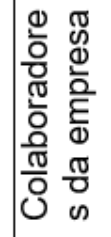 & 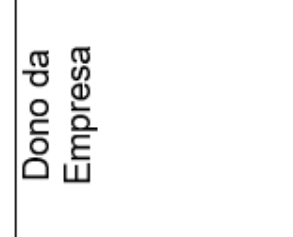 & 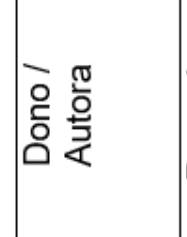 & 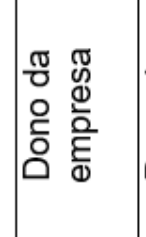 & 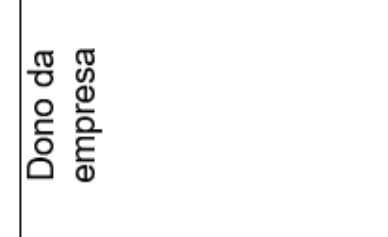 \\
\hline 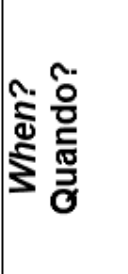 & 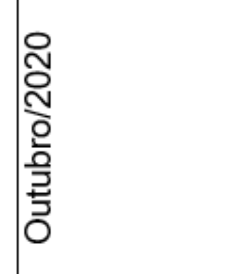 & 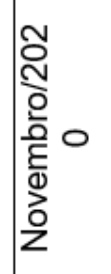 & 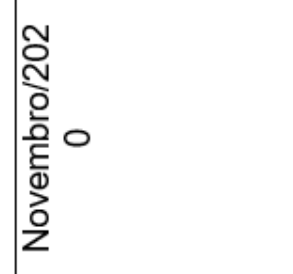 & 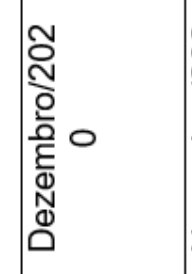 & 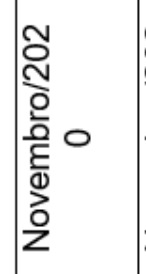 & 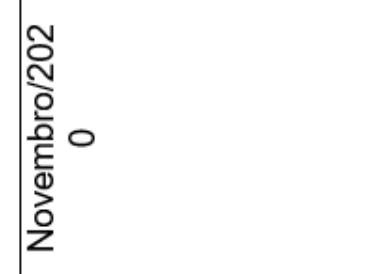 \\
\hline 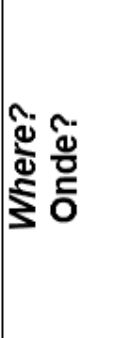 & 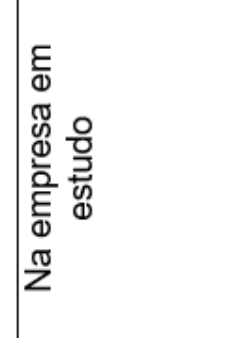 & 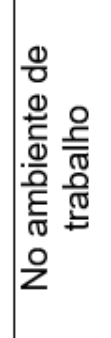 & 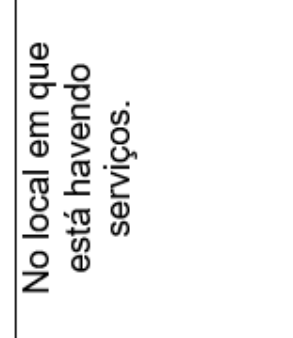 & 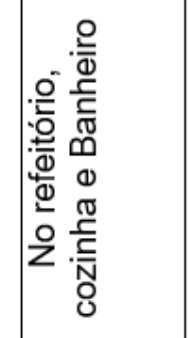 & 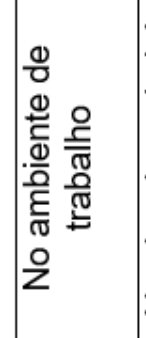 & 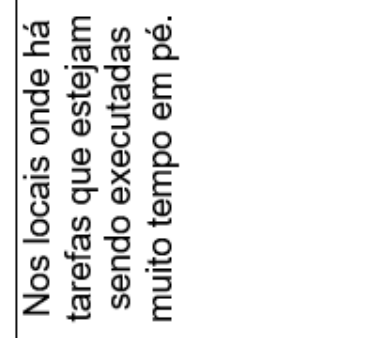 \\
\hline 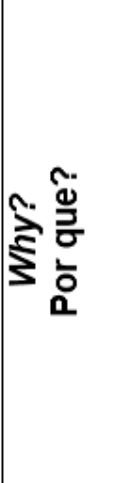 & 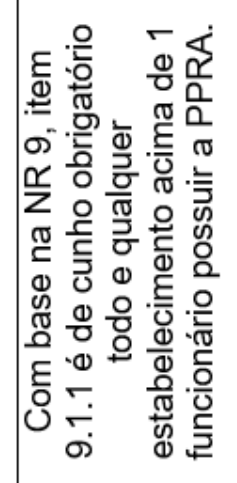 & 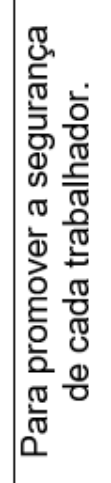 & 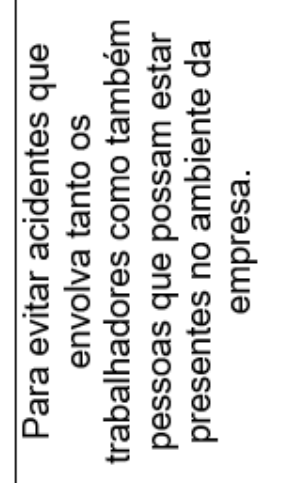 & 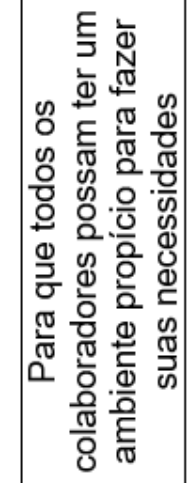 & 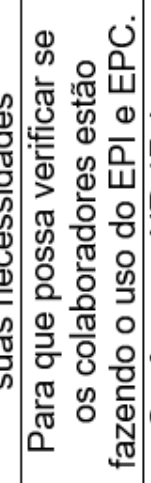 & 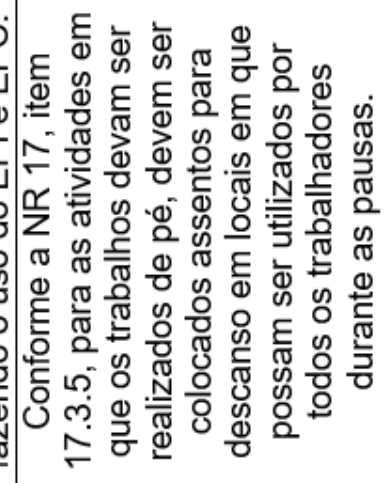 \\
\hline 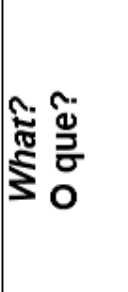 & 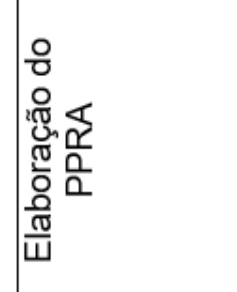 & 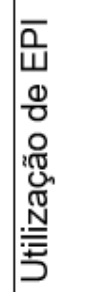 & 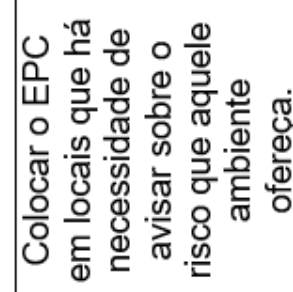 & 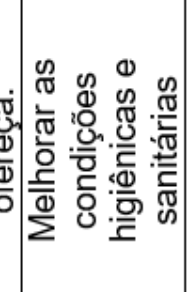 & 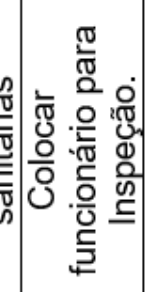 & 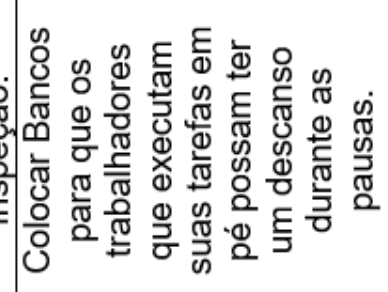 \\
\hline
\end{tabular}




\begin{tabular}{|c|c|c|c|}
\hline $\begin{array}{l}8 \\
0 \\
0 \\
0 \\
0 \\
0\end{array}$ & 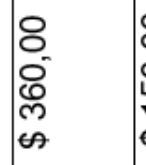 & 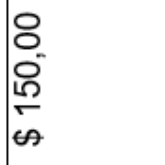 & $\begin{array}{l}8 \\
0 \\
8 \\
0 \\
0\end{array}$ \\
\hline 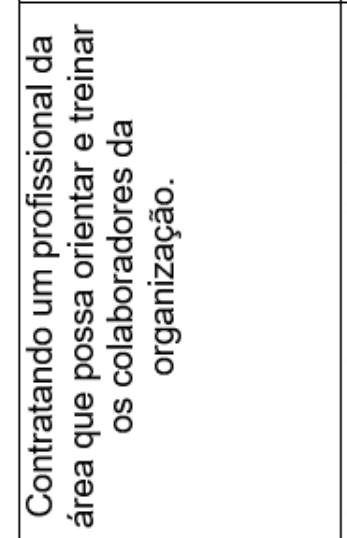 & 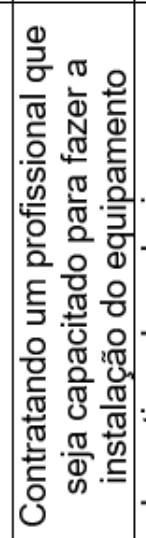 & 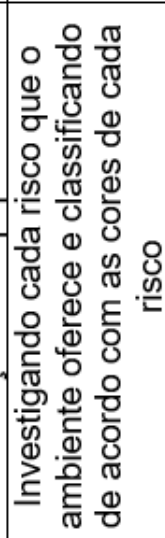 & 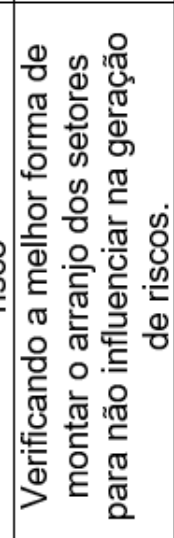 \\
\hline 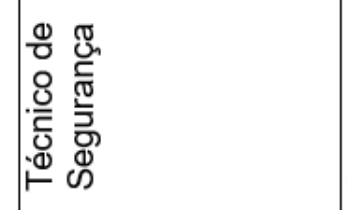 & 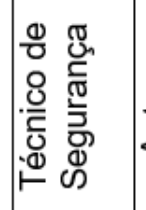 & 要 & 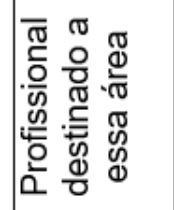 \\
\hline 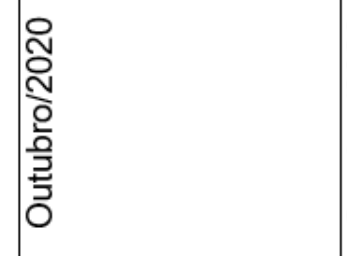 & . & 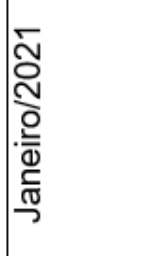 & 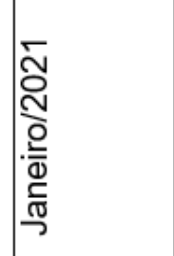 \\
\hline 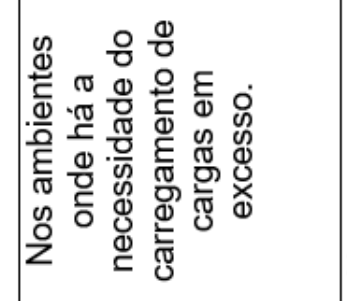 & 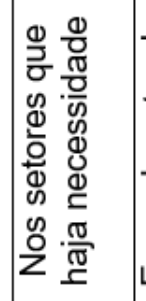 & 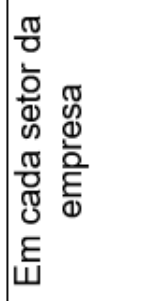 & 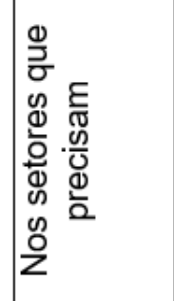 \\
\hline 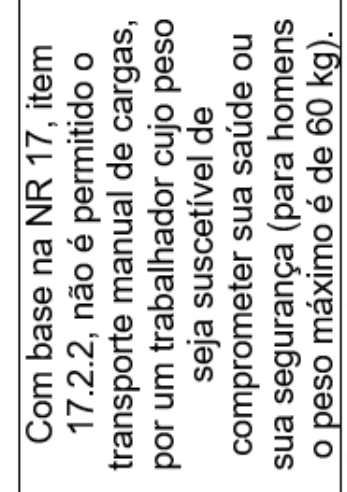 & 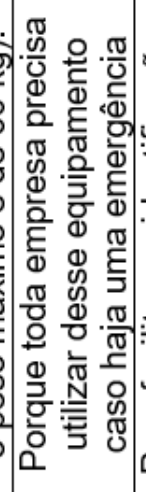 & 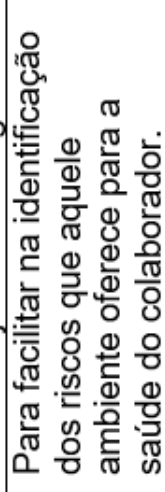 & 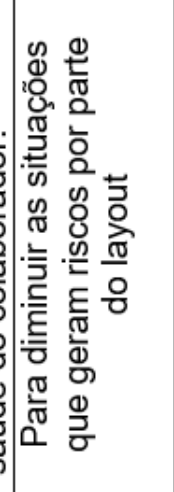 \\
\hline 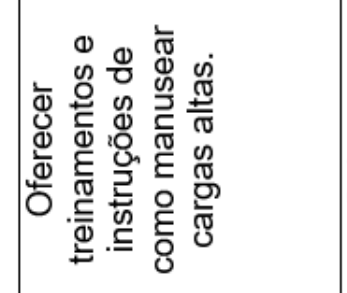 & 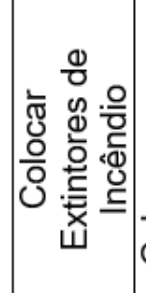 & 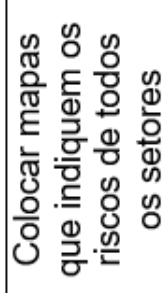 & 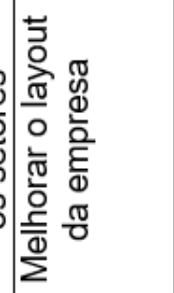 \\
\hline
\end{tabular}


Antes da aplicação da ferramenta na empresa, foi verificada uma desordem no ambiente. O gestor não sabia da importância de ter um plano de ação para minimizar os impactos dos riscos para seus colaboradores.

De acordo com Seleme e Stadler (2012), o 5W2H é uma ferramenta de gestão empregada no planejamento estratégico de empresas, fazendo um check List de atividades específicas que devem ser desenvolvidas com o máximo de clareza e eficiência por todos os envolvidos.

Uma das importâncias da utilização do PPRA nas empresas segundo Barsano e Barbosa (2012) é que ele determina atos que certifique a proteção da saúde e integridade dos trabalhadores, considerando possíveis riscos nos ambientes de trabalho.

Diante das ações previstas e das soluções aqui apresentada, a empresa afirmou que neste momento não poderia aplicar as soluções e ações presente nesse relatório por não ter condições financeiras em caixa nesse momento para realizar, infelizmente a empresa está a ponto de decretar falência.

\section{$5 S$}

Conforme a análise que foi realizada na organização, verificou-se a necessidade de uma ferramenta que servisse como auxílio para organização do ambiente e também de mudança de hábitos das pessoas que ali estão envolvidas, diante disso foi aplicada a ferramenta 5S, que irá ajudar nessa reorganização conforme pode ser apresentado no quadro 3.

Quadro 3 - Aplicação do 5 S

\begin{tabular}{|l|l|}
\hline \multicolumn{1}{|c|}{ Denominação } & \multicolumn{1}{c|}{ Aplicação } \\
\hline Seire (utilização) & $\begin{array}{l}\text { Separar os materiais que são úteis dos que não são, } \\
\text { evitando acúmulos. }\end{array}$ \\
\hline Seiton (organização) & $\begin{array}{l}\text { Organizar o ambiente de trabalho de forma eficaz, } \\
\text { facilitando a localização de objetos. }\end{array}$ \\
\hline Seito (limpeza) & $\begin{array}{l}\text { Melhorar a limpeza do ambiente e também dos } \\
\text { maquinários. }\end{array}$ \\
\hline Seiketsu (padronização) & $\begin{array}{l}\text { Criar padrões para que sejam seguidos, } \\
\text { assegurando assim a saúde mental e física dos } \\
\text { funcionários. }\end{array}$ \\
\hline Shitsuke (disciplina) & $\begin{array}{l}\text { Ter um monitoramento para que todas as outras } \\
\text { ações citadas acima sejam cumpridas e utilizados } \\
\text { continuamente. }\end{array}$ \\
\hline
\end{tabular}

Fonte: Autor (2021)

Para Gozzi (2015, p. 48), o 5S é um programa de reeducação e treinamento que permite a mudança de hábitos das pessoas em relação aos recursos que se encontram à sua disposição, especialmente ao que se refere à organização, limpeza e saúde. Verificou-se na empresa hábitos inadequados que colocavam em risco a saúde dos colaboradores, tais como: desordem do ambiente e de realizações de tarefas, materiais expostos em locais inadequados, isso tudo favorece a situações geradoras de riscos para os trabalhadores. 


\section{CONSIDERAÇÕES FINAIS}

A presente pesquisa teve como proposta apresentar um plano de melhorias com medidas protetivas de riscos de acidentes de trabalho gerados na empresa através do Plano de Ação para a mesma.

Quando se fala em segurança, a empresa precisa ter uma boa gestão que possa orientar os colaboradores. A falta de segurança dentro do ambiente de trabalho para os colaboradores pode ocasionar problemas graves, tanto para o empregado quanto para o empregador, então é preciso estar atento a cada detalhe.

Um grande problema que foi encontrado na organização foi a desorganização do ambiente, e através dessa análise pode-se observar que esse obstáculo faz com que situações de riscos apareçam no ambiente de trabalho, a falta de organização faz com que as pessoas não tenham um foco naquilo que estejam fazendo, essa distração pode provocar acidentes. É notório que a empresa em estudo precisa de uma gestão que possa orientá-la a respeito das situações que geram riscos para dentro da organização, sem um auxílio de um gestor que possa estar monitorando os riscos existentes na organização, a empresa poderá ter problemas futuros.

Mediante os fatos levantados e as não conformidades identificadas, foi sugerido a meIhoria do processo aplicando as ferramentas da qualidade, a exemplo do $5 \mathrm{~W} 2 \mathrm{H}$, fluxograma, questionário semiestruturado, Diagrama de Ishikawa e o 5S, essas ferramentas ajudarão no crescimento e no desenvolvimento empresarial, assim também como ajudarão a minimizar as situações que geram riscos de acidentes de trabalho.

Para que possa potencializar o plano de melhoria, é preciso fazer a união das ferramentas da qualidade com as normas regulamentadoras, pois ao trabalhar em conjunto com todas as normas vistas, a empresa poderá ter um grande avanço na melhoria da gestão dos riscos dentro de sua organização, prevenindo situações indesejadas e atribuindo valores para a sua empresa, todos têm a ganhar ao colocar um sistema de gestão de segurança dentro de sua organização.

Diante das soluções aqui apresentada, a empresa afirmou que não teria condições de executar as modificações sugeridas para melhoria da saúde e integridade dos colaboradores, pois por ter declarado que estava em processo de falência. Sendo assim, verifica-se que os objetivos desse trabalho foram alcançados com sucesso, como pode ser observado na análise dos resultados. 


\section{REFERÊNCIAS}

BARROS, Cesar; BONAFINI, Fernanda. Ferramentas da Qualidade. São Paulo: Pearson, 2014.

BARSANO, Paulo; BARBOSA, Rildo. Segurança do Trabalho: Guia Prático e Didático. São Paulo: látria, 2012.

FERREIRA DA COSTA, Marco Antonio; BARROZO DA COSTA, Maria de Fátima. Segurança e Saúde no Trabalho: Cidadania, Competitividade e Produtividade. 2. ed. Rio de Janeiro: Qualytimark, 2005.

GOZZI, Marcelo. Pupim. Gestão da Qualidade em Bens de Serviço. São Paulo: Pearson, 2015.

MORAES, Cosmo. Manual de Segurança e Saúde no Trabalho: Normas Regulamentadoras- NRs. 13. ed. São Paulo: Difusão, 2017.

SELEME, Robson; STADLER, Humberto. Controle da Qualidade: As Ferramentas Essenciais. São Paulo: Intersaberes, 2012.

UBIRAJARA; SANTOS SOUZA, Luan. Guia de orientação de TCC's. Aracaju: FANESE, 2016 (caderno). 


\section{Organizador}

\section{Alexandre Manoel dos Santos}

Nascido em 1962, é natural de São Paulo/SP. Reside atualmente em Laranjeiras do Sul/PR. Possui graduação em Engenharia, Área Civil, Habilitação em Engenharia de Produção Civil, pela Universidade Federal de Santa Catarina - UFSC (1985). É especialista em Metodologias de Desenvolvimento de Sistemas Computacionais, pela FURB/Blumenau/SC(1999). Obteve o título de Mestre em Métodos Numéricos em Engenharia, pela UFPR(2003), no Curso de Pós-Graduação em Métodos Numéricos em Engenharia-PPGMNE da Universidade Federal do Paraná - UFPR, Área de Concentração: Mecânica dos Sólidos Computacional. Obteve o título de Doutor em Engenharia, em junho de 2019, no Programa de Pós-Graduação em Engenharia de Produção - PPGEP/UFSC, Área de concentração: Logística e Transporte, na Universidade Federal de Santa Catarina - UFSC, na seguinte Linha de Pesquisa: Otimização e Gerenciamento de Sistemas de Transportes e de Serviços Públicos e Emergenciais. Atualmente é Professor Adjunto-D na Universidade Federal da Fronteira Sul - UFFS, Campus Laranjeiras do Sul/PR, desde Março/2010, atuando também como Pesquisador. Tem experiência na área de Engenharia Civil e na área de Engenharia de Produção, com ênfase em Métodos Numéricos em Engenharia e em Pesquisa Operacional. Possui especial interesse nos seguintes temas: Pesquisa Operacional, Otimização de Sistemas de Produção, Logística e Transporte, Mecânica Computacional, Mesh Quality, Método dos Elementos Finitos, Método das Diferenças Finitas, Abordagem Energética (variacional) para resolver indeterminações em Engenharia, Equilíbrio em Redes, Relação Perimetral - RP, Mesh Generation, Sistemas de Banco de Dados, na Plataforma JAVA, DELPHI, Computação Gráfica, Visualização Científica e Mediação do Conhecimento utilizando Informática na Educação. 


\section{Índice A}

acidentes 92, 93, 95, 99, 100, 102, 103, 107

acumulação $24,27,28,29,30,32,33,36,38,39$

ambiente $11,26,39,43,55,56,83,86,91,92,93,94,95,96,98,99,100,102,106$, 107

autônoma 80,86

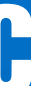

cadeia $8,11,18,19,60,61,64,65,75,76$

capacidade $24,25,27,28,29,30,31,32,33,34,36,38,39,72,74$

cargas $42,51,52,54,56,91,96,102$

cervejaria $79,80,81,83,88$

circular 7, 8, 9, 11, 12, 18, 20, 21, 22, 52

clientes 25, 26, 42, 43, 44, 45, 46, 47, 48, 49, 51, 53, 54, 56, 57, 61, 62, 63, 66, 68, 98 compósito $8,13,16,17,18$

desperdício 60, 61, 62, 63, 64, 70, 74, 76

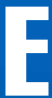

economia $7,8,9,11,12,18,22,27,28$

eficientes $25,26,80$

empresa $24,25,26,27,28,30,32,33,34,36,37,38,39,42,44,56,60,61,62,64,65$, $76,81,82,86,87,90,91,92,93,94,95,96,99,100,101,102,103,106,107$ empresas $25,26,27,28,29,30,31,32,38,39,43,61,80,83,106$ engenharia $10,25,30,36,54,57,63,76$

enxuto $60,61,62$

EPls 91, 92, 94, 99, 100, 102

ergonomia $42,56,57,93$

espaço $41,42,43,44,45,48,49,51,52,57,63,70,81,99$

E

fibra $8,17,18$

físico $27,41,42,43,44,45,48,49,50,51,52,57,58,92,95,96,99,100,101,102$ fluxo $44,45,60,61,62,64,65,66,70,71,72,75,76$

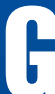

gerenciamento $24,26,81,82,91,103$

gestão $9,24,26,32,33,34,35,36,37,38,39,61,62,75,76,83,88,91,92,93,102$, 106, 107

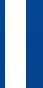

inovação $24,25,26,30,31,32,33,34,35,36,37,38,39$

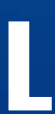

layout 42, 44, 46, 49, 51, 52, 54, 72, 102

levantamento 34, 42, 52, 54, 56, 65, 93, 95, 96, 100, 102

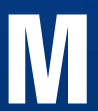

manual 42, 52, 54, 56, 57, 76, 95, 96, 100, 102

manutenção 28, 43, 58, 80, 81, 82, 84, 86, 87, 99

mapeamento $25,60,61,64,65,66,70,72,91,96$

moagem 13, 60, 61, 65, 66, 70, 71, 76 
NRs $91,92,108$

organização $30,38,54,56,61,63,64,73,91,92,93,94,96,100,102,106,107$

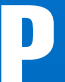

pensamento $25,60,62$

polímero $8,10,12,13,17$

problema $13,44,47,49,52,54,58,74,75,84,86,93,95,107$

produção $9,10,11,12,13,14,25,26,28,30,33,34,60,61,62,63,64,65,66,67,70$, $71,72,73,74,75,76,81,82,84,87,93,94,96,98,100,101$

produtos $9,10,12,13,25,26,27,29,30,34,40,60,61,63,65,66,67,68,70,73,74$, $75,81,84$

0

qualidade $25,26,28,34,35,36,42,43,56,57,60,62,65,68,71,75,80,81,82,83$, $84,86,87,89,91,93,94,96,102,103,107$

$\mathbf{R}$

reciclado $7,8,10,11,13,14,15,17,18,19,20$

reciclagem $8,9,10,11,12,13,17,21$

recravadeira $79,80,81,84,85,86,87,88$

riscos 33, 53, 54, 86, 90, 91, 92, 93, 94, 95, 96, 99, 100, 101, 102, 106, 107

s

sistema $3,11,27,38,43,61,62,65,66,70,73,74,75,76,81,107$

suprimentos $60,61,75,76$

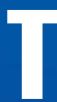

tecnológica $24,25,27,28,29,30,32,33,36,37,38,39$

TPM 79, 80, 81, 82, 83, 84, 86, 88, 89

trabalho $18,24,26,31,32,33,35,36,37,38,39,42,52,57,60,63,64,65,71,74,75$, $76,80,82,85,86,90,91,92,93,94,95,96,97,98,99,100,102,103,106,107$ trigo $60,61,65,66,67,71,76$

valor $10,13,17,26,27,43,56,60,61,62,63,64,65,66,70,75,76,87$ vegetal $8,14,18$ 


\section{AYAEDITORA}

2021 